\title{
DOUGLAS SEGALLA CARAGELASCO
}

Efeito da terapia com células tronco mesenquimais na proteinúria de cães com doença renal crônica

São Paulo

2017 
Efeito da terapia com células tronco mesenquimais na proteinúria de cães com doença renal crônica

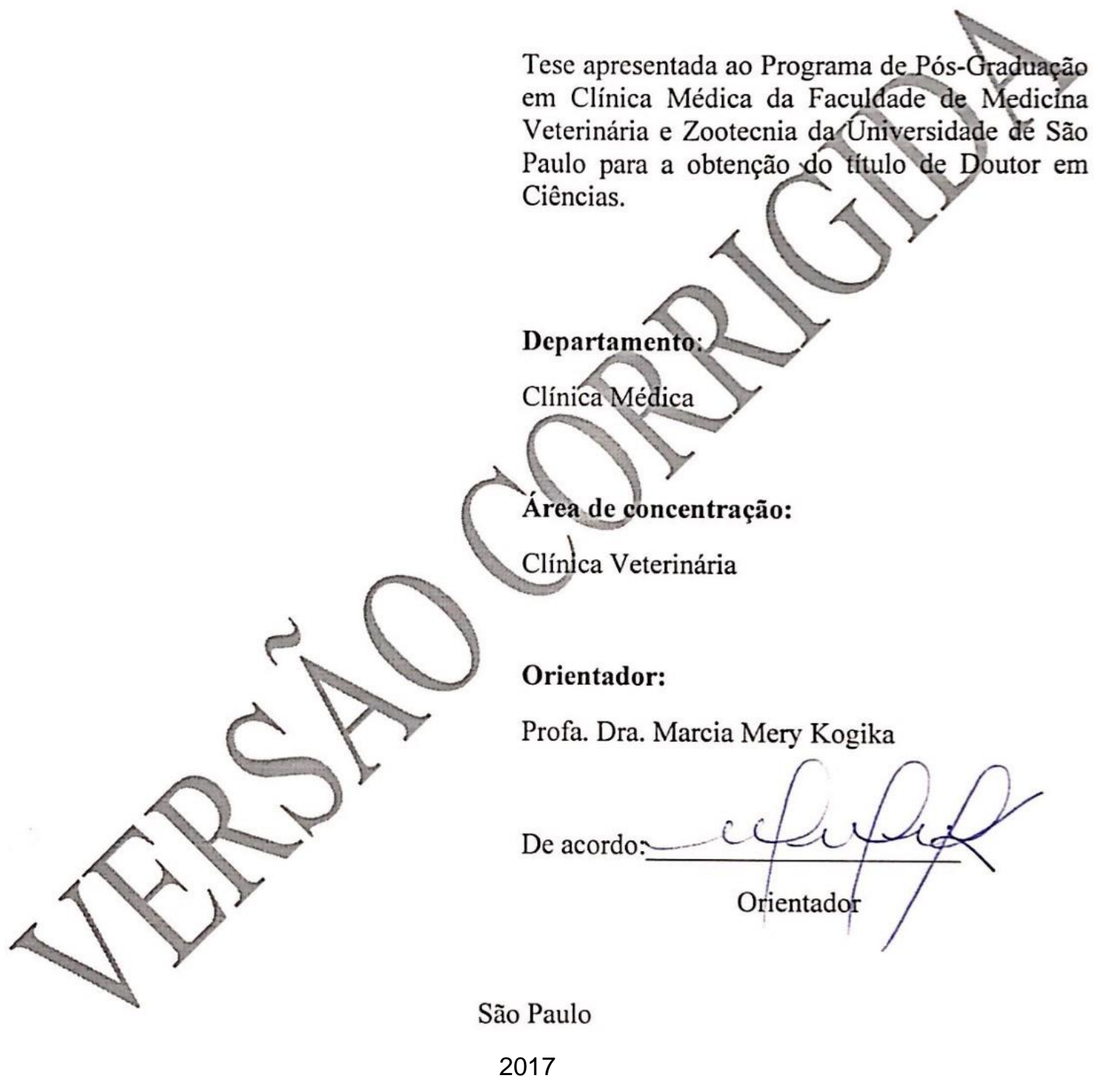

Obs: A versão original encontra-se disponível na Biblioteca da FMVZ/USP 
Autorizo a reprodução parcial ou total desta obra, para fins acadêmicos, desde que citada a fonte

\section{DADOS INTERNACIONAIS DE CATALOGAÇÃO NA PUBLICAÇĀO}

(Biblioteca Virginie Buff D'Ápice da Faculdade de Medicina Veterinária e Zootecnia da Universidade de São Paulo)

Caragelasco, Douglas Segalla

Efeito da terapia com células tronco mesenquimais na proteinúria de cáes com

FMVZ doença renal crônica / Douglas Segalla Caragelasco. - 2017.

$145 \mathrm{f}: \mathrm{i}$.

Tese (Doutorado) - Universidade de Sáo Paulo. Faculdade de Medicina Veterinária e Zootecnia. Departamento de Clínica Médica, Să Paulo, 2017.

Programa de Pós-Graduaçäo: Clínica Veterinária.

Área de concentraçäo: Clínica Veterinária.

Orientador: Profa. Dra. Marcia Mery Kogika.

1. Canino. 2. Nefropatia. 3. Proteina Urinária. 4. Eletroforese. 5. Western Blot. I. Título. 


\section{Nome: CARAGELASCO, Douglas Segalla}

Título: Efeito da terapia com células tronco mesenquimais na proteinúria de cães com doença renal crônica

Tese apresentada ao programa de PósGraduação em Clínica Médica da Faculdade de Medicina Veterinária e Zootecnia da Universidade de São Paulo para a obtenção de título de Doutor em Ciências

\section{Aprovado em:}

Prof. Dr. Instituição

Julgamento Assinatura

Prof. Dr. Instituição

Julgamento Assinatura

Prof. Dr. Instituição

Julgamento Assinatura

Prof. Dr. Instituição

Julgamento Assinatura

Prof. Dr. Instituição

Julgamento Assinatura 
Anexo A - Certificado de aprovação da comissão de ética no uso de animais da Faculdade de Medicina Veterinária e Zootecnia da Universidade de São Paulo do projeto temático.

UNIVERSIDADE DE SÃO PAULO

\section{CERTIFICADO}

Certificamos que o Projeto intitulado "Avaliaçào da terapia com células tronco na doença renal crônica em cães", protocolado sob o n 1914/2010, utilizando 56 (cinquenta e seis) cães, sob a responsabilidade da Profa. Dra. Márcia Mery Kogika, está de acordo com os principios éticos de experimentação animal da "Comissão de Ética no uso de animais" da Faculdade de Medicina Veterinária e Zootecnia da Universidade de São Paulo e foi aprovado em reuniāo de $24 / 03 / 2010$.

We certify that the Research "Stem cells therapy evaluation in dogs with chronic kidney disease", protocol number 1914/2010, utilizing 56 (fifty-six) dogs, under the responsibility Profa. Dra. Márcia Mery Kogika, agree with Ethical Principles in Animal Research adopted by "Ethic Committee in the use of animals" of the School of Veterinary Medicine and Animal Science of University of Sato Paulo and was approved in the meeting of day 03/24/2010.

São Paulo, 25 de março de 2010

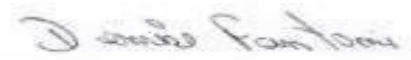

Profa. Dra. Denise Tabacchi Fantoni Presidente 


\section{Anexo B - Certificado de aprovação da comissão de ética no uso de animais da Faculdade de Medicina Veterinária e Zootecnia da Universidade de São Paulo do projeto apresentado nesta tese.}

UNIVERSIDADE DE SÃo PAULO

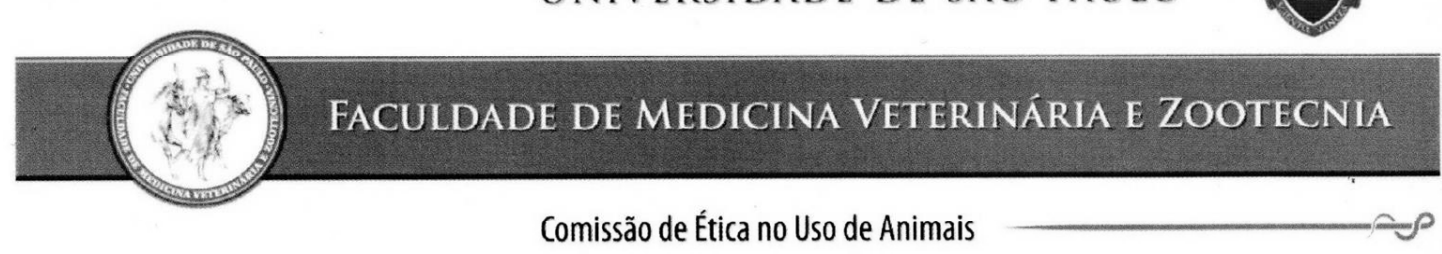

\section{CERTIFICADO}

Certificamos que o Projeto intitulado "Efeito da terapia com células tronco mesenquimais na proteinúria de cães com doença renal crônica", protocolado sob o $\mathrm{n}^{\circ} 3140 / 2013$, utilizando 40 (quarenta) cães, sob a responsabilidade da Profa. Dra. Marcia Mery Kogika, foi aprovado em reunião de 16/10/2013 e está de acordo com os princípios éticos de experimentação animal da Comissão de Ética no Uso de Animais da Faculdade de Medicina Veterinária e Zootecnia da Universidade de São Paulo.

We certify that the Research "Effect of mesenchymal stem cells therapy on proteinuria in dogs with chronic kidney disease", protocol number 3140/2013, utilizing 40 (forty) dogs, under the responsibility Profa. Dra. Marcia Mery Kogika, was approved in the meeting of day 16/10/2013 and agree with Ethical Principles in Animal Research adopted by Ethic Committee in the Use of Animals of the School of Veterinary Medicine and Animal Science of University of São Paulo.

São Paulo, 27 de novembro de 2013.

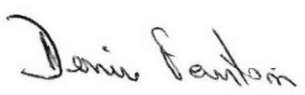

Denise Tabacchi Fantoni Presidente 


\section{AGRADECIMENTOS}

À minha querida esposa Mariana Paula Martinho Caragelasco, pelo companheirismo, paciência e compreensão durante o período do estudo, aos meus pais e irmãos por todo o apoio e incentivo nesta difícil jornada.

À FAPESP pelo apoio financeiro referente ao Projeto Temático (Processo n 2010/19012-0) e à Professora Lucia da Conceição Andrade da Disciplina de Nefrologia da Faculdade de Medicina da Universidade de São Paulo como Pesquisadora Responsável pelo referido Projeto junto à FAPESP e a CAPES pela bolsa concedida durante o estudo.

À minha orientadora, Profa. Dra. Marcia Mery Kogika, por todas as oportunidades, ensinamentos e por ser um exemplo de pesquisadora.

Aos funcionários do Serviço de Laboratório Clínico do Departamento de Clínica Médica / Hospital Veterinário da Faculdade de Medicina Veterinária e Zootecnia da Universidade de São Paulo, Maria Helena da Silva Pelissari, Claudia Regina Stricagnolo, Clara Mori, Edna Santana dos Santos, Creide Donizete Costa por todos os ensinamentos, pela colaboração nos exames e nas técnicas laboratoriais.

As veterinárias do serviço de clínica médica da Faculdade de Medicina Veterinária e Zootecnia da Universidade de São Paulo, Denise Simões, Bruna Coelho, Khadine Kanayama e Andrea Andrade, pelo auxilio na seleção de novos casos e por passar seu conhecimento. Ao enfermeiro Milton Gregório por toda a ajuda durante as coletas.

À todos do laboratório de Pesquisa Básica em Nefrologia (LIM-12, FMUSP), em especial a Dra. Thalita Rojas pelos ensinamentos na técnica de Western Blotting e por compartilhar todo seu conhecimento de maneira tão generosa.

Aos meus companheiros nesta caminhada Cinthia Ribas Martorelli, Fernanda Chicharo Chacar e Natalia Garla, obrigado por todos os momentos felizes, todas as discussões relevantes e troca de ensinamentos.

À todos os tutores dos pacientes que concordaram com a participação neste projeto de pesquisa, permitindo que a ciência avance. 


\section{RESUMO}

\section{CARAGELASCO, D. S. Efeito da terapia com células tronco mesenquimais}

na proteinúria de cães com doença renal crônica. 2017. 145 f. Tese (Doutorado) - Faculdade de Medicina Veterinária e Zootecnia da Universidade de São Paulo, São Paulo, 2017.

A proteinúria de origem renal é um indicador de lesão e atua na progressão da doença renal crônica em cães. Na rotina clínica, várias são as recomendações em relação à terapia de manutenção, que visam minimizar ou retardar a progressão da doença. Com o recente progresso na pesquisa sobre a terapia com as células tronco mesenquimais (CTM), tem-se discutido sobre a possibilidade de minimização dos mecanismos inflamatórios e imunológicos de autoperpetuação da lesão renal com a sua utilização, assim a análise sequencial das proteínas urinárias por métodos qualitativos, tais como a eletroforese em gel de poliacrilamida (SDS-PAGE) e a imunodetecção das proteínas por Western Blot pode trazer subsídios para esta avaliação. Portanto, como hipótese, suscitase que a administração de CTM em cães com DRC possa trazer benefícios com o intuito de minimizar o desenvolvimento da proteinúria, contribuindo para 0 retardo na velocidade de progressão da doença renal. Trata-se de um estudo prospectivo, longitudinal e duplo-cego em que foram avaliados 22 cães com DRC, tratados com solução fisiológica (SF) ou CTM e avaliados a cada 30 a 45 dias em 12 momentos, divididos em grupos de acordo com o estágio da doença, grupo A (estágio 2, SF:n=6, CTM:n=3) e grupo B (estágio 3, SF:n=6, CTM:n=7). Observou-se que os cães do Grupo B apresentaram proteinúria mais intensa, maior porcentagem de proteínas de alto peso molecular, maior imunodetecção de albumina, proteínas ligadas ao retinol e a vitamina $D$ e menor imunodetecção de proteína de Tamm-Horsfall ao longo do acompanhamento, quando comparado ao Grupo A. Os resultados obtidos nesse estudo não permitiram definir conclusões contundentes de que a terapia com a CTM tenha trazido alterações importantes que indicassem o seu benefício. Os dados sugerem que os cães nos estágios iniciais da DRC (estágio 2) poderiam ser os mais favorecidos com a referida terapia, entretanto mais estudos contemplando um número maior de animais, como o maior tempo de acompanhamento devem ser conduzidos para tal investigação.

Palavras chave: Canino. Nefropatia. Proteína Urinária. Eletroforese. Western Blot 


\section{ABSTRACT}

CARAGELASCO, D. S. Effect of mesenchymal stem cell therapy on the proteinuria of dogs with chronic kidney disease. 2017. 145 f. Tese (Doutorado) - Faculdade de Medicina Veterinária e Zootecnia da Universidade de São Paulo, São Paulo, 2017.

Protein of renal origin is an indicator of injury and acts on the progression of chronic kidney disease in dogs. In the clinical routine, several recommendations regarding maintenance therapy are aimed at minimizing or delaying the progression of the disease. With the recent progress in the research on mesenchymal stem cell therapy (CTM), it has been discussed the possibility of minimizing the inflammatory and immunological mechanisms of self-perpetuation of the renal lesion with its use, thus the sequential analysis of the urinary proteins by qualitative methods such as polyacrylamide gel electrophoresis (SDS-PAGE) and the immunodetection of proteins by Western blot can prove the efficacy of the therapy. Therefore, as hypothesis, it is suggested that the administration of CTM in dogs with CKD can fetch benefits in order to minimize the development of proteinuria, contributing to the delay in the rate of progression of renal disease. This is a prospective, longitudinal, double-blind study in which 22 dogs with CKD were treated with physiological solution (SF) or CTM and evaluated every 30 to 45 days in 12 moments divided into groups according to (stage 2, SF: $n=6$, CTM: $n=3$ ) and group $B$ (stage $3, S F: n=6, C T M: n=7$ ). Group B dogs were found to have more intense proteinuria, a higher percentage of high molecular weight proteins, greater albumin immunodetection as well as retinol-binding protein and vitamin D-binding protein, and decreased Tamm-Horsfall protein immunodetection throughout follow-up, when compared to Group A. The results obtained in this study did not allow to draw conclusive conclusions that CTM therapy brought important changes that indicated its benefit. The data suggest that dogs in the early stages of CKD (stage 2) could be the most favored with such therapy, however more studies contemplating a larger number of animals, such as longer follow-up, should be conducted for such investigation.

Key words: Canine. Nephropathy. Proteinuria. Electrophoresis. Western Blot 


\section{SUMÁRIO}

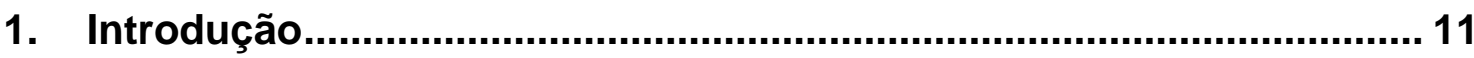



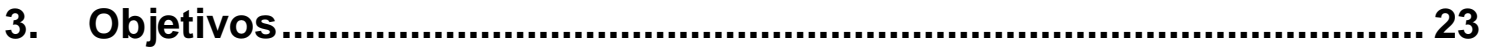

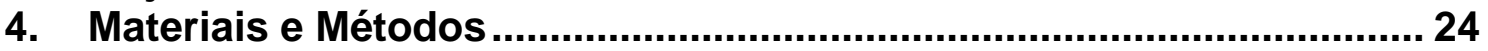

4.1 Coleta de material biológico e realização de exames.............................. 27

4.1.1 Coleta de urina ................................................................................. 27

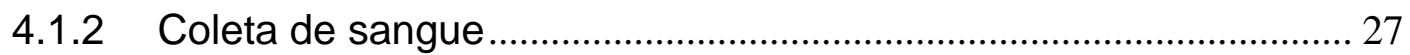

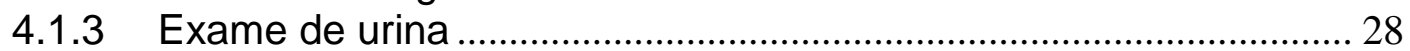

4.1.4 Determinações das concentrações séricas de creatinina, ureia, albumina, proteínas totais, fosfatase alcalina, alanina aminotransferase, triglicérides e colesterol ............................................................................ 28

4.1.5 Determinação da concentração urinária de creatinina ...................... 29

4.1.6 Determinação da concentração urinária de proteína........................... 29

4.1.7 Determinação da razão proteína: creatinina urinária (RPC)............ 30

4.1.8 Determinação das proteínas urinárias por eletroforese ................... 31

4.1.9 Imunodetecção por Western Blotting ……………………………..... 33

4.1.10 Separação de células-tronco mesenquimais a partir do cordão

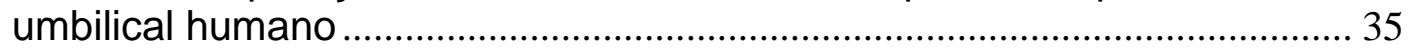

4.2 Aplicação de células-tronco mesenquimais ...................................................... 39

4.3 Mensuração da Pressão Arterial Sistêmica..................................................... 40

4.4 Análise estatística ................................................................................... 41

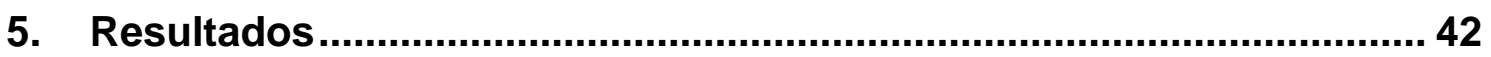

5.1 Razão proteína/creatinina urinária $(R P C)$.......................................................... 47

5.2 Proteínas de alto peso molecular (PM > $60 \mathrm{kDa}$; HMWP) detectadas pela eletroforese de proteinas urinárias ....................................................................... 54

5.3 Proteínas de baixo peso molecular (LMWP) detectadas pela eletroforese de

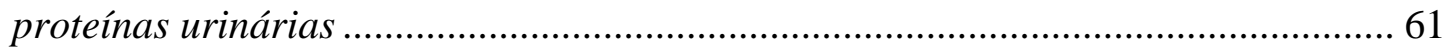

5.4 Número de bandas de proteínas de alto peso molecular (BHMWP) na urina detectadas pela eletroforese em SDS-PAGE …………………………................... 67

5.5 Número de bandas de proteínas de baixo peso molecular (BLMWP) detectadas na

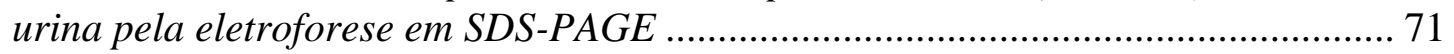



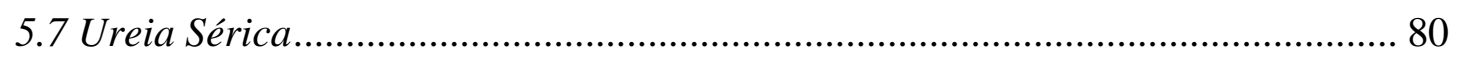

5.8 Imunodetecção da Albumina por western blot .................................................... 86

5.9 Imunodetecção da proteína ligada à vitamina D por western blot ....................... 90

5.10 Imunodetecção da proteína ligada ao retinol por western blot .......................... 93

5.11 Imunodetecção da proteína de Tamm-Horsfall por western blot........................ 96

5.12 Pressão Arterial Sistólica ........................................................................... 100

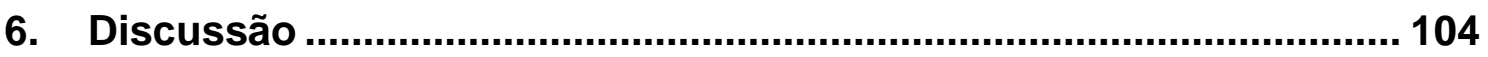



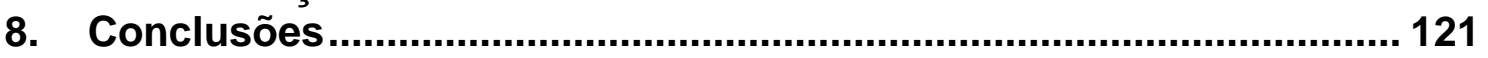

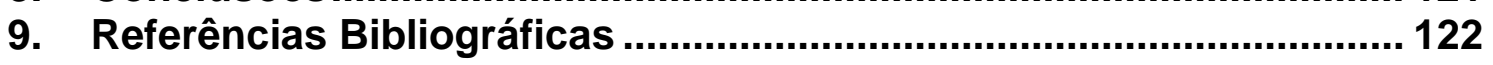




\section{Introdução}

A doença renal crônica (DRC) pode ser considerada o tipo mais comum de doença renal em cães, independente da raça ou idade do paciente (POLZIN; OSBOURNE; ROSS, 2005; POLZIN, 2011), com considerável morbidade (LEES, 2004). Em cães, o diagnóstico de DRC ocorre em média aos sete anos de idade (POLZIN; OSBOURNE; ROSS, 2005), sendo que, nesta faixa etária, pelo menos 10\% dos cães já foram diagnosticados com DRC (BROWN, 2008).

A DRC apresenta evolução insidiosa, com desencadeantes multifatoriais, além de ser progressiva e irreversível (POLZIN; OSBOURNE; ROSS, 2005; POLZIN, 2011). Entretanto, no momento do diagnóstico, nem sempre é possível identificar as causas que iniciaram ou desencadearam a lesão renal, dada a sua fisiopatologia complexa, e que progride em decorrência de mecanismos independentes da etiologia(POLZIN; OSBOURNE; ROSS, 2005; POLZIN, 2011).

A DRC pode decorrer de doenças glomerulares, que devido a redução do fluxo sanguíneo renal pode resultar em atrofia das células tubulares, acarretando posteriormente em lesões tubulares, e em decorrência deste processo, favorece a perda precoce dos néfrons (QUAGLIA; STRATTA, 2009; POLZIN, 2011). Ainda, a inflamação e a fibrose também podem agravar o referido mecanismo, por exacerbar a perda do número e da função dos néfrons, pois ocorre substituição do tecido funcional (néfrons) por tecido conjuntivo afuncional (POLZIN; OSBOURNE; ROSS, 2005). Descreve-se que as doenças tubulares também podem causar posteriormente lesões glomerulares, embora os mecanismos não estejam completamente elucidados(BROWN et al., 2013). 
A lesão renal pode ser detectada por alterações microscópicas ou macroscópicas, por exames laboratoriais e de imagem, denominados marcadores de doença renal. A magnitude do comprometimento das estruturas renais e da função renal é o que determina as variações das manifestações clínicas(LEES, 2004).

De acordo com a IRIS (International Renal Interest Society), a evolução da DRC pode ser classificada em quatro estágios para o cão, além do estado de risco, designado por cães com concentrações de creatinina sérica menor que 1,4 mg/dL e sem alteração nos marcadores de doença renal; estágio 1, o cão não apresenta azotemia, mas constatam-se alterações nos marcadores de doença renal, como proteinúria persistente, alteração dos exames de imagem dos rins com ou sem hipertensão arterial sistêmica; estágio 2, o animal apresenta azotemia discreta e persistente (creatinina sérica entre 1,4 mg/dL e $2,0 \mathrm{mg} / \mathrm{dL}$ em cães normovolêmicos com presença de alterações nos marcadores de doença renal, podendo ou não apresentar manifestações clínicas; estágio 3, a azotemia persistente é de intensidade moderada (creatinina sérica entre $2,1 \mathrm{mg} / \mathrm{dL}$ a $5,0 \mathrm{mg} / \mathrm{dL}$ em cães normovolêmicos, com manifestações clínicas mais marcantes, como poliúria, polidipsia, emagrecimento progressivo, entre outras; e estágio 4, a azotemia persistente é mais intensa (creatinina sérica superior a 5,0 mg/dL em cães normovolêmicos e as manifestações clínicas são mais evidentes (LEES, 2004; POLZIN, 2013)

O glomérulo renal atua como um filtro, permitindo a passagem de água e pequenas moléculas pela barreira de filtração para formar o ultrafiltrado glomerular, as moléculas de maior tamanho não ultrapassam esta barreira. Proteínas com peso molecular maior que 70 kDa são retidas na circulação, 
enquanto moléculas menores que $40 \mathrm{kDa}$ passam livremente para o ultrafiltrado glomerular. Albumina, de peso molecular de $66 \mathrm{kDa}$, é retida e somente pequenas quantidades de albumina podem estar presentes no ultrafiltrado glomerular (WATERS et al., 1997)

Entretanto, a constatação persistente de maior concentração urinária de proteínas pode ser considerada como um indicador de lesão renal, sendo esta de origem glomerular ou tubular, e que pode ser detectada antes mesmo do desenvolvimento de azotemia renal ou do agravamento da lesão renal (LEES, 2004; POLZIN; OSBOURNE; ROSS, 2005; GRAUER, 2011; POLZIN, 2013).

A hipertensão arterial e sua associação com a proteinúria é reconhecida como um fator de risco para pacientes com DRC em humanos e camundongos (ROSS, 1992; WOLF; BUTZMANN; WENZEL, 2003). Existem poucos estudos em cães que associam a taxa de filtração glomerular, a proteinúria e a hipertensão (FINCO et al., 1999; BROWN et al., 2003; JACOB; ARIZA; OSBORN, 2003; JACOB et al., 2005). O trabalho de Wehner e colaboradores (WEHNER; HARTMANN; HIRSCHBERGER, 2008) encontrou uma correlação entre diminuição da taxa de filtração glomerular e aumento da proteinúria em cães com DRC, e também mostraram que os cães com hipertensão apresentaram uma menor sobrevida.

A proteinúria pode ser detectada por testes semiquantitativos de baixo custo e de fácil execução, como com a utilização de fitas reagentes comerciais. Neste teste, o grupo amino das proteínas liga-se ao reagente "indicador" impregnado no papel filtro da fita, causando alteração de cor. A cor é comparada com um padrão, mas a comparação é subjetiva (MARSHALL; WILLIAMS, 2000; GREGORY F. GRAUER, 2010). No entanto, para se obter um resultado mais 
preciso da concentração de proteína na urina, métodos bioquímicos colorimétricos (MCELDERRY; TARBIT; PIERCE, 1982) devem ser empregados. Nestes testes bioquímicos, a amostra a quantificar é posta em contato com um reagente especifico, de modo a desenvolver uma cor cuja intensidade é diretamente proporcional à concentração da substância na solução original, e a concentração da substância pode ser aferida utilizando a espectrofotometria, que permite mensurar o espectro de absorção da substância, ou seja, a quantidade de luz que é absorvida em um determinado comprimento de onda (ANNESLEY; ROCKWOOD; SHERMAN, 2008).

O método de Bradford consiste na ligação do corante de Coomassie Blue G250 com a proteína da amostra. O corante em sua forma livre apresenta-se na cor vermelha e ao ligar-se com a proteína da amostra, passa a apresentar-se em cor azul. Esta ligação do corante com a proteína ocorre de maneira rápida (aproximadamente dois minutos) e esta ligação é estável apenas por aproximadamente uma hora (BRADFORD, 1976).

Com os valores da concentração de proteínas na urina, como também da concentração urinária de creatinina, calcula-se a razão proteína urinária/creatinina urinária (RPC), que fornece informações importantes sobre a gravidade da doença e da evolução da mesma, além de auxiliar na detecção precoce de doença renal, bem como avaliar a resposta ao tratamento (GRAUER, 2007, 2011). Vale ressaltar que as causas de proteinúria pré e pós-renais devem ser excluídas.

A análise das proteínas urinárias por métodos qualitativos tais como a eletroforese em gel de poliacrilamida (SDS-PAGE) e a imunodetecção por Western Blot de proteínas especificas como a albumina, proteína de Tamm- 
Horsfall, proteínas ligadas ao retinol e a vitamina D, podem elucidar a origem da lesão renal (LEE et al., 2013; CHACAR et al., 2017). A classificação das proteínas de acordo com seu peso molecular permite a associação com a presença de disfunções glomerulares, tubulares ou mistas (KSHIRSAGAR; WIGGINS, 1986; LE BRICON et al., 1998).

A espécie canina apresenta rápida evolução da DRC quando comparado com outras espécies, a exemplo do gato e, assim, desperta-se grande interesse no estudo de terapias que possam retardar a progressão da doença, sendo que atualmente o foco principal do tratamento consiste na manutenção desses pacientes e tem como base o controle dos mecanismos fisiopatológicos envolvidos na autoperpetuação da doença renal.

Na rotina clínica, várias são as recomendações em relação à terapia de manutenção, que visam a minimizar ou retardar a progressão da doença, como o controle da acidose metabólica, diminuição da hiperfosfatemia, manutenção do equilíbrio hídrico, controle de manifestações concomitantes a uremia, como náusea, vômito e perda de apetite e no que tange ao tratamento dietético, este é recomendado a partir do estágio 2 da DRC nos cães e que compreende aqueles que apresentam valores de concentrações séricas de creatinina, em paciente normovolêmico, entre 1,4 a 2,0 mg/dL. Os principais objetivos da terapia dietética baseiam-se no fornecimento da necessidade energética diária, controle da azotemia, evitando a uremia, acidose metabólica, hipertensão e hiperfiltração glomerular, prevenir o desenvolvimento do hiperparatireoidismo secundário renal por meio do controle da hiperfosfatemia e hipocalcemia, a fim de evitar a ocorrência de desmineralização, calcificação metastática em tecidos moles, incluindo os rins, bem como o comprometimento da medula óssea, minimizar o 
desequilíbrio eletrolítico, bem como a deficiência de vitaminas do complexo B, necessidade de suplementação de ácidos graxos, os quais parecem apresentar ação anti-inflamatória e anti-agregação plaquetária. (BURKHOLDER, 2000; BROWN et al., 2013; POLZIN, 2013)

Com o recente progresso na pesquisa sobre a terapia com as célulastronco, tratamentos que visam a possibilidade de regeneração tecidual, ou mesmo de minimizar os mecanismos de autoperpetuação da lesão renal (inflamatórios e imunológicos), têm sido propostos como uma nova estratégia terapêutica na DRC (MOLLURA; HARE; RABB, 2003; BRODIE; HUMES, 2005; YOKOO et al., 2006; CHOI et al., 2009; GATTI et al., 2011; LIM et al., 2011; ZHU; LERMAN; LERMAN, 2013).

As células-tronco são definidas como aquelas capazes de se diferenciar em linhagens celulares especializadas, porém se autorregenerando a cada ciclo de divisão celular para manter a reserva de células-tronco (AL-AWQATI; OLIVER, 2002; MOLLURA; HARE; RABB, 2003). São classicamente divididas em dois grandes grupos: (1) células-tronco embrionárias e (2) células-tronco adultas ou somáticas, dependendo se sua origem for de tecido embrionário ou tecido adulto como medula óssea, cérebro e cordão umbilical, respectivamente.

As células-tronco se caracterizam por apresentarem ciclo celular lento, capacidade de proliferação in vitro, localização em nichos específicos com acesso a suprimento sanguíneo e interação com células próprias daqueles tecidos, que previnem o aumento na velocidade do ciclo celular (AL-AWQATI; OLIVER, 2002). A medula óssea e o cordão umbilical apresentam múltiplos tipos de células-tronco e os principais grupos são: hematopoiéticas, mesenquimais, células progenitoras adultas multipotentes e as "side population cells" (WAGNER 
et al., 2005). Em 2004, Morigi (MORIGI, 2004) demonstrou que as célulastroncos mesenquimais apresentam tropismo pelos rins e melhoram a função renal na doença renal aguda em camundongos.

Em 2009 (CHOl et al., 2009), foi demonstrado em modelo experimental de DRC em ratos, que o uso de células-tronco diminuiria a progressão da doença renal. No referido estudo foi realizada a nefrectomia unilateral e a retirada de $2 / 3$ do parênquima do outro rim, sendo este o modelo de indução clássico para o acompanhamento da progressão de doença renal. A semelhança da progressão da doença renal humana e canina, os ratos evoluem com proteinúria, hipertensão e progridem lentamente para a falência renal na DRC. Após cinco meses de estudo foi possível observar que as células-tronco mesenquimais favoreceram os ratos, preservando a função renal e atenuando a injuria renal e proteinuria (CHOl et al., 2009).

O cordão umbilical representa uma fonte alternativa de células-tronco mesenquimais devido a sua fácil aquisição (MAYANI; LANSDORP, 1998; LEE et al., 2004). Células-tronco mesenquimais (CTM) de origem fetal são bastante viáveis para estudo por estes conterem menos anormalidades genéticas e maior capacidade proliferativa (BROOKE et al., 2007). A obtenção ou a purificação dessas células é o cerne da questão, pois o isolamento destas células depende da existência de marcadores espécie-específicos que possam assegurar a obtenção do tipo adequado de células. Desta forma, estudos interespécies têm sido propostos, devido a possibilidade de purificação e identificação adequada das células das espécies mais estudadas (GATTI et al., 2011; VILLANUEVA et al., 2011). 
Ainda devido à dificuldade na extração de grande quantidade de célulastronco, o cultivo celular tem sido empregado com a finalidade de viabilizar maior quantidade de célula adequada para a terapia. Diversos estudos demonstram a segurança de aplicação de células-tronco mesenquimais humanas em outras espécies animais, inclusive em animais não-imunossuprimidos, o que pode estar relacionado à ação imunomoduladora encontrada neste tipo de célula (LIM et al., 2011; ZUCCONI et al., 2011; VIEIRA et al., 2012).

Os mecanismos pelos quais as CTM alcançam o tecido renal e promovem sua reparação são multifatoriais. Após a infusão, a CTM migra primeiramente para os locais de lesão. Para este efeito, a CTM expressa dois tipos de receptores de homing: CXCR4 para o fator derivado de células do estroma e CD44 para o ácido hialurônico. Em seguida a CTM, libera fatores de crescimento ou citocinas anti-inflamatórias no local da lesão. As CTM liberam micropartículas transportando citocinas anti-inflamatórias e fatores de crescimento que promovem a reparação renal através da internalização nas células (ZHU; LERMAN; LERMAN, 2013).

Estudos sobre os efeitos das microvesículas derivadas de CTM em modelos de lesão renal demonstraram um efeito "renoprotetor". Bruno e colaboradores relatou que microvesículas derivadas de CTM modulavam a proteção contra a injúria renal aguda, tal como visto pela administração intravenosa de CTM (BRUNO et al., 2009). Gatti e colaboradores demonstrou que a administração única de microvesículas derivadas de CTM humanas, imediatamente após o modelo de lesão de isquemia-reperfusão, atuaram contra o desenvolvimento de lesão renal aguda e perda crônica de função visto no referido modelo (GATTI et al., 2011) 
Todas essas ações atenuam a inflamação renal e permitem regeneração vascular. Além disso, os efeitos anti-apoptóticos das CTM podem prevenir a perda de células. As CTM parecem ter pelo menos alguma capacidade para substituir células danificadas ou possivelmente exercem alguns efeitos parácrinos. No entanto, a regressão do remodelamento estrutural de longa data, como a fibrose e a perda de microvasculatura, é difícil de alcançar com qualquer intervenção terapêutica (ZHU; LERMAN; LERMAN, 2013; CAPCHA, 2015).

Uma vez que a inflamação parece estar presente em todas as fases da DRC, as ações imunomoduladoras das CTM parecem ser um meio alternativo de supressão renal da inflamação de longo prazo e com menos efeitos colaterais. Na maioria dos modelos com DRC induzida experimentalmente, a administração CTM resultou na melhoria da função renal, diminuição da inflamação, e redução da fibrose renal (NINICHUK et al., 2006; CAVAGLIERI et al., 2009; SEMEDO et al., 2009; LEE et al., 2010b; VILLANUEVA et al., 2011; RODRIGUES et al., 2017). Assim, a terapia CTM pode ser uma abordagem nova e eficaz para retardar a progressão da DRC e melhorar a função renal (QUIMBY et al., 2013; CÓNDOR et al., 2016; RODRIGUES et al., 2017).

Levando em consideração a dificuldade de obtenção de células-tronco mesenquimais oriundas do cordão umbilical de cães e a carência de marcadores específicos para cães, a opção pela utilização de células-tronco mesenquimais oriundas do cordão umbilical de humanos no protocolo de terapia dos cães com doença renal crônica parece ser uma opção viável e coerente, principalmente quando consideramos que as células-tronco mesenquimais são possíveis de serem isoladas de forma purificada, apresentam baixa imunogenicidade e 
modulam ou suprimem a resposta imunológica (STAGG, 2007; CÓNDOR et al., 2016; RODRIGUES et al., 2017).

Modelos experimentais utilizando animais de companhia são interessantes quando comparamos a semelhança entre as afecções humanas e animais, mas sua complexidade desencoraja a maioria dos pesquisadores. Além disso estudos utilizando animais de companhia sofrem mais influencias exteriores, por envolver tutores e seus desejos, e por se basear muitas vezes em observações comportamentais, manifestações clinicas feitas pelos tutores, aspectos que não existiriam utilizando modelos de experimentação animal em laboratórios (HOFFMAN; DOW, 2016).

Mas ao se levar em conta a interação tutor - animal que temos atualmente pode-se dizer que os animais de companhia são considerados membros da família para a maioria dos tutores, tendo os mesmos cuidados e atenção que um humano portador da comorbidade teria, e a atenção que esses pacientes recebem de seus tutores é infinitamente maior do que um animal em um modelo de experimentação animal receberia, já que mudanças mínimas comportamentais são percebidas e relatadas prontamente aos investigadores (HOFFMAN; DOW, 2016).

Por apresentar uma expectativa de vida menor que os humanos, pesquisas envolvendo sobrevivência e doenças degenerativas são muito mais fáceis de serem concluídas ao se utilizar um modelo animal (HOFFMAN; DOW, 2016). 


\section{Justificativa e Hipótese}

O presente estudo longitudinal, visa avaliar se a terapia com as célulastronco mesenquimais pode contribuir com a diminuição da velocidade de progressão da DRC, observando se os cães com DRC que receberam a referida terapia não desenvolveriam proteinúria ou se esta não se intensificaria ao longo da evolução da DRC. A avaliação das proteínas presentes na urina é realizada por métodos quantitativo e qualitativo determinação da concentração urinária, imunodetecção de proteínas específicas, além da identificação dos pesos moleculares. Assim, para melhor caracterização das proteínas presentes na urina propõe-se realizar a dosagem de proteína por colorimetria, pelo método de Bradford, e consequente determinação da razão proteína/creatinina urinária (RPC), além da avaliação pelos métodos qualitativos tais como a eletroforese de proteínas urinárias em gel de poliacrilamida para determinação dos pesos moleculares, e a identificação de proteínas específicas pela técnica de imunodetecção por western blot referente a três proteínas indicativas de lesão tubular, ou seja, a proteína ligada ao retinol, a proteína ligada à vitamina D e a proteína de Tamm-Horsfall e, ainda, a imunodetecção da albumina relacionada, principalmente, a lesão glomerular. Essas variáveis serão comparadas aos dados observados nos cães com DRC-placebo, ou seja, aqueles com DRC que receberam somente a solução fisiológica e submetidos apenas a terapia de manutenção rotineiramente preconizada.

Portanto, como hipótese, suscita-se que a administração de células tronco mesenquimais (CTM) em cães com DRC nos estágios 2 ou 3 possa trazer 
benefícios com o intuito de minimizar o desenvolvimento da proteinúria, pela avaliação quantitativa e qualitativa, e assim contribuir para o retardo na velocidade de progressão da doença renal. 


\section{Objetivos}

Investigar, pela determinação sequencial das proteínas urinárias por métodos quantitativo e qualitativo, se os cães com DRC nos estágios 2 ou 3 submetidos à terapia com células tronco mesenquimais apresentam, durante a evolução da doença, ausência ou menor intensidade de proteinúria quando comparados aos cães com DRC nos estágios 2 ou 3 que receberam apenas solução fisiológica (placebo) e entre os estágios. 


\section{Materiais e Métodos}

O presente projeto foi aprovado na Comissão de Ética no Uso de Animais da Faculdade de Medicina Veterinária e Zootecnia da Universidade de São Paulo sob Protocolo número 3140/2013; este estudo é um subprojeto vinculado ao Projeto Temático da FAPESP (Processo número 2010/19012-0) e que está aprovado na Comissão de Comissão de Ética no Uso de Animais da FMVZ-USP (Protocolo 1914/2010).

Para a seleção dos cães com DRC, foram atendidos um total de 255 animais com doença renal durante o período de 2013 a 2015. A exclusão dos cães se deu principalmente por presença de doenças concomitantes.

Dos cães inclusos para o estudo, 1 cão foi excluído por ter apresentado reações adversas durante a aplicação da CTM ou solução fisiológica (placebo), não completando o volume total de infusão. Assim, neste presente estudo foram acompanhados 22 cães com DRC, acompanhados em 12 ocasiões por um período aproximado de 12 a 15 meses ou até o óbito. Estes animais foram divididos em dois grupos: Grupo A constituído por nove cães no estágio 2 da DRC, sendo que desses, seis cães receberam solução fisiológica (Grupo A-SF) e os outros três receberam células tronco de origem mesenquimal (Grupo ACTM); Grupo B foi composto por 13 cães com DRC no estágio 3 em que seis cães receberam solução fisiológica (Grupo B-SF) e sete animais as células tronco de origem mesenquimal (Grupo B-CTM). O estudo foi prospectivo, longitudinal e duplo cego. As avaliações dos cães foram realizadas a cada 30 a 50 dias e os intervalos designados como T0 (início sem administração das 
células tronco ou solução fisiológica) e subsequentemente como T1, T2, T3, T4, T5, T6, T7, T8, T9, T10, T11 e T12. Os animais de ambos os grupos receberam o tratamento conservador, ou de manutenção, conforme preconizado na literatura (POLZIN, 2013). Como critério de exclusão foi instituído a doença renal crônica nos estágios 1 ou 4, qualquer tipo de neoplasia, outra afecção que pudesse evoluir com proteinúria tais como hiperadrenocorticismo, piodermite crônica, doenças infecciosas (erliquiose), entre outras, como aqueles recebendo terapias que possam alterar a taxa de filtração glomerular como corticoides, inibidores da enzima de conversão de angiotensina ou anti-inflamatórios não esteroidais.

Os cães com DRC foram provenientes do atendimento do Serviço de Clínica Médica de Pequenos Animais - Departamento de Clínica Médica / Hospital Veterinário da Faculdade de Medicina Veterinária e Zootecnia da Universidade de São Paulo.

A cada avaliação sequencial, os cães foram submetidos à mensuração da pressão arterial pelo método do doppler vascular, conforme proposto pelo consenso de hipertensão (BROWN et al., 2007), coleta de sangue para realização de hemograma e contagem de plaquetas, bioquímica sérica (ureia, creatinina, albumina, proteínas totais, colesterol, triglicérides, alanina aminotransferase (ALT) e fosfatase alcalina (FA) e coleta de urina para o exame de urina e urocultura.

O exame ultrassonográfico foi realizado para avaliação dos rins, como também para assegurar a ausência de possíveis doenças concomitantes que pudessem interferir na avaliação da proteinúria, e conforme apresentado nos apêndices AC, BC, CC e DC. Os pacientes foram avaliados antes da aplicação 
da CTM (T0), após 6 meses (T6) e após 12 meses (T12), ou até antes do óbito. e o procedimento era sempre realizado por um mesmo indivíduo (no caso, de um professor da área de diagnóstico por imagem do Departamento de Cirurgia da FMVZ-USP).

Para o grupo controle (placebo com solução fisiológica) foram selecionados 15 cães clinicamente normais (sem alterações em ultrassonografia abdominal, pressão arterial, hemograma, perfis séricos renal e hepático, triglicérides e colesterol, hemogasometria venosa, cálcio total, cálcio iônico, fósforo, sódio e potássio, exame de urina e urocultura com antibiograma). 
4.1Coleta de material biológico e realização de exames

\subsubsection{Coleta de urina}

Foram coletadas $10 \mathrm{ml}$ de urina por cistocentese ou cateterismo uretral e processadas em até 4 horas para realização do exame de urina e 30 minutos para a urocultura (NORRIS et al., 2000). Após centrifugação a 1500 G por 10 minutos, o sobrenadante das amostras de urina foi armazenado a temperatura de $80^{\circ} \mathrm{C}$ negativo para as determinações de proteína que foi utilizada para 0 cálculo da razão proteína/creatinina urinária (RPC) (SMETS et al., 2010a), para a eletroforese de proteínas urinárias, como também para a imunodetecção de proteínas específicas por western blotting (proteína ligada ao retinol, proteína ligada à vitamina $\mathrm{D}$, albumina e proteína de Tamm-Horsfall).

\subsubsection{Coleta de sangue}

Foi coletado $10 \mathrm{ml}$ de sangue de modo asséptico por punção das veias jugulares externas, cefálicas ou safenas, sendo que o volume de $2 \mathrm{ml}$ foi acondicionado em frascos com EDTA (para hemograma e contagem de plaquetas), $1 \mathrm{ml}$ para hemogasometria (na seringa com heparina de lítio) e 0 restante do volume colocados em 2 tubos de com gel ativador de coagulação para obtenção de soro para exames bioquímicos. 


\subsubsection{Exame de urina}

As amostras de urina foram avaliadas em relação às características físicas, químicas e exame do sedimento urinário conforme as técnicas empregadas rotineiramente no Laboratório Clínico do Departamento de Clínica Médica/Hospital Veterinário da FMVZ/USP.

4.1.4 Determinações das concentrações séricas de creatinina, ureia, albumina, proteínas totais, fosfatase alcalina, alanina aminotransferase, triglicérides e colesterol

As amostras foram mensuradas com a utilização de analisador automático, Labmax-240, utilizando os seguintes reagentes: Creatinina (Labtest REF. 96-300, Brasil), Ureia (Diasys REF. 131019910023, Alemanha), Albumina (Labtest REF 19-1/250, Brasil), Proteína Total (Labtest REF 99/250, Brasil), Fosfatase Alcalina (Biosystems REF 11593, Espanha), Alanina Aminotrasferase (Biosystems REF 11533, Espanha), Triglicerides (Biosystems REF 11528, Espanha) e Colesterol (Kovalent REF MS80115310040, Brasil) de acordo com as técnicas normalmente utilizadas no Serviço de Laboratório Clínico do Departamento de Clínica Médica / Hospital Veterinário da FMVZ/USP. 


\subsubsection{Determinação da concentração urinária de creatinina}

A determinação da concentração de creatinina urinária foi realizada por meio da diluição das amostras em solução salina para atingir linearidade. Foi utilizada a solução de ácido pícrico pois em meio alcalino esta reage com a creatinina produzindo picrato de creatinina, uma substância com comprimento de onda de $515 \mathrm{~nm}$, processada em analisador automático Labmax-240 (LUSTGARDEN; WENK, 1972). A concentração da creatinina urinária foi utilizada para o cálculo da RPC, com a finalidade de corrigir possíveis erros causados pela diluição ou concentração da amostra (LEES et al., 2005; HARLEY; LANGSTON, 2012).

4.1.6 Determinação da concentração urinária de proteína

A técnica de Bradford (BRADFORD, 1976) (azul brilhante de Coomassie G-250) foi empregada para a determinação da proteína urinária e as mensurações de uma mesma amostra realizada em duplicata, considerando-se como adequada uma variação máxima de 5\% entre as duplicatas, utilizando-se o sobrenadante da urina, obtido após centrifugação. Estas amostras foram armazenadas a temperatura de $-80^{\circ} \mathrm{C}$ até o momento da realização da análise. O método baseia-se na ligação do corante aos resíduos $\mathrm{NH}_{3}{ }^{+}$presentes nas proteínas, sendo essa ligação completada em cerca de dois minutos após o início da reação, desenvolvendo cor estável por uma hora, passível de absorção 
e leitura em comprimento de onda de 595 nm, mensurado no espectrofotômetro E-225 D (Celm, Brasil). Como solução padrão foi utilizado um padrão aquoso de proteínas totais (Labtest REF - 99, Brasil).

4.1.7 Determinação da razão proteína: creatinina urinária (RPC)

O cálculo da razão foi obtido pela divisão do valor da concentração urinária da proteína $(\mathrm{mg} / \mathrm{dL})$ pelo valor da concentração urinária da creatinina (mg/dL). 


\subsubsection{Determinação das proteínas urinárias por eletroforese}

Para a avaliação qualitativa das proteínas urinárias foi empregado o método de eletroforese em gel de poliacrilamida (SDS-PAGE), com gel de empilhamento com concentração de 4\% e gel de separação a 10\% (LE BRICON et al., 1998; SCHULTZE; JENSEN, 1998; GIORI et al., 2011).

O volume de urina colocado nos poços dos géis com a finalidade para que todos os poços mantivessem a concentração de $1 \mu \mathrm{g}$ de proteína/poço, foi calculado ou determinado de acordo com a concentração de proteína mensurada previamente pelo método de Bradford. Para uma melhor visualização das bandas de proteínas no gel, foi utilizado um padrão de peso molecular (Precision Plus Protein ${ }^{\mathrm{TM}}$ Kaleidoscope Standards \#161-0375 - Bio-Rad( $)$ ). A corrida eletroforética foi realizada com o uso de uma fonte elétrica (Fonte para eletroforese PS5-0003N Bio Agency Biotecnologia $\AA^{\circledR}$ ) com a miliamperagem préfixada em 40 mA. Para visualização das bandas de proteínas de acordo com o peso molecular, foi utilizada a coloração de nitrato de prata (KSHIRSAGAR; WIGGINS, 1986) e a imagem foi processada eletronicamente por meio de um sistema de densitometria (Densitômetro modelo Epson Expression® 1680) e analisada pelo software (Vision Works Ultra-Violet Products Ltd.®). A quantidade de proteína encontrada nas Regiões A (alto peso molecular ou > $60 \mathrm{kDa}$ ) e B (baixo peso molecular ou < $60 \mathrm{kDa}$ ) foi determinada após a obtenção do valor da porcentagem da densidade óptica da região analisada em relação à densidade óptica total de todo o traçado eletroforético, sendo o cálculo final baseado na quantidade total de proteína $(1 \mu \mathrm{g})$. A técnica utilizada seguiu os padrões préestabelecidos pelo Laboratório de Pesquisa do Departamento de Clínica Médica 
da FMVZ/USP em pesquisas anteriores e publicações (Processos FAPESP no 03/10426-3, 06/50468-5, 05/57490-3 e 09/53071-7) (CAVALCANTE et al., 2007, 2013; BACIC et al., 2010a; CARAGELASCO et al., 2017). 


\subsubsection{Imunodetecção por Western Blotting}

A imunodetecção de proteínas específicas por Western blotting foi realizada em amostras de urina coletadas nos momentos T0, T6 e T12. Foram determinadas as proteínas de alto peso molecular como a albumina (aproximadamente $69 \mathrm{kDa}$ ) (PAREKH et al., 2007) e a proteína de TammHorsfall (90 a 130 kDa) (DEVUSYST; DAHAN; PIRSON, 2005) e as de baixo peso molecular, como a proteína ligada a vitamina D (VDBP; aproximadamente 52 kDa) (TIAN et al., 2014), a proteína ligada ao retinol (RBP; aproximadamente 20 kDa) (PALLET et al., 2014). Essa técnica requer a realização da eletroforese em gel para a separação das proteínas, e o volume utilizado da amostra de urina foi determinado com base no cálculo considerando a concentração de creatinina urinária e diluído em buffer $(3,55 \mathrm{ml}$ de água destilada, $1,25 \mathrm{ml}$ de 0,5 Tris $\mathrm{HCl}$ $\mathrm{pH}$ 6,8, 2,5 ml de glicerol, $2,0 \mathrm{ml}$ de SDS $10 \%$ e 0,2 $\mathrm{ml}$ de 0,5\% de bromofenol blue). Foi empregado o padrão de peso molecular (Precision Plus Protein ${ }^{\top \mathrm{M}}$ WesternC Standards \#161-0376 - Bio-Rad(®), e as bandas de proteínas identificadas foram então transferidas do gel para uma membrana de PVDF por meio de eletroblotting; para evitar a ligação inespecífica de proteínas, foi realizado o bloqueio dos blots utilizando-se leite em pó desnatado a 5\%, diluído em TBS-T (24,2 g Tris base; 29,2 NaCl; 3,36 EDTA para 1 litro de água destilada) por uma hora.

Na sequência, as membranas foram incubadas com os seguintes anticorpos específicos diluídos em TBS-T: Anti-albumin antibody (espécieespecífico para o cão), ab112986, Abcam (1:500); Anti-Vitamin D Binding Protein antibody (espécie reativo para humanos, homologia para a espécie canina), 
ab95469, Abcam (1:500); Anti-Retinol Binding Protein RBP antibody (espéciereativo para humanos, homologia para a espécie canina) ab48624, Abcam (1:250); anti-Tamm-Horsfall protein (espécie-reativo para humanos, homologia para a espécie canina) AB733, EMD Millipore Corporation (1:100) (ZARAGOZA, CONCEPCIÓN BARRERA et al., 2003).

O sistema de quimiluminescência foi empregado para a revelação (ECL, Amersham) pela marcação com horseradish (HRP), para a determinação da intensidade da presença de albumina, VDBP, RBP ou THP. A análise semiquantitativa dessas proteínas foi efetuada com o auxílio do software Image J, National Institutes of Health que foi avaliada as bandas das referidas proteínas por meio de densitometria. Tendo-se obtido as mensurações da densitometria das bandas de proteínas, a média obtida a partir dos cães do grupo controle foi calculada. Os resultados obtidos da densitometria dos cães doentes foram então divididos pela média dos valores dos cães controle. Assim, os resultados da densitometria dos cães doentes foram interpretados em comparação aos animais controle (RAILA et al., 2007; CHACAR, 2015; CHACAR et al., 2017). Os valores finais foram multiplicados por 100 e expressos em porcentagem 
4.1.10 Separação de células-tronco mesenquimais a partir do cordão umbilical humano

As células-tronco mesenquimais (CTM) utilizadas neste estudo são provenientes do cordão umbilical humano obtido no pós-parto de voluntarias, após serem devidamente orientadas sobre o objetivo do procedimento e concordar com o termo de consentimento. Todos os procedimentos realizados foram aprovados pela Comissão de Ética do Hospital Universitário (HU-USP) (1278/13), pela comissão Interna para Avaliação de Projetos de Pesquisa (CIAPP) da Clínica Obstétrica do Hospital das Clínicas da Faculdade de Medicina da Universidade de São Paulo (276/10) e pela comissão de Ética para Análise de Projetos de Pesquisa (CAPPesq) da Diretoria Clínica do Hospital das Clínicas da Faculdade de Medicina na Universidade de São Paulo, que inclui aprovação no Comitê de Ética em Pesquisa da Faculdade de Medicina da Universidade de São Paulo (CEP-FMUSP) (0003/11).

Os cordões foram armazenados em meio de transporte (tampão fosfatosalino (PBS), penicilina $300 \mathrm{U} / \mathrm{mL}$, estreptomicina $300 \mu \mathrm{g} / \mathrm{mL}$ e heparina $25 \mathrm{U} / \mathrm{mL}$ ) em gelo até o laboratório, onde houve processamento do material para a extração de seu estroma, em até 24 horas após a coleta do cordão.

O processamento foi realizado de forma estéril dentro de uma cabine de biossegurança tipo II. O cordão foi lavado com PBS e cortado em pedaços de aproximadamente $2 \mathrm{~cm}$ de comprimento para facilitar a manipulação cirúrgica em placas de Petri. Em cada pedaço foi feita uma incisão longitudinal, com posterior dissecção dos vasos, para se obter apenas o conteúdo do estroma dos cordões. As porções de estroma reservadas foram novamente cortadas, desta 
vez em pedaços de 1 a $5 \mathrm{~mm}$, chamados de explantes, com aplicação sobre placas de cultura em plástico aderente de 6 poços (Corning, Sigma-Aldrich, St. Louis, EUA).

Após cerca de 20 a 30 minutos, os explantes secavam e aderiam às placas. Neste momento, cerca de 3 a $4 \mathrm{~mL}$ de meio de cultura completo composto por meio a-MEM com glutamina (Sigma-Aldrich, St. Louis, EUA), suplementado com bicarbonato para $\mathrm{pH} 7,3$; por $20 \%$ de soro fetal bovino (SFB) com inativação do complemento por calor (Sigma-Aldrich, St. Louis, EUA) e por antibióticos (penicilina 300U/mL, estreptomicina $300 \mu \mathrm{g} / \mathrm{mL}$, Life Technologies, Waltham, EUA), foi acrescentado às placas com explantes, e as placas foram armazenadas em estufa a $37^{\circ} \mathrm{C}$ com $5 \%$ de $\mathrm{CO}_{2}$ por 15 a 20 dias, sem troca de meio, com observação dos explantes em placa em microscópio invertido cerca de 2 a 3 vezes por semana.

Após 15 a 20 dias, em geral, havia início de migração de células do explante para a placa, e colônias de células começavam a se formar nas adjacências dos explantes. Essas células, fusiformes e aderentes à placa, já eram as CTM iniciando processo de proliferação. Passou-se então a se trocar o meio de cultura das placas de 2 a 3 vezes por semana, até que as células atingissem cerca de $80 \%$ de confluência.

Os explantes foram então retirados e desprezados, e as células aderidas foram tratadas com cerca de $1 \mathrm{~mL}$ de tripsina $0,25 \%$ (Life Technologies, Waltham, EUA) por poço, e colocadas em estufa a $37^{\circ} \mathrm{C}$ com $5 \%$ de $\mathrm{CO}_{2}$ por 5 minutos. Após esse tempo, observava-se o desprendimento celular ao microscópio invertido. Quando praticamente todas as células se desprendiam da placa, o meio de cultura com as células soltas era passado para tubos cônicos de $15 \mathrm{~mL}$ 
de capacidade (Corning, Sigma-Aldrich, St. Louis, EUA), com centrifugação a $500 x g$ por 10 minutos a $20^{\circ} \mathrm{C}$. As células se depositavam no fundo dos tubos, e o meio era aspirado e desprezado.

As células eram ressuspendidas em $1 \mathrm{~mL}$ de meio de cultura completo para contagem em câmara de Neubauer, e em seguidas replaqueadas. $\mathrm{O}$ replaqueamento em geral foi feito com o uso de 1 a $10 \times 10^{4}$ células por $\mathrm{mm}^{2} \mathrm{de}$ placa, e a escolha entre o replaqueamento em placas de 6 poços, garrafas de $25 \mathrm{~cm}^{2}$ ou garrafas de $75 \mathrm{~cm}^{2}$ variou de acordo com a quantidade de células que se obtinha ao final de cada tripsinização. Cada procedimento de tripsinização foi considerado uma passagem (P). Assim, células originadas do explante, em P0, após tripsinizadas passavam a ser células de primeira passagem, em P1. Células entre a terceira e a quinta passagem foram utilizadas como tratamento no animais. 


\subsubsection{Ensaios de diferenciação}

Os ensaios de diferenciação celular foram feitos a partir de CTM de segunda passagem, semeadas em placas de 6 poços, a $1 \times 10^{5}$ células por poço. Cada 2 poços foram reservados para uma das 3 linhagens de diferenciação: adipogênica, condrogênica e osteogênica. Foram acrescentados os meios de indução próprios para cada diferenciação.

Para diferenciação adipogênica: meio basal de diferenciação de adipócito STEMPRO® com suplemento para adipogênese STEMPROß (Life Technologies, Waltham, EUA), além de gentamicina a $10 \mathrm{mg} / \mathrm{mL}$ (Life Technologies, Waltham, EUA);

Para diferenciação condrogênica: meio basal de diferenciação de condrócito STEMPRO® com suplemento para condrogênese STEMPROß (Life Technologies, Waltham, EUA), além de gentamicina a $10 \mathrm{mg} / \mathrm{mL}$ (Life Technologies, Waltham, EUA);

Para diferenciação osteogênica: meio basal de diferenciação de osteócito STEMPRO® com suplemento para osteogênese STEMPRO® (Life Technologies, Waltham, EUA), além de gentamicina a $10 \mathrm{mg} / \mathrm{mL}$ (Life Technologies, Waltham, EUA).

Os meios de diferenciação foram trocados 2 a 3 vezes por semana, e as células foram mantidas em incubadora a $37^{\circ} \mathrm{C}$ com $5 \%$ de $\mathrm{CO}_{2}$. As induções adipogênica e condrogênica foram realizadas por 14 dias, enquanto a indução osteogênica foi realizada por 21 dias. 
Após a indução completa, a diferenciação foi confirmada por meio de colorações específicas:

- Coloração Oil-red para confirmar a transformação adipogênica pela visualização do acúmulo de vacúolos lipídicos citoplasmáticos;

- Coloração Alcian blue para confirmar a diferenciação condrogênica pela visualização de polissacarídeos sulfatados;

- Coloração vermelho de alizarina para confirmar a diferenciação osteogênica pela visualização de sais de cálcio.

\subsection{Aplicação de células-tronco mesenquimais}

Após o descongelamento das células, as células eram suspendidas em $1 \mathrm{~mL}$ de solução fisiológica. Após contagem, eram diluídas em maior volume para permitir a concentração de $1 \times 10^{6}$ células para cada $2 \mathrm{~mL}$, sendo que foram aplicadas $1 \times 10^{6}$ células / $\mathrm{kg}$ de peso de cada animal (portanto, um volume de $2 \mathrm{~mL} / \mathrm{kg}$ ), e esta solução mantida sob refrigeração até 30 minutos antes da administração intravenosa em veia periférica (cefálica) no momento T0, sendo o período de infusão de aproximadamente 30 minutos. O conteúdo da seringa para cada cão era determinado por apenas um operador e as seringas eram envolvidas em papel alumínio com o intuito de dificultar a visualização e a identificação do conteúdo, pois espera-se que a solução contendo as CTM fosse turva. 


\subsection{Mensuração da Pressão Arterial Sistêmica}

A pressão a arterial sistólica foi mensurada pelo método indireto com Doppler (Modelo 811-B Doppler Ultrassonic Flow Detector, Parks Medical Eletronics, Inc - Oregon, EUA), utilizando manguitos de largura correspondente a $40 \%$ em relação a medida total da circunferência do terço médio da rádio e ulna (membro torácico esquerdo ou direito).

Os pacientes eram aclimatados em um local calmo e quieto, sem outros animais e na presença do tutor por 10 minutos antes da mensuração. Antes da mensuração foi realizada a tricotomia entre os coxins carpal e metacarpiano, e utilizado gel acústico para o uso do transdutor de ultrassom.

Era permitido que o paciente fosse mantido em decúbito esternal ou lateral esquerdo ou direito ou, ainda, sentado, desde que o membro utilizado na mensuração estivesse na altura da válvula aórtica.

Foram realizadas seis mensurações e o valor considerado como a pressão arterial sistêmica sistólica do paciente foi dada pela média aritmética das mensurações.

A mensuração da pressão não foi realizada nos pacientes agressivos, ou em estado extremamente agitados. Foi considerado como hipertensão sistêmica quando a pressão sistólica fosse superior a $160 \mathrm{~mm} \mathrm{Hg}$, em 3 mensurações no intervalo de 15 dias. 


\subsection{Análise estatística}

Em todas as variáveis foram calculados os valores mínimo, máximo, média, desvio padrão da média e o erro padrão da média.

$\mathrm{Na}$ avaliação eletroforética das proteínas urinárias foi calculada a porcentagem de proteínas de alto peso molecular (HMWP) e porcentagem de proteínas de baixo peso molecular (LMWP).

Para a análise de distribuição dos dados foi utilizado o teste de Kolgorov Smirnov. No caso de distribuição paramétrica, foi empregado a análise de variância (one-way ANOVA) para avaliação das médias obtidas ao longo dos tempos de acompanhamento, e quando de distribuição não paramétrica, o teste de Kruskal-Wallis. A significância foi considerada para $\alpha<5 \%$. Para a comparação de duas médias, utilizou-se o teste $t$ de Student não pareado, quando verificada a distribuição paramétrica dos dados, e quando não paramétrica, aplicou-se o teste de Mann Whitney. Para ambos, considerou-se como nível de significância $<0,05$. Para os testes de comparação múltipla, utilizou-se os testes de Turkey-Kramer e Dunn nos dados de distribuições paramétricas e não-parametricas, respectivamente. Para ambos, considerou-se como nível de significância $p<0,05$. A área sob a curva (area under the curve AUC) foi calculada utilizando a regra da aproximação trapezoidal com o emprego de software especifico para análise (TALLARIDA; MURRAY, 1987). Foi considerado para o cálculo da área do grupo controle o valor constante obtido na mensuração pontual. Os softwares utilizados foram InStat (GraphPad), versão 3.01 e GraphPad Prism (GraphPad), versão 7. 


\section{Resultados}

As identificações dos 22 cães com DRC estão apresentados nos Quadros 1, 2, 3 e 4, sendo que destes nove animais encontravam-se no estágio 2 e treze no estágio 3. A identificação dos cães com DRC que receberam a terapia celular (subgrupos A-CTM e B-CTM) ou a solução fisiológica (subgrupos A-SF e B-SF) estão listados nos Quadros 1, 2, 3 e 4, sendo que como o estudo foi randomizado, a identificação dos cães, segundo os tratamentos, só foi revelada ao final do período de acompanhamento.

Quadro 1 - Identificação dos cães com doença renal crônica do GRUPO A (estágio 2), de acordo com prontuário de identificação no nosocômio, idade, definição racial ou não, sexo e tempo de acompanhamento, que receberam solução fisiológica (subgrupo ASF), atendidos no HOVET - Hospital Veterinário da Faculdade de Medicina Veterinária e Zootecnia da USP. São Paulo, 2017.

\begin{tabular}{|cccccc|}
\hline & Prontuário* & Idade (meses) & Definição racial & Sexo & T \\
\hline A1 & 231082 & 24 & Bulldogue americano & Fêmea & 12 \\
A2 & 160347 & 120 & Pug & Macho & 12 \\
A3 & 233197 & 36 & Golden Retriever & Fêmea & 12 \\
A4 & 239477 & 144 & Labrador Retriever & Macho & 12 \\
A5 & 241878 & 25 & SRD & Fêmea & 12 \\
A6 & 128489 & 180 & Lhasa Apso & Macho & 12 \\
\hline
\end{tabular}

Quadro 2 - Identificação dos cães com doença renal crônica do GRUPO A (estágio 2), de acordo com prontuário de identificação no nosocômio, idade, definição racial ou não, sexo, e tempo de acompanhamento que receberam células tronco mesenquimal (subgrupo A-CTM), atendidos no HOVET - Hospital Veterinário da Faculdade de Medicina Veterinária e Zootecnia da USP. São Paulo, 2017.

\begin{tabular}{|lccccc|}
\hline & Prontuário $^{*}$ & Idade (meses) & Definição racial & Sexo & T \\
\hline A7 & 190915 & 192 & Poodle & Fêmea & 12 \\
A8 & 237753 & 168 & Poodle & Macho & 12 \\
A9 & 210375 & 75 & Shih Tzu & Fêmea & 12 \\
\hline
\end{tabular}

* $\mathrm{n}^{\circ}$ Prontuário HOVET FMVZ-USP; T = tempo de acompanhamento (meses) 
Quadro 3 - Identificação dos cães com doença renal crônica do GRUPO B (estágio 3), de acordo com prontuário de identificação no nosocômio, idade, definição racial ou não, sexo, e tempo de acompanhamento que receberam solução fisiológica (subgrupo BSF), atendidos no HOVET - Hospital Veterinário da Faculdade de Medicina Veterinária e Zootecnia da USP. São Paulo, 2017.

\begin{tabular}{|lccccc|}
\hline & Prontuário* & Idade (meses) & Definição racial & Sexo & T \\
\hline B1 & 238417 & 24 & Shin tzu & Fêmea & 12 \\
B2 & 230168 & 120 & Poodle & Macho & 5 \\
B3 & 238752 & 144 & Yorkshire & Macho & 4 \\
B4 & 92802 & 192 & Fox Paulistinha & Macho & 12 \\
B5 & 243222 & 92 & Pastor Alemão & Fêmea & 5 \\
B6 & 239008 & 63 & Lhasa Apso & Fêmea & 4 \\
\hline
\end{tabular}

Quadro 4 - Identificação dos cães com doença renal crônica do GRUPO B (estágio 3), de acordo com prontuário de identificação no nosocômio, idade, definição racial ou não, sexo, e tempo de acompanhamento que receberam células tronco mesenquimais (subgrupo B-CTM), atendidos no HOVET - Hospital Veterinário da Faculdade de Medicina Veterinária e Zootecnia da USP. São Paulo, 2017.

\begin{tabular}{|cccccc|}
\hline & Prontuário* $^{*}$ & Idade (meses) & Definição racial & Sexo & T \\
\hline B7 & 231333 & 24 & Golden Retriever & Fêmea & 9 \\
B8 & 206515 & 120 & Yorkshire & Macho & 12 \\
B9 & 209003 & 132 & Pinscher & Macho & 12 \\
B10 & 167883 & 120 & Pitbull & Macho & 2 \\
B11 & 236951 & 204 & SRD & Fêmea & 4 \\
B12 & 237411 & 192 & Poodle & Fêmea & 2 \\
B13 & 239380 & 96 & Teckel & Macho & 7 \\
\hline
\end{tabular}

* $\mathrm{n}^{\circ}$ Prontuário HOVET FMVZ-USP; SRD = sem raça definida; T = tempo de acompanhamento (meses)

Dois cães com DRC foram excluídos por terem apresentado efeitos adversos durante a infusão das CTM tais como sincopes, convulsões e alterações gastrentéricas, e estes não completaram o volume total de infusão. Ainda, outros dois animais (A7 e A8) que também apresentaram reações adversas, mas que receberam o volume total da solução contendo as CTM, não foram excluídos e, portanto, acompanhados no estudo. O cão A7 apresentou manifestação clínica similar a síncope no final do período da infusão, que durou por um curto período de tempo (aproximadamente 5 segundos), bem como defecação involuntária, e observou-se breve recuperação, mantendo-se alerta, sem alterações respiratórias, cardíacas, temperatura corpórea e mucosas aparentes e nenhum tratamento foi realizado ou necessário. Nos dias 
subsequentes, este cão A7 estava assintomático, e nenhuma alteração foi detectada em seu perfil laboratorial ou clínico ao longo dos dias subsequentes. O cão A8, durante a administração intravenosa de CTM, apresentou convulsões tônico-clônicas no final do período da infusão, sendo que esta era caracterizada por espasmos tônico-clônicos que perduraram por aproximadamente 2 minutos, apresentando também sialorreia, micção e defecação involuntária e, ainda, perda parcial da consciência. Foi necessária a instituição de terapia para o cão A8, sendo administrado diazepam (0,5 mg / $\mathrm{kg}$, por via intravenosa), cessando o episódio convulsivo, e no período pós-icto houve a recuperação gradual da consciência e nenhuma manifestação clínica subsequente anormal foi notada; durante os dias de acompanhamento pós-aplicação das CTM, o animal não apresentou nenhum outro episódio convulsivo.

Todos os cães do GRUPO A foram acompanhados durante o período de pelo menos 12 meses, mas no atinente ao GRUPO B, nem todos os cães com DRC no estágio 3 completaram o período de acompanhamento proposto por virem a óbito. No subgrupo B-SF, o cão B2 que após crise de dor decorrente de discopatia foi levado para atendimento em clínica da iniciativa privada e seu proprietário optou por eutanásia (óbito antes de T6). O cão B3 do subgrupo BSF apresentou descompensação da doença renal crônica, manifestando crise urêmica, e desenvolvimento de acidose metabólica e o óbito ocorreu após T3. No atinente ao cão B5, também do subgrupo B-SF (acompanhado até T3), o proprietário decidiu não mais participar do estudo, alegando motivos pessoais, sendo que esta possibilidade estava de acordo com o Termo de Consentimento Livre e Esclarecido da Comissão de Ética. 
Dentre os animais do GRUPO B (subgrupo B-CTM) que receberam células tronco mesenquimais, o óbito ocorreu no cão B7 (óbito após T8) que apresentou descompensação da doença renal crônica (crise urêmica) desencadeado após episódio de desidratação intensa com agravamento da acidose metabólica e anemia. O animal B10 do subgrupo B-CTM (óbito após T2) teve descompensação da DRC com posterior desenvolvimento de acidose metabólica. O cão B11 do mesmo referido subgrupo (óbito após T4) desenvolveu edema pulmonar agudo decorrente de insuficiência cardíaca congestiva. O cão B12 do subgrupo B-CTM (óbito após T2) foi eutanásiado por colega, após alterações em coluna cervical, e o cão B13 (óbito após T7) apresentou também descompensação da DRC, com agravamento da desidratação e desenvolvimento de acidose metabólica e anemia.

Dos 15 cães clinicamente normais selecionados para compor o grupo controle, estes não apresentavam alterações no exame ultrassonográfico do abdômen, como também sem anormalidades na pressão arterial sistêmica, no hemograma, na avaliação sérica dos perfis renal e hepático, triglicérides, colesterol, cálcio total, cálcio iônico, fósforo, sódio e potássio, como na hemogasometria, e no exame de urina e urocultura. Ainda, nesses cães clinicamente normais, foram determinadas a razão proteína/creatinina urinária (RPC), a eletroforese de proteínas urinárias (Tabela 1). 
Tabela 1 - Valores individuais e estatística descritiva da razão proteína/creatinina urinária (RPC), da porcentagem de bandas de alto peso molecular (HMWP), da porcentagem de bandas de baixo peso molecular (LMWP), do número de bandas de alto peso molecular (BHMWP) e do número de bandas de baixo peso molecular (BLMWP) na avaliação pontual de cães do grupo controle - clinicamente normais (C1 a C15). São Paulo, 2017.

\begin{tabular}{cccccc}
\hline Controle & RPC & \% HMWP & \%LMWP & BHMWP & BLMWP \\
C 1 & 0,07 & 51,5 & 48,5 & 2 & 2 \\
C 2 & 0,09 & 70,1 & 29,9 & 2 & 1 \\
C 3 & 0,09 & 66,9 & 33,1 & 2 & 1 \\
C 4 & 0,18 & 100,0 & 0 & 1 & 0 \\
C 5 & 0,41 & 100,0 & 0 & 1 & 0 \\
C 6 & 0,11 & 100,0 & 0 & 2 & 0 \\
C 7 & 0,23 & 51,7 & 48,3 & 2 & 2 \\
C 8 & 0,22 & 100,0 & 0 & 2 & 0 \\
C 9 & 0,09 & 14,2 & 85,7 & 2 & 1 \\
C 10 & 0,34 & 28,2 & 71,8 & 1 & 1 \\
C 11 & 0,07 & 100,0 & 0 & 1 & 0 \\
C 12 & 0,03 & 74,8 & 25,1 & 2 & 1 \\
C 13 & 0,08 & 100,0 & 0 & 2 & 0 \\
C 14 & 0,07 & 79,6 & 20,4 & 3 & 1 \\
C 15 & 0,12 & 30,5 & 69,5 & 1 & 1 \\
\hline Média & 0,15 & 71,2 & 28,8 & 1,7 & 0,7 \\
D.P. & 0,10 & 30,0 & 30,0 & 0,6 & 0,7 \\
Mediana & 0,09 & 74,8 & 25,1 & 2,0 & 1,0 \\
EPM & 0,02 & 7,7 & 7,7 & 0,1 & 0,2 \\
Min & 0,03 & 14,2 & 0 & 1,0 & 0 \\
Max & 0,41 & 100,0 & 85,7 & 3,0 & 2,0 \\
\hline & & & & &
\end{tabular}




\subsection{Razão proteína/creatinina urinária (RPC)}

$\mathrm{Na}$ Tabela 2 estão dispostos os valores individuais da RPC do subgrupo A-SF e observa-se que um cão (A1) já apresentava proteinúria desde o início do período de acompanhamento (RPC em T0 de 1,10) e que persistiu ao longo de todos os tempos de observação, sendo a média de 1,49 ( \pm DP 0,65$)$. O cão A3, deste mesmo subgrupo A-SF, apenas apresentou proteinúria no momento T9 ( $R P C=1,20)$. Os cães do subgrupo A-CTM não eram proteinúricos e também não desenvolveram proteinúria avaliada pela RCP ao longo dos tempos de observação, ou seja, durante o período aproximado de 12 meses.

Tabela 2 - Valores individuais e estatística descritiva da razão proteína/creatinina urinária (RPC) dos cães dos subgrupos A-SF (A1 a A6) e A-CTM (A7 a A9), na avaliação sequencial durante a evolução da doença renal crônica. São Paulo, 2017.

\begin{tabular}{cccccccccc}
\hline & A1 & A2 & A3 & A4 & A5 & A6 & A7 & A8 & A9 \\
\hline T0 & 1,10 & 0,15 & 0,06 & 0,08 & 0,09 & 0,10 & 0,26 & 0,34 & 0,04 \\
T1 & 1,22 & 0,11 & 0,17 & 0,33 & 0,12 & 0,11 & 0,50 & 0,14 & 0,02 \\
T2 & 0,76 & 0,14 & 0,05 & 0,21 & $* *$ & 0,15 & $* *$ & 0,17 & 0,01 \\
T3 & 3,45 & 0,12 & 0,01 & 0,08 & $* *$ & $* *$ & 0,45 & 0,38 & 0,03 \\
T4 & 1,44 & 0,09 & 0,54 & 0,05 & $* *$ & 0,28 & $* *$ & 0,65 & 0,03 \\
T5 & 1,32 & 0,02 & 0,03 & 0,13 & 0,12 & 0,29 & $* *$ & 0,22 & 0,03 \\
T6 & 0,94 & 0,07 & 0,06 & 0,08 & 0,10 & 0,26 & $* *$ & 0,19 & 0,06 \\
T7 & 1,16 & 0,32 & 0,01 & 0,19 & $* *$ & 0,32 & $* *$ & $* *$ & $* *$ \\
T8 & 1,42 & 0,08 & 0,03 & 0,13 & $* *$ & 0,42 & $* *$ & $* *$ & 0,04 \\
T9 & 1,90 & 0,06 & 1,20 & 0,10 & $* *$ & 0,49 & $* *$ & 0,33 & $* *$ \\
T10 & 1,58 & 0,06 & $* *$ & 0,12 & $* *$ & $* *$ & $* *$ & 0,29 & $* *$ \\
T11 & 1,42 & 0,07 & 0,03 & 0,32 & $* *$ & 0,16 & $* *$ & 0,16 & 0,34 \\
T12 & 1,71 & 0,03 & 0,25 & 0,23 & 0,06 & 0,22 & 0,25 & 0,12 & 0,30 \\
\hline Média & 1,49 & 0,10 & 0,20 & 0,15 & 0,09 & 0,25 & 0,36 & 0,27 & 0,09 \\
D.P. & 0,65 & 0,07 & 0,34 & 0,09 & 0,02 & 0,12 & 0,12 & 0,15 & 0,12 \\
Median & 1,42 & 0,08 & 0,05 & 0,13 & 0,10 & 0,26 & 0,35 & 0,22 & 0,03 \\
EPM & 0,18 & 0,02 & 0,10 & 0,02 & 0,01 & 0,03 & 0,06 & 0,04 & 0,03 \\
Min & $\mathbf{0 , 7 6}$ & 0,02 & 0,01 & 0,05 & 0,06 & 0,10 & 0,25 & 0,12 & 0,01 \\
Max & $\mathbf{3 , 4 5}$ & 0,32 & 1,20 & 0,33 & 0,12 & 0,49 & 0,50 & 0,65 & 0,34 \\
$\boldsymbol{\Delta}$ & 0,61 & $-0,12$ & 0,19 & 0,15 & $-0,03$ & 0,12 & $-0,01$ & $-0,22$ & 0,26
\end{tabular}

D.P. = desvio padrão; ${ }^{*}$ Amostra não coletada; A-SF = subgrupo A de cães com doença renal crônica no estágio 2 que recebeu solução fisiológica; A-CTM: subgrupo A de cães com doença renal crônica no estágio 2 que grupo que recebeu célula tronco mesenquimal; $\boldsymbol{\Delta}$ = diferença entre o ultimo tempo de acompanhamento e o T0 
Em relação aos cães do GRUPO B (estágio 3 da DRC; Tabela 3), observou-se no subgrupo B-SF que dois cães (B2 e B3) já iniciaram o período de acompanhamento com proteinúria, ocorrendo o aumento de sua magnitude ao longo dos tempos de observação; os demais cães deste subgrupo B-SF, que não eram proteinúricos, mantiveram-se com a RPC normal, a exceção do cão B4 que somente nos momentos T2 e T3 apresentou discreto aumento da RPC $(0,68$ e 0,72 , respectivamente) e que nos demais tempos os valores da RPC foram igual ou inferior a 0,5 .

No subgrupo B-CTM, a maioria dos cães apresentava proteínúria (RPC > 0,5) já no início do tempo de acompanhamento, a exceção dos cães B9 e B11, e somente o animal B9 evoluiu com proteinúria mais intensa até T12 $(2,49 \pm 2,86)$; nos demais cães que iniciaram com proteinúria em T0 (B7, B8, B10, B12 e B13), o aumento da intensidade da proteinúria foi detectada somente nos cães B7 e B13 e os demais cães, B8, B10 e B12, mantiveram a intensidade da proteinúria nos mesmos patamares ou diminuíram. 
Tabela 3 - Valores individuais e estatística descritiva da razão proteína/creatinina urinária (RPC) dos cães dos subgrupos B-SF (B1 a B6) e B-CTM (B7 a B13), na avaliação sequencial durante a evolução da doença renal crônica. São Paulo, 2017.

\begin{tabular}{|c|c|c|c|c|c|c|c|c|c|c|c|c|c|}
\hline & B1 & B2 & B3 & B4 & B5 & B6 & B7 & B8 & B9 & B10 & B11 & B12 & B13 \\
\hline T0 & 0,01 & 1,71 & 3,43 & 0,24 & 0,27 & 0,26 & 1,07 & 1,05 & 0,31 & 2,75 & 0,22 & 0,67 & 3,89 \\
\hline T1 & 0,28 & 2,08 & 7,67 & 0,42 & $* *$ & 0,50 & 1,69 & 0,76 & 1,49 & 3,20 & 0,33 & 0,27 & ** \\
\hline T2 & 0,14 & 5,69 & 4,48 & 0,68 & 0,14 & 0,21 & 1,77 & 0,83 & 0,50 & 1,35 & 0,20 & $\dagger$ & 11,05 \\
\hline T3 & 0,02 & 4,16 & 5,62 & 0,72 & 0,12 & 0,36 & 1,13 & 2,17 & 0,28 & $\dagger$ & 0,27 & & ** \\
\hline T4 & 0,02 & 3,68 & $\dagger$ & 0,23 & & $\dagger$ & 2,00 & 0,55 & 0,25 & & 0,21 & & ** \\
\hline T5 & 0,01 & 1,84 & & 0,17 & & & 2,70 & 0,90 & 5,58 & & $\dagger$ & & ** \\
\hline T6 & 0,02 & $\dagger$ & & 0,21 & & & 2,34 & 0,84 & 0,33 & & & & 6,23 \\
\hline T7 & 0,19 & & & 0,47 & & & 2,00 & 1,71 & 1,66 & & & & 4,27 \\
\hline T8 & 0,15 & & & 0,28 & & & 2,00 & 2,73 & 3,22 & & & & $\dagger$ \\
\hline T9 & 0,01 & & & 0,22 & & & $\dagger$ & 1,76 & 10,40 & & & & \\
\hline T10 & 0,08 & & & 0,27 & & & & 1,30 & 2,53 & & & & \\
\hline T11 & 0,11 & & & 0,50 & & & & 1,80 & 3,34 & & & & \\
\hline T12 & 0,20 & & & 0,48 & & & & 0,82 & 2,47 & & & & \\
\hline Média & 0,09 & 3,19 & 5,30 & 0,37 & 0,17 & 0,33 & 1,85 & 1,32 & 2,48 & 2,43 & 0,24 & 0,47 & 6,36 \\
\hline D.P. & 0,09 & 1,59 & 1,81 & 0,18 & 0,08 & 0,12 & 0,52 & 0,65 & 2,86 & 0,96 & 0,05 & 0,28 & 3,29 \\
\hline Mediana & 0,08 & 2,88 & 5,05 & 0,28 & 0,14 & 0,31 & 2,00 & 1,05 & 1,66 & 2,75 & 0,22 & 0,47 & 5,25 \\
\hline EPM & 0,02 & 0,65 & 0,90 & 0,05 & 0,04 & 0,06 & 0,17 & 0,18 & 0,79 & 0,55 & 0,02 & 0,20 & 1,64 \\
\hline Min & 0,01 & 1,71 & 3,43 & 0,17 & 0,12 & 0,21 & 1,07 & 0,55 & 0,25 & 1,35 & 0,20 & 0,27 & 3,89 \\
\hline Max & 0,28 & 5,69 & 7,67 & 0,72 & 0,27 & 0,50 & 2,70 & 2,73 & 10,40 & 3,20 & 0,33 & 0,67 & 11,05 \\
\hline$\Delta$ & 0,19 & 0,13 & 2,19 & 0,24 & $-0,15$ & 0,10 & 0,93 & $-0,23$ & 2,16 & $-1,40$ & $-0,01$ & $-0,40$ & 0,38 \\
\hline
\end{tabular}

Na Tabela 4 observa-se que houve diferença da RPC entre os subgrupos A-CTM e B-CTM $(P<0,0001)$, e não foi detectada diferença entre os subgrupos A-SF e B-SF $(P=0,88)$. Somente o subgrupo B-CTM foi diferente em relação ao controle $(P<0,0001)$. Houve diferença entre os subgrupos B-SF e B-CTM $(P<$ $0,0001)$ e não entre os grupos A-SF e A-CTM $(P=0,990)$.

Tabela 4 - Avaliação estatística (valores de $\mathrm{P}$ na análise de variância - one way ANOVA) da razão proteína/creatinina urinária (RPC) dos cães dos GRUPOS A e B, referentes aos respectivos subgrupos (A-SF e A-CTM; B-SF e B-CTM) e grupo controle, cães clinicamente normais. São Paulo, 2017.

\begin{tabular}{cccccc}
\hline & A-SF & A-CTM & B-SF & B-CTM & Controle \\
\hline A-SF & & 0,99 & 0,88 & $<0,0001$ & 0,9487 \\
A-CTM & 0,99 & & 0,30 & $<0,0001$ & 0,99 \\
B-SF & 0,88 & 0,30 & & $<0,0001$ & 0,13 \\
B-CTM & $<0,001$ & $<0,001$ & $<0,001$ & & $<0,001$ \\
Controle & 0,94 & 0,99 & 0,13 & $<0,001$ & \\
\hline
\end{tabular}

A-SF = cães com doença renal crônica no estágio 2 que receberam solução fisiológica; A-CTM: cães com doença renal crônica no estágio 2 que receberam célula tronco mesenquimal; B-SF = cães com doença renal crônica no estágio 3 que receberam solução fisiológica; $\mathbf{B}$ CTM: cães com doença renal crônica no estágio 3 que receberam célula tronco mesenquimal 
Para fins de comparação das médias da RPC em cada tempo de avaliação e entre os subgrupos A-SF e A-CTM, observou-se que os valores maiores de RPC nos pacientes do subgrupo A-SF ao se comparar com os cães do subgrupo A-CTM, entretanto, sem diferença significante (Tabela 5), os valores foram então plotados em um gráfico de dispersão com linha de tendência para avaliação do comportamento da variável ao longo do tempo (Figura 1).

Tabela 5 - Estatística descritiva dos valores médios da razão proteína/creatinina urinária (RPC) nos diferentes tempos de avaliação (T0 a T12) dos cães com doença renal crônica no estágio 2 (GRUPO A) referentes aos subgrupos A-SF e A-CTM. São Paulo, 2017.

\begin{tabular}{|c|c|c|c|}
\hline Estagio 2 & A-SF (média $\pm \mathrm{DP}$ ) & A-CTM (média $\pm \mathrm{DP}$ ) & \\
\hline TO & $0,27( \pm 0,43) ; n=6$ & $0,21( \pm 0,15) ; n=3$ & \\
\hline T1 & $0,34( \pm 0,43) ; n=6$ & $0,22( \pm 0,24) ; n=3$ & \\
\hline T2 & $0,26( \pm 0,28) ; n=6$ & $0,09( \pm 0,11) ; n=3$ & \\
\hline T3 & $0,91( \pm 1,69) ; n=6$ & $0,28( \pm 0,22) ; n=3$ & \\
\hline T4 & $0,48( \pm 0,57) ; n=6$ & $0,34( \pm 0,43) ; n=3$ & \\
\hline T5 & $0,31( \pm 0,50) ; n=6$ & $0,12( \pm 0,13) ; n=3$ & \\
\hline T6 & $0,25( \pm 0,34) ; n=6$ & $0,12( \pm 0,09) ; n=3$ & \\
\hline T7 & $0,40( \pm 0,44) ; n=6$ & $0,14( \pm 0,15) ; n=3$ & \\
\hline T8 & $0,41( \pm 0,58) ; n=6$ & $0,04( \pm 0,00) ; n=3$ & \\
\hline T9 & $0,75( \pm 0,78) ; n=6$ & $0,33( \pm 0,00) ; n=3$ & \\
\hline T10 & $0,58( \pm 0,86) ; n=6$ & $0,29( \pm 0,00) ; n=3$ & \\
\hline T11 & $0,40( \pm 0,58) ; n=6$ & $0,25( \pm 0,12) ; n=3$ & \\
\hline T12 & $0,41( \pm 0,64) ; n=6$ & $0,22( \pm 0,09) ; n=3$ & \\
\hline Média & $0,44( \pm 0,19)$ & $0,20( \pm 0,09)$ & $P=0,99$ \\
\hline
\end{tabular}


FIGURA 1 - Gráfico de dispersão dos valores médios da razão proteína/creatinina urinária (RPC) nos diferentes tempos de avaliação (T0 a T12) dos cães com doença renal crônica no estágio 2 (GRUPO A) referentes aos subgrupos A-SF e A-CTM. São Paulo, 2017.



Na Tabela 6 observa-se que os valores da RPC dos cães do subgrupo BCTM foram maiores que o subgrupo B-SF $(P<0,0001)$, os valores foram então plotados em um gráfico de dispersão com linha de tendência para avaliação do comportamento da variável ao longo do tempo (Figura 2).

Tabela 6 - Estatística descritiva dos valores médios da razão proteína/creatinina urinária (RPC) nos diferentes tempos de avaliação dos cães com doença renal crônica no estágio 3 (GRUPO B) referentes aos subgrupos B-SF e B-CTM . São Paulo, 2017.

\begin{tabular}{|c|c|c|}
\hline Estagio 3 & B-SF (média \pm DP) & B-CTM (média \pm DP) \\
\hline T0 & $0,98( \pm 1,34) ; n=6$ & $1,42( \pm 1,37) ; n=7$ \\
\hline T1 & $2,19( \pm 3,15) ; n=6$ & $1,29( \pm 1,10) ; n=7$ \\
\hline T2 & $1,89( \pm 2,51) ; n=6$ & $2,61( \pm 4,17) ; n=6$ \\
\hline T3 & $1,83( \pm 2,42) ; n=3$ & $0,96( \pm 0,90) ; n=5$ \\
\hline T4 & $1,31( \pm 2,05) ; n=3$ & $0,75( \pm 0,84) ; n=5$ \\
\hline T5 & $0,67( \pm 1,01) ; n=2$ & $3,06( \pm 2,36) ; n=4$ \\
\hline T6 & $0,11( \pm 0,13) ; n=2$ & $2,43( \pm 2,67) ; n=4$ \\
\hline T7 & $0,33( \pm 0,19) ; n=2$ & $2,41( \pm 1,24) ; n=4$ \\
\hline T8 & $0,21( \pm 0,09) ; n=2$ & $2,65( \pm 0,61) ; n=3$ \\
\hline T9 & $0,11( \pm 0,14) ; n=2$ & $6,08( \pm 6,10) ; n=2$ \\
\hline T10 & $0,17( \pm 0,13) ; n=2$ & $1,91( \pm 0,86) ; n=2$ \\
\hline $\mathrm{T} 11$ & $0,30( \pm 0,27) ; n=2$ & $2,57( \pm 1,08) ; n=2$ \\
\hline T12 & $0,34( \pm 0,19) ; n=2$ & $1,64( \pm 1,16) ; n=2$ \\
\hline Média & $0,80( \pm 0,75)$ & $2,29( \pm 1,34)$ \\
\hline
\end{tabular}

$\overline{\mathrm{DP}}$ = desvio padrão da média; B-SF = cães com doença renal crônica no estágio 3 que recebeu solução fisiológica; B-CTM: cães com doença renal crônica no estágio 3 que recebeu célula tronco mesenquimal 
FIGURA 2 - Gráfico de dispersão dos valores médios da razão proteína/creatinina urinária (RPC) nos diferentes tempos de avaliação (T0 a T12) dos cães com doença renal crônica no estágio 3 (GRUPO B) referentes aos subgrupos B-SF e B-CTM. São Paulo, 2017.

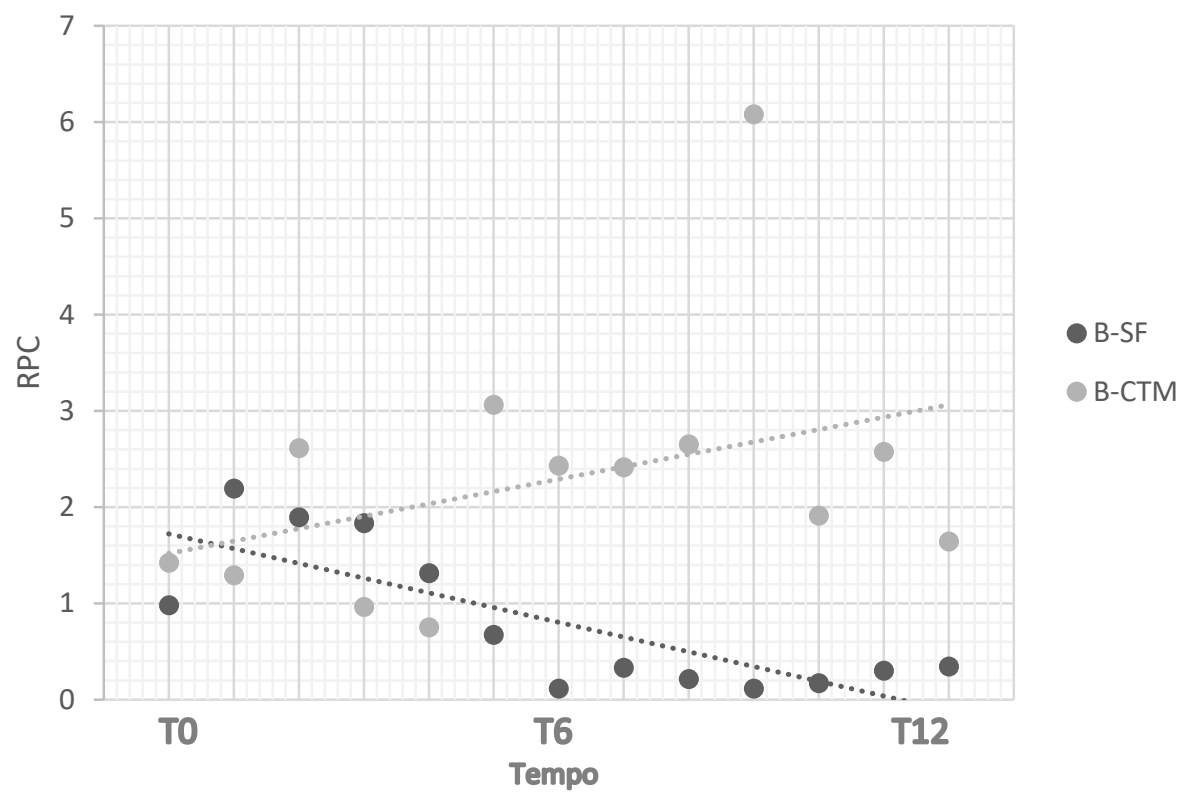

A configuração dos valores médios da RPC ao longo do período de observação, nos diferentes tempos, dos subgrupos A-SF, A-CTM, B-SF e B-CTM estão dispostos na Figura 3. Os cães do Grupo B, estágio 3 da DRC, subgrupos B-SF e B-CTM já iniciaram o período de observação com proteinúria, não se observando diminuição significante da RPC ao longo do tempo de acompanhamento. 
Figura 3 - Valores médios da razão proteína/creatinina urinária (RPC) dos cães dos Grupos A e B e respectivos subgrupos A-SF $(n=6)$, A-CTM $(n=3)$, B-SF $(n=6)$ e B-CTM $(\mathrm{n}=7)$, na avaliação sequencial durante a evolução da doença renal crônica. São Paulo, 2017.

\section{RPC}

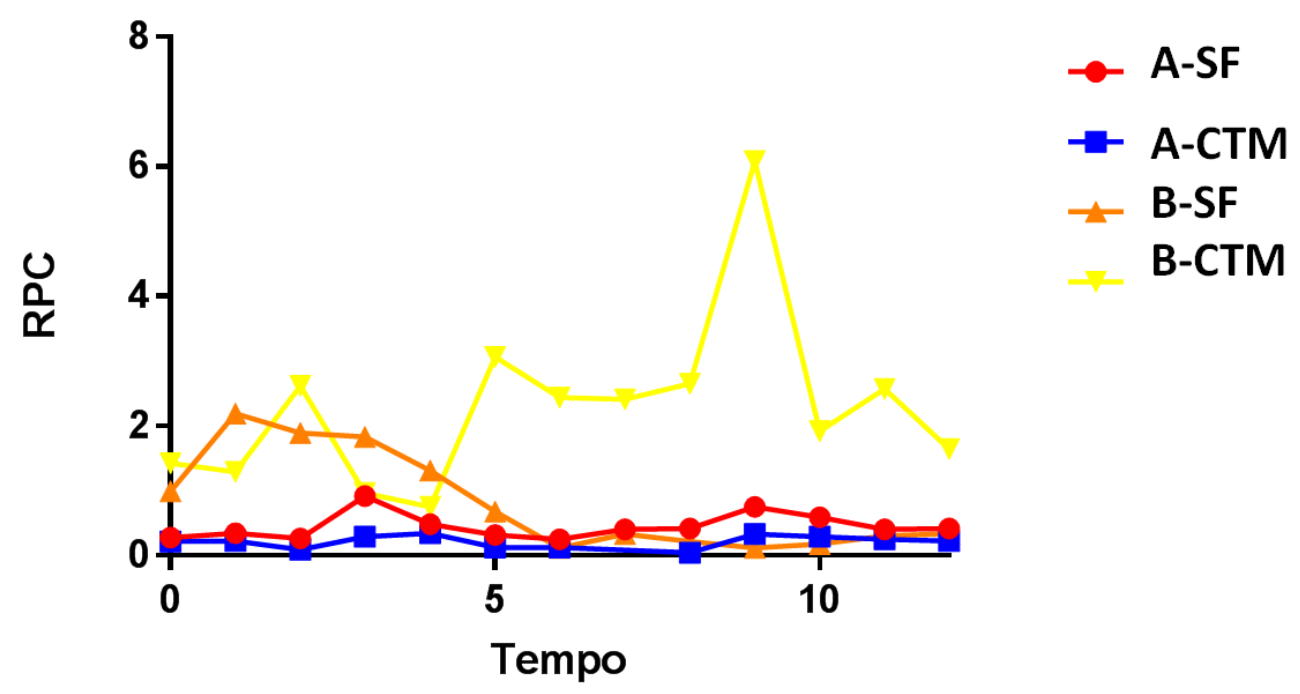

A-SF = cães com doença renal crônica no estágio 2 que receberam solução fisiológica; A-CTM: cães com doença renal crônica no estágio 2 que receberam célula tronco mesenquimal; B-SF = cães com doença renal crônica no estágio 3 que receberam solução fisiológica; BCTM: cães com doença renal crônica no estágio 3 que receberam célula tronco mesenquimal;

O cálculo da área sob a curva confirmou que o subgrupo B-CTM apresentou os maiores valores de RPC ao longo do tempo (Tabela 7).

Tabela 7 - Cálculo da área sob a curva (AREA) da razão proteína/creatinina urinária (RPC) dos cães dos grupos A e B, respectivos subgrupos A-SF $(n=6)$, A-CTM $(n=3)$, B-SF ( $n=6)$ e B-CTM $(n=7)$, na avaliação sequencial durante a evolução da doença renal crônica. São Paulo, 2017.

\begin{tabular}{cccccc}
\multicolumn{1}{c}{} & A-SF & A-CTM & B-SF & B-CTM & Controle \\
\hline AREA & 5,46 & 2,39 & 9,81 & 28,28 & 1,93 \\
Erro & 1,78 & 0,44 & 3,77 & 6,15 & 0 \\
IC 95\% & $1,97-8,96$ & $1,53-3,26$ & $2,42-17,21$ & $16,22-40,33$ & \\
\hline
\end{tabular}

A-SF = cães com doença renal crônica no estágio 2 que receberam solução fisiológica; A-CTM: cães com doença renal crônica no estágio 2 que receberam célula tronco mesenquimal; B-SF = cães com doença renal crônica no estágio 3 que receberam solução fisiológica; BCTM: cães com doença renal crônica no estágio 3 que receberam célula tronco mesenquimal; Controle = cães clinicamente normais; IC = intervalo de confiança. 
5.2 Proteínas de alto peso molecular (PM > 60 kDa; HMWP) detectadas pela eletroforese de proteínas urinárias

Os cães $A 4, A 5$ e $A 6$ do subgrupo $A-S F$ e os cães $A 7, A 8$ e $A 9$ do subgrupo A-CTM apresentaram média da porcentagem de proteínas de alto peso molecular (HMWP) inferior a 50\% ao longo do período de observação.

$\mathrm{Na}$ avaliação sequencial ao longo dos tempos, nota-se que no subgrupo A-SF não houve variação intensa na porcentagem de proteínas de alto peso molecular, sendo que o desvio-padrão (DP) variou de 4,9 a 23,5. No referente ao subgrupo A-CTM, a variação ao longo do período de observação também foi discreta, entretanto o cão A9 apresentou a maior oscilação na porcentagem de proteínas de alto peso molecular com variação de mínima e máxima de 15,6 e $69,7 \%$, respectivamente (Tabela 8 ). 
Tabela 8 - Valores individuais e estatística descritiva da porcentagem de proteínas de alto peso molecular $(>60 \mathrm{kDa})$ na urina determinada pela eletroforese SDS-PAGE na avaliação sequencial durante a evolução (T0 a T12) da doença renal crônica em cães do GRUPO A, subgrupos A-SF (A1 a A6) e A-CTM (A7 a A9). São Paulo, 2017.

\begin{tabular}{|c|c|c|c|c|c|c|c|c|c|}
\hline & $\mathrm{A1}^{*}$ & A2 & A3 & A4 & A5 & A6 & A7 & A8 & A9 \\
\hline T0 & 58,15 & 100,0 & 53,78 & 60,48 & 18,01 & 42,58 & 47,08 & 0 & 15,58 \\
\hline T1 & 77,90 & 100,0 & 57,95 & 51,15 & 13,77 & 29,85 & 50,65 & 33,60 & 53,73 \\
\hline T2 & 78,59 & 52,69 & 49,97 & 30,25 & ** & 33,21 & ** & 50,21 & 33,47 \\
\hline T3 & 100,0 & 56,50 & 33,22 & 48,24 & ** & ** & 38,71 & 47,77 & 69,67 \\
\hline T4 & 85,02 & 55,68 & 53,15 & 44,95 & ** & 40,27 & ** & ** & 68,50 \\
\hline T5 & ** & 51,48 & 67,62 & 57,30 & 18,60 & 34,95 & ** & 47,67 & 65,31 \\
\hline T6 & 68,74 & 53,81 & 51,39 & 50,37 & 25,89 & 36,62 & ** & 48,55 & 21,16 \\
\hline T7 & 52,64 & 84,87 & 57,35 & 44,90 & ** & 31,27 & ** & 46,90 & ** \\
\hline T8 & 53,91 & 56,18 & 58,75 & ** & ** & 28,94 & ** & 43,84 & 20,54 \\
\hline T9 & 57,83 & 68,05 & 40,79 & 44,06 & ** & 43,74 & ** & 50,82 & ** \\
\hline T10 & 63,24 & 41,62 & ** & 54,55 & ** & ** & ** & 38,43 & ** \\
\hline T11 & 59,17 & 37,97 & 62,35 & 48,11 & ** & 42,24 & ** & ** & 17,86 \\
\hline T12 & 54,35 & 40,94 & 50,54 & 66,55 & 24,20 & 45,13 & 43,12 & 0 & 24,82 \\
\hline Média & 67,46 & 61,52 & 53,07 & 46,22 & 20,09 & 37,16 & 44,89 & 31,36 & 39,06 \\
\hline D.P. & 14,90 & 20,91 & 9,22 & 16,47 & 4,92 & 5,90 & 5,14 & 22,26 & 22,63 \\
\hline Mediana & 61,20 & 55,68 & 53,46 & 48,24 & 18,60 & 36,62 & 45,10 & 43,84 & 29,14 \\
\hline EPM & 4,30 & 5,80 & 2,66 & 4,57 & 2,20 & 1,77 & 2,57 & 6,17 & 7,15 \\
\hline Min & 52,64 & 37,97 & 33,22 & 0 & 13,77 & 28,94 & 38,71 & 0 & 15,58 \\
\hline Max & 100 & 100 & 67,62 & 66,55 & 25,89 & 45,13 & 50,65 & 50,82 & 69,67 \\
\hline$\Delta$ & $-3,80$ & $-59,06$ & $-3,24$ & 6,07 & 6,19 & 2,55 & $-3,96$ & 0 & 9,24 \\
\hline
\end{tabular}

No subgrupo B-SF, na avaliação sequencial dos tempos, observa-se pouca variação da porcentagem de proteínas de alto peso molecular, com variação do DP de 3,1 a 14,6\% e de forma semelhante nos cães do subgrupo BCTM em que a variação da DP foi de 16 a 24,2\%; o cão B12 que veio a óbito antes de T2 não apresentou em dois momentos de avaliação proteínas de alto peso molecular. Nos cães do subgrupo B-SF, a presença mais intensa de proteínas de alto peso molecular (> 50\%) somente foi observada em um cão (B3) e em três cães (B7, B8 e B10) do subgrupo B-CTM. No geral, nota-se diminuição da quantidade de proteínas de alto peso molecular, principalmente no subgrupo B-SF (Tabela 9). 
Tabela 9 - Valores individuais e estatística descritiva da porcentagem de proteínas de alto peso molecular $(>60 \mathrm{kDa})$ na urina determinada pela eletroforese SDS-PAGE na avaliação sequencial durante a evolução (T0 a T12 ou até o óbito) da doença renal crônica em cães do GRUPO B, subgrupos B-SF (B1 a B6) e B-CTM (B7 a B13). São Paulo, 2017.

\begin{tabular}{|c|c|c|c|c|c|c|c|c|c|c|c|c|c|}
\hline Grupo B & B1 & B2* $^{*}$ & B3* $^{*}$ & B4 & B5 & B6 & B7* $^{*}$ & B8* & B9* & B10* & B11 & B12* $^{*}$ & B13* $^{*}$ \\
\hline T0 & 36,46 & 57,61 & 83,51 & 19,04 & 0 & 10,93 & 57,99 & 57,85 & 34,99 & 42,30 & 14,77 & 0 & 17,45 \\
\hline $\mathrm{T} 1$ & 62,53 & 51,79 & 80,98 & 17,81 & ** & 32,88 & 83,26 & 60,92 & 40,55 & 39,25 & 35,10 & 0 & ** \\
\hline T2 & 43,88 & 47,92 & 80,18 & 22,29 & 0 & 32,86 & 55,54 & 100,00 & 36,38 & 70,11 & 48,81 & $\dagger$ & 13,29 \\
\hline T3 & 51,76 & 43,56 & 82,28 & 27,54 & 10,17 & 15,11 & 84,18 & 64,32 & 42,25 & $\dagger$ & 23,33 & & ** \\
\hline T4 & 43,38 & 41,67 & $\dagger$ & 20,90 & & $\dagger$ & 51,86 & 65,26 & 32,63 & & 25,61 & & ** \\
\hline T5 & 46,74 & 27,80 & & 17,35 & & & 57,65 & 60,88 & 32,14 & & $t$ & & ** \\
\hline T6 & 27,59 & $\dagger$ & & 20,61 & & & 33,28 & 61,42 & ** & & & & 51,93 \\
\hline $\mathrm{T7}$ & 44,34 & & & 19,67 & & & 54,08 & 50,89 & 31,14 & & & & 41,39 \\
\hline T8 & $\star \star$ & & & 15,22 & & & 50,10 & 38,77 & 35,94 & & & & $\dagger$ \\
\hline T9 & 45,35 & & & 22,48 & & & $\dagger$ & 48,76 & ** & & & & \\
\hline T10 & 43,33 & & & 18,01 & & & & 43,47 & 34,32 & & & & \\
\hline $\mathrm{T} 11$ & 40,50 & & & 21,42 & & & & 8,01 & 6,82 & & & & \\
\hline T12 & 41,44 & & & 18,74 & & & & 7,86 & 43,10 & & & & \\
\hline Média & 43,94 & 45,05 & 81,73 & 20,08 & 3,39 & 22,94 & 58,66 & 51,41 & 33,66 & 50,55 & 29,52 & 0 & 31,05 \\
\hline D.P. & 8,30 & 10,22 & 1,46 & 3,06 & 5,87 & 11,58 & 16,01 & 24,24 & 9,74 & 17,00 & 12,98 & 0 & 18,64 \\
\hline Mediana & 43,63 & 45,74 & 81,63 & 19,67 & 0,00 & 23,98 & 55,54 & 57,85 & 25,61 & 42,30 & 25,61 & 0 & 29,42 \\
\hline EPM & 2,39 & 4,17 & 0,73 & 0,84 & 3,39 & 5,79 & 5,33 & 6,72 & 2,94 & 9,81 & 5,80 & 0 & 9,32 \\
\hline Min & 27,59 & 27,80 & 80,18 & 15,22 & 0,00 & 10,93 & 33,28 & 7,86 & 6,82 & 39,25 & 14,77 & 0 & 13,29 \\
\hline Max & 62,53 & 57,61 & 83,51 & 27,54 & 10,17 & 32,88 & 84,18 & 100 & 43,10 & 70,11 & 48,81 & 0 & 51,93 \\
\hline$\Delta$ & 4,98 & $-29,81$ & $-1,23$ & $-0,3$ & 10,17 & 4,18 & $-7,89$ & $-49,99$ & 8,11 & 27,81 & 10,84 & 0 & 23,94 \\
\hline
\end{tabular}

Todos os subgrupos dos Grupos A e B apresentaram diferença significante da porcentagem de proteínas de alto peso molecular em relação ao grupo controle (Tabela 10), indicando a perda urinária de proteínas possivelmente decorrente de comprometimento glomerular.

Tabela 10 - Avaliação estatística (análise de variância - one way ANOVA) da porcentagem de proteínas de alto peso molecular (HMWP) dos cães dos GRUPOS A e B, referentes aos respectivos subgrupos (A-SF e A-CTM; B-SF e B-CTM) e grupo controle, cães clinicamente normal. São Paulo, 2017.

\begin{tabular}{llllll}
\hline & A-SF & A-CTM & B-SF & B-CTM & Controle \\
\hline A-SF & & 0,45 & 0,04 & 0,53 & 0,02 \\
A-CTM & 0,45 & & 0,98 & 0,99 & $<0,0001$ \\
B-SF & 0,04 & 0,98 & & 0,96 & $<0,0001$ \\
B-CTM & 0,53 & 0,99 & 0,96 & & $<0,0001$ \\
Controle & 0,02 & $<0,0001$ & $<0,0001$ & $<0,0001$ & \\
\hline
\end{tabular}

A-SF = cães com doença renal crônica no estágio 2 que receberam solução fisiológica; A-CTM: cães com doença renal crônica no estágio 2 que receberam célula tronco mesenquimal; B-SF = cães com doença renal crônica no estágio 3 que receberam solução fisiológica; BCTM: cães com doença renal crônica no estágio 3 que receberam célula tronco mesenquimal; Controle = cães clinicamente normais 
Os cães do subgrupo A-SF apresentaram média (> 50\%) da porcentagem de proteínas de alto peso molecular maiores quando comparada com os cães do subgrupo A-CTM, entretanto essa diferença não foi significante (Tabela 11), os valores foram então plotados em um gráfico de dispersão com linha de tendência para avaliação do comportamento da variável ao longo do tempo (Figura 4).

Tabela 11 - Estatística descritiva das médias da porcentagem de proteínas de alto peso molecular (HMWP) dos cães com doença renal crônica no estágio 2 (GRUPO A) subgrupos A-SF e A-CTM ao longo dos tempos de acompanhamento. São Paulo, 2017.

\begin{tabular}{|c|c|c|c|}
\hline Estagio 2 & A-SF $( \pm D P)$ & $\mathrm{A}-\mathrm{CTM}( \pm \mathrm{DP})$ & \\
\hline T0 & $55,50( \pm 26,78) ; n=6$ & $20,88( \pm 23,98) ; n=3$ & \\
\hline T1 & $55,10( \pm 31,32) ; n=6$ & $45,99( \pm 10,84) ; n=3$ & \\
\hline $\mathrm{T} 2$ & $48,94( \pm 19,30) ; n=6$ & $41,84( \pm 11,83) ; n=3$ & \\
\hline T3 & $59,49( \pm 28,67) ; n=6$ & $52,05( \pm 15,91) ; n=3$ & \\
\hline T4 & $55,81( \pm 17,46) ; n=6$ & $34,25( \pm 48,43) ; n=3$ & \\
\hline T5 & $45,99( \pm 19,35) ; n=6$ & $56,49( \pm 12,47) ; n=3$ & \\
\hline T6 & $47,80( \pm 14,82) ; n=6$ & $34,85( \pm 19,36) ; n=3$ & \\
\hline T7 & $54,20( \pm 19,78) ; n=6$ & $46,90( \pm 0,00) ; n=3$ & \\
\hline T8 & $39,55( \pm 25,14) ; n=6$ & $32,19( \pm 16,47) ; n=3$ & \\
\hline T9 & $50,89( \pm 11,64) ; n=6$ & $50,82( \pm 0,00) ; n=3$ & \\
\hline T10 & $53,13( \pm 10,87) ; n=6$ & $38,43( \pm 0,00) ; n=3$ & \\
\hline $\mathrm{T} 11$ & $49,96( \pm 10,54) ; n=6$ & $8,93( \pm 12,62) ; n=3$ & \\
\hline $\mathrm{T} 12$ & $46,95( \pm 14,20) ; n=6$ & $22,64( \pm 21,64) ; n=3$ & \\
\hline Média & $51,79( \pm 5,81)$ & $37,40( \pm 13,81)$ & $P=0,45$ \\
\hline
\end{tabular}


FIGURA 4 - Gráfico de dispersão dos valores médios da porcentagem de proteínas de alto peso molecular (HMWP) nos diferentes tempos de avaliação (T0 a T12) dos cães com doença renal crônica no estágio 2 (GRUPO A) referentes aos subgrupos A-SF e A-CTM. São Paulo, 2017.

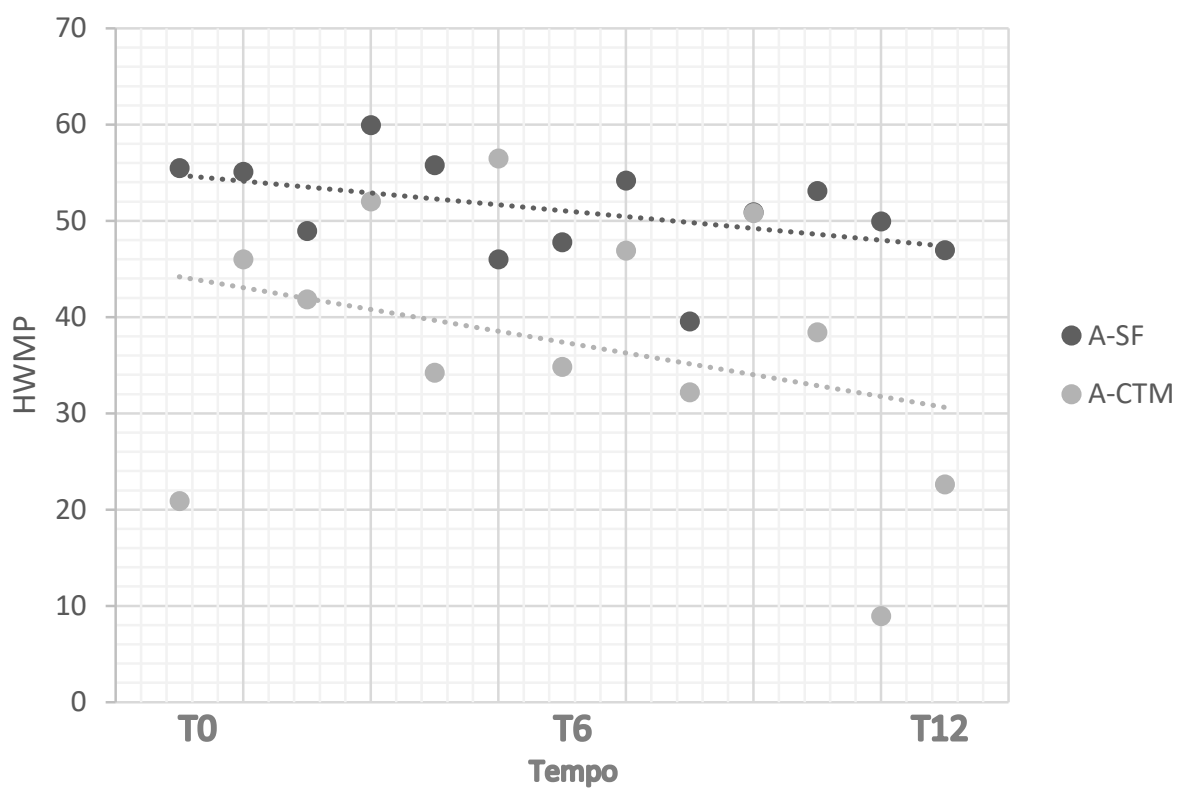

Quanto aos subgrupos B-SF e B-CTM, ambos apresentaram média das porcentagens de proteínas de alto peso molecular inferior a 39\% e sem diferença significante entre eles, indicando, por outro lado, o predomínio de perda de proteína urinária de baixo peso molecular em ambos os subgrupos (Tabela 12), os valores foram então plotados em um gráfico de dispersão com linha de tendência para avaliação do comportamento da variável ao longo do tempo (Figura 5). 
Tabela 12 - Estatística descritiva das médias da porcentagem de proteína de alto peso molecular (HMWP) dos cães com doença renal crônica no estágio 3 (GRUPO B) segundo os subgrupos B-SF e B-CTM ao longo dos tempos de acompanhamento. São Paulo, 2017.

\begin{tabular}{ccc}
\hline Estagio 3 & B-SF $( \pm \mathrm{DP})$ & B-CTM $( \pm \mathrm{DP})$ \\
\hline T0 & $34,59( \pm 31,34) ; \mathrm{n}=6$ & $32,19( \pm 22,32) ; \mathrm{n}=7$ \\
T1 & $49,19( \pm 24,72) ; \mathrm{n}=6$ & $43,18( \pm 27,83) ; \mathrm{n}=7$ \\
T2 & $37,85( \pm 26,94) ; \mathrm{n}=6$ & $54,02( \pm 29,57) ; \mathrm{n}=6$ \\
T3 & $38,40( \pm 26,78) ; \mathrm{n}=6$ & $53,52( \pm 26,42) ; \mathrm{n}=5$ \\
T4 & $35,31( \pm 12,51) ; \mathrm{n}=3$ & $43,84( \pm 18,08) ; \mathrm{n}=5$ \\
T5 & $30,63( \pm 14,89) ; \mathrm{n}=3$ & $50,22( \pm 15,74) ; \mathrm{n}=4$ \\
T6 & $24,10( \pm 4,93) ; \mathrm{n}=2$ & $48,87( \pm 14,31) ; \mathrm{n}=4$ \\
T7 & $32,00( \pm 17,44) ; \mathrm{n}=2$ & $44,37( \pm 10,33) ; \mathrm{n}=4$ \\
T8 & $15,22( \pm 0,00) ; \mathrm{n}=2$ & $41,60( \pm 7,49) ; \mathrm{n}=3$ \\
T9 & $33,91( \pm 16,17) ; \mathrm{n}=2$ & $48,76( \pm 0,00) ; \mathrm{n}=2$ \\
T10 & $30,67( \pm 17,90) ; \mathrm{n}=2$ & $38,89( \pm 6,47) ; \mathrm{n}=2$ \\
T11 & $30,96( \pm 13,49) ; \mathrm{n}=2$ & $7,41( \pm 0,84) ; \mathrm{n}=2$ \\
T12 & $30,09( \pm 16,05) ; \mathrm{n}=2$ & $25,48( \pm 24,91) ; \mathrm{n}=2$ \\
\hline Média & $32,53( \pm 7,85)$ & $40,95( \pm 12,93)$ \\
\hline EPM $=$ erro padrão da média; B-SF $=$ cães com doença renal crônica no estágio 3 que receberam solução fisiológica; B-CTM: cães com
\end{tabular}

FIGURA 5 - Gráfico de dispersão dos valores médios da porcentagem de proteína de alto peso molecular (HMWP) razão proteína/creatinina urinária (RPC) nos diferentes tempos de avaliação (T0 a T12) dos cães com doença renal crônica no estágio 3 (GRUPO B) referentes aos subgrupos B-SF e B-CTM. São Paulo, 2017.



A demonstração gráfica dos valores médios da porcentagem de proteínas de alto peso molecular na urina de cães com DRC nos estágios 2 ou 3 (Grupos A e B) segundo os respectivos subgrupos, avaliados ao longo dos tempos de observação, está configurada na Figura 5; e a área sob a curva calculada foi 
maior no subgrupo A-SF, indicando que nos demais subgrupos, a perda urinária maior de proteína foi a de baixo peso molecular (Tabela 13).

Tabela 13 - Cálculo da área sob a curva (AREA) das porcentagens de proteína na urina de alto peso molecular (HMWP) dos cães dos grupos $A$ e $B$, subgrupos A-SF (A1 a A6), A-CTM (A7 a A9), B-SF (B1 a B6) e B-CTM (B7 a B13), na avaliação sequencial durante a evolução da doença renal crônica. São Paulo, 2017.

\begin{tabular}{|c|c|c|c|c|c|}
\hline & A-SF & A-CTM & B-SF & B-CTM & Controle \\
\hline AREA & 604,50 & 464,50 & 370,50 & 466,90 & 881,70 \\
\hline Erro & 51,00 & 46,59 & 40,68 & 52,96 & 0 \\
\hline IC 95\% & $504,5-704,4$ & $373,2-555,8$ & $290,8-450,2$ & $363,1-570,8$ & \\
\hline
\end{tabular}

A-SF = cães com doença renal crônica no estágio 2 que receberam solução fisiológica; A-CTM: cães com doença renal crônica no estágio 2 que receberam célula tronco mesenquimal; B-SF = cães com doença renal crônica no estágio 3 que receberam solução fisiológica; $\mathbf{B}-$ CTM: cães com doença renal crônica no estágio 3 que receberam célula tronco mesenquimal; Controle = cães clinicamente normais; IC $=$ intervalo de confiança.

Figura 5 - Valores médios da porcentagem de proteína urinária de alto peso molecular (HMWP) dos cães dos Grupos A e B, subgrupos A-SF (A1 a A6), A-CTM (A7 a $A 9), B-S F$ (B1 a B6) e B-CTM (B7 a B13), na avaliação sequencial durante a evolução da doença renal crônica. São Paulo, 2017.

H M W P

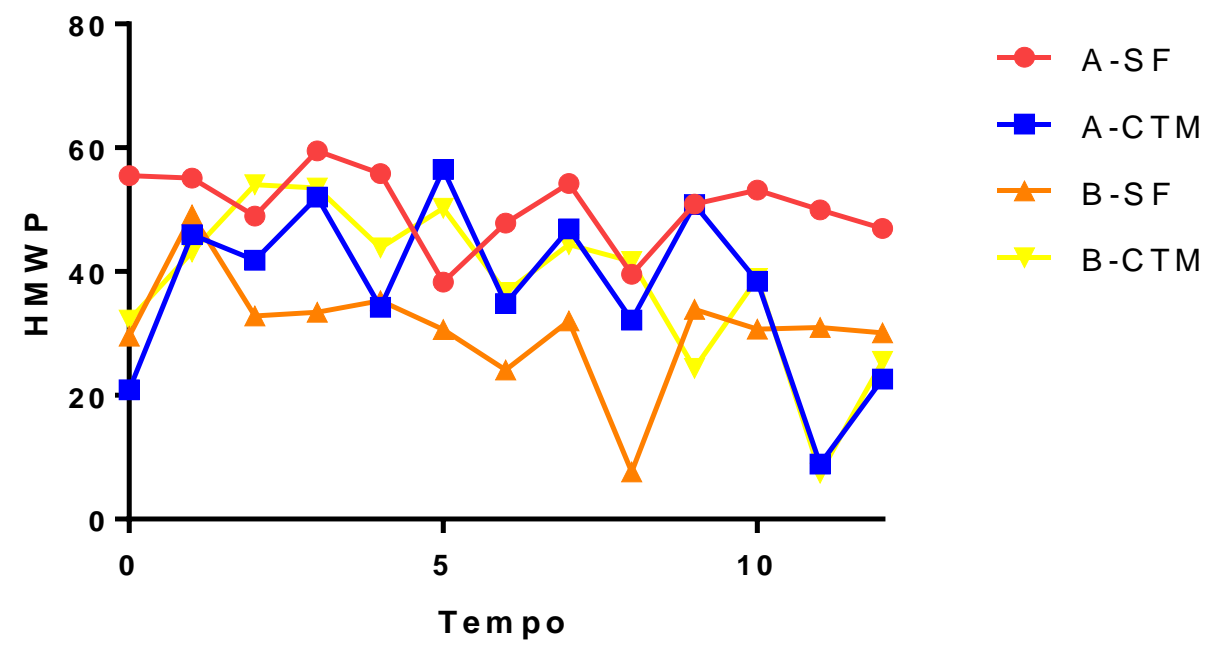

A-SF = cães com doença renal crônica no estágio 2 que receberam solução fisiológica; A-CTM: cães com doença renal crônica no estágio 2 que receberam célula tronco mesenquimal; B-SF = cães com doença renal crônica no estágio 3 que receberam solução fisiológica; BCTM: cães com doença renal crônica no estágio 3 que receberam célula tronco mesenquimal 
5.3 Proteínas de baixo peso molecular (LMWP) detectadas pela eletroforese de proteínas urinárias

No subgrupo A-SF, a metade do número de cães (A4, A5 e A6) apresentou predomínio (> 54\%) de perda de proteína urinária de baixo peso molecular na análise longitudinal dos 12 tempos de acompanhamento. No atinente ao subgrupo A-CTM, todos os cães (A7, A8 e A9) apresentaram perda urinária de proteínas de baixo peso molecular com porcentagem superior a $55 \%$ (Tabela 13)

Tabela 13 - Valores individuais e estatística descritiva da porcentagem de proteínas de baixo peso molecular $(<60 \mathrm{kDa}$ ) segundo a eletroforese SDS-PAGE, na avaliação sequencial durante a evolução da doença renal crônica em cães do Grupo A. São Paulo, 2017.

\begin{tabular}{|c|c|c|c|c|c|c|c|c|c|}
\hline Grupo A & A1 & A2 & A3 & A4 & A5 & A6 & A7 & A8 & A9 \\
\hline TO & 41,85 & 0 & 46,22 & 39,52 & 81,99 & 57,42 & 52,92 & 100,00 & 84,42 \\
\hline $\mathrm{T} 1$ & 22,10 & 0 & 42,05 & 48,85 & 86,23 & 70,15 & 49,35 & 66,40 & 46,27 \\
\hline T2 & 21,41 & 47,31 & 50,03 & 69,75 & $\star \star *$ & 66,79 & ** & 49,79 & 66,53 \\
\hline T3 & 0 & 43,50 & 66,78 & 51,76 & ** & $\star *$ & 61,29 & 52,33 & 30,33 \\
\hline T4 & 14,98 & 44,32 & 46,85 & 55,05 & $\star *$ & 59,73 & $* *$ & 100,00 & 31,50 \\
\hline T5 & $\star *$ & 48,52 & 32,38 & 42,70 & 81,40 & 65,05 & $\star \star$ & 52,33 & 34,69 \\
\hline T6 & 31,26 & 46,19 & 48,61 & 49,63 & 74,11 & 63,38 & ** & 51,45 & 78,83 \\
\hline T7 & 47,36 & 15,13 & 42,65 & 55,10 & ** & 68,73 & ** & 53,10 & ** \\
\hline T8 & 46,09 & 43,82 & 41,25 & $* *$ & ** & 71,06 & ** & 56,16 & 79,46 \\
\hline T9 & 42,17 & 31,95 & 59,21 & 55,94 & $\star *$ & 56,26 & ** & 49,18 & ** \\
\hline T10 & 36,76 & 58,38 & $\star *$ & 45,45 & ** & $* *$ & ** & 61,57 & $\star *$ \\
\hline T11 & 40,83 & 62,03 & 37,65 & 51,89 & $\star *$ & 57,76 & $\star *$ & 100,00 & 82,14 \\
\hline $\mathrm{T} 12$ & 45,65 & 59,06 & 49,46 & 33,45 & 75,80 & 54,87 & 56,88 & 100,00 & 75,18 \\
\hline Média & 32,53 & 38,47 & 46,92 & 49,94 & 79,90 & 62,83 & 55,11 & 68,63 & 60,93 \\
\hline D.P. & 14,90 & 20,91 & 9,22 & 9,25 & 4,92 & 5,90 & 5,14 & 22,26 & 22,62 \\
\hline Mediana & 38,79 & 44,32 & 46,53 & 50,69 & 81,40 & 63,38 & 54,90 & 56,16 & 70,85 \\
\hline EPM & 4,30 & 5,80 & 2,66 & 2,67 & 2,20 & 1,77 & 2,57 & 6,17 & 7,15 \\
\hline Min & 0 & 0 & 32,38 & 33,45 & 74,11 & 54,87 & 49,35 & 49,18 & 30,33 \\
\hline Max & 47,36 & 62,03 & 66,78 & 69,75 & 86,23 & 71,06 & 61,29 & 100 & 84,42 \\
\hline$\Delta$ & 3,80 & 59,06 & 3,24 & $-6,07$ & $-6,19$ & $-2,55$ & 3,96 & 0 & $-9,24$ \\
\hline
\end{tabular}

A-SF = subgrupo A de cães com doença renal crônica no estágio 2 que recebeu solução fisiológica (A1 a A6):

A-CTM: subgrupo A de cães com doença renal crônica no estágio 2 que grupo que recebeu célula tronco mesenquimal (A7 a A9)

No Grupo B, subgrupos B-SF e B-CTM, houve o predomínio (> 54\%) de proteínas de baixo peso molecular, principalmente no subgrupo B-SF, sendo que neste subgrupo, somente um cão (B3) apresentou porcentagem inferior a 50\%. 
No subgrupo B-CTM, 57\% dos cães apresentaram perda de proteínas de baixo peso molecular superior a $68 \%$ (Tabela 14$)$.

Tabela 14 - Valores individuais e da estatística descritiva da porcentagem de proteínas de baixo peso molecular $(<60 \mathrm{kDa})$ segundo a eletroforese SDS-PAGE, na avaliação sequencial durante a evolução da doença renal crônica em cães do Grupo B. São Paulo, 2017.

\begin{tabular}{|c|c|c|c|c|c|c|c|c|c|c|c|c|c|}
\hline Grupo B & B1 & B2 & B3 & B4 & B5 & B6 & B7 & B8 & B9 & B10 & B11 & B12 & B13 \\
\hline T0 & 63,54 & 42,39 & 16,49 & 80,96 & 100 & 89,07 & 42,01 & 42,15 & 65,01 & 57,70 & 85,23 & 100,00 & 82,55 \\
\hline $\mathrm{T} 1$ & 37,47 & 48,21 & 19,02 & 82,19 & $* *$ & 67,12 & 16,74 & 39,80 & 59,45 & 60,74 & 64,90 & 100,00 & ** \\
\hline T2 & 56,12 & 52,08 & 19,82 & 77,71 & 100 & 67,14 & 44,46 & 0 & 63,62 & 29,89 & 51,19 & $\dagger$ & 86,71 \\
\hline T3 & 48,24 & 56,44 & 17,72 & 72,46 & 89,83 & 84,89 & 15,82 & 35,68 & 57,75 & $t$ & 76,67 & & ** \\
\hline T4 & 56,62 & 58,33 & $t$ & 79,10 & & $t$ & 48,14 & 34,74 & 67,37 & & 74,39 & & ** \\
\hline T5 & 53,26 & 72,20 & & 82,65 & & & 42,35 & 39,12 & 67,86 & & $t$ & & ** \\
\hline T6 & 72,41 & $†$ & & 79,39 & & & 66,72 & 38,58 & ** & & & & 48,07 \\
\hline $\mathrm{T7}$ & 55,66 & & & 80,33 & & & 45,92 & 49,11 & 68,86 & & & & 58,61 \\
\hline T8 & $* \star$ & & & 84,78 & & & 49,90 & 61,23 & 64,06 & & & & † \\
\hline T9 & 54,65 & & & 77,52 & & & $\dagger$ & 51,24 & ** & & & & \\
\hline T10 & 56,57 & & & 81,99 & & & & 56,53 & 65,68 & & & & \\
\hline T11 & 59,5 & & & 78,58 & & & & 91,99 & 93,18 & & & & \\
\hline T12 & 58,56 & & & 81,26 & & & & 92,14 & 56,83 & & & & \\
\hline Média & 56,05 & 54,94 & 18,26 & 79,91 & 96,61 & 77,05 & 41,34 & 48,63 & 66,33 & 49,44 & 70,47 & 100 & 68,98 \\
\hline D.P. & 8,30 & 10,22 & 1,46 & 3,06 & 5,87 & 11,58 & 16,01 & 24,21 & 9,78 & 17,00 & 12,98 & 0 & 18,64 \\
\hline Mediana & 56,34 & 54,26 & 18,37 & 80,33 & 100,00 & 76,01 & 44,46 & 42,15 & 65,01 & 57,70 & 74,39 & 100 & 70,58 \\
\hline EPM & 2,39 & 4,17 & 0,73 & 0,84 & 3,39 & 5,79 & 5,33 & 6,71 & 2,94 & 9,81 & 5,80 & 0 & 9,32 \\
\hline Min & 37,47 & 42,39 & 16,49 & 72,46 & 89,83 & 67,12 & 15,82 & 0 & 56,83 & 29,89 & 51,19 & 100 & 48,07 \\
\hline $\operatorname{Max}$ & 72,41 & 72,20 & 19,82 & 84,78 & 100,00 & 89,07 & 66,72 & 92,14 & 93,18 & 60,74 & 85,23 & 100 & 86,71 \\
\hline$\Delta$ & $-4,98$ & 29,81 & 1,23 & 0,30 & $-10,17$ & $-4,18$ & 7,89 & 49,99 & $-8,18$ & $-27,81$ & $-10,84$ & 0 & $-23,94$ \\
\hline
\end{tabular}

A porcentagem de proteínas na urina de baixo peso molecular de todos os cães dos subgrupos dos Grupos A e B foi significantemente diferente dos cães clinicamente normais (controle) (Tabela 15). 
Tabela 15 - Avaliação estatística (análise de variância - one way ANOVA) das porcentagens de proteínas de baixo peso molecular (LMWP) dos cães dos GRUPOS A e B, segundo os respectivos subgrupos (A-SF e A-CTM; B-SF e B-CTM) e grupo controle, cães clinicamente normais. São Paulo, 2017.

\begin{tabular}{|c|c|c|c|c|c|}
\hline & A-SF & A-CTM & B-SF & B-CTM & Controle \\
\hline A-SF & & 0,45 & 0,05 & 0,54 & 0,02 \\
\hline A-CTM & 0,45 & & 0,98 & 0,99 & $<0,0001$ \\
\hline B-SF & 0,05 & 0,98 & & 0,96 & $<0,0001$ \\
\hline B-CTM & 0,54 & 0,99 & 0,96 & & $<0,0001$ \\
\hline Controle & 0,02 & $<0,0001$ & $<0,0001$ & $<0,0001$ & \\
\hline
\end{tabular}

$\mathrm{Na}$ análise sequencial das médias das porcentagens de proteínas urinária de baixo peso molecular obtidas em cada um dos tempos, comparando-se entre os subgrupos A-SF e A-CTM (Tabela 16), os valores foram então plotados em um gráfico de dispersão com linha de tendência para avaliação do comportamento da variável ao longo do tempo (Figura 6), como também entre os subgrupos B-SF e B-CTM (Tabela 17), observa-se que não houve diferença entre os subgrupos, mas houve a perda predominantemente de proteínas de baixo peso molecular, principalmente nos subgrupos A-CTM, B-SF e B-CTM, os valores foram então plotados em um gráfico de dispersão com linha de tendência para avaliação do comportamento da variável ao longo do tempo (Figura 7). 
Tabela 16 - Estatística descritiva das porcentagens de proteína de baixo peso molecular (LMWP) na urina dos cães com doença renal crônica no estágio 2 (GRUPO A) referentes aos subgrupos A-SF e A-CTM ao longo dos tempos de acompanhamento. São Paulo, 2017.

\begin{tabular}{ccc}
\hline Estagio 2 & A-SF $( \pm D P)$ & A-CTM $( \pm D P)$ \\
\hline T0 & $65,40( \pm 31,38) ; n=6$ & $79,11( \pm 23,98) ; n=3$ \\
T1 & $50,80( \pm 24,72) ; n=6$ & $54,00( \pm 10,84) ; n=3$ \\
T2 & $62,14( \pm 26,94) ; n=6$ & $54,00( \pm 10,84) ; n=3$ \\
T3 & $61,59( \pm 26,78) ; n=6$ & $58,16( \pm 11,83) ; n=3$ \\
T4 & $44,18( \pm 17,46) ; n=6$ & $47,98( \pm 15,93) ; n=3$ \\
T5 & $54,01( \pm 19,35) ; n=6$ & $43,51( \pm 12,47) ; n=3$ \\
T6 & $52,19( \pm 14,82) ; n=6$ & $43,44( \pm 10,47) ; n=3$ \\
T7 & $45,79( \pm 19,78) ; n=6$ & $65,14( \pm 19,36) ; n=3$ \\
T8 & $50,55( \pm 13,81) ; n=6$ & $67,81( \pm 16,47) ; n=3$ \\
T9 & $49,10( \pm 11,64) ; n=6$ & $66,55( \pm 17,47) ; n=3$ \\
T10 & $46,86( \pm 10,87) ; n=6$ & $49,18( \pm 0,00) ; n=3$ \\
T11 & $50,03( \pm 10,54) ; n=6$ & $61,57( \pm 0,00) ; n=3$ \\
T12 & $53,04( \pm 14,20) ; n=6$ & $91,07( \pm 12,62) ; n=3$ \\
\hline Média & $52,74( \pm 6,54)$ & $60,35( \pm 14,03)$ \\
\hline DP = Desvio padrão da média; A-SF = cães com doença renal crônica no estágio 2 que receberam solução fisiológica; A-CTM: cães
\end{tabular}

FIGURA 6 - Gráfico de dispersão dos valores médios da porcentagem de proteína de baixo peso molecular (LMWP) nos diferentes tempos de avaliação (T0 a T12) dos cães com doença renal crônica no estágio 2 (GRUPO A) referentes aos subgrupos A-SF e A-CTM. São Paulo, 2017.

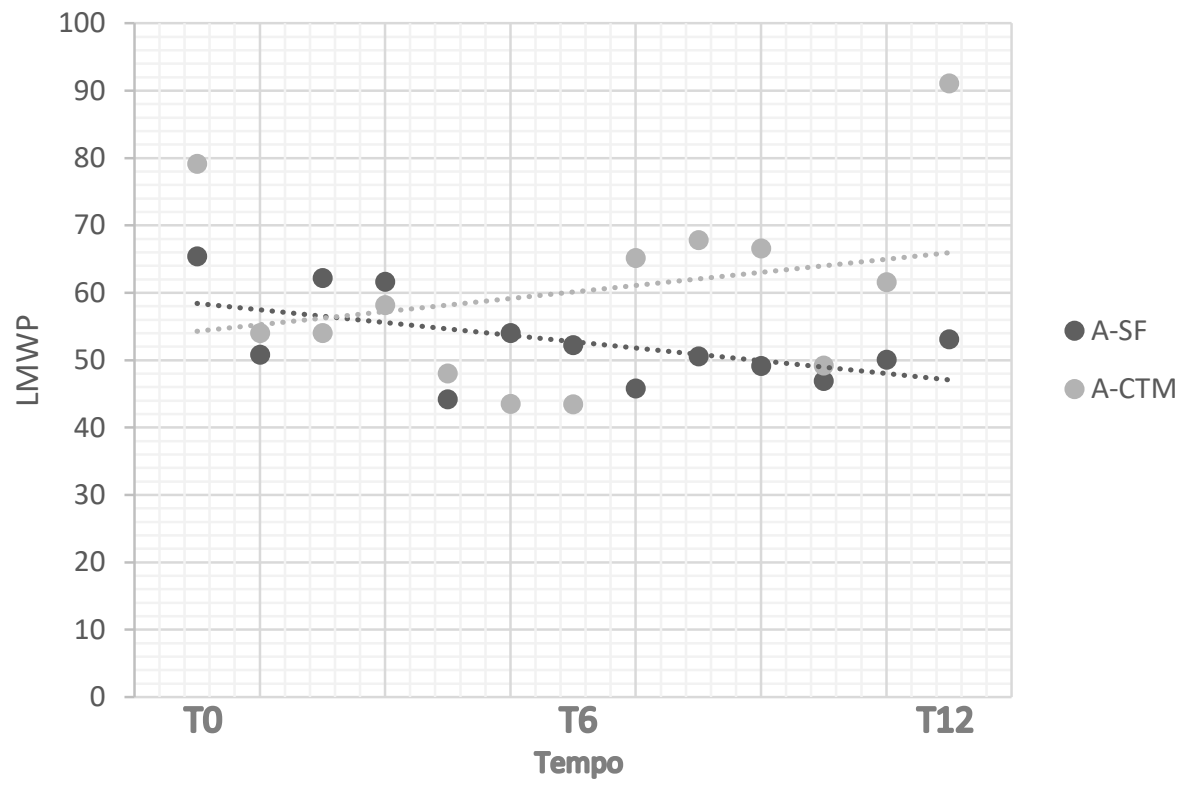


Tabela 17 - Estatística descritiva das porcentagens de proteína de baixo peso molecular (LMWP) na urina dos cães com doença renal crônica no estágio 3 (GRUPO B) referentes aos subgrupos B-SF e B-CTM ao longo dos tempos de acompanhamento. São Paulo, 2017.

\begin{tabular}{ccc}
\hline Estagio 3 & B-SF $( \pm$ DP $)$ & B-CTM $( \pm D P)$ \\
\hline T0 & $70,40( \pm 23,40) ; n=6$ & $67,80( \pm 22,32) ; n=7$ \\
T1 & $50,80( \pm 24,72) ; n=6$ & $56,93( \pm 27,74) ; n=7$ \\
T2 & $67,14( \pm 19,18) ; n=6$ & $45,97( \pm 29,57) ; n=6$ \\
T3 & $66,59( \pm 18,46) ; n=6$ & $46,48( \pm 26,42) ; n=5$ \\
T4 & $64,68( \pm 12,51) ; n=3$ & $56,16( \pm 18,08) ; n=5$ \\
T5 & $69,37( \pm 14,89) ; n=3$ & $49,77( \pm 15,74) ; n=4$ \\
T6 & $75,90( \pm 4,93) ; n=2$ & $51,12( \pm 14,31) ; n=4$ \\
T7 & $67,99( \pm 17,44) ; n=2$ & $55,62( \pm 10,33) ; n=4$ \\
T8 & $84,78( \pm 0,00) ; n=2$ & $58,39( \pm 7,49) ; n=3$ \\
T9 & $66,08( \pm 16,17) ; n=2$ & $51,24( \pm 0,00) ; n=2$ \\
T10 & $69,28( \pm 17,97) ; n=2$ & $61,10( \pm 6,47) ; n=2$ \\
T11 & $69,04( \pm 13,49) ; n=2$ & $92,58( \pm 0,84) ; n=2$ \\
T12 & $69,91( \pm 16,05) ; n=2$ & $74,48( \pm 24,96) ; n=2$ \\
\hline Média & $68,61( \pm 7,45)$ & $59,04( \pm 12,93)$ \\
\hline DP = Desvio padrão da média; B-SF $=$ cães com doença renal crônica no estágio 3 que receberam solução fisiológica; B-CTM: cães
\end{tabular}

FIGURA 7 - Gráfico de dispersão dos valores médios da porcentagem de proteína de baixo peso molecular (LMWP)-nos diferentes tempos de avaliação (T0 a T12) dos cães com doença renal crônica no estágio 3 (GRUPO B) referentes aos subgrupos B-SF e B-CTM. São Paulo, 2017.

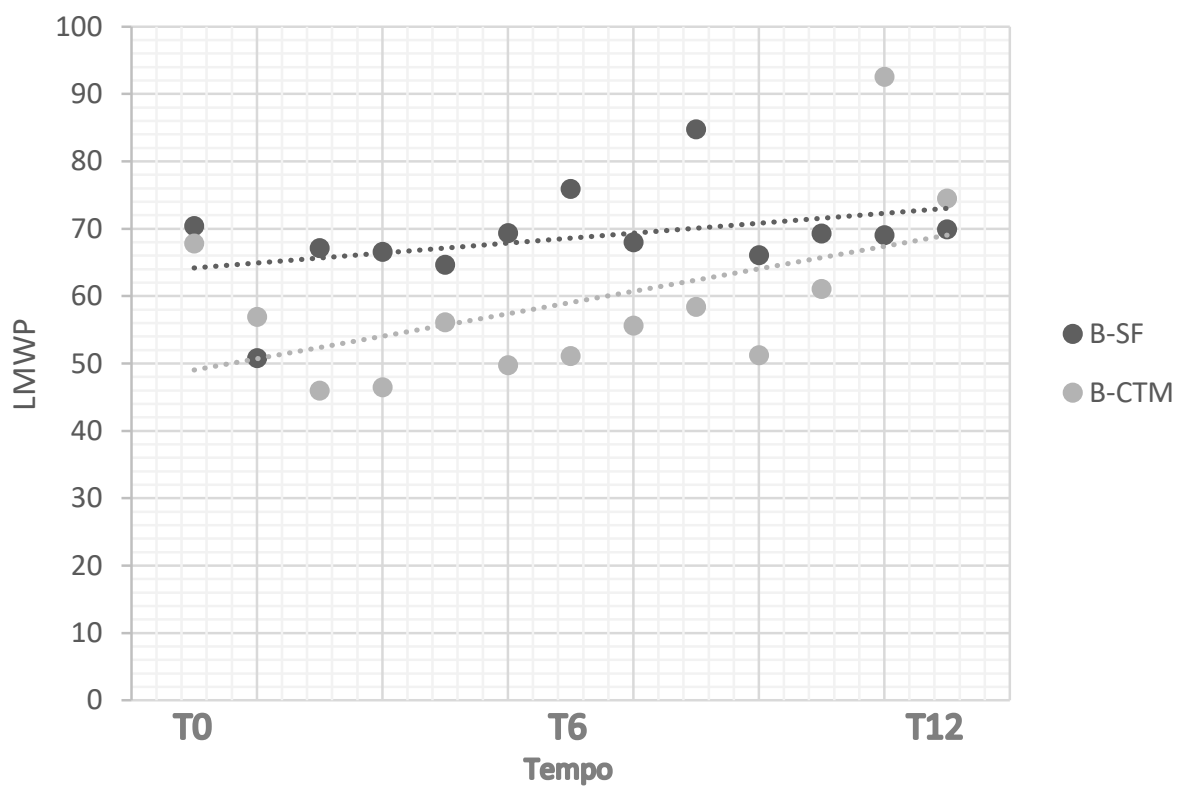

Na Figura 8 e na Tabela 18, segundo a análise da área calculada sob a curva obtida ao longo do período de observação, todos os subgrupos apresentaram valores superiores de proteínas de baixo peso molecular na urina 
em comparação com os cães clinicamente normais, sendo que os subgrupos A-

CTM, B-SF e B-CTM apresentaram em maior intensidade.

Tabela 18 - Cálculo da área sob a curva (AREA) das porcentagens de proteínas na urina de baixo peso molecular (LMWP) dos cães dos grupos $A$ e $B$, subgrupos A-SF (A1 a A6), A-CTM (A7 a A9), B-SF (B1 a B6) e B-CTM (B7 a B13), na avaliação sequencial durante a evolução da doença renal crônica. São Paulo, 2017.

\begin{tabular}{cccccc}
\hline & A-SF & A-CTM & B-SF & B-CTM & Controle \\
\hline AREA & 596,00 & 717,90 & 829,40 & 733,20 & 318,3 \\
Erro & 51,42 & 50,33 & 40,70 & 52,95 & 0 \\
IC 95\% & $495,3-696,8$ & $619,2-816,5$ & $749,7-909,2$ & $629,4-836,9$ &
\end{tabular}

A-SF = cães com doença renal crônica no estágio 2 que receberam solução fisiológica; A-CTM: cães com doença renal crônica no estágio 2 que receberam célula tronco mesenquimal; B-SF = cães com doença renal crônica no estágio 3 que receberam solução fisiológica; $\mathbf{B}-$ CTM: cães com doença renal crônica no estágio 3 que receberam célula tronco mesenquimal; Controle = cães clinicamente normais; IC $=$ intervalo de confiança.

Figura 8 - Valores médios da porcentagem de proteína de baixo peso molecular (LMWP) na urina dos cães dos grupos $A$ e $B$, respectivos subgrupos A-SF (A1 a A6), ACTM (A7 a A9), B-SF (B1 a B6) e B-CTM (B7 a B13), na avaliação sequencial durante a evolução da doença renal crônica. São Paulo, 2017.

\section{M W P}



A-SF = cães com doença renal crônica no estágio 2 que receberam solução fisiológica; A-CTM: cães com doença renal crônica no estágio 2 que receberam célula tronco mesenquimal; B-SF = cães com doença renal crônica no estágio 3 que receberam solução fisiológica; BCTM: cães com doença renal crônica no estágio 3 que receberam célula tronco mesenquimal 
5.4 Número de bandas de proteínas de alto peso molecular (BHMWP) na urina detectadas pela eletroforese em SDS-PAGE

O maior número de bandas de proteínas de alto peso molecular nos cães do Grupo A foi detectado no subgrupo A-SF, principalmente nos cães A3 e A4 (Tabela 19).

Tabela 19 - Valores individuais do número de bandas de proteínas na urina de alto peso molecular ( $>60 \mathrm{kDa}$ ) obtidas na eletroforese SDS-PAGE, na avaliação sequencial durante a evolução da doença renal crônica em cães do Grupo A, subgrupos A-SF (A1 a A6) e A-CTM (A7 a A9). São Paulo, 2017

\begin{tabular}{cccccccccc}
\hline Grupo A & $\mathbf{A 1}$ & $\mathbf{A 2}$ & $\mathbf{A 3}$ & $\mathbf{A 4}$ & $\mathbf{A 5}$ & $\mathbf{A 6}$ & $\mathbf{A 7}$ & $\mathbf{A 8}$ & $\mathbf{A 9}$ \\
\hline T0 & 1 & 2 & 2 & 2 & 1 & 2 & 3 & 0 & 1 \\
T1 & 1 & 2 & 2 & 1 & 1 & 2 & 3 & 1 & 2 \\
T2 & 1 & 2 & 2 & 1 & $* *$ & 3 & $* *$ & 1 & 1 \\
T3 & 1 & 2 & 5 & 3 & $* *$ & $* *$ & 4 & 1 & 2 \\
T4 & 1 & 2 & 1 & 2 & $* *$ & 2 & $* *$ & 0 & 2 \\
T5 & $* *$ & 3 & 2 & 3 & 1 & 2 & $* *$ & 1 & 2 \\
T6 & 1 & 2 & 3 & 3 & 2 & 2 & $* *$ & 1 & 2 \\
T7 & 1 & 2 & 2 & 2 & $* *$ & 1 & $* *$ & 2 & $* *$ \\
T8 & 1 & 2 & 5 & $* *$ & $* *$ & 1 & $* *$ & 3 & 1 \\
T9 & 1 & 2 & 3 & 3 & $* *$ & 1 & $* *$ & 3 & $* *$ \\
T10 & 1 & 2 & $* *$ & 4 & $* *$ & $* *$ & $* *$ & 3 & $* *$ \\
T11 & 1 & 2 & 2 & 3 & $* *$ & 2 & $* *$ & 0 & 1 \\
T12 & 1 & 1 & 1 & 3 & 1 & 2 & 3 & 0 & 1 \\
Média & 1,00 & 2,00 & 2,50 & 2,30 & 1,20 & 1,81 & 3,25 & 1,23 & 1,50 \\
D.P. & 0,00 & 0,40 & 1,31 & 1,10 & 0,44 & 0,60 & 0,50 & 1,16 & 0,52 \\
Mediana & 1,00 & 2,00 & 2,00 & 3,00 & 1,00 & 2,00 & 3,00 & 1,00 & 1,50 \\
EPM & 0,00 & 0,11 & 0,37 & 0,30 & 0,20 & 0,18 & 0,25 & 0,32 & 0,16 \\
Min & 1,00 & 1,00 & 1,00 & 0,00 & 1,00 & 1,00 & 3,00 & 0,00 & 1,00 \\
Max & 1,00 & 3,00 & 5,00 & 4,00 & 2,00 & 3,00 & 4,00 & 3,00 & 2,00 \\
\hline D.P. $=$ desvio padrão & $* *$ Amostra não coletada & EPM $=$ erro padrão da média & \\
A-CTM: subgrupo A A de cães com doença renal crônica no estágio 2 que grupo que recebeu célula tronco mesenquimal (A7 a A9)
\end{tabular}

Em relação aos cães do Grupo B, o maior número de bandas de proteínas de alto peso molecular foi detectado na urina do cão B1 do subgrupo B-SF e no subgrupo B-CTM no cão B9 (Tabela 20). 
Tabela 20 - Valores individuais do número de bandas de proteínas de alto peso molecular (>60 kDa) obtidas na eletroforese SDS-PAGE, na avaliação sequencial durante a evolução da doença renal crônica em cães do Grupo B, subgrupos B-SF (B1 a B6) e B-CTM (B7 a B13). São Paulo, 2017

\begin{tabular}{|c|c|c|c|c|c|c|c|c|c|c|c|c|c|}
\hline Grupo B & B1 & B2 & B3 & B4 & B5 & B6 & B7 & B8 & B9 & B10 & B11 & B12 & B13 \\
\hline T0 & 3 & 3 & 1 & 2 & 0 & 1 & 2 & 2 & 4 & 1 & 1 & 1 & 1 \\
\hline T1 & 4 & 1 & 1 & 2 & ** & 2 & 2 & 2 & 2 & 1 & 3 & 1 & ** \\
\hline T2 & 3 & 1 & 1 & 2 & 0 & 2 & 2 & 1 & 3 & 2 & 1 & $\dagger$ & 1 \\
\hline T3 & 4 & 1 & 1 & 2 & 1 & 1 & 2 & 2 & 3 & $t$ & 1 & & ** \\
\hline T4 & 3 & 2 & $t$ & 2 & & $\dagger$ & 2 & 1 & 3 & & 2 & & ** \\
\hline T5 & 3 & 1 & & 2 & & & 1 & 1 & 2 & & $t$ & & ** \\
\hline T6 & 2 & $\dagger$ & & 2 & & & 1 & 1 & ** & & & & 2 \\
\hline T7 & 3 & & & 2 & & & 1 & 3 & 2 & & & & 2 \\
\hline T8 & ** & & & 2 & & & 1 & 2 & 2 & & & & \\
\hline T9 & 3 & & & 2 & & & $\dagger$ & 2 & ** & & & & \\
\hline T10 & 2 & & & 2 & & & & 2 & 2 & & & & \\
\hline $\mathrm{T} 11$ & 3 & & & 2 & & & & 1 & 1 & & & & \\
\hline $\mathrm{T} 12$ & 3 & & & 1 & & & & 1 & 2 & & & & \\
\hline Média & 3,00 & 1,50 & 1,00 & 1,92 & 0,33 & 1,50 & 1,55 & 1,61 & 2,36 & 1,33 & 1,60 & 1,00 & 1,50 \\
\hline D.P. & 0,60 & 0,83 & 0,00 & 0,27 & 0,57 & 0,57 & 0,52 & 0,65 & 0,80 & 0,57 & 0,89 & 0,00 & 0,57 \\
\hline Mediana & 3,00 & 1,00 & 1,00 & 2,00 & 2,00 & 1,50 & 2,00 & 2,00 & 2,00 & 1,00 & 1,00 & 1,00 & 1,50 \\
\hline EPM & 0,17 & 0,34 & 0,00 & 0,00 & 0,07 & 0,28 & 0,17 & 0,18 & 0,24 & 0,33 & 0,40 & 0,00 & 0,28 \\
\hline Min & 2,00 & 1,00 & 1,00 & 1,00 & 0,00 & 1,00 & 1,00 & 1,00 & 1,00 & 1,00 & 1,00 & 1,00 & 1,00 \\
\hline Max & 4,00 & 3,00 & 1,00 & 2,00 & 1,00 & 2,00 & 2,00 & 3,00 & 4,00 & 2,00 & 3,00 & 1,00 & 2,00 \\
\hline
\end{tabular}

Apesar de alguns cães dos Grupos A e B terem apresentado aumento do número de bandas de proteínas de alto peso molecular, não foi detectada diferença significante dos subgrupos A-SF, A-CTM, B-SF e B-CTM em comparação com os cães clinicamente normais (Tabelas 21, 22 e 23).

Tabela 21 - Avaliação estatística (análise de variância - one way ANOVA) do número de bandas de proteínas de alto peso molecular na urina dos cães dos Grupos A e B e respectivos subgrupos (A-SF e A-CTM; B-SF e B-CTM) e grupo controle, cães clinicamente normais. São Paulo, 2017.

\begin{tabular}{cccccc}
\hline & A-SF & A-CTM & B-SF & B-CTM & Controle \\
\hline A-SF & & 0,99 & 0,99 & 0,82 & 0,99 \\
A-CTM & 0,99 & & 0,94 & 0,99 & 0,99 \\
B-SF & 0,99 & 0,94 & & 0,99 & 0,52 \\
B-CTM & 0,82 & 0,99 & 0,99 & 0,93 \\
Controle & 0,99 & 0,99 & 0,52 & 0,99 & \\
\hline
\end{tabular}

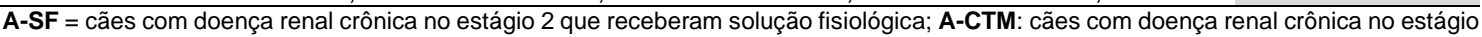
2 que receberam célula tronco mesenquimal; B-SF = cães com doença renal crônica no estágio 3 que receberam solução fisiológica; $\mathbf{B}$ CTM: cães com doença renal crônica no estágio 3 que receberam célula tronco mesenquimal 
Tabela 22 - Estatística descritiva das médias do número de bandas de proteínas na urina de alto peso molecular dos cães com doença renal crônica no estágio 2 (GRUPO A) referentes aos subgrupos A-SF e A-CTM ao longo dos tempos de acompanhamento. São Paulo, 2017.

\begin{tabular}{ccc}
\hline Estagio & A-SF $( \pm D P)$ & A-CTM $( \pm D P)$ \\
\hline T0 & $1,66( \pm 0,51) ; n=6$ & $1,33( \pm 1,52) ; n=3$ \\
T1 & $1,50( \pm 0,54) ; n=6$ & $2,00( \pm 1,00) ; n=3$ \\
T2 & $1,80( \pm 0,83) ; n=6$ & $1,00( \pm 0,00) ; n=3$ \\
T3 & $2,75( \pm 1,70) ; n=6$ & $2,33( \pm 1,52) ; n=3$ \\
T4 & $1,60( \pm 0,54) ; n=6$ & $1,00( \pm 1,41) ; n=3$ \\
T5 & $1,83( \pm 1,16) ; n=6$ & $1,50( \pm 0,70) ; n=3$ \\
T6 & $2,16( \pm 0,75) ; n=6$ & $1,50( \pm 0,70) ; n=3$ \\
T7 & $1,60( \pm 0,54) ; n=6$ & $2,00( \pm 0,00) ; n=3$ \\
T8 & $1,80( \pm 1,92) ; n=6$ & $2,00( \pm 1,41) ; n=3$ \\
T9 & $2,00( \pm 1,00) ; n=6$ & $3,00( \pm 0,00) ; n=3$ \\
T10 & $2,33( \pm 1,52) ; n=6$ & $3,00( \pm 0,00) ; n=3$ \\
T11 & $2,00( \pm 0,70) ; n=6$ & $0,50( \pm 0,70) ; n=3$ \\
T12 & $1,50( \pm 0,83) ; n=6$ & $1,33( \pm 1,52) ; n=3$ \\
Média & $1,88( \pm 0,36)$ & $1,73( \pm 0,75)$ \\
\hline
\end{tabular}

DP = Desvio padrão da média; A-SF = cães com doença renal crônica no estágio 2 que receberam solução fisiológica; A-CTM: cães com doença renal crônica no estágio 2 que receberam célula tronco mesenquimal

Tabela 23 - Estatística descritiva dos valores do número de bandas de alto peso molecular dos cães com doença renal crônica no estágio 3 (GRUPO B) referentes aos subgrupos B-SF e B-CTM ao longo dos tempos de acompanhamento. São Paulo, 2017.

\begin{tabular}{ccc}
\hline Estagio 3 & B-SF $( \pm \mathrm{DP})$ & B-CTM $( \pm \mathrm{DP})$ \\
\hline T0 & $1,66( \pm 1,21) ; \mathrm{n}=6$ & $1,71( \pm 1,11) ; \mathrm{n}=7$ \\
T1 & $2,00( \pm 1,22) ; \mathrm{n}=6$ & $1,83( \pm 0,75) ; \mathrm{n}=7$ \\
T2 & $1,50( \pm 1,04) ; \mathrm{n}=6$ & $1,66( \pm 0,81) ; \mathrm{n}=6$ \\
T3 & $1,66( \pm 1,21) ; \mathrm{n}=6$ & $2,00( \pm 0,81) ; \mathrm{n}=5$ \\
T4 & $2,33( \pm 0,57) ; \mathrm{n}=3$ & $2,00( \pm 0,81) ; \mathrm{n}=5$ \\
T5 & $2,00( \pm 1,00) ; \mathrm{n}=3$ & $1,33( \pm 0,57) ; \mathrm{n}=4$ \\
T6 & $2,00( \pm 0,00) ; \mathrm{n}=2$ & $1,33( \pm 0,57) ; \mathrm{n}=4$ \\
T7 & $2,50( \pm 0,70) ; \mathrm{n}=2$ & $2,00( \pm 0,81) ; \mathrm{n}=4$ \\
T8 & $2,00( \pm 0,00) ; \mathrm{n}=2$ & $1,66( \pm 0,57) ; \mathrm{n}=3$ \\
T9 & $2,50( \pm 0,70) ; \mathrm{n}=2$ & $2,00( \pm 0,00) ; \mathrm{n}=2$ \\
T10 & $2,00( \pm 0,00) ; \mathrm{n}=2$ & $2,00( \pm 0,00) ; \mathrm{n}=2$ \\
T11 & $2,50( \pm 0,70) ; \mathrm{n}=2$ & $1,00( \pm 0,00) ; \mathrm{n}=2$ \\
T12 & $2,00( \pm 1,41) ; \mathrm{n}=2$ & $1,50( \pm 0,70) ; \mathrm{n}=2$ \\
\hline Média & $2,05( \pm 0,33)$ & $1,69( \pm 0,32)$ \\
\hline DP = Desvio padrão da média; B-SF = cães com doença renal crônica no estágio 3 que receberam solução fisiológica; B-CTM: cães com
\end{tabular}
doença renal crônica no estágio 3 que receberam célula tronco mesenquimal

Os valores médios do número de bandas de proteínas na urina relacionada a aquelas de alto peso molecular dos subgrupos A-SF, A-CTM, BSF e B-CTM detectados ao longo do período de observação estão configurados na Figura 9, e as áreas calculadas sob a curva foram semelhantes entre os grupos, incluindo o grupo controle (Tabela 24). 
Figura 9 - Valores da média do número de bandas de proteínas na urina de alto molecular (BHMWP) dos cães dos Grupos A e B, subgrupos A-SF (A1 a A6), A-CTM (A7 a A9), B-SF (B1 a B6) e B-CTM (B7 a B13) ao longo da avaliação sequencial durante a evolução dos cães com doença renal crônica. São Paulo, 2017.

B H M W P

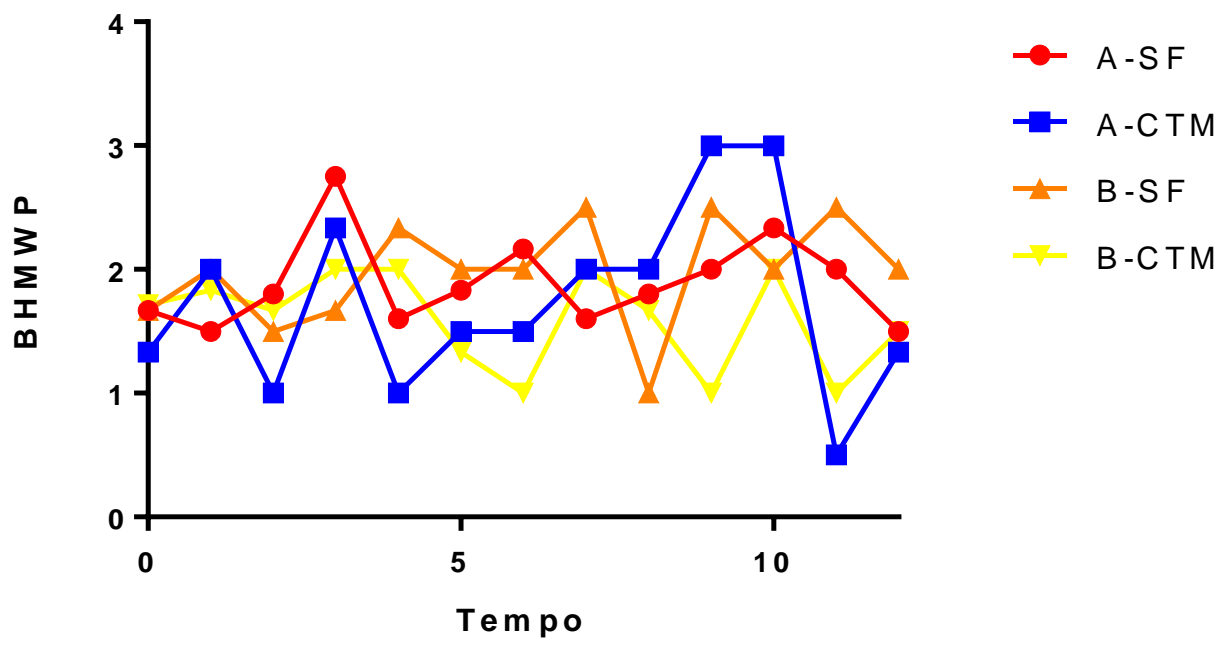

A-SF = cães com doença renal crônica no estágio 2 que receberam solução fisiológica; $\mathbf{A}$-CTM: cães com doença renal crônica no estágio 2 que receberam célula tronco mesenquimal; B-SF = cães com doença renal crônica no estágio 3 que receberam solução fisiológica; BCTM: cães com doença renal crônica no estágio 3 que receberam célula tronco mesenquimal;

Tabela 24 - Cálculo da área sob a curva (AREA) do número de bandas de proteínas na urina de alto peso molecular (HMWP) dos cães dos Grupos A e B, subgrupos ASF (A1 a A6), A-CTM (A7 a A9), B-SF (B1 a B6) e B-CTM (B7 a B13), ao longo da avaliação sequencial durante a evolução da doença renal crônica. São Paulo, 2017.

\begin{tabular}{cccccc}
\hline AREA & A-SF & A-CTM & B-SF & B-CTM & Controle \\
\hline Área & 22,97 & 21,17 & 23,83 & 19,11 & 20,00 \\
Erro & 2,68 & 2,36 & 2,30 & 1,92 & 0 \\
IC 95\% & $17,7-28,24$ & $16,54-25,80$ & $19,31-28,35$ & $15,33-22,89$ &
\end{tabular}

A-SF = cães com doença renal crônica no estágio 2 que receberam solução fisiológica; A-CTM: cães com doença renal crônica no estágio 2 que receberam célula tronco mesenquimal; B-SF = cães com doença renal crônica no estágio 3 que receberam solução fisiológica; $\mathbf{B}$ CTM: cães com doença renal crônica no estágio 3 que receberam célula tronco mesenquimal; Controle = cães clinicamente normais; IC = intervalo de confiança. 
5.5 Número de bandas de proteínas de baixo peso molecular (BLMWP) detectadas na urina pela eletroforese em SDS-PAGE

$\mathrm{Na}$ avaliação sequencial, observa-se no subgrupo A-SF, que o maior número de bandas de proteínas de baixo peso molecular foi detectado nos cães A3 e A6, e no subgrupo A-CTM no cão A7 e A8, sendo que neste último animal, principalmente ao final do período de observação (Tabela 25).

Tabela 25 - Valores individuais do número de bandas de proteínas na urina de baixo peso molecular (BLMWP) detectadas pela eletroforese SDS-PAGE, ao longo da avaliação sequencial durante a evolução da doença renal crônica em cães do Grupo A, subgrupos A-SF (A1 a A6) e A-CTM (A7 a A9). São Paulo, 2017

\begin{tabular}{|c|c|c|c|c|c|c|c|c|c|}
\hline Grupo A & A1 & A2 & A3 & A4 & A5 & A6 & A7 & A8 & A9 \\
\hline T0 & 2 & 0 & 2 & 2 & 1 & 2 & 5 & 1 & 2 \\
\hline T1 & 1 & 0 & 2 & 1 & 1 & 5 & 5 & 2 & 2 \\
\hline T2 & 1 & 1 & 2 & 3 & ** & 5 & ** & 1 & 2 \\
\hline T3 & 0 & 2 & 5 & 2 & $* *$ & $* *$ & 5 & 1 & 1 \\
\hline T4 & 1 & 1 & 2 & 2 & $\star *$ & 4 & ** & 1 & 1 \\
\hline T5 & 4 & 3 & 2 & 2 & 1 & 4 & ** & 1 & 1 \\
\hline T6 & 1 & 2 & 5 & 3 & 2 & 4 & ** & 1 & 1 \\
\hline T7 & 3 & 1 & 3 & 3 & ** & 6 & ** & 3 & ** \\
\hline T8 & 3 & 2 & 4 & 2 & $* *$ & 5 & ** & 3 & 2 \\
\hline T9 & 3 & 1 & 5 & 4 & $* *$ & 3 & ** & 3 & ** \\
\hline T10 & 2 & 2 & $* *$ & 2 & $* *$ & ** & ** & 4 & ** \\
\hline T11 & 2 & 2 & 2 & 3 & ** & 5 & ** & 2 & 2 \\
\hline T12 & 2 & 1 & 2 & 2 & 2 & 7 & 4 & 5 & 2 \\
\hline Média & 1,92 & 1,38 & 3,00 & 2,38 & 1,40 & 4,54 & 4,75 & 2,15 & 1,60 \\
\hline D.P. & 1,11 & 0,86 & 1,34 & 0,76 & 0,54 & 1,36 & 0,50 & 1,34 & 0,51 \\
\hline Mediana & 2,00 & 1,00 & 2,00 & 2,00 & 1,00 & 5,00 & 5,00 & 2,00 & 2,00 \\
\hline EPM & 0,30 & 0,24 & 0,38 & 0,21 & 0,24 & 0,41 & 0,25 & 0,37 & 0,16 \\
\hline Min & 0,00 & 0,00 & 2,00 & 1,00 & 1,00 & 2,00 & 4,00 & 1,00 & 1,00 \\
\hline Max & 4,00 & 3,00 & 5,00 & 4,00 & 2,00 & 7,00 & 5,00 & 5,00 & 2,00 \\
\hline
\end{tabular}

Na Tabela 26 observa-se que no subgrupo B-SF os cães B1, B4, B5 e B6 e no subgrupo B-CTM os cães B8, B9, B10, B11 e B13 apresentaram os maiores números de bandas de proteínas. $\mathrm{Na}$ avaliação sequencial não foi evidente o 
aumento ou a diminuição do número de bandas ao longo do período de observação.

Tabela 26 - Valores individuais do número de bandas de proteínas na urina de baixo peso molecular $(<60 \mathrm{kDa})$ detectadas pela eletroforese SDS-PAGE, ao longo da avaliação sequencial durante a evolução da doença renal crônica em cães do Grupo B, subgrupos B-SF (B1 a B6) e B-CTM (B7 a B13). São Paulo, 2017

\begin{tabular}{|c|c|c|c|c|c|c|c|c|c|c|c|c|c|}
\hline Grupo B & B1 & B2 & B3 & B4 & B5 & B6 & B7 & B8 & B9 & B10 & B11 & B12 & B13 \\
\hline T0 & 5 & 3 & 3 & 7 & 4 & 6 & 2 & 4 & 5 & 4 & 4 & 2 & 4 \\
\hline $\mathbf{T 1}$ & 2 & 2 & 1 & 7 & ** & 4 & 1 & 3 & 6 & 3 & 4 & 2 & ** \\
\hline T2 & 4 & 3 & 3 & 8 & 4 & 4 & 3 & 0 & 5 & 1 & 3 & $\dagger$ & 4 \\
\hline T3 & 3 & 2 & 3 & 5 & 6 & 5 & 1 & 2 & 5 & $t$ & 2 & & ** \\
\hline $\mathrm{T4}$ & 4 & 3 & $\dagger$ & 8 & & $t$ & 3 & 3 & 7 & & 3 & & $\star *$ \\
\hline T5 & 3 & 3 & & 8 & & & 2 & 3 & 6 & & $t$ & & ** \\
\hline T6 & 4 & $t$ & & 6 & & & 3 & 3 & 7 & & & & 3 \\
\hline T7 & 3 & & & 6 & & & 3 & 4 & 6 & & & & 4 \\
\hline T8 & 4 & & & 6 & & & 3 & 4 & 6 & & & & \\
\hline T9 & 3 & & & 6 & & & $\dagger$ & 5 & 5 & & & & \\
\hline T10 & 4 & & & 7 & & & & 6 & 7 & & & & \\
\hline $\mathrm{T} 11$ & 3 & & & 6 & & & & 7 & 8 & & & & \\
\hline T12 & 3 & & & 3 & & & & 6 & 7 & & & & \\
\hline Média & 3,46 & 2,66 & 2,50 & 6,38 & 4,66 & 4,75 & 2,33 & 3,84 & 6,15 & 2,66 & 3,20 & 2,00 & 3,75 \\
\hline D.P. & 0,77 & 0,51 & 1,00 & 1,38 & 1,15 & 0,95 & 0,86 & 1,86 & 0,98 & 1,52 & 0,83 & 0,00 & 0,50 \\
\hline Mediana & 3,00 & 3,00 & 3,00 & 6,00 & 4,00 & 4,50 & 3,00 & 4,00 & 6,00 & 3,00 & 3,00 & 2,00 & 4,00 \\
\hline EPM & 0,77 & 0,21 & 0,50 & 0,38 & 0,66 & 0,47 & 0,28 & 0,51 & 0,27 & 0,88 & 0,37 & 0,00 & 0,25 \\
\hline Min & 2,00 & 2,00 & 1,00 & 3,00 & 4,00 & 4,00 & 1,00 & 0,00 & 5,00 & 1,00 & 2,00 & 2,00 & 3,00 \\
\hline Max & 5,00 & 3,00 & 3,00 & 8,00 & 6,00 & 6,00 & 3,00 & 7,00 & 8,00 & 4,00 & 4,00 & 2,00 & 4,00 \\
\hline
\end{tabular}

Nos cães do Grupo B nota-se que o número de bandas de proteínas de baixo peso molecular na urina tende a ser maior quando comparado ao Grupo A, conforme confirmado pela análise estatística (Tabela 27).

Tabela 27 - Avaliação estatística (análise de variância - one way ANOVA) do número de bandas de proteínas de baixo peso molecular na urina dos cães dos Grupos A e B e os respectivos subgrupos (A-SF e A-CTM; B-SF e B-CTM). São Paulo, 2017.

\begin{tabular}{cccccc}
\hline & A-SF & A-CTM & B-SF & B-CTM & Controle \\
\hline A-SF & & 0.99 & $<0.001$ & $<0.001$ & $<0.001$ \\
A-CTM & 0.99 & & $<0.001$ & $<0.001$ & 0.0004 \\
B-SF & $<0.001$ & $<0.001$ & & 0.99 & $<0.001$ \\
B-CTM & $<0.001$ & $<0.001$ & 0.99 & $<0.001$ \\
Controle & $<0.001$ & 0.0004 & $<0.001$ & $<0.001$ & $<$ \\
\hline
\end{tabular}

A-SF = subgrupo A de cães com doença renal crônica no estágio 2 que recebeu solução fisiológica; $\mathbf{A}$-CTM: subgrupo A de cães com doença renal crônica no estágio 2 que grupo que recebeu célula tronco mesenquimal; B-SF = subgrupo A de cães com doença renal crônica no estágio 2 que recebeu solução fisiológica; B-CTM: subgrupo A de cães com doença renal crônica no estágio 2 que grupo que recebeu célula tronco mesenquimal; Controle = cães clinicamente normais 
Não se observa diferença no número de bandas de proteínas de baixo peso molecular entre os subgrupos A-SF e A-CTM, como também entre os subgrupos B-SF e B-CTM (Tabelas 28 e 29).

Tabela 28 - Estatística descritiva da média do número de bandas de proteínas de baixo peso molecular na urina dos cães com doença renal crônica no estágio 2 (GRUPO A) referentes aos subgrupos A-SF e A-CTM ao longo dos tempos de acompanhamento. São Paulo, 2017.

\begin{tabular}{ccc}
\hline Estagio 2 & A-SF $( \pm D P)$ & A-CTM $( \pm D P)$ \\
\hline T0 & $1,50( \pm 0,83) ; n=6$ & $2,66( \pm 2,08) ; n=3$ \\
T1 & $1,66( \pm 1,75) ; n=6$ & $3,00( \pm 1,73) ; n=3$ \\
T2 & $2,40( \pm 1,67) ; n=6$ & $1,50( \pm 0,70) ; n=3$ \\
T3 & $2,25( \pm 2,06) ; n=6$ & $2,33( \pm 2,30) ; n=3$ \\
T4 & $2,00( \pm 1,22) ; n=6$ & $1,00( \pm 0,00) ; n=3$ \\
T5 & $2,66( \pm 1,21) ; n=6$ & $1,00( \pm 0,00) ; n=3$ \\
T6 & $2,83( \pm 1,47) ; n=6$ & $1,00( \pm 0,00) ; n=3$ \\
T7 & $3,20( \pm 1,78) ; n=6$ & $3,00( \pm 0,00) ; n=3$ \\
T8 & $3,20( \pm 1,30) ; n=6$ & $2,50( \pm 0,70) ; n=3$ \\
T9 & $3,20( \pm 1,48) ; n=6$ & $3,00( \pm 0,00) ; n=3$ \\
T10 & $2,00( \pm 0,00) ; n=6$ & $4,00( \pm 0,00) ; n=3$ \\
T11 & $2,80( \pm 1,30) ; n=6$ & $2,00( \pm 0,00) ; n=3$ \\
T12 & $2,66( \pm 2,16) ; n=6$ & $3,66( \pm 1,52) ; n=3$ \\
\hline Média & $2,48( \pm 0,57)$ & $2,35( \pm 1,00)$ \\
\hline
\end{tabular}

DP = Desvio padrão da média; A-SF = cães com doença renal crônica no estágio 2 que receberam solução fisiológica; A-CTM: cães com doença renal crônica no estágio 2 que receberam célula tronco mesenquimal

Tabela 29 - Estatística descritiva da média do número de bandas de proteínas de baixo peso molecular na urina dos cães com doença renal crônica no estágio 3 (GRUPO B) referentes aos subgrupos B-SF e B-CTM ao longo dos tempos de acompanhamento. São Paulo, 2017.

\begin{tabular}{ccc}
\hline Estagio 3 & B-SF $( \pm D P)$ & $B-C T M( \pm D P)$ \\
\hline T0 & $4,66( \pm 1,63) ; n=6$ & $3,57( \pm 1,13) ; n=7$ \\
T1 & $3,20( \pm 2,38) ; n=6$ & $3,16( \pm 1,72) ; n=7$ \\
T2 & $4,33( \pm 1,86) ; n=6$ & $2,66( \pm 1,86) ; n=6$ \\
T3 & $4,00( \pm 1,54) ; n=6$ & $2,50( \pm 1,73) ; n=5$ \\
T4 & $5,00( \pm 2,64) ; n=3$ & $4,00( \pm 2,00) ; n=5$ \\
T5 & $4,66( \pm 2,88) ; n=3$ & $3,66( \pm 2,08) ; n=4$ \\
T6 & $5,00( \pm 1,41) ; n=2$ & $4,00( \pm 2,00) ; n=4$ \\
T7 & $4,50( \pm 2,12) ; n=2$ & $4,25( \pm 1,25) ; n=4$ \\
T8 & $5,00( \pm 1,41) ; n=2$ & $4,33( \pm 1,52) ; n=3$ \\
T9 & $4,50( \pm 2,12) ; n=2$ & $5,00( \pm 0,00) ; n=2$ \\
T10 & $5,50( \pm 2,12) ; n=2$ & $6,50( \pm 0,70) ; n=2$ \\
T11 & $4,50( \pm 2,12) ; n=2$ & $7,50( \pm 0,70) ; n=2$ \\
T12 & $3,00( \pm 0,00) ; n=2$ & $6,50( \pm 0,70) ; n=2$ \\
\hline Média & $4,45( \pm 0,70)$ & $4,43( \pm 1,54)$
\end{tabular}

DP = Desvio padrão da média; B-SF = cães com doença renal crônica no estágio 3 que receberam solução fisiológica; B-CTM: cães com doença renal crônica no estágio 3 que receberam célula tronco mesenquimal 
A configuração das médias do número de bandas de proteínas de baixo peso molecular na urina dos Grupos A e B, e respectivos subgrupos, está apresentado na Figura 10, e o cálculo da área sob a curva obtida ao longo do período de observação na Tabela 30.

Figura 10 - Valores da média do número de bandas de proteína de baixo peso molecular (BLMWP) na urina dos cães dos Grupos A e B, subgrupos A-SF (A1 a A6), A-CTM (A7 a A9), B-SF (B1 a B6) e B-CTM (B7 a B13), ao longo da avaliação sequencial durante a evolução da doença renal crônica. São Paulo, 2017.

\section{B L M W P}

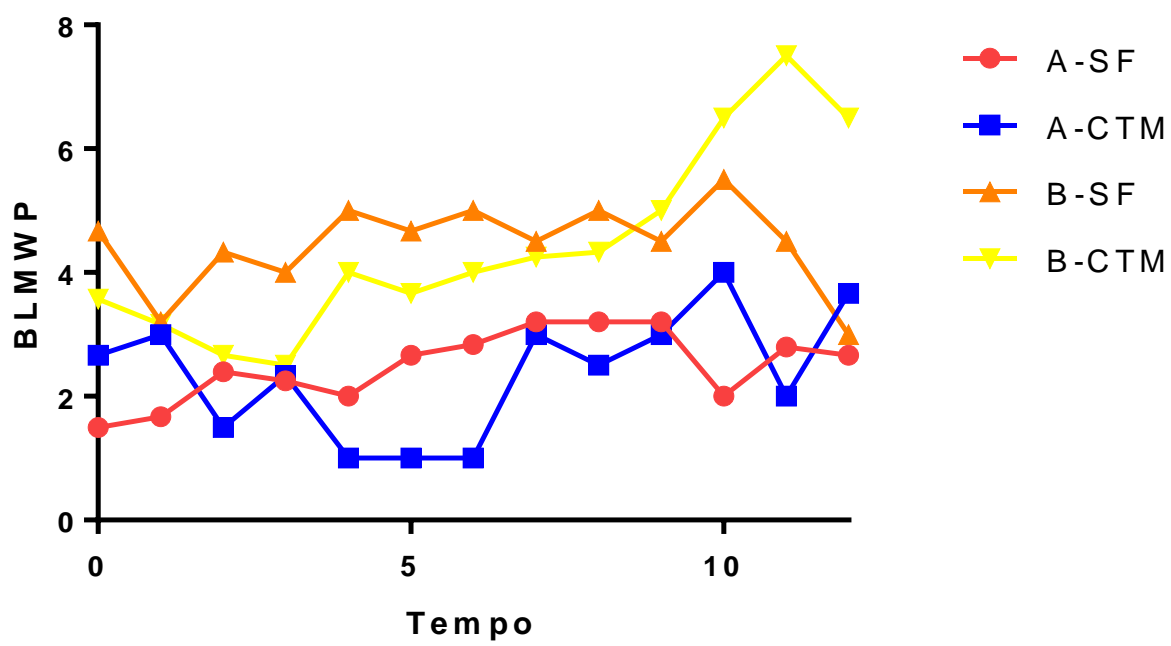

A-SF = cães com doença renal crônica no estágio 2 que receberam solução fisiológica; A-CTM: cães com doença renal crônica no estágio 2 que receberam célula tronco mesenquimal; B-SF = cães com doença renal crônica no estágio 3 que receberam solução fisiológica; BCTM: cães com doença renal crônica no estágio 3 que receberam célula tronco mesenquimal

Tabela 30 - Cálculo da área sob a curva (AREA) do número de bandas de proteínas de baixo peso molecular (LMWP) na urina dos cães dos Grupos $A$ e B, subgrupos ASF (A1 a A6), A-CTM (A7 a A9), B-SF (B1 a B6) e B-CTM (B7 a B13), na avaliação sequencial durante a evolução da doença renal crônica. São Paulo, 2017.

\begin{tabular}{cccccc}
\hline AREA & A-SF & A-CTM & B-SF & B-CTM & Controle \\
\hline Área & 30,30 & 27,50 & 54,03 & 52,62 & 8,00 \\
Erro & 3,65 & 2,51 & 5,01 & 3,71 & 0 \\
IC 95\% & $23,13-37,47$ & $22,57-32,43$ & $44,21-63,86$ & $45,34-59,90$ &
\end{tabular}

A-SF = cães com doença renal crônica no estágio 2 que receberam solução fisiológica; A-CTM: cães com doença renal crônica no estágio 2 que receberam célula tronco mesenquimal; B-SF = cães com doença renal crônica no estágio 3 que receberam solução fisiológica; $\mathbf{B}$ CTM: cães com doença renal crônica no estágio 3 que receberam célula tronco mesenquimal 


\subsection{Creatinina Sérica}

Apenas o cão A1 do Grupo A apresentou concentrações de creatinina sérica superior a 2,0 mg/dL e que persistiu ao longo do período de observação, ou seja, houve a mudança da DRC para o estágio 3 (Tabela 31).

Tabela 31 - Valores individuais e da estatística descritiva da concentração de creatinina sérica ( $\mathrm{mg} / \mathrm{dL})$, na avaliação sequencial durante a evolução da doença renal crônica em cães do Grupo A, subgrupos A-SF (A1 a A6) e A-CTM (A7 a A9). São Paulo, 2017.

\begin{tabular}{|c|c|c|c|c|c|c|c|c|c|}
\hline Grupo A & A1 & A2 & A3 & A4 & A5 & A6 & A7 & A8 & A9 \\
\hline T0 & 1,70 & 1,60 & 2,00 & 1,60 & 1,50 & 1,50 & 1,30 & 1,50 & 1,70 \\
\hline T1 & 1,90 & 1,70 & 1,90 & 1,60 & 1,50 & 1,40 & 1,80 & 1,80 & 2,00 \\
\hline T2 & 1,90 & 1,40 & 2,10 & 1,50 & 1,70 & 1,50 & 1,00 & 2,10 & 1,70 \\
\hline T3 & 1,80 & 1,50 & 1,90 & 1,50 & 1,50 & 1,20 & 0,90 & 2,50 & 1,60 \\
\hline T4 & 1,80 & 1,90 & 1,80 & 2,00 & 1,40 & 1,30 & 1,20 & 1,90 & 1,70 \\
\hline T5 & 1,80 & 1,20 & 2,10 & 1,90 & 1,40 & 1,40 & ** & 2,30 & 1,90 \\
\hline T6 & 1,90 & 1,60 & 1,90 & 2,00 & 1,50 & 1,50 & 1,00 & 2,10 & 1,90 \\
\hline T7 & 2,40 & 1,40 & 1,80 & 1,80 & 1,40 & 1,50 & 1,10 & 1,90 & $* *$ \\
\hline T8 & 2,10 & 1,50 & 2,00 & 1,80 & 1,30 & 2,20 & 1,10 & 1,90 & 1,90 \\
\hline T9 & 2,20 & 1,70 & 1,90 & 1,80 & 1,30 & 1,70 & 1,20 & 1,90 & ** \\
\hline T10 & 2,60 & 1,30 & 2,00 & 1,90 & 1,50 & 1,40 & 1,20 & 1,60 & ** \\
\hline T11 & 2,80 & 1,50 & 2,20 & 1,70 & 1,30 & 1,40 & 1,10 & 1,80 & 1,90 \\
\hline T12 & 2,40 & 1,60 & 1,90 & 1,60 & 1,00 & 1,90 & 1,00 & 1,80 & 1,90 \\
\hline Média & 2,10 & 1,53 & 1,96 & 1,74 & 1,40 & 1,53 & 1,15 & 1,93 & 1,82 \\
\hline D.P. & 0,35 & 0,18 & 0,11 & 0,17 & 0,16 & 0,26 & 0,23 & 0,26 & 0,13 \\
\hline Mediana & 1,90 & 1,50 & 1,90 & 1,80 & 1,40 & 1,50 & 1,10 & 1,90 & 1,90 \\
\hline EPM & 0,09 & 0,05 & 0,03 & 0,04 & 0,04 & 0,07 & 0,06 & 0,07 & 0,04 \\
\hline Min & 1,70 & 1,20 & 1,80 & 1,50 & 1,00 & 1,20 & 0,90 & 1,50 & 1,60 \\
\hline Max & 2,80 & 1,90 & 2,20 & 2,00 & 1,70 & 2,20 & 1,80 & 2,50 & 2,00 \\
\hline$\Delta$ & 0,70 & 0 & $-0,10$ & 0 & $-0,50$ & 0,40 & $-0,30$ & 0,30 & 0,20 \\
\hline
\end{tabular}

A mudança para o estágio 4 dos cães do Grupo B (estágio 3 da DRC) foi observada somente nos cães do subgrupo B-CTM, sendo que dos cinco cães (B7, B10, B11, B12 e B13) que vieram a óbito durante o período de observação, os cães B7, B10 e B13 haviam evoluído com o aumento da azotemia (Tabela 32). 
Tabela 32 - Valores individuais e da estatística descritiva da concentração de creatinina sérica ( $\mathrm{mg} / \mathrm{dL})$, na avaliação sequencial durante a evolução da doença renal crônica em cães do Grupo B, subgrupos B-SF (B1 a B6) e B-CTM (B7 a B13). São Paulo, 2017.

\begin{tabular}{|c|c|c|c|c|c|c|c|c|c|c|c|c|c|}
\hline Grupo B & B1 & B2 & B3 & B4 & B5 & B6 & B7 & B8 & B9 & B10 & B11 & B12 & B13 \\
\hline T0 & 2,50 & 2,40 & 2,70 & 2,40 & 2,80 & 2,40 & 4,20 & 2,30 & 2,10 & 4,70 & 4,40 & 3,20 & 2,50 \\
\hline T1 & 2,20 & 1,90 & 3,00 & 2,40 & 3,10 & 2,40 & 4,70 & 2,30 & 1,80 & 6,30 & 4,30 & 2,60 & 3,20 \\
\hline T2 & 2,50 & 1,80 & 3,90 & 2,90 & 2,90 & * & 4,60 & 2,60 & 2,70 & 7,10 & 4,10 & $t$ & 2,40 \\
\hline T3 & 2,50 & 2,50 & 3,40 & 2,60 & 3,00 & 2,20 & 5,90 & 2,70 & 3,10 & $\dagger$ & 4,20 & & 3,10 \\
\hline T4 & 2,40 & 3,80 & $\dagger$ & 2,50 & 3,40 & $\dagger$ & 5,40 & 2,70 & 2,90 & & 4,30 & & 2,80 \\
\hline T5 & 2,50 & 2,10 & & 3,10 & & & 4,90 & 2,50 & 2,80 & & $t$ & & 3,70 \\
\hline T6 & 2,70 & $\dagger$ & & 3,10 & & & 6,10 & 2,80 & 2,40 & & & & 4,00 \\
\hline $\mathrm{T7}$ & 2,90 & & & 2,70 & & & 6,20 & 2,50 & 2,60 & & & & 6,00 \\
\hline T8 & 3,00 & & & 2,60 & & & 6,50 & 2,90 & 2,900 & & & & $\dagger$ \\
\hline T9 & 3,10 & & & 3,30 & & & 6,40 & 3,10 & 2,10 & & & & \\
\hline T10 & 3,10 & & & 3,30 & & & $\dagger$ & 3,50 & 3,00 & & & & \\
\hline T11 & 2,90 & & & 3,40 & & & & 3,30 & 3,30 & & & & \\
\hline $\mathrm{T} 12$ & 2,80 & & & 4,10 & & & & 3,60 & 3,30 & & & & \\
\hline Média & 2,70 & 2,41 & 3,25 & 2,93 & 3,04 & 2,35 & 5,49 & 2,83 & 2,69 & 6,03 & 4,26 & 2,90 & 3,46 \\
\hline D.P. & 0,28 & 0,73 & 0,51 & 0,48 & 0,23 & 0,07 & 0,83 & 0,42 & 0,47 & 1,22 & 0,11 & 0,42 & 1,16 \\
\hline Mediana & 2,70 & 2,25 & 3,20 & 2,90 & 3,00 & 2,40 & 5,65 & 2,70 & 2,80 & 6,30 & 4,30 & 2,90 & 3,15 \\
\hline EPM & 0,08 & 0,29 & 0,25 & 0,13 & 0,10 & 0,04 & 0,26 & 0,11 & 0,13 & 0,70 & 0,05 & 0,30 & 0,41 \\
\hline Min & 2,20 & 1,80 & 2,70 & 2,40 & 2,80 & 2,27 & 4,20 & 2,30 & 1,80 & 4,70 & 4,10 & 2,60 & 2,40 \\
\hline Max & 3,10 & 3,80 & 3,90 & 4,10 & 3,40 & 2,40 & 6,50 & 3,60 & 3,30 & 7,10 & 4,40 & 3,20 & 6,00 \\
\hline$\Delta$ & 0,30 & $-0,30$ & 0,70 & 1,70 & 0,60 & 0,20 & 2,20 & 1,30 & 1,20 & 2,40 & $-0,10$ & $-0,60$ & 3,50 \\
\hline
\end{tabular}

Nos cães do Grupo B nota-se concentrações maiores de creatinina, observando-se diferença significante entre os cães dos grupo A e controle (Tabela 33).

Tabela 33 - Avaliação estatística (análise de variância - one way ANOVA) da concentração de creatinina sérica dos cães dos Grupos A e B, referentes aos respectivos subgrupos (A-SF e A-CTM; B-SF e B-CTM). São Paulo, 2017.

\begin{tabular}{llllll}
\hline & A-SF & A-CTM & B-SF & B-CTM & Controle \\
\hline A-SF & & 0,98 & $<0,001$ & $<0,001$ & $<0,001$ \\
A-CTM & 0,98 & & $<0,001$ & $<0,001$ & $<0,001$ \\
B-SF & $<0,001$ & $<0,001$ & & $<0,001$ & $<0,001$ \\
B-CTM & $<0,001$ & $<0,001$ & $<0,001$ & & $<0,001$ \\
Controle & $<0,001$ & $<0,001$ & $<0,001$ & $<0,001$ & \\
\hline A-SF & & & &
\end{tabular}

A-SF = cães com doença renal crônica no estágio 2 que receberam solução fisiológica; A-CTM: cães com doença renal crônica no estágio 2 que receberam célula tronco mesenquimal; B-SF = cães com doença renal crônica no estágio 3 que receberam solução fisiológica; BCTM: cães com doença renal crônica no estágio 3 que receberam célula tronco mesenquimal

Os cães do Grupo A apresentaram concentrações semelhantes de creatinina sérica durante todo o período de acompanhamento, conforme 
destacado na Tabela 34, os valores foram então plotados em um gráfico de dispersão com linha de tendência para avaliação do comportamento da variável ao longo do tempo (Figura 11).

Tabela 34 - Estatística descritiva das concentrações de creatinina sérica dos cães com doença renal crônica no estágio 2 (GRUPO A) referentes aos subgrupos A-SF e A-CTM ao longo dos tempos de acompanhamento. São Paulo, 2017.

\begin{tabular}{ccc}
\hline Estagio & A-SF $( \pm \mathrm{DP})$ & A-CTM $( \pm \mathrm{DP})$ \\
\hline T0 & $1,65( \pm 0,18) ; \mathrm{n}=6$ & $1,50( \pm 0,20) ; \mathrm{n}=3$ \\
T1 & $1,66( \pm 0,20) ; \mathrm{n}=6$ & $1,86( \pm 0,11) ; \mathrm{n}=3$ \\
T2 & $1,68( \pm 0,27) ; \mathrm{n}=6$ & $1,60( \pm 0,55) ; \mathrm{n}=3$ \\
T3 & $1,56( \pm 0,25) ; \mathrm{n}=6$ & $1,66( \pm 0,80) ; \mathrm{n}=3$ \\
T4 & $1,70( \pm 0,28) ; \mathrm{n}=6$ & $1,60( \pm 0,36) ; \mathrm{n}=3$ \\
T5 & $1,63( \pm 0,35) ; \mathrm{n}=6$ & $2,10( \pm 0,28) ; \mathrm{n}=3$ \\
T6 & $1,73( \pm 0,22) ; \mathrm{n}=6$ & $1,66( \pm 0,58) ; \mathrm{n}=3$ \\
T7 & $1,71( \pm 0,38) ; \mathrm{n}=6$ & $1,63( \pm 0,46) ; \mathrm{n}=3$ \\
T8 & $1,81( \pm 0,35) ; \mathrm{n}=6$ & $1,63( \pm 0,46) ; \mathrm{n}=3$ \\
T9 & $1,76( \pm 0,29) ; \mathrm{n}=6$ & $1,66( \pm 0,40) ; \mathrm{n}=3$ \\
T10 & $1,78( \pm 0,48) ; \mathrm{n}=6$ & $1,40( \pm 0,28) ; \mathrm{n}=3$ \\
T11 & $1,81( \pm 0,57) ; \mathrm{n}=6$ & $1,45( \pm 0,49) ; \mathrm{n}=3$ \\
T12 & $1,73( \pm 0,46) ; \mathrm{n}=6$ & $1,40( \pm 0,56) ; \mathrm{n}=3$ \\
\hline Média & $1,70( \pm 0,07)$ & $1,62( \pm 0,19)$ \\
\hline DP= desvio padrão da média; A-SF $=$ cães com doença renal crônica no estágio 2 que receberam solução fisiológica; A-CTM: cães com doença renal crônica
\end{tabular}

DP= desvio padrão da média; $\mathbf{A - S F}$ = cães com doença renal crônica no estágio 2 que receberam solução fisiológica; $\mathbf{A}$-CTM: cães com doença renal crônica no estágio 2 que receberam célula tronco mesenquimal

FIGURA 11 - Gráfico de dispersão dos valores médios séricos de creatinina nos diferentes tempos de avaliação (T0 a T12) dos cães com doença renal crônica no estágio 2 (GRUPO A) referentes aos subgrupos A-SF e A-CTM. São Paulo, 2017.

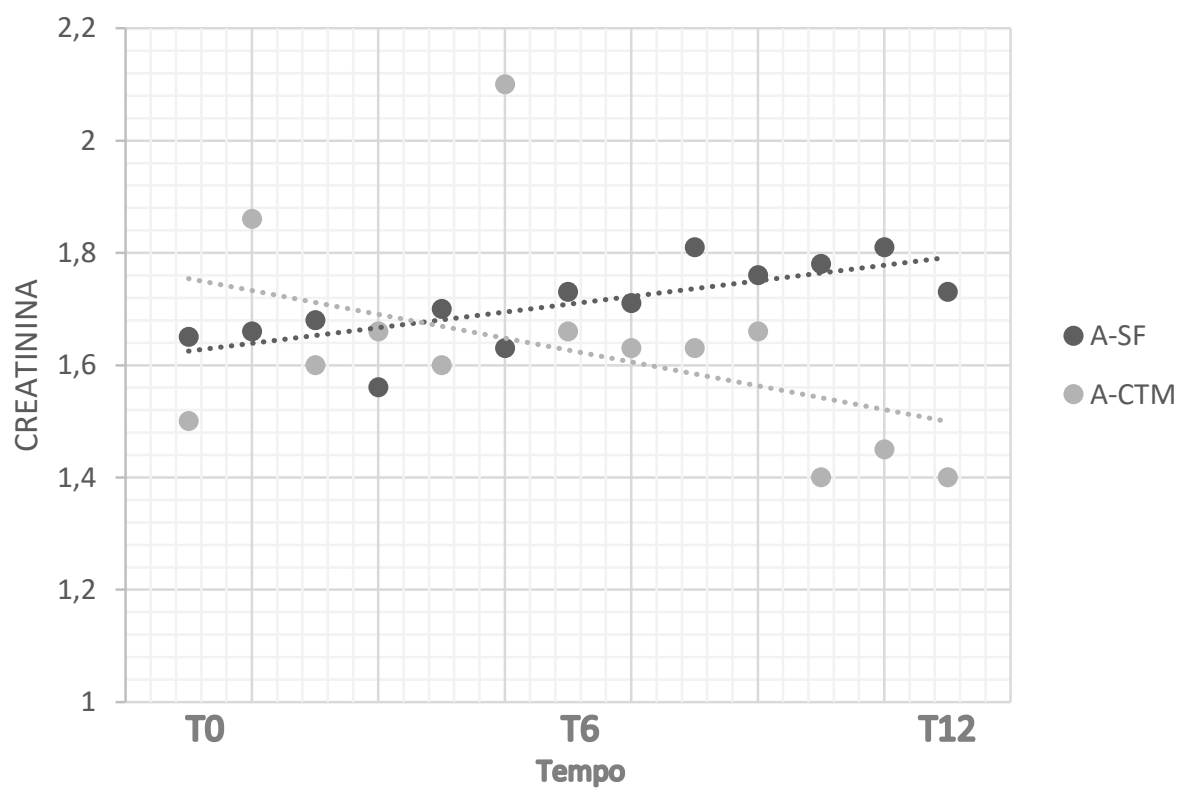


Os cães do subgrupo B-CTM em T0 apresentavam concentrações séricas de creatinina maiores que do subgrupo B-SF (Tabela 35), os valores foram então plotados em um gráfico de dispersão com linha de tendência para avaliação do comportamento da variável ao longo do tempo (Figura 12). Corroborado esses dados pelo cálculo da área sob a curva que foi maior para o subgrupo B-CTM (Tabela 36), como também pela avaliação da curva (Figura 13).

Tabela 35 - Estatística descritiva das concentrações de creatinina sérica dos cães com doença renal crônica no estágio 3 (GRUPO B) referentes aos subgrupos B-SF e B-CTM ao longo dos tempos de acompanhamento. São Paulo, 2017.

\begin{tabular}{|c|c|c|c|}
\hline Estagio 3 & $\mathrm{~B}-\mathrm{SF}( \pm \mathrm{DP})$ & B-CTM ( \pm DP $)$ & \\
\hline T0 & $2,53( \pm 0,17) ; n=6$ & $3,34( \pm 1,08) ; n=7$ & \\
\hline T1 & $2,50( \pm 0,46) ; n=6$ & $3,60( \pm 1,58) ; n=7$ & \\
\hline T2 & $2,80( \pm 0,76) ; n=6$ & $3,91( \pm 1,79) ; n=6$ & \\
\hline T3 & $2,70( \pm 0,42) ; n=6$ & $3,80( \pm 1,30) ; n=5$ & \\
\hline T4 & $3,02( \pm 0,68) ; n=3$ & $3,62( \pm 1,19) ; n=5$ & \\
\hline T5 & $2,56( \pm 0,50) ; n=3$ & $3,47( \pm 1,07) ; n=4$ & \\
\hline T6 & $2,90( \pm 0,28) ; n=2$ & $3,82( \pm 1,66) ; n=4$ & \\
\hline $\mathrm{T} 7$ & $2,80( \pm 0,14) ; n=2$ & $4,32( \pm 2,05) ; n=4$ & \\
\hline T8 & $2,80( \pm 0,28) ; n=2$ & $4,10( \pm 2,07) ; n=3$ & \\
\hline T9 & $3,20( \pm 0,14) ; n=2$ & $3,86( \pm 2,25) ; n=2$ & \\
\hline T10 & $3,06( \pm 0,04) ; n=2$ & $3,25( \pm 0,35) ; n=2$ & \\
\hline T11 & $3,15( \pm 0,35) ; n=2$ & $3,30( \pm 0,00) ; n=2$ & \\
\hline T12 & $3,45( \pm 0,91) ; n=2$ & $3,45( \pm 0,21) ; n=2$ & \\
\hline Média & $2,88( \pm 0,28)$ & $3,68( \pm 0,32)$ & $P<0,001$ \\
\hline
\end{tabular}

DP = desvio padrão da média; B-SF = cães com doença renal crônica no estágio 3 que receberam solução fisiológica; $B$-CTM: cães com doença renal crônica no estágio 3 que receberam célula tronco mesenquimal

Tabela 36 - Cálculo da área sob a curva (AREA) da concentração de creatinina sérica dos cães dos Grupos A e B, subgrupos A-SF, A-CTM, B-SF e B-CTM, na avaliação sequencial durante a evolução da doença renal crônica. São Paulo, 2017.

\begin{tabular}{cccccc}
\hline AREA & A-SF & A-CTM & B-SF & B-CTM & Controle \\
\hline Área & 20,58 & 19,72 & 34,5 & 44,47 & 11,65 \\
Erro & 0,86 & 1,16 & 1,11 & 3,68 & 0 \\
IC 95\% & $18,89-22,26$ & $17,44-22$ & $32,32-36,68$ & $37,26-51,69$ & \\
\hline
\end{tabular}

A-SF = cães com doença renal crônica no estágio 2 que receberam solução fisiológica; A-CTM: cães com doença renal crônica no estágio 2 que receberam célula tronco mesenquimal; B-SF = cães com doença renal crônica no estágio 3 que receberam solução fisiológica; $\mathbf{B}-$ СTM: cães com doença renal crônica no estágio 3 que receberam célula tronco mesenquimal; Controle = cães clinicamente normais; IC $=$ intervalo de confiança 
FIGURA 12 - Gráfico de dispersão dos valores médios séricos de creatinina nos diferentes tempos de avaliação (T0 a T12) dos cães com doença renal crônica no estágio 3 (GRUPO B) referentes aos subgrupos B-SF e B-CTM. São Paulo, 2017.

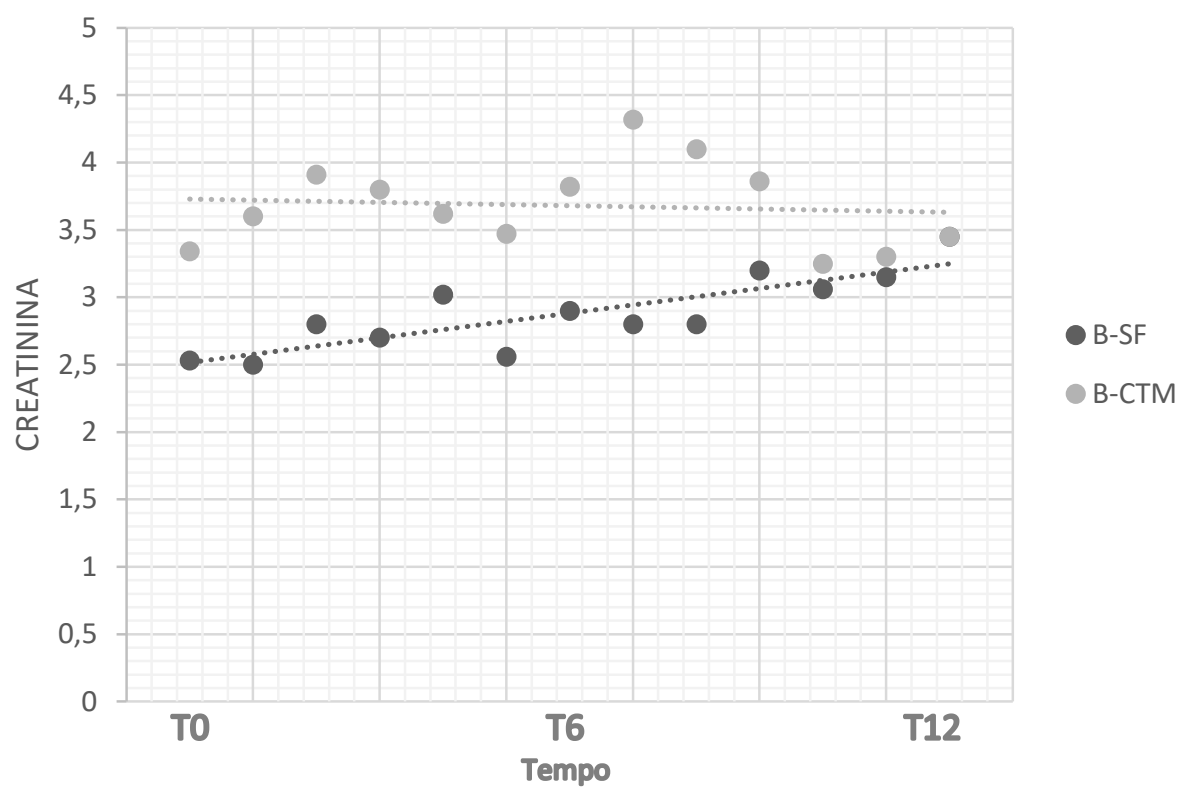

Figura 13 - Valores médios da concentração de creatinina sérica dos cães dos Grupos A e B, e respectivos subgrupos A-SF, A-CTM, B-SF e B-CTM, na avaliação sequencial durante a evolução da doença renal crônica. São Paulo, 2017.

\section{Creatinin a}

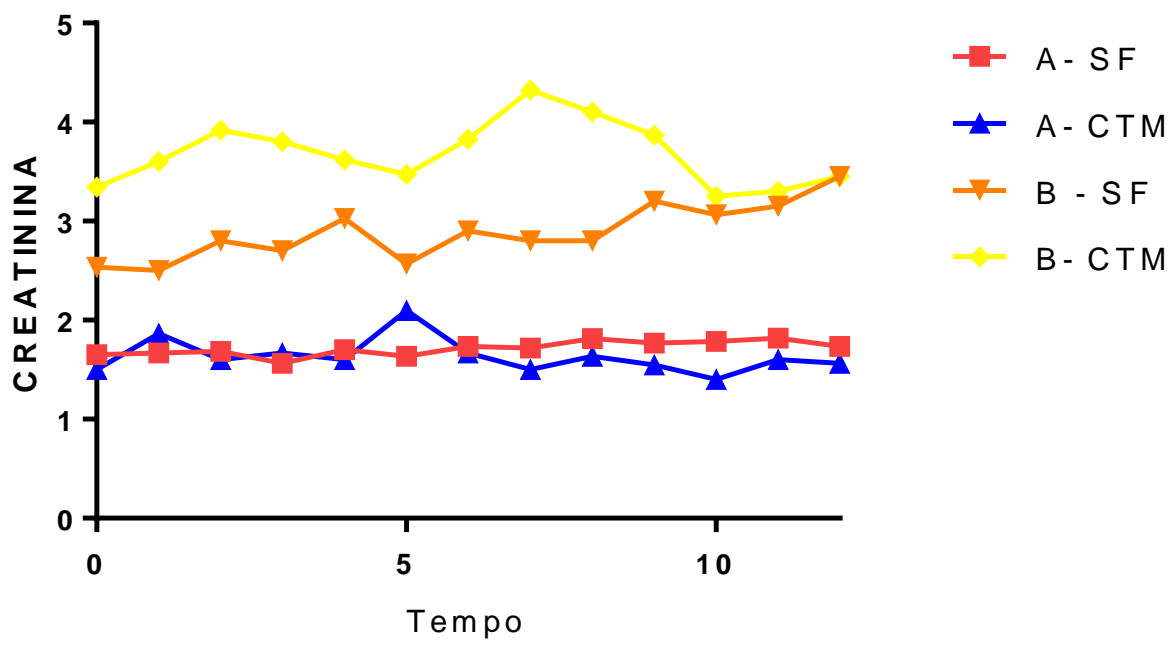

A-SF = cães com doença renal crônica no estágio 2 que receberam solução fisiológica; A-CTM: cães com doença renal crônica no estágio 2 que receberam célula tronco mesenquimal; B-SF = cães com doença renal crônica no estágio 3 que receberam solução fisiológica; BCTM: cães com doença renal crônica no estágio 3 que receberam célula tronco mesenquimal 


\subsection{Ureia Sérica}

Concentrações sérica de ureia superior a $150 \mathrm{mg} / \mathrm{dL}$ foram detectadas ao longo da evolução da DRC em apenas um cão do subgrupo A-SF (A6) e, pontualmente, no cão A8 em T5; nos demais cães dos subgrupos A-SF e A-CTM, as oscilações nas concentrações de ureia ao longo dos tempos de acompanhamento não ultrapassaram $150 \mathrm{mg} / \mathrm{dL}$ (Tabela 37). No atinente ao Grupo B, as concentrações superiores a $300 \mathrm{mg} / \mathrm{dL}$ foram observadas em apenas um cão (B3) do subgrupo B-SF, mas detectadas em todos os cães (B7 a B13) do subgrupo B-CTM, principalmente ao final do período de acompanhamento, em que a concentração sérica de ureia foi superior ao patamares mencionados, sendo que no cão B7 foi observada a maior concentração ( $456,0 \mathrm{mg} / \mathrm{dL}$ ) e este, posteriormente foi a óbito (Tabela 38)

Tabela 37 - Valores individuais e da estatística descritiva da ureia sérica ( $\mathrm{mg} / \mathrm{dL}$ ), na avaliação sequencial durante a evolução da doença renal crônica em cães do Grupo A, subgrupos A-SF (A1 a A6) e A-CTM (A7 a A9). São Paulo, 2017.

\begin{tabular}{|c|c|c|c|c|c|c|c|c|c|}
\hline Grupo $\mathrm{A}$ & A1 & A2 & A3 & A4 & A5 & A6 & A7 & A8 & A9 \\
\hline T0 & 54,50 & 39,80 & 68,50 & 68,50 & 57,80 & 62,40 & 134,60 & 96,50 & 87,20 \\
\hline T1 & 63,40 & 39,50 & 90,00 & 54,80 & 76,60 & 53,90 & 104,40 & 115,40 & 120,60 \\
\hline T2 & 70,00 & 32,70 & 67,20 & 66,80 & 77,80 & 58,80 & 113,70 & 133,70 & 89,50 \\
\hline T3 & 74,90 & 40,20 & 101,10 & 47,60 & 72,10 & 82,90 & 68,80 & 140,50 & 83,80 \\
\hline T4 & 52,30 & 33,20 & 57,40 & 54,70 & 69,40 & 71,00 & 99,50 & 144,30 & 91,20 \\
\hline T5 & 69,90 & 36,80 & 53,10 & 79,90 & 88,10 & 81,90 & ** & 160,50 & 95,70 \\
\hline T6 & 96,30 & 43,60 & 54,40 & 75,40 & 58,10 & 82,80 & 64,70 & 116,00 & 101,90 \\
\hline T7 & 113,60 & 48,10 & 72,20 & 62,30 & 52,40 & 104,40 & 97,30 & 92,10 & ** \\
\hline T8 & 88,50 & 45,20 & 62,00 & 56,20 & 70,00 & 194,00 & 75,60 & 107,40 & 89,70 \\
\hline T9 & 74,30 & 53,40 & 62,50 & 64,60 & 54,60 & 150,40 & 66,40 & 127,10 & ** \\
\hline T10 & 75,00 & 38,00 & 61,30 & 72,60 & 66,30 & 108,80 & 77,00 & 110,00 & ** \\
\hline T11 & 86,60 & 36,60 & 64,40 & 83,00 & 50,90 & 101,30 & 63,40 & 66,90 & 99,70 \\
\hline T12 & 74,80 & 43,40 & 61,80 & 56,80 & 60,90 & 137,40 & 73,00 & 84,40 & 78,50 \\
\hline Média & 76,46 & 40,80 & 67,37 & 64,86 & 65,76 & 99,23 & 86,53 & 114,98 & 93,78 \\
\hline D.P. & 16,71 & 5,87 & 13,76 & 10,77 & 11,19 & 40,68 & 22,91 & 26,26 & 11,74 \\
\hline Mediana & 74,80 & 39,80 & 62,50 & 64,60 & 66,30 & 82,90 & 76,30 & 115,40 & 90,45 \\
\hline EPM & 4,63 & 1,62 & 3,81 & 2,98 & 3,10 & 11,28 & 6,61 & 7,28 & 3,71 \\
\hline Min & 52,30 & 32,70 & 53,10 & 47,60 & 50,90 & 53,90 & 63,40 & 66,90 & 78,50 \\
\hline Max & 113,60 & 53,40 & 101,10 & 83,00 & 88,10 & 194,00 & 134,60 & 160,50 & 120,60 \\
\hline$\Delta$ & 20,30 & 3,60 & $-6,70$ & $-11,70$ & 3,10 & 75,00 & $-61,60$ & $-12,10$ & $-8,70$ \\
\hline
\end{tabular}


Tabela 38 - Valores individuais e da estatística descritiva da ureia sérica ( $\mathrm{mg} / \mathrm{dL})$, na avaliação sequencial durante a evolução da doença renal crônica em cães do Grupo B, subgrupos B-SF (B1 a B6) e B-CTM (B7 a B13). São Paulo, 2017.

\begin{tabular}{|c|c|c|c|c|c|c|c|c|c|c|c|c|c|}
\hline Grupo B & B1 & B2 & B3 & B4 & B5 & B6 & B7 & B8 & B9 & B10 & B11 & B12 & B13 \\
\hline T0 & 92,30 & 183,20 & 271,20 & 63,00 & 101,10 & 212,00 & 171,30 & 153,30 & 185,80 & 252,60 & 318,80 & 300,70 & 200,70 \\
\hline T1 & 101,90 & 133,20 & 338,10 & 64,90 & 66,10 & 219,40 & 222,90 & 196,00 & 154,70 & 310,00 & 247,90 & 190,40 & 274,30 \\
\hline T2 & 90,20 & 134,60 & 311,40 & 70,00 & 68,40 & $* *$ & 210,90 & 182,90 & 188,00 & 336,30 & 201,70 & $\dagger$ & 252,70 \\
\hline T3 & 77,90 & 163,40 & 316,00 & 98,30 & 64,50 & 221,00 & 237,70 & 283,60 & 256,50 & $\dagger$ & 280,60 & & 246,10 \\
\hline T4 & 100,80 & 292,80 & $\dagger$ & 146,80 & 83,10 & $t$ & 199,80 & 204,10 & 226,70 & & 202,90 & & 195,80 \\
\hline T5 & 83,20 & 136,20 & & 153,90 & & & 213,70 & 206,00 & 183,80 & & $\dagger$ & & 196,40 \\
\hline T6 & 129,50 & $\dagger$ & & 161,10 & & & 354,90 & 277,30 & 230,40 & & & & 240,30 \\
\hline T7 & 101,20 & & & 162,20 & & & 258,80 & 282,60 & 227,90 & & & & 381,00 \\
\hline T8 & 97,70 & & & 179,30 & & & 276,50 & 276,60 & 277,70 & & & & $t$ \\
\hline T9 & 117,20 & & & 223,60 & & & 456,00 & 336,30 & 187,10 & & & & \\
\hline T10 & 114,00 & & & 157,40 & & & $\dagger$ & 320,60 & 303,60 & & & & \\
\hline T11 & 85,80 & & & 202,80 & & & & 330,70 & 335,30 & & & & \\
\hline T12 & 119,80 & & & 283,90 & & & & 322,40 & 291,70 & & & & \\
\hline Média & 100,88 & 181,44 & 306,44 & 151,32 & 76,64 & 217,46 & 260,25 & 259,41 & 234,55 & 299,63 & 250,38 & 245,55 & 248,41 \\
\hline D.P. & 15,49 & 65,67 & 33,67 & 65,32 & 15,54 & 4,80 & 85,38 & 62,90 & 55,07 & 42,80 & 50,55 & 77,99 & 61,04 \\
\hline Mediana & 100,80 & 163,40 & 311,40 & 157,40 & 68,40 & 219,40 & 230,30 & 277,30 & 227,90 & 310,00 & 247,90 & 245,55 & 243,20 \\
\hline EPM & 4,29 & 29,36 & 19,44 & 18,11 & 6,95 & 2,77 & 27,00 & 17,44 & 15,27 & 24,71 & 22,61 & 55,15 & 21,58 \\
\hline Min & 77,90 & 133,20 & 271,20 & 63,00 & 64,50 & 212,00 & 171,30 & 153,30 & 154,70 & 252,60 & 201,70 & 190,40 & 195,80 \\
\hline Max & 129,50 & 292,80 & 338,10 & 283,90 & 101,10 & 221,00 & 456,00 & 336,30 & 335,30 & 336,30 & 318,80 & 300,70 & 381,00 \\
\hline$\Delta$ & 27,50 & $-47,00$ & 44,80 & 220,90 & $-18,00$ & 9,00 & 284,70 & 169,10 & 105,90 & 83,70 & $-115,90$ & $-110,30$ & 180,30 \\
\hline
\end{tabular}

Houve diferença entre os subgrupos A-CTM e A-SF $(P=0,016)$, assim como entre os subgrupos B-SF e B-CTM $(P<0,001)$ em que o subgrupo B-SF apresentou as menores concentrações de ureia (Tabela 39).

Tabela 39 - Avaliação estatística (análise de variância - one way ANOVA) das concentrações séricas de ureia dos cães dos Grupos A e B, referentes aos respectivos subgrupos (A-SF e A-CTM; B-SF e B-CTM). São Paulo, 2017.

\begin{tabular}{cccccc}
\hline & A-SF & A-CTM & B-SF & B-CTM & Controle \\
\hline A-SF & & 0,016 & $<0,001$ & $<0,001$ & 0,06 \\
A-CTM & 0,016 & & $<0,001$ & $<0,001$ & $<0,001$ \\
B-SF & $<0,001$ & $<0,001$ & & $<0,001$ & $<0,001$ \\
B-CTM & $<0,001$ & $<0,001$ & $<0,001$ & $<0,001$ \\
Controle & 0,06 & $<0,001$ & $<0,001$ & $<0,001$ & \\
\hline
\end{tabular}

$\overline{\mathbf{A}-\mathbf{S F}}$ = cães com doença renal crônica no estágio 2 que receberam solução fisiológica; $\mathbf{A - C T M : ~ c a ̃ e s ~ c o m ~ d o e n c ̧ a ~ r e n a l ~ c r o ̂ n i c a ~ n o ~ e s t a ́ g i o ~}$ 2 que receberam célula tronco mesenquimal; B-SF = cães com doença renal crônica no estágio 3 que receberam solução fisiológica; $\mathbf{B}$ CTM: cães com doença renal crônica no estágio 3 que receberam célula tronco mesenquimal 
As concentrações de ureia se mantiveram constantes durante todos os tempos de acompanhamento em todos os subgrupos dos Grupos A e B, entretanto, nos subgrupos A-CTM e B-CTM, desde o início do acompanhamento, a azotemia era mais intensa (Tabelas 40 e 41), os valores foram então plotados em gráficos de dispersão com linha de tendência para avaliação do comportamento da variável ao longo do tempo (Figura 14 e 15).

Tabela 40 - Estatística descritiva das concentrações de ureia sérica dos cães com doença renal crônica no estágio 2 (GRUPO A) referentes aos subgrupos A-SF e A-CTM ao longo dos tempos de acompanhamento. São Paulo, 2017.

\begin{tabular}{ccc}
\hline Estagio 2 & A-SF $( \pm \mathrm{DP})$ & $\mathrm{A}-\mathrm{CTM}( \pm \mathrm{DP})$ \\
\hline T0 & $58,58( \pm 10,78) ; \mathrm{n}=6$ & $106,10( \pm 25,11) ; \mathrm{n}=3$ \\
T1 & $63,03( \pm 17,98) ; \mathrm{n}=6$ & $113,46( \pm 8,27) ; \mathrm{n}=3$ \\
T2 & $62,21( \pm 15,69) ; \mathrm{n}=6$ & $112,30( \pm 22,13) ; \mathrm{n}=3$ \\
T3 & $69,80( \pm 22,59) ; \mathrm{n}=6$ & $97,70( \pm 37,81) ; \mathrm{n}=3$ \\
T4 & $56,33( \pm 13,71) ; \mathrm{n}=6$ & $111,66( \pm 28,56) ; \mathrm{n}=3$ \\
T5 & $68,28( \pm 19,68) ; \mathrm{n}=6$ & $128,10( \pm 45,82) ; \mathrm{n}=3$ \\
T6 & $68,43( \pm 19,75) ; \mathrm{n}=6$ & $94,20( \pm 26,50) ; \mathrm{n}=3$ \\
T7 & $75,50( \pm 27,40) ; \mathrm{n}=6$ & $93,02( \pm 3,88) ; \mathrm{n}=3$ \\
T8 & $85,98( \pm 54,87) ; \mathrm{n}=6$ & $94,23( \pm 16,59) ; \mathrm{n}=3$ \\
T9 & $76,63( \pm 36,92) ; \mathrm{n}=6$ & $90,66( \pm 32,12) ; \mathrm{n}=3$ \\
T10 & $70,33( \pm 23,02) ; \mathrm{n}=6$ & $93,50( \pm 23,33) ; \mathrm{n}=3$ \\
T11 & $70,46( \pm 24,22) ; \mathrm{n}=6$ & $65,15( \pm 2,47) ; \mathrm{n}=3$ \\
T12 & $72,51( \pm 33,34) ; \mathrm{n}=6$ & $78,70( \pm 8,06) ; \mathrm{n}=3$ \\
\hline Média & $69,08( \pm 7,94)$ & $98,36( \pm 16,27)$
\end{tabular}
com doença renal crônica no estágio 2 que receberam célula tronco mesenquimal 
FIGURA 14 - Gráfico de dispersão dos valores médios da ureia sérica nos diferentes tempos de avaliação (T0 a T12) dos cães com doença renal crônica no estágio 2 (GRUPO A) referentes aos subgrupos A-SF e A-CTM. São Paulo, 2017.

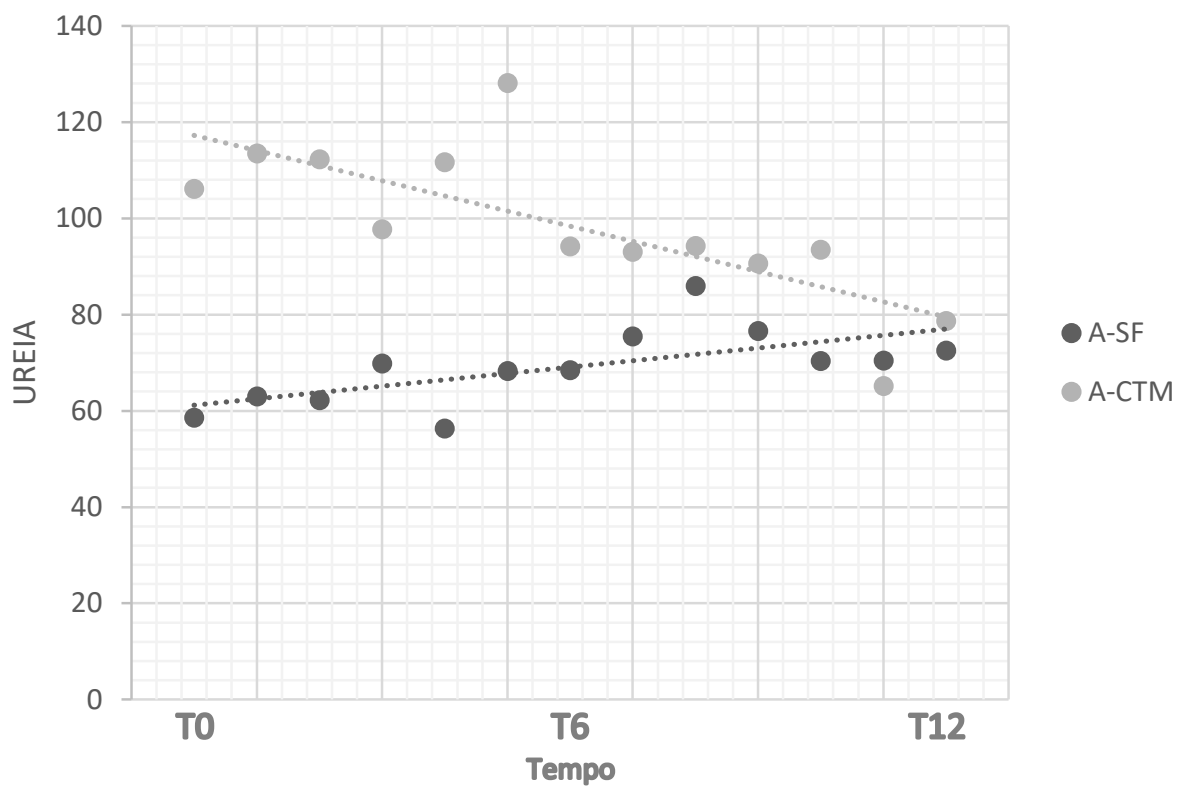

Tabela 41 - Estatística descritiva das concentrações de ureia sérica dos cães com doença renal crônica no estágio 3 (GRUPO B) referentes aos subgrupos B-SF e B-CTM ao longo dos tempos de acompanhamento. São Paulo, 2017.

\begin{tabular}{ccc}
\hline Estagio 3 & $\mathrm{~B}-\mathrm{SF}( \pm \mathrm{DP})$ & $\mathrm{B}-\mathrm{CTM}( \pm \mathrm{DP})$ \\
\hline T0 & $153,80( \pm 81,04) ; \mathrm{n}=6$ & $226,17( \pm 65,10) ; \mathrm{n}=7$ \\
T1 & $153,93( \pm 106,75) ; \mathrm{n}=6$ & $228,02( \pm 53,38) ; \mathrm{n}=7$ \\
T2 & $134,92( \pm 102,21) ; \mathrm{n}=6$ & $228,75( \pm 58,23) ; \mathrm{n}=6$ \\
T3 & $125,02( \pm 65,73) ; \mathrm{n}=6$ & $260,90( \pm 20,49) ; \mathrm{n}=5$ \\
T4 & $155,87( \pm 95,14) ; \mathrm{n}=3$ & $205,86( \pm 12,08) ; \mathrm{n}=5$ \\
T5 & $118,55( \pm 49,99) ; \mathrm{n}=3$ & $199,97( \pm 12,89) ; \mathrm{n}=4$ \\
T6 & $145,30( \pm 22,34) ; \mathrm{n}=2$ & $275,72( \pm 56,51) ; \mathrm{n}=4$ \\
T7 & $131,70( \pm 43,13) ; \mathrm{n}=2$ & $287,57( \pm 66,18) ; \mathrm{n}=4$ \\
T8 & $138,50( \pm 57,70) ; \mathrm{n}=2$ & $276,93( \pm 0,66) ; \mathrm{n}=3$ \\
T9 & $170,40( \pm 75,23) ; \mathrm{n}=2$ & $326,46( \pm 134,72) ; \mathrm{n}=2$ \\
T10 & $135,70( \pm 30,68) ; \mathrm{n}=2$ & $312,10( \pm 12,02) ; \mathrm{n}=2$ \\
T11 & $144,30( \pm 82,73) ; \mathrm{n}=2$ & $333,00( \pm 3,25) ; \mathrm{n}=2$ \\
T12 & $201,85( \pm 116,04) ; \mathrm{n}=2$ & $307,05( \pm 21,70) ; \mathrm{n}=2$ \\
\hline Média & $146,91( \pm 21,62)$ & $266,80( \pm 45,68)$ \\
\hline EPM = erro padrão da média; B-SF $=$ cães com doença renal crônica no estágio 3 que receberam solução fisiológica; B-CTM: cães com
\end{tabular}


FIGURA 15 - Gráfico de dispersão dos valores médios da ureia sérica nos diferentes tempos de avaliação (T0 a T12) dos cães com doença renal crônica no estágio 3 (GRUPO B) referentes aos subgrupos B-SF e B-CTM. São Paulo, 2017.



A Figura 16 configura os perfis médios das concentrações de ureia sérica ao longo dos tempos de observação, como também, corroborado pela análise do cálculo sob a curva, observa-se que o subgrupo B-CTM apresentou a maior área, ou seja, as maiores concentrações de ureia, e no subgrupo A-SF as menores concentrações, havendo diferença significativa entre A-SF e B-CTM. Foi constatada diferença entre os subgrupos B-SF e B-CTM $(P<0,001)$ (Tabela 42). 
Figura 16 - Valores das médias das concentrações de ureia sérica dos cães dos Grupos A e B, subgrupos A-SF, A-CTM, B-SF e B-CTM, na avaliação sequencial durante a evolução da doença renal crônica. São Paulo, 2017

\section{U reia}



A-SF = cães com doença renal crônica no estágio 2 que receberam solução fisiológica; $\mathbf{A}$-CTM: cães com doença renal crônica no estágio 2 que receberam célula tronco mesenquimal; B-SF = cães com doença renal crônica no estágio 3 que receberam solução fisiológica; BCTM: cães com doença renal crônica no estágio 3 que receberam célula tronco mesenquimal

Tabela 42 - Cálculo da área sob a curva (AREA) da concentração sérica de ureia dos cães dos Grupos A e B, subgrupos A-SF, A-CTM, B-SF e B-CTM, na avaliação sequencial durante a evolução da doença renal crônica. São Paulo, 2017.

\begin{tabular}{cccccc}
\hline AREA & A-SF & A-CTM & B-SF & B-CTM & Controle \\
\hline Área & 832,6 & 1202,0 & 1770,0 & 3202,0 & 539,2 \\
Erro & 66,72 & 67,06 & 188,3 & 132,7 & 0 \\
\hline
\end{tabular}

IC 95\% $\quad 7018-963,3 \quad 1071-1334 \quad 1401-2139 \quad 2942-3462$

A-SF = cães com doença renal crônica no estágio 2 que receberam solução fisiológica; A-CTM: cães com doença renal crônica no estágio 2 que receberam célula tronco mesenquimal; B-SF = cães com doença renal crônica no estágio 3 que receberam solução fisiológica; $\mathbf{B}-$ CTM: cães com doença renal crônica no estágio 3 que receberam célula tronco mesenquimal; Controle = cães clinicamente normais; IC = intervalo de confiança. 
5.8 Imunodetecção da Albumina por western blot

No subgrupo A-SF, o cão A1 apresentou diminuição da albumina na urina que correspondeu aproximadamente $30 \%$ ao final do período de acompanhamento, e os cães A3 e A6 houve diminuição de 11,4 e 16,5\%, respectivamente. No subgrupo A-CTM, diminuição de $43 \%$ da albuminúria foi detectada em T12 no cão A7, e uma perda intensa de albumina no cão A8 entre T0 e T6 (aumento de 275\%), com retorno ao patamar próximo ao inicial em T12 (Tabela 43).

Tabela 43 - Valores individuais da densitometria (\%) obtidos pelo western blot para detecção de albumina na urina em relação ao controle (densitometria obtida cães clinicamente normais) nas avaliações sequenciais durante a evolução da doença renal crônica em cães do Grupo A, subgrupos A-SF (A1 a A6) e A-CTM (A7 a A9). São Paulo, 2017

\begin{tabular}{cccccccccc}
\hline Grupo A & A1 & A2 & A3 & A4 & A5 & A6 & A7 & A8 & A9 \\
\hline T0 & $\mathbf{1 2 8 , 6 4}$ & 91,31 & $\mathbf{1 3 1 , 2 1}$ & 71,94 & $\mathbf{1 1 8 , 6 4}$ & $\mathbf{1 2 0 , 4 4}$ & $\mathbf{2 1 4 , 5 7}$ & 80,33 & 91,90 \\
T6 & 83,87 & 69,05 & & 47,23 & & $\mathbf{1 2 5 , 3 7}$ & $\mathbf{2 2 1 , 4 7}$ & 75,45 \\
T12 & 77,72 & 63,16 & 116,24 & 99,37 & $\mathbf{1 2 2 , 5 4}$ & 100,56 & $\mathbf{1 2 1 , 9 3}$ & $\mathbf{1 1 1 , 6 4}$ & 85,92 \\
\hline
\end{tabular}

Os cães do Grupo B apresentaram porcentagens da densitometria para albumina maiores quando comparadas com os cães do Grupo A. No subgrupo B-SF não foram observados aumentos da intensidade de albuminúria ao longo dos tempos de acompanhamento, entretanto o cão B3 já iniciou o período de acompanhamento com albuminúria mais intensa quando comparada aos demais cães do grupo, e que perdurou até T3, seguido de óbito. Em relação ao subgrupo B-CTM, também não foram observadas variações marcantes ao longo dos 
tempos de acompanhamento, e somente os cães B12 e B13 já iniciaram com albuminúria mais intensa, de 468,97 e 330,03\%, respectivamente (Tabela 44).

Tabela 44 - Valores individuais da densitometria (\%) obtidos pelo western blot para detecção de albumina na urina em relação ao controle (densitometria obtida cães clinicamente normais) nas avaliações sequenciais durante a evolução da doença renal crônica em cães do Grupo B, subgrupos B-SF (B1 a B6) e B-CTM (B7 a B13). São Paulo, 2017

\begin{tabular}{|c|c|c|c|c|c|c|c|c|c|c|c|c|c|}
\hline Grupo B & B1 & B2 & B3 & B4 & B5 & B6 & B7 & B8 & B9 & $\mathrm{B} 10$ & B11 & B12 & B13 \\
\hline $\begin{array}{l}\text { T0 } \\
\text { T1 }\end{array}$ & 132,29 & 74,75 & 321,30 & 126,74 & 111,91 & 124,00 & 153,90 & 151,05 & 85,08 & 132,65 & 37,83 & $\begin{array}{l}468,97 \\
469,00\end{array}$ & 330,03 \\
\hline T2 & & & & & & & & & & 132,63 & & $t$ & \\
\hline T3 & & & 320,07 & & & & & & & $t$ & & & \\
\hline T4 & & 78,54 & $\dagger$ & & 129,94 & 94,50 & & & & & 85,52 & & \\
\hline T5 & & $\dagger$ & & & & $\dagger$ & & & & & $\dagger$ & & \\
\hline $\begin{array}{l}\text { T6 } \\
\text { T7 }\end{array}$ & 144,87 & & & 131,72 & & & $\begin{array}{c}166,70 \\
+\end{array}$ & 141,07 & 50,40 & & & & $\begin{array}{c}368,44 \\
+\end{array}$ \\
\hline T12 & 142,87 & & & 127,88 & & & & 147,72 & 92,96 & & & & \\
\hline
\end{tabular}

Não foram verificadas alterações significantes da intensidade da albuminúria entre os cães dos subgrupos A-SF versus A-CTM e B-SF versus BCTM (Tabelas 45 e 46).

Tabela 45 - Estatística descritiva dos valores da densitometria (\%) referente a imunodetecção da albumina urinária por western blot dos cães com doença renal crônica no estágio 2 (GRUPO A), referentes aos subgrupos A-SF e A-CTM, ao longo dos tempos de acompanhamento. São Paulo, 2017.

\begin{tabular}{|c|c|c|c|}
\hline Estagio 2 & A-SF $( \pm \mathrm{DP})$ & A-CTM ( \pm DP $)$ & \\
\hline T0 & $110,36( \pm 23,57) ; n=6$ & $128,93( \pm 74,38) ; n=3$ & \\
\hline T6 & $81,38( \pm 32,96) ; n=6$ & $148,36( \pm 103,25) ; n=3$ & \\
\hline T12 & $96,59( \pm 22,61) ; n=6$ & $106,49( \pm 18,54) ; n=3$ & \\
\hline Média & $96,11( \pm 14,96)$ & $127,92( \pm 20,95)$ & $P=0,096$ \\
\hline
\end{tabular}


Tabela 46 - Estatística descritiva dos valores da densitometria (\%) referente a imunodetecção da albumina urinária por western blot dos cães com doença renal crônica no estágio 3 (GRUPO B), referentes aos subgrupos B-SF e B-CTM, ao longo dos tempos de acompanhamento. São Paulo, 2017.

\begin{tabular}{ccc}
\hline Estagio 3 & B-SF $( \pm \mathrm{DP})$ & $\mathrm{B}-\mathrm{CTM}( \pm \mathrm{DP})$ \\
\hline T0 & $148,49( \pm 87,14) ; \mathrm{n}=6$ & $194,21( \pm 151,43) ; \mathrm{n}=7$ \\
T6 & $138,29( \pm 9,29) ; \mathrm{n}=2$ & $181,65( \pm 134,15) ; \mathrm{n}=4$ \\
T12 & $135,37( \pm 10,60) ; \mathrm{n}=2$ & $120,34( \pm 38,72) ; \mathrm{n}=2$ \\
\hline Média & $140,71( \pm 6,88)$ & $165,40( \pm 39,52)$ \\
\hline DP = desvio padrão da média; B-SF = cães com doença renal crônica no estágio 3 que receberam solução fisiológica; B-CTM: cães com doença renal crônica \\
no estágio 3 que receberam célula tronco mesenquimal
\end{tabular}

Na Figura 17 estão representados os valores das médias da densitometria (\%) referente a albumina urinária dos cães dos Grupos A e B, e respectivos subgrupos, e o cálculo das áreas sob as curvas indicou que os cães dos subgrupos B-SF e B-CTM apresentaram a maior área e que, portanto, corresponderia a presença de quantidade maior de albumina (Tabela 47).

Figura 17 - Valores médios da porcentagem da densitometria na imunodetecção da Albumina (WBALB) por western blot dos cães dos Grupos A e B, e respectivos subgrupos A-SF, A-CTM, B-SF e B-CTM, na avaliação sequencial durante a evolução da doença renal crônica. São Paulo, 2017.

\section{W B A L B}

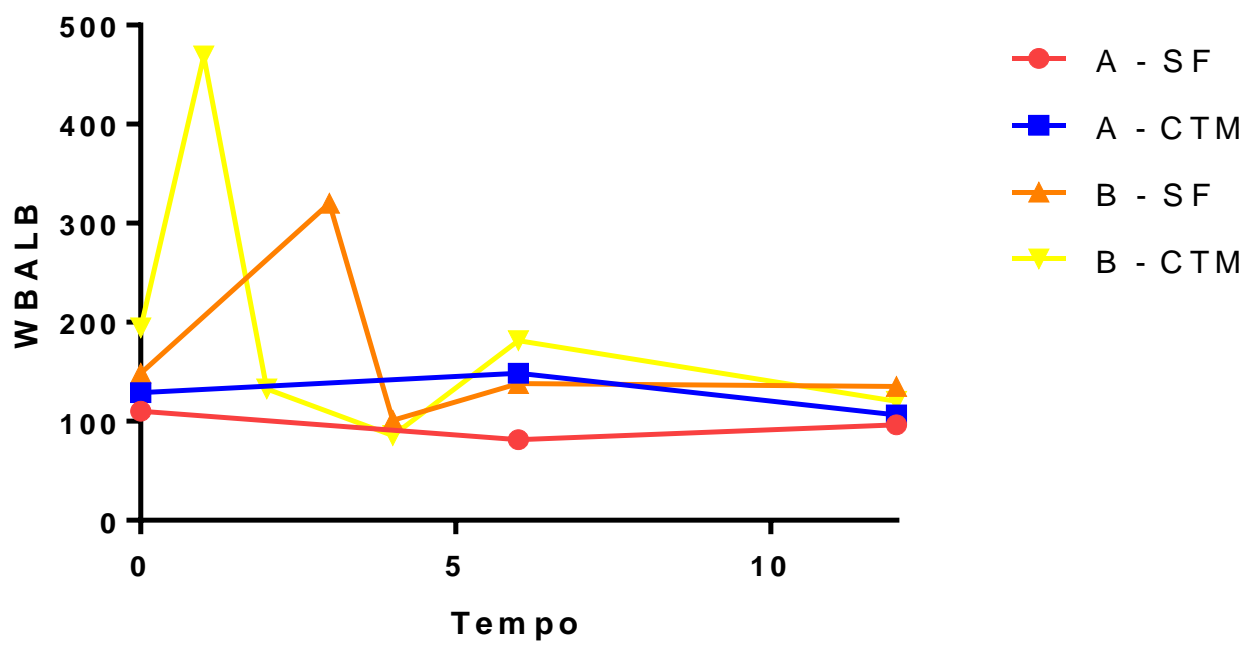

A-SF = cães com doença renal crônica no estágio 2 que receberam solução fisiológica; A-CTM: cães com doença renal crônica no estágio 2 que receberam célula tronco mesenquimal; B-SF = cães com doença renal crônica no estágio 3 que receberam solução fisiológica; BCTM: cães com doença renal crônica no estágio 3 que receberam célula tronco mesenquimal 
Tabela 47 - Cálculo da área sob a curva (AREA) pela densitometria referente a imunodetecção da albumina na urina por western blot dos cães dos Grupos A e B, subgrupos A-SF, A-CTM, B-SF e B-CTM, na avaliação sequencial durante a evolução da doença renal crônica. São Paulo, 2017.

\begin{tabular}{cccccc}
\hline & A-SF & A-CTM & B-SF & B-CTM & Controle \\
\hline AREA & 1109 & 1597 & 1974 & 2024 & 799,5 \\
Erro & 170,8 & 494,8 & 140,8 & 446,3 & 0 \\
IC 95\% & $774,5-1444$ & $637,3-2567$ & $1698-2250$ & $1149-2898$
\end{tabular}

A-SF = cães com doença renal crônica no estágio 2 que receberam solução fisiológica; A-CTM: cães com doença renal crônica no estágio 2 que receberam célula tronco mesenquimal; B-SF = cães com doença renal crônica no estágio 3 que receberam solução fisiológica; BCTM: cães com doença renal crônica no estágio 3 que receberam célula tronco mesenquimal

Na figura 18 apresenta-se a imagem da imunodetecção da albumina urinária por western blot, exemplificando a maior densitometria do paciente B12 468,97\% (T0) e 469\% (T1), quando comparado ao controle 83,91\% (C1), 95,56\% (C2) e 120,52\% (C3) e ao paciente A8 80,33\% (T0), 221,47\% (T6) e 111,64 (T12).

Figura 18 - Imunodetecção de albumina urinária por western blot, demonstrando perda maior de albumina do paciente 12 do Grupo $B$, quando comparado ao grupo controle e ao paciente 8 do Grupo A. São Paulo, 2017.

Controle

C1 C2 C3
Grupo A Grupo B

Animal 8 Animal 12

$\begin{array}{lllll}\text { T0 } & \text { T6 } & \text { T12 } & \text { T0 } & \text { T1 }\end{array}$ 


\subsection{Imunodetecção da proteína ligada à vitamina $\mathbf{D}$ por western blot}

No subgrupo A-SF e A-CTM, a intensidade da densitometria para a detecção de VDBP de todos os cães ao longo do período de observação permaneceram nos mesmos patamares (Tabela 48), assim como para os subgrupos B-SF e B-CTM (Tabela 51). No subgrupo A-SF, discreto aumento da VDBP foi observado no cão A1 (variação de 161,38 a $151,81 \%$ ) e no cão A5 (112,24 e 120,45\%) e no subgrupo A-CTM, no cão A7 (133,57 e 136,13\%). No atinente ao subgrupo B-SF, discreto aumento da densidade da VDBP foi constatado nos cães B1 (variação de 129,53 a 136,56\%), B4 (113,0 a 125,01\%) e B6 $(111,45$ e 112,13) e no subgrupo B-CTM, somente o cão A7 apresentou perda urinária de VDBP na magnitude de 133,57 a 136,13\% (Tabela 49).

Tabela 48 - Valores individuais da densitometria (\%) obtidos pelo western blot para detecção da proteína ligada à vitamina $D$ (VDBP), na avaliação sequencial durante a evolução da doença renal crônica em cães do Grupo A, subgrupos A-SF (A1 a A6) e ACTM (A7 a A9). São Paulo, 2017

\begin{tabular}{cccccccccc}
\hline Grupo A & A1 & A2 & A3 & A4 & A5 & A6 & A7 & A8 & A9 \\
\hline T0 & $\mathbf{1 6 1 , 3 8}$ & 105,39 & 126,27 & 98,56 & $\mathbf{1 1 2 , 2 4}$ & $\mathbf{1 0 5 , 5 6}$ & $\mathbf{1 3 3 , 5 7}$ & 97,04 & 100,35 \\
T6 & $\mathbf{1 5 2 , 1 4}$ & 103,99 & 96,41 & 99,14 & $\star \star$ & $\mathbf{1 0 6 , 3 3}$ & $\star \star$ & 95,60 & 105,34 \\
T12 & $\mathbf{1 5 1 , 8 1}$ & 104,93 & 95,67 & 104,35 & $\mathbf{1 2 0 , 4 5}$ & $\mathbf{1 0 8 , 1 3}$ & $\mathbf{1 3 6 , 1 3}$ & 92,23 & 106,11 \\
\hline
\end{tabular}

Tabela 49 - Valores individuais da densitometria (\%) obtidos pelo western blot para detecção de proteína ligada à vitamina $D$ (VDBP), na avaliação sequencial durante a evolução da doença renal crônica em cães do Grupo B, subgrupos B-SF e B-CTM. São

\begin{tabular}{|c|c|c|c|c|c|c|c|c|c|c|c|c|c|}
\hline Grupo B & B1 & B2 & B3 & B4 & B5 & B6 & B7 & B8 & B9 & B10 & B11 & B12 & B13 \\
\hline $\begin{array}{l}\text { T0 } \\
\text { T1 }\end{array}$ & 129,53 & 69,22 & 96,42 & 113,00 & 98,76 & 111,45 & 94,90 & 137,24 & 128,06 & 186,42 & 102,87 & $\begin{array}{c}93,12 \\
101,25\end{array}$ & 93,87 \\
\hline T2 & & & & & & & & & & 146,74 & & $t$ & \\
\hline T3 & & & 86,66 & & & & & & & $t$ & & & \\
\hline T4 & & 74,34 & $\dagger$ & & 99,55 & 112,13 & & & & & 100,97 & & \\
\hline T5 & & $\dagger$ & & & & $\dagger$ & & & & & $t$ & & \\
\hline T6 & 131,43 & & & 106,36 & & & 99,86 & 157,55 & 142,98 & & & & 96,03 \\
\hline T7 & & & & & & & $t$ & & & & & & $t$ \\
\hline T12 & 136,56 & & & 125,01 & & & & 157,31 & 131,22 & & & & \\
\hline
\end{tabular}


Ao comparar as médias das porcentagens da densidade da VDBP na urina dos cães do subgrupo A-SF e A-CTM, nota-se que são semelhantes (Tabela 50), e o subgrupo B-CTM apresentou perda de VDBP urinária um pouco maior que os demais subgrupos (Tabela 51).

Tabela 50 - Estatística descritiva da densitometria (\%) na imunodetecção da proteína ligada a vitamina D (VDBP) por western blot dos cães com doença renal crônica no estágio 2 (GRUPO A) referentes aos subgrupos A-SF e A-CTM. São Paulo, 2017.

\begin{tabular}{|c|c|c|c|}
\hline Estagio 2 & $\mathrm{~A}-\mathrm{SF}( \pm \mathrm{DP})$ & $\mathrm{A}-\mathrm{CTM}( \pm \mathrm{DP})$ & \\
\hline T0 & $101,60( \pm 35,56) ; n=6$ & $110,32( \pm 20,20) ; n=3$ & \\
\hline T6 & $94,34( \pm 39,67) ; n=6$ & $100,47( \pm 6,88) ; n=3$ & \\
\hline $\mathrm{T} 12$ & $99,82( \pm 37,09) ; n=6$ & $111,49( \pm 22,43) ; n=3$ & \\
\hline Média & $98,58( \pm 3,78)$ & $107,42( \pm 6,05)$ & $P=0,098$ \\
\hline
\end{tabular}

no estágio 2 que receberam célula tronco mesenquimal

Tabela 51 - Estatística descritiva da densitometria (\%) na imunodetecção da proteína ligada a vitamina $D$ (VDBP) por western blot dos cães com doença renal crônica no estágio 3 (GRUPO B) referentes aos subgrupos B-SF e B-CTM. São Paulo, 2017.

\begin{tabular}{ccc}
\hline Estagio 3 & $\mathrm{B}-\mathrm{SF}( \pm \mathrm{DP})$ & $\mathrm{B}-\mathrm{CTM}( \pm \mathrm{DP})$ \\
\hline T0 & $103,06( \pm 20,38) ; \mathrm{n}=6$ & $118,25( \pm 35,61) ; \mathrm{n}=7$ \\
T6 & $118,89( \pm 17,72) ; \mathrm{n}=2$ & $121,88( \pm 33,70) ; \mathrm{n}=4$ \\
T12 & $130,78( \pm 8,16) ; \mathrm{n}=2$ & $144,26( \pm 18,44) ; \mathrm{n}=2$ \\
\hline Média & $117,57( \pm 13,90)$ & $128,13( \pm 14,08)$ \\
\hline DP = desvio padrão da média; B-SF $=$ cães com doença renal crônica no estágio 3 que receberam solução fisiológica; B-CTM: cães com doença renal crônica
\end{tabular}
no estágio 3 que receberam célula tronco mesenquimal

Na Figura 19 está configurada os valores médios da densitometria da VDBP dos cães dos Grupos A e B, e respectivos subgrupos, e na Tabela 52 está apresentado o cálculo dos valores das áreas sob a curva, observando-se que nos cães dos subgrupos B-SF e B-CTM há uma tendência maior a perda de VDBP urinária quando comparada aos cães do Grupo A. 
Figura 19 - Valores médios da porcentagem da densitometria avaliada pela imunodetecção da proteína ligada a vitamina D (WBVDBP) por western blot dos cães dos Grupos A e B, e respectivos subgrupos A-SF, A-CTM, B-SF e B-CTM, na avaliação sequencial durante a evolução da doença renal crônica. São Paulo, 2017.

\section{W B V D B P}

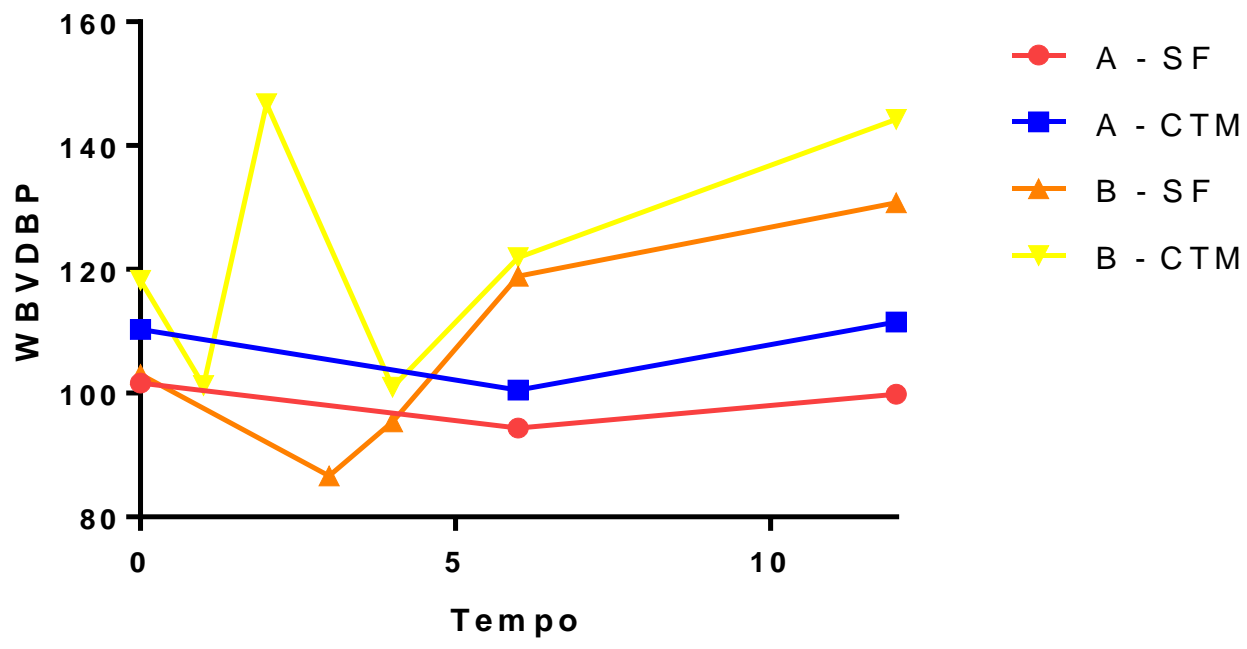

A-SF = cães com doença renal crônica no estágio 2 que receberam solução fisiológica; A-CTM: cães com doença renal crônica no estágio 2 que receberam célula tronco mesenquimal; B-SF = cães com doença renal crônica no estágio 3 que receberam solução fisiológica; BCTM: cães com doença renal crônica no estágio 3 que receberam célula tronco mesenquimal

Tabela 52 - Cálculo da área sob a curva (AREA) da imunodetecção da proteína ligada a vitamina D (VDBP) por western blot dos cães dos grupos $A$ e $B$, subgrupos A-SF, ACTM, B-SF e B-CTM, na avaliação sequencial durante a evolução da doença renal crônica. São Paulo, 2017.

\begin{tabular}{llllll}
\hline & \multicolumn{1}{c}{ A-SF } & \multicolumn{1}{c}{ A-CTM } & \multicolumn{1}{c}{ B-SF } & \multicolumn{1}{c}{ B-CTM } & \multicolumn{1}{c}{ Controle } \\
\hline AREA & 1170 & 1268 & 1339 & 1503 & 799,5 \\
Erro & 22830 & 95,18 & 71,70 & 121,40 & 0 \\
IC 95\% & $723-1618$ & $1082-1455$ & $1198-1479$ & $1265-1741$ & \\
\hline A-SF
\end{tabular}

A-SF = cães com doença renal crônica no estágio 2 que receberam solução fisiológica; A-CTM: cães com doença renal crônica no estágio 2 que receberam célula tronco mesenquimal; B-SF = cães com doença renal crônica no estágio 3 que receberam solução fisiológica; BCTM: cães com doença renal crônica no estágio 3 que receberam célula tronco mesenquimal; Controle = cães clinicamente normais; IC = intervalo de confiança. 


\subsection{Imunodetecção da proteína ligada ao retinol por western blot}

Os valores das porcentagens da densitometria obtidos nos cães do Grupo A, subgrupos A-SF e A-CTM, estão apresentadas na Tabela 64, e nota-se que no subgrupo A-SF, no cão A2 em T6, houve a diminuição de 29\% da RBP em relação a T0, e o cão A5 deste mesmo subgrupo teve discreto aumento e permaneceu nos mesmos patamares em T0 e T12. No subgrupo A-CTM, no cão A8 ocorreu o aumento de 74\% em T6 e a diminuição em T12, mas não retornou ao patamar inicial (T0) (Tabela 53).

Tabela 53 - Valores individuais das porcentagens da densitometria obtidas no western blot para detecção da proteína ligada ao Retinol (RBP), na avaliação sequencial durante a evolução da doença renal crônica em cães do Grupo A, subgrupos A-SF (A1 a A6) e A-CTM (A7 a A9). São Paulo, 2017

\begin{tabular}{cccccccccc}
\hline Grupo A & A1 & A2 & A3 & A4 & A5 & A6 & A7 & A8 & A9 \\
\hline T0 & 76,73 & $\mathbf{1 7 7 , 3 2}$ & 80,03 & 90,24 & 120,33 & 99,43 & 110,38 & 92,20 & 112,34 \\
T6 & 93,65 & $\mathbf{1 2 5 , 8 9}$ & $* *$ & 89,78 & $* *$ & 98,65 & $* *$ & $\mathbf{1 6 0 , 5 5}$ & 111,55 \\
T12 & 88,39 & $\mathbf{1 2 8 , 1 1}$ & 74,25 & 93,44 & 117,56 & 101,34 & 103,23 & $\mathbf{1 2 3 , 2 0}$ & 110,45 \\
\hline
\end{tabular}

Nos cães do subgrupo B-SF, no geral, as porcentagens da densitometria da proteína ligada ao Retinol (RBP) mantiveram-se em níveis semelhantes ao valor de T0 ao longo do período de observação ou até o óbito e somente os cães B1, B2 e B3 apresentaram perda de RBP na urina. O subgrupo B-CTM já em T0 apresentava densidade maior de RBP em comparação ao subgrupo B-SF nesse mesmo momento, e a proteína ligada ao Retinol foi detectada em dois cães, no animal B8 observou-se a diminuição da densidade em T12 de 23,7\% em relação ao valor da basal e no cão B10, a diminuição foi de 44,6\% em T3 (óbito de B10 
antes de T4); os demais cães do subgrupo B-CTM, B7, BB12 e B13, mantiveram porcentagens altas da densitometria da RBP ao longo período de acompanhamento (Tabela 54).

Tabela 54 - Valores individuais das porcentagens da densitometria obtidas no western blot para detecção da proteína ligada ao Retinol(RBP), na avaliação sequencial durante a evolução da doença renal crônica em cães do Grupo B, subgrupos B-SF (B1 a B6) e B-CTM (B7 a B13). São Paulo, 2017

\begin{tabular}{|c|c|c|c|c|c|c|c|c|c|c|c|c|c|}
\hline & B1 & B2 & B3 & B4 & B5 & $\mathrm{B} 6$ & B7 & B8 & B9 & $\mathrm{B} 10$ & B11 & $\mathrm{B} 12$ & $\mathrm{~B} 13$ \\
\hline T0 & 116,83 & 193,96 & 311,62 & 66,30 & 99,34 & 103,54 & 367,79 & 234,63 & 95,00 & 345,83 & 95,29 & 270,24 & 273,24 \\
\hline T1 & & & & & & & & & & & & 250,03 & \\
\hline $\mathrm{T} 2$ & & & & & & & & & & & & & \\
\hline T3 & & & 307,29 & & & & & & & 190,28 & & & \\
\hline T4 & & 146,49 & $\dagger$ & & 98,44 & 105,12 & & & & $\dagger$ & 98,53 & & \\
\hline T5 & & $\dagger$ & & & & $\dagger$ & & & & & $\dagger$ & & \\
\hline T6 & 121,68 & & & 69,96 & & & 359,18 & 202,13 & 98,33 & & & & 264,45 \\
\hline $\mathrm{T7}$ & & & & & & & $\dagger$ & & & & & &  \\
\hline T12 & 131,15 & & & 65,58 & & & & 185,86 & 101,66 & & & & \\
\hline
\end{tabular}

O Grupo B, subgrupos B-SF e B-CTM, apresentaram médias de RBP maiores quando comparadas ao Grupo A (Tabelas 55 e 56).

Tabela 55 - Estatística descritiva da porcentagem da densitometria pela imunodetecção da proteína ligada ao Retinol (RBP) por western blot dos cães com doença renal crônica no estágio 2 (GRUPO A) referentes aos subgrupos A-SF e A-CTM. São Paulo, 2017.

\begin{tabular}{|c|c|c|c|}
\hline Estagio 2 & A-SF $( \pm D P)$ & A-CTM ( \pm DP $)$ & \\
\hline T0 & $107,34( \pm 37,69) ; n=6$ & $104,97( \pm 11,10) ; n=3$ & \\
\hline T6 & $101,99( \pm 16,34) ; n=6$ & $136,05( \pm 34,64) ; n=3$ & \\
\hline T12 & $100,51( \pm 19,69) ; n=6$ & $107,34( \pm 17,61) ; n=3$ & \\
\hline Média & $103,28( \pm 3,59)$ & $116,12( \pm 17,30)$ & $P=0,276$ \\
\hline
\end{tabular}
no estágio 2 que receberam célula tronco mesenquimal

Tabela 56 - Estatística descritiva da porcentagem da densitometria pela imunodetecção da proteína ligada ao Retinol (RBP) por western blot dos cães com doença renal crônica no estágio 3 (GRUPO B) referentes aos subgrupos B-SF e B-CTM. São Paulo, 2017.

\begin{tabular}{cccc}
\hline Estagio 3 & $\mathrm{B}-\mathrm{SF}( \pm \mathrm{DP})$ & $\mathrm{B}-\mathrm{CTM}( \pm \mathrm{DP})$ & \\
\hline T0 & $179,91( \pm 116,94) ; \mathrm{n}=6$ & $219,03( \pm 102,55) ; \mathrm{n}=7$ & \\
T6 & $183,60( \pm 154,23) ; \mathrm{n}=2$ & $188,30( \pm 83,91) ; \mathrm{n}=4$ & \\
T12 & $98,36( \pm 46,36) ; \mathrm{n}=2$ & $143,76( \pm 59,53) ; \mathrm{n}=2$ & \\
\hline Média & $153,95( \pm 48,18)$ & $183,69( \pm 37,84)$ & $\mathrm{P}=0,447$ \\
\hline
\end{tabular}

DP = desvio padrão da média; B-SF = cães com doença renal crônica no estágio 3 que receberam solução fisiológica; $\mathbf{B}-\mathbf{C T M}$ : cães com doença renal crônica no estágio 3 que receberam célula tronco mesenquimal 
Na Figura 20 está configurada os valores médios da porcentagem da densidade da proteína ligada ao Retinol dos subgrupos dos Grupos A e B, e a área calculada sob a curva (Tabela 57) indica que os maiores valores foram para o Grupo B, sendo que no subgrupo B-CTM foi mais evidente.

Figura 20 - Valores médios da porcentagem da densitometria avaliada pela imunodetecção da proteína ligada ao Retinol por western blot (WBRET) dos cães dos Grupos A e B, subgrupos A-SF, A-CTM, B-SF e B-CTM, na avaliação sequencial durante a evolução da doença renal crônica. São Paulo, 2017.

\section{W B R E T}

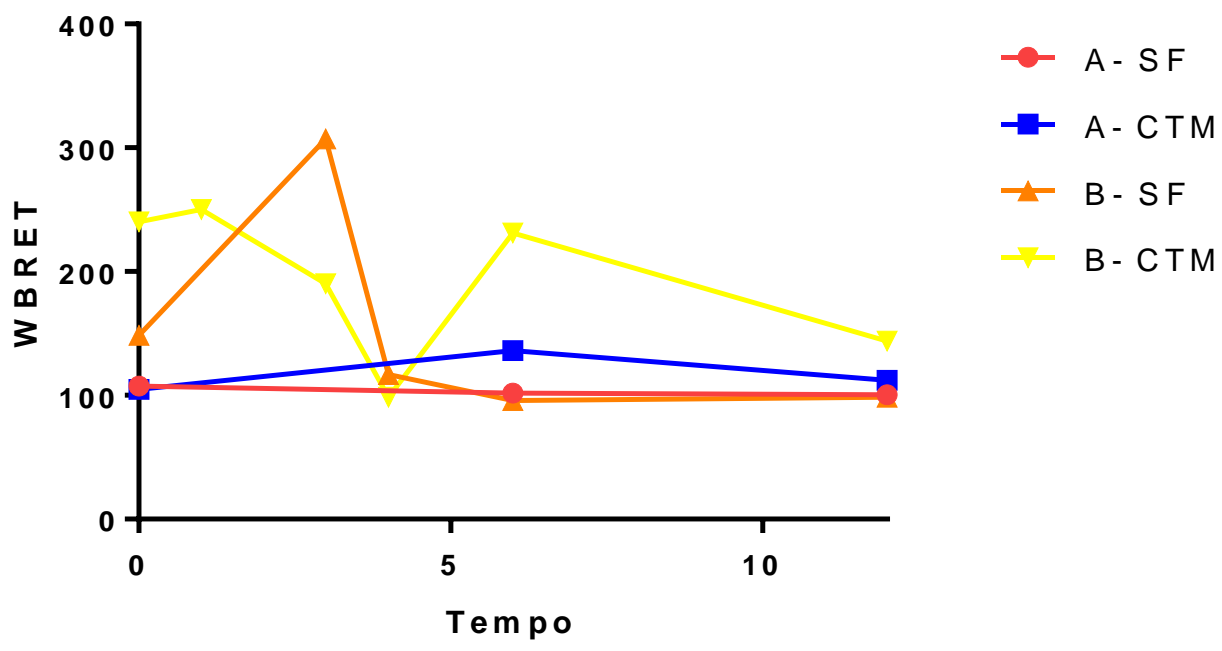

A-SF = cães com doença renal crônica no estágio 2 que receberam solução fisiológica; A-CTM: cães com doença renal crônica no estágio 2 que receberam célula tronco mesenquimal; B-SF = cães com doença renal crônica no estágio 3 que receberam solução fisiológica; BCTM: cães com doença renal crônica no estágio 3 que receberam célula tronco mesenquimal

Tabela 57 - Cálculo da área sob a curva (AREA) da porcentagem da densitometria na imunodetecção da proteína ligada ao Retinol (RBP) por western blot dos cães dos Grupos A e B e respectivos subgrupos A-SF, A-CTM, B-SF e B-CTM, na avaliação sequencial durante a evolução da doença renal crônica. São Paulo, 2017.

\begin{tabular}{cccccc}
\hline & A-SF & A-CTM & B-SF & B-CTM & Controle \\
\hline AREA & 1236 & 146 & 1691,00 & $\mathbf{2 2 8 4}$ & 799,5 \\
Erro & 145,2 & 153,8 & 228,00 & 393,5 & 0 \\
IC 95\% & $950,9-1520$ & $1167-1769$ & $1244-2138$ & $1513-3055$ & \\
\hline
\end{tabular}

A-SF = cães com doença renal crônica no estágio 2 que receberam solução fisiológica; A-CTM: cães com doença renal crônica no estágio 2 que receberam célula tronco mesenquimal; B-SF = cães com doença renal crônica no estágio 3 que receberam solução fisiológica; $\mathbf{B}-$ CTM: cães com doença renal crônica no estágio 3 que receberam célula tronco mesenquimal; Controle = cães clinicamente normais; IC = intervalo de confiança 
5.11 Imunodetecção da proteína de Tamm-Horsfall por western blot

As porcentagens da densitometria para a proteína de Tamm-Horsfall nos cães do Grupo A mantiveram-se semelhantes desde T0 a T12, e somente no cão A1, do subgrupo A-SF, detectou-se diminuição de 51,1 e 46,7\% nos momentos T6 e T12, respectivamente, como descrito na Tabela 58. Ainda nesta referida tabela observa-se que o cão A8 do subgrupo A-CTM apresentou, desde o início do período de observação, porcentagem menor que 59\% de proteínas de Tamm-Horsfall em relação ao controle.

Tabela 58 - Valores individuais da porcentagem da densitometria obtidas pelo western blot para detecção da proteína de Tamm-Horsfall, na avaliação sequencial durante a evolução da doença renal crônica em cães do Grupo A, subgrupos A-SF (A1 a A6) e ACTM (A7 a A9). São Paulo, 2017

\begin{tabular}{cccccccccc}
\hline Grupo A & A1 & A2 & A3 & A4 & A5 & A6 & A7 & A8 & A9 \\
\hline T0 & 87,35 & 92,74 & 79,27 & 82,47 & 113,33 & 91,93 & 94,59 & $\mathbf{5 8 , 4 7}$ & 103,86 \\
T6 & $\mathbf{4 4 , 5 9}$ & 90,34 & 73,27 & 87,16 & $* *$ & 127,27 & $* *$ & $\mathbf{4 5 , 4 5}$ & 118,13 \\
T12 & $\mathbf{4 0 , 7 9}$ & 88,53 & 90,80 & 82,36 & 144,19 & 122,92 & 94,67 & $\mathbf{4 5 , 3 6}$ & 159,63 \\
\hline
\end{tabular}

No atinente ao acompanhamento longitudinal do Grupo B, a diminuição da densidade da proteína de Tamm-Horsfall ocorreu em três cães, sendo apenas um (B4) do subgrupo B-SF que foi de $44,2 \%$ em T12 em relação a T0, e cinco dos seis cães desse subgrupo apresentavam, desde o início, diminuição da quantidade de proteína de Tamm-Horsfall, ou seja, menor que $69 \%$ em relação ao controle. No subgrupo B-CTM, os cães B7 e B10 apresentaram diminuição de 25 e 33,7\%, respectivamente, nos tempos T6 e T3 em relação a T0, e o óbito ocorreu após os referidos tempos. Nos demais cães do Grupo B, as oscilações das porcentagens das densidades foram inferiores a 25\% (Tabela 59). 
Tabela 59 - Valores individuais da porcentagem da densitometria obtidas pelo western blot para detecção da proteína de Tamm-Horsfall, na avaliação sequencial durante a evolução da doença renal crônica em cães do Grupo B, subgrupos B-SF (B1 a B6) e BCTM (B7 a B13). São Paulo, 2017

\begin{tabular}{|c|c|c|c|c|c|c|c|c|c|c|c|c|c|}
\hline Grupo B & B1 & B2 & B3 & B4 & B5 & B6 & B7 & B8 & B9 & B10 & B11 & B12 & B13 \\
\hline $\begin{array}{l}\text { T0 } \\
\text { T1 }\end{array}$ & 61,57 & 75,10 & 58,06 & 55,95 & 134,01 & 85,70 & 60,17 & 58,70 & 61,35 & 59,32 & 46,82 & $\begin{array}{l}29,35 \\
30,75\end{array}$ & 68,86 \\
\hline T2 & & & & & & & & & & 33,38 & & $t$ & \\
\hline T3 & & & 63,08 & & & & & & & $\dagger$ & & & \\
\hline T4 & & 73,67 & $t$ & & 116,98 & 75,57 & & & & & 57,18 & & \\
\hline T5 & & $\dagger$ & & & & $\dagger$ & & & & & $\dagger$ & & \\
\hline $\begin{array}{l}\text { T6 } \\
\text { T7 }\end{array}$ & 53,12 & & & 61,14 & & & $\begin{array}{c}45,22 \\
t\end{array}$ & 48,57 & 64,07 & & & & $\begin{array}{c}54,10 \\
\mathbf{t}\end{array}$ \\
\hline T12 & 63,83 & & & 31,24 & & & & 57,17 & 44,67 & & & & \\
\hline
\end{tabular}

Ao analisar as médias dos Grupos A e B e respectivos subgrupos, observa-se que os cães dos subgrupos B-SF e B-CTM apresentam quantidade menor da proteína de Tamm-Horsfall em relação ao Grupo A (Tabelas 60 e 61).

Tabela 60 - Estatística descritiva dos valores da imunodetecção da proteína de TammHorsfall por western blot dos cães com doença renal crônica no estágio 2 (GRUPO A) referentes aos subgrupos A-SF e A-CTM. São Paulo, 2017.

\begin{tabular}{|c|c|c|c|}
\hline Estagio 2 & A-SF $( \pm \mathrm{DP})$ & A-CTM ( \pm DP $)$ & \\
\hline T0 & $91,18( \pm 12,05) ; n=6$ & $85,64( \pm 23,98) ; n=3$ & \\
\hline T6 & $84,52( \pm 29,95) ; n=6$ & $81,79( \pm 51,39) ; n=3$ & \\
\hline $\mathrm{T} 12$ & $94,93( \pm 35,65) ; n=6$ & $99,88( \pm 57,31) ; n=3$ & \\
\hline Média & $90,21( \pm 5,27)$ & $89,10( \pm 9,52)$ & $P=0,868$ \\
\hline
\end{tabular}
no estágio 2 que receberam célula tronco mesenquimal

Tabela 61 - Estatística descritiva dos valores da imunodetecção da proteína de TammHorsfall por western blot dos cães com doença renal crônica no estágio 3 (GRUPO B) referentes aos subgrupos B-SF e B-CTM. São Paulo, 2017.

\begin{tabular}{cccc}
\hline Estagio 3 & $\mathrm{B}-\mathrm{SF}( \pm \mathrm{DP})$ & $\mathrm{B}-\mathrm{CTM}( \pm \mathrm{DP})$ & \\
\hline T0 & $78,39( \pm 29,52) ; \mathrm{n}=6$ & $54,93( \pm 13,01) ; \mathrm{n}=7$ & \\
T6 & $57,13( \pm 5,67) ; \mathrm{n}=2$ & $52,99( \pm 8,24) ; \mathrm{n}=4$ & \\
T12 & $47,53( \pm 23,04) ; \mathrm{n}=2$ & $50,92( \pm 8,83) ; \mathrm{n}=2$ & \\
\hline Média & $61,01( \pm 15,79)$ & $52,94( \pm 2,00)$ & $\mathrm{P}=0,429$ \\
\hline $\mathrm{DP}=$ desvio padrão da média; B-SF $=$ cães com doença renal crônica no estágio 3 que receberam solução fisiológica; B-CTM: cães com doença renal crônica
\end{tabular}

no estágio 3 que receberam célula tronco mesenquimal

Na Figura 21, como também na Tabela 64, observa-se os cães com DRC dos subgrupos B-SF e B-CTM apresentaram a menor concentração da proteína de Tamm-Horsfall ao longo dos tempos de observação, sendo que 
especificamente para o subgrupo B-CTM, a área foi inferior a 50\% em relação ao Grupo A (Tabela 62).

Figura 21 - Valores médios das porcentagens da densidade na imunodetecção da proteína de Tamm-Horsfall (WBTHP) por western blot dos cães dos Grupos A e B, subgrupos A-SF, A-CTM, B-SF e B-CTM, na avaliação sequencial durante a evolução da doença renal crônica. São Paulo, 2017.

\section{W B THP}

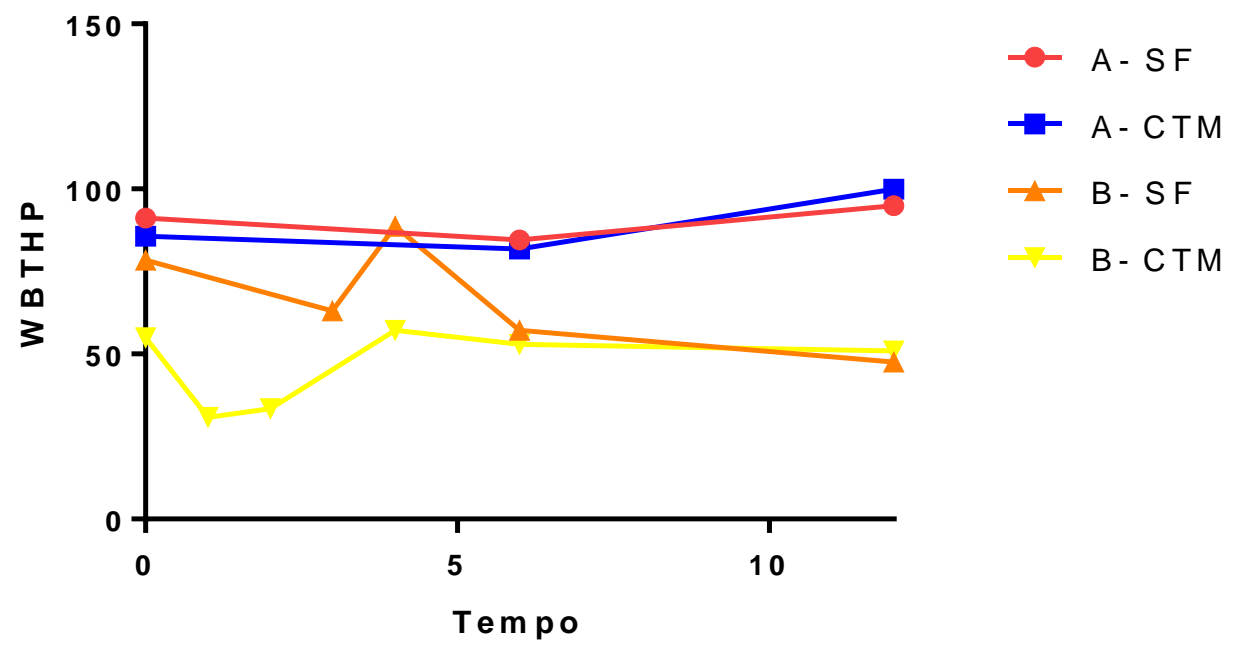

A-SF = cães com doença renal crônica no estágio 2 que receberam solução fisiológica; $\mathbf{A}$-CTM: cães com doença renal crônica no estágio 2 que receberam célula tronco mesenquimal; B-SF = cães com doença renal crônica no estágio 3 que receberam solução fisiológica; BCTM: cães com doença renal crônica no estágio 3 que receberam célula tronco mesenquimal

Tabela 62 - Cálculo da área sob a curva (AREA) das médias das porcentagens da densidade na imunodetecção da proteína de Tamm-Horsfall por western blot dos cães dos grupos A e B, subgrupos A-SF, A-CTM, B-SF e B-CTM, na avaliação sequencial durante a evolução da doença renal crônica. São Paulo, 2017.

\begin{tabular}{cccccc}
\hline AREA & A-SF & A-CTM & B-SF & B-CTM & Controle \\
\hline Área & 1065.00 & 1047.00 & 748.00 & 587.40 & 799,5 \\
Erro & 170.00 & & & & \\
IC 95\% & $732.30-1399$ & $485.10-1610$ & $574.8-921.2$ & $513.4-661.4$ & 0
\end{tabular}

A-SF = cães com doença renal crônica no estágio 2 que receberam solução fisiológica; A-CTM: cães com doença renal crônica no estágio 2 que receberam célula tronco mesenquimal; B-SF = cães com doença renal crônica no estágio 3 que receberam solução fisiológica; BCTM: cães com doença renal crônica no estágio 3 que receberam célula tronco mesenquimal; Controle = cães clinicamente normais; IC = intervalo de confiança

Na figura 22 apresenta-se a imagem da imunodetecção da proteína de Tamm-Horsfall por western blot, exemplificando a maior densitometria do grupo controle 103,60\%(C4), 105,31\%(C5) e 91,08\%(C6), quando comparado ao 
paciente 4 55,95\%(T0), 61,14\%(T6) e 31,24\%(T12), paciente 9 61,35\% (T0), $64,07 \%$ (T6) e $44,67 \%$ (T12) e paciente $1059,32 \%$ (T0) e 33,38\% (T1), todos pertencentes ao Grupo B.

Figura 22 - Imunodeteç̧ão da proteína de Tamm-Horsfall por western blot, demonstrando excreção menor dos paciente 4, 9 e 10 do Grupo B, quando comparado ao grupo controle. São Paulo, 2017.

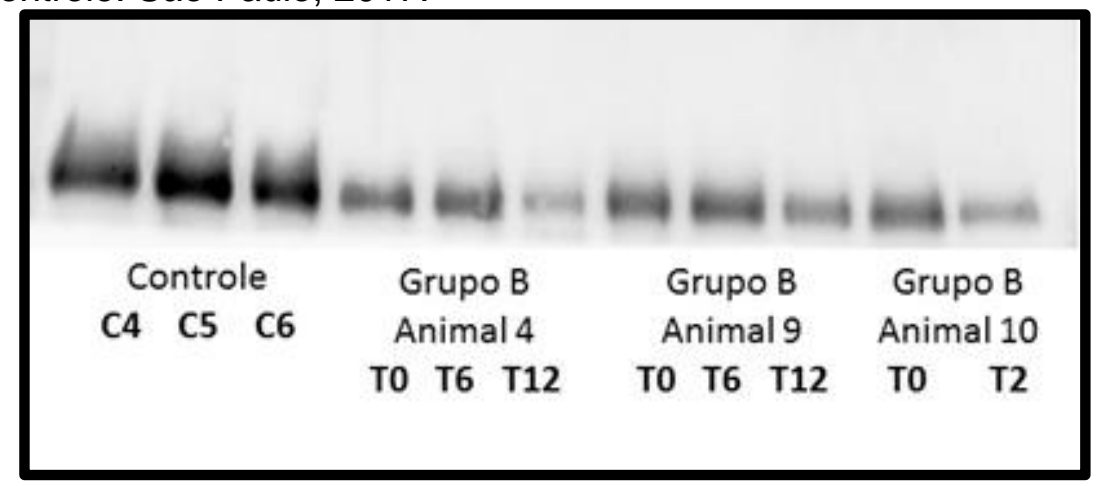




\subsection{Pressão Arterial Sistólica}

A pressão arterial sistólica nos cães do Grupo A mantiveram-se nos patamares de normalidade ( $<160 \mathrm{mmHg})$ e, pontualmente, nos cães A2 e A7 houve um discreto aumento em T1 e T3 e em T1, respectivamente. Em todos os cães dos subgrupos A-SF e A-CTM houve momentos da impossibilidade de mensuração da pressão arterial devido, principalmente, a agitação e indocilidade dos animais (Tabela 63). No atinente ao Grupo B, também no subgrupo B-SF foi observado aumento da pressão arterial sistólica em momentos pontuais, tais como no cão B2 (em T0 e T3), no cão B3 (em T0 e T1) e no cão B4 (em T0 e T3). No que concerne aos cães do subgrupo B-CTM, o aumento da pressão sistólica foi detectado no cão B7 em T2 e T3 (PA mensurado até T7), no cão B8 em T0 e T1 (PA mensurado até T5), no cão B10 em T1 e T2 (óbito em T4), no cão B11 em T0 e T1 (óbito em T6) e no cão B12 apresentou discreto aumento em T0 e em T1 (óbito em T2) (Tabela 64).

O aumento da intensidade da proteinúria coincidiu no cão B3 do subgrupo B-SF e no subgrupo B-CTM nos cães B7 em T2, no B8 em T0, no B10 em T1. 
Tabela 63 - Valores individuais e estatística descritiva da pressão arterial sistólica (PAS; mm hg) dos cães dos subgrupos A-SF (A1 a A6) e A-CTM (A7 a A9), na avaliação sequencial durante a evolução da doença renal crônica. São Paulo, 2017.

\begin{tabular}{cccccccccc}
\hline & $\mathrm{A} 1$ & $\mathrm{~A} 2$ & $\mathrm{~A} 3$ & $\mathrm{~A} 4$ & $\mathrm{~A}$ & $\mathrm{~A}$ & $\mathrm{~A}$ & $\mathrm{~A}$ & $\mathrm{~A}$ \\
\hline T0 & $* *$ & 139,00 & 141,00 & 122,00 & 131,00 & 120,00 & $\mathbf{1 7 4 , 0 0}$ & 144,00 & 124,00 \\
T1 & $* *$ & $\mathbf{1 6 8 , 0 0}$ & 145,00 & $* *$ & 130,00 & 138,00 & $* *$ & $* *$ & 131,00 \\
T2 & $* *$ & 137,00 & 175,00 & $* *$ & $* *$ & $* *$ & $* *$ & $* *$ & 138,00 \\
T3 & $* *$ & $\mathbf{1 6 1 , 0 0}$ & 158,00 & 133,00 & $* *$ & $* *$ & $* *$ & $* *$ & $* *$ \\
T4 & $* *$ & 120,00 & 160,00 & 133,00 & $* *$ & $* *$ & $* *$ & 133,00 & 131,00 \\
T5 & $* *$ & 101,00 & $* *$ & $* *$ & 140,00 & 145,00 & $* *$ & $* *$ & $* *$ \\
T6 & $* *$ & 108,00 & 115,00 & $* *$ & $* *$ & 128,00 & $* *$ & $* *$ & 131,00 \\
T7 & $* *$ & $* *$ & $* *$ & $* *$ & $* *$ & 130,00 & $* *$ & $* *$ & $* *$ \\
T8 & $* *$ & $* *$ & $* *$ & 144,00 & $* *$ & 134,00 & $* *$ & 131,00 & $* *$ \\
T9 & $* *$ & $* *$ & $* *$ & $* *$ & 138,00 & $* *$ & $* *$ & $* *$ & $* *$ \\
T10 & $* *$ & 127,00 & $* *$ & $* *$ & $* *$ & 144,00 & $* *$ & $* *$ & $* *$ \\
T11 & $* *$ & $* *$ & 140,00 & $* *$ & $* *$ & $* *$ & $* *$ & $* *$ & 130,00 \\
T12 & $* *$ & 152,00 & 130,00 & 136,00 & 141,00 & 142,00 & $* *$ & 144,00 & 132,00 \\
\hline Média & $* *$ & 134,00 & 145,00 & 133,00 & 136,00 & 135,00 & 174,00 & 138,00 & 131,00 \\
Mediana & $* *$ & 137,00 & 143,00 & 133,00 & 138,00 & 136,00 & 174,00 & 138,00 & 131,00 \\
DP & $* *$ & 21,72 & 17,53 & 7,06 & 4,60 & 8,21 & 0 & 6,04 & 4,43 \\
CV & $* *$ & 16,12 & 12,05 & 5,28 & 3,38 & 6,07 & 0 & 4,38 & 3,38 \\
Mín. & $* *$ & 101,00 & 115,00 & 122,00 & 130,00 & 120,00 & 174,00 & 131,00 & 124,00 \\
Máx. & $* *$ & 168,00 & 175,00 & 144,00 & 141,00 & 145,00 & 174,00 & 144,00 & 138,00 \\
$\Delta$ & $* *$ & 13,00 & $-11,00$ & 14,00 & 10,00 & 22,00 & $* *$ & 0 & 8,00
\end{tabular}

D.P. = desvio padrão; ${ }^{* *}$ impossibilidade da realização da mensuração; EPM = erro padrão da média; $†$ Óbito; $\overline{C V}=$ coeficiente de variação $\quad \Delta$ = diferença entre o ultimo tempo de acompanhamento e o T0

B-SF = subgrupo A de cães com doença renal crônica no estágio 3 que recebeu solução fisiológica; $\mathbf{B}$-CTM: subgrupo A de cães com doença renal crônica no estágio 3 que grupo que recebeu célula tronco mesenquimal

Tabela 64 - Valores individuais e estatística descritiva da pressão arterial sistólica (PAS; mm hg) dos cães dos subgrupos B-SF (B1 a B6) e B-CTM (B7 a B13), na avaliação sequencial durante a evolução da doença renal crônica. São Paulo, 2017.

\begin{tabular}{|c|c|c|c|c|c|c|c|c|c|c|c|c|c|}
\hline & B1 & B2 & B3 & B4 & B5 & B6 & B7 & B8 & B9 & B10 & B11 & B12 & B13 \\
\hline T0 & 138,00 & 182,00 & 205,00 & 201,00 & 131,00 & 130,00 & 146,00 & 211,00 & 171,00 & 213,00 & 184,00 & 163,00 & 122,00 \\
\hline T1 & 115,00 & 140,00 & 233,00 & $* *$ & 123,00 & $* *$ & 160,00 & 163,00 & 127,00 & 175,00 & 216,00 & 178,00 & ** \\
\hline T2 & 138,00 & 137,00 & ** & 148,00 & 135,00 & ** & 166,00 & 133,00 & 160,00 & 153,00 & 112,00 & $\dagger$ & ** \\
\hline T3 & $\star *$ & 164,00 & ** & 214,00 & $\star *$ & 133,00 & 193,00 & 175,00 & 143,00 & $\dagger$ & 161,00 & & ** \\
\hline T4 & $* *$ & 143,00 & ** & 150,00 & ** & 141,00 & 150,00 & 164,00 & 158,00 & & 88,00 & & ** \\
\hline T5 & ** & 130,00 & $\dagger$ & 148,00 & $\dagger$ & $\dagger$ & 142,00 & 132,00 & 158,00 & & $\dagger$ & & ** \\
\hline T6 & ** & $\dagger$ & & 131,00 & & & 128,00 & ** & 120,00 & & & & 130,00 \\
\hline T7 & 116,00 & & & 120,00 & & & $* *$ & ** & 122,00 & & & & $t$ \\
\hline T8 & 136,00 & & & 130,00 & & & ** & ** & $* *$ & & & & \\
\hline T9 & 140,00 & & & $* *$ & & & ** & ** & ** & & & & \\
\hline T10 & 131,00 & & & ** & & & $\dagger$ & 125,00 & ** & & & & \\
\hline T11 & ** & & & ** & & & & ** & 141,00 & & & & \\
\hline T12 & 136,00 & & & 110,00 & & & & 211,00 & ** & & & & \\
\hline Média & 131,00 & 149,00 & 219,00 & 150,00 & 129,00 & 134,00 & 155,00 & 164,00 & 144,00 & 188,00 & 157,00 & 168,00 & 124,00 \\
\hline Mediana & 136,00 & 141,00 & 219,00 & 148,00 & 131,00 & 133,00 & 150,00 & 163,00 & 143,00 & 194,00 & 172,00 & 163,00 & 122,00 \\
\hline DP & 9,42 & 17,96 & 14,00 & 33,27 & 4,99 & 4,64 & 19,25 & 31,71 & 17,43 & 25,70 & 44,29 & 6,93 & 3,77 \\
\hline CV & 7,17 & 12,03 & 6,39 & 22,15 & 3,85 & 3,45 & 12,42 & 19,31 & 12,07 & 13,64 & 28,10 & 4,12 & 3,02 \\
\hline Mín. & 115,00 & 130,00 & 205,00 & 110,00 & 123,00 & 130,00 & 128,00 & 125,00 & 120,00 & 153,00 & 88,00 & 163,00 & 122,00 \\
\hline Máx. & 140,00 & 182,00 & 233,00 & 214,00 & 135,00 & 141,00 & 193,00 & 211,00 & 171,00 & 213,00 & 216,00 & 178,00 & 130,00 \\
\hline$\Delta$ & $-2,00$ & $-52,00$ & 28,00 & $-91,00$ & 4,00 & 11,00 & $-18,00$ & 0,00 & $-30,00$ & $-60,00$ & $-96,00$ & 15,00 & 8,00 \\
\hline
\end{tabular}

$\Delta=$ diferença entre o ultimo tempo de acompanhamento e o T0

B-SF = subgrupo A de cães com doença renal crônica no estágio 3 que recebeu solução fisiológica; $\mathbf{B}-\mathbf{C T M}$ : subgrupo A de cães com doença renal crônica no estágio 3 que grupo que recebeu célula tronco mesenquimal

Nas Tabelas 65 e 66 observa-se que os cães do subgrupo B (BSF e BCTM) apresentaram as médias da pressão arterial sistólica maiores que os cães 
do Grupo A, e a área calculada sob a curva dos subgrupos B-SF e B-CTM confirma a referida observação (Figura 23 e Tabela 67).

Tabela 65 - Estatística descritiva dos valores da pressão arterial sistólica (PAS) dos cães com doença renal crônica no estágio 2 (GRUPO A) referentes aos subgrupos ASF e A-CTM. São Paulo, 2017.

\begin{tabular}{ccc}
\hline Estagio & A-SF $( \pm D P)$ & A-CTM $( \pm D P)$ \\
\hline T0 & $130,60( \pm 9,55) ; n=6$ & $147,33( \pm 25,16) ; n=3$ \\
T1 & $145,25( \pm 16,35) ; n=6$ & $131,00( \pm 0,00) ; n=3$ \\
T2 & $156,00( \pm 26,87) ; n=6$ & $138,00( \pm 0,00) ; n=3$ \\
T3 & $150,66( \pm 15,37) ; n=6$ & $* n=3$ \\
T4 & $137,66( \pm 20,40) ; n=6$ & $132,00( \pm 1,41) ; n=3$ \\
T5 & $128,66( \pm 24,09) ; n=6$ & $131,00( \pm 0,00) ; n=3$ \\
T6 & $117,00( \pm 10,14) ; n=6$ & $* * n=3$ \\
T7 & $130,00( \pm 0,00) ; n=6$ & $131,00( \pm 0,00) ; n=3$ \\
T8 & $139,00( \pm 7,07) ; n=6$ & $* * ; n=3$ \\
T9 & $138,00( \pm 0,00) ; n=6$ & $* * ; n=3$ \\
T10 & $135,50( \pm 12,02) ; n=6$ & $130,00( \pm 0,00) ; n=3$ \\
T11 & $140,00( \pm 0,00) ; n=6$ & $138,00( \pm 8,48) ; n=3$ \\
T12 & $140,20( \pm 8,13) ; n=6$ & $134,79( \pm 5,99)$ \\
\hline Média & $137,57( \pm 9,99)$ &
\end{tabular}
com doença renal crônica no estágio 2 que receberam célula tronco mesenquimal

Tabela 66 - Estatística descritiva dos valores da pressão arterial sistólica (PAS) dos cães com doença renal crônica no estágio 3 (GRUPO B) referentes aos subgrupos BSF e B-CTM. São Paulo, 2017.

\begin{tabular}{|c|c|c|}
\hline Estagio 3 & $\mathrm{~B}-\mathrm{SF}( \pm \mathrm{DP})$ & $\mathrm{B}-\mathrm{CTM}( \pm \mathrm{DP})$ \\
\hline TO & $164,50( \pm 35,47) ; n=6$ & $172,85( \pm 33,16) ; n=7$ \\
\hline T1 & $152,75( \pm 54,50) ; n=6$ & $169,83( \pm 28,99) ; n=7$ \\
\hline $\mathrm{T} 2$ & $139,50( \pm 5,80) ; n=6$ & $144,80( \pm 22,15) ; n=6$ \\
\hline T3 & $170,33( \pm 40,87) ; n=6$ & $168,00( \pm 21,19) ; n=5$ \\
\hline T4 & $144,88( \pm 4,50) ; n=3$ & $140,00( \pm 35,13) ; n=5$ \\
\hline T5 & $139,00( \pm 12,72) ; n=3$ & $144,00( \pm 13,11) ; n=4$ \\
\hline T6 & $131,00( \pm 0,00) ; n=2$ & $126,00( \pm 5,29) ; n=4$ \\
\hline T7 & $118,00( \pm 2,82) ; n=2$ & $122,00( \pm 0,00) ; n=4$ \\
\hline T8 & $133,00( \pm 4,24) ; n=2$ & ${ }^{\star *} ; n=3$ \\
\hline T9 & $140,00( \pm 0,00) ; n=2$ & ${ }^{\star *} ; n=2$ \\
\hline T10 & $131,00( \pm 0,00) ; n=2$ & $125,00( \pm 0,00) ; n=2$ \\
\hline $\mathrm{T} 11$ & $* * ; n=2$ & $141,00( \pm 0,00) ; n=2$ \\
\hline T12 & $123,00( \pm 18,38) ; n=2$ & $211,00( \pm 0,00) ; n=2$ \\
\hline
\end{tabular}

EPM = erro padrão da média; B-SF = cães com doença renal crônica no estágio 3 que receberam solução fisiológica; B-CTM: cães com doença renal crônica no estágio 3 que receberam célula tronco mesenquimal 
Figura 23 - Valores médios das porcentagens da pressão arterial sistólica (PAS) dos cães dos Grupos A e B, subgrupos A-SF, A-CTM, B-SF e B-CTM, na avaliação sequencial durante a evolução da doença renal crônica. São Paulo, 2017.

\section{P AS}



Tabela 67 - Cálculo da área sob a curva (AREA) das médias das porcentagens da pressão arterial sistólica (PAS) dos cães dos grupos A e B, subgrupos A-SF, A-CTM, B-SF e B-CTM, na avaliação sequencial durante a evolução da doença renal crônica. São Paulo, 2017.

\begin{tabular}{ccccc}
\hline AREA & A-SF & A-CTM & B-SF & B-CTM \\
\hline Área & 1653 & 1594 & 1670 & 1720 \\
Erro & 36,05 & 13,43 & 55,63 & 43,39 \\
IC 95\% & $1582-1724$ & $1568-1620$ & $1561-1779^{*}$ & $1635-1805$ \\
\hline
\end{tabular}




\section{Discussão}

Dos cães com DRC que foram selecionados para o estudo, houve a necessidade da exclusão de um paciente (labrador retriever - fêmea de 5 anos) por ter manifestado reações adversas que ocorreram logo no início da infusão da solução salina com CTM, sendo que o tratamento que havia sido empregado foi revelado somente após a decisão de suspender a infusão da solução e excluir o animal do estudo. Efeitos adversos agudos após a aplicação intravenosa de células tronco foram relatados em humanos, ratos e camundongos (LAZARUS et al., 2005; HARE et al., 2009; KARUSSIS et al., 2010; LEE et al., 2010a). Os efeitos adversos observados no presente estudo para o cão labrador retriever, possivelmente, foram decorrentes pela formação de microtrombos na circulação sanguínea em decorrência da agregação das CTM, uma vez que a aderência dessas células constitui-se em característica ímpar (LEE et al., 2010a) e que, por conseguinte, causaram o comprometimento da hemodinâmica cerebral e, assim, ocasionando os episódios convulsivos; ainda, as manifestações gástricas e entéricas podem também ter origem do comprometimento da hemodinâmica, como descrito nos estudos (RINGDE et al., 2006; HARE et al., 2009; ZHANG et al., 2010). No atinente ao segundo cão da raça golden retriever que também foi excluído e que apresentou efeito adverso, este foi manifestado por uma reação anafilática que provavelmente ocorreu em consequência da presença de resquício de alguma substância oriunda do meio de cultivo celular, a exemplo do soro fetal bovino que é utilizado na cultura celular (SPEES et al., 2004; SHAHDADFAR et al., 2005). 
Assim, diante destes fatos, é importante estar ciente de que a aplicação terapêutica de CTM pode não ser completamente inócua ou isenta de efeitos colaterais e que as reações adversas devem ser de conhecimento e, ainda, que o nosocômio deve estar atento e preparado para o pronto atendimento quando de qualquer ocorrência. Também outros dois cães do subgrupo A-CTM (A7 e A8) desenvolveram reações adversas, entretanto no final da administração da solução fisiológica com CTM, e que foram retratadas como síncope e convulsões, respectivamente, sendo que possivelmente estas manifestações poderiam estar relacionadas com a formação de microtrombos devido a característica de alta agregação das CTM e que, por conseguinte, comprometeu a hemodinâmica cerebral (LAZARUS et al., 2005; ZHANG et al., 2008; KARUSSIS et al., 2010; LEE et al., 2010a).

Apesar de poder ocorrer inesperados efeitos adversos decorrentes da aplicação de CTM, em um estudo realizado por Lee e colaboradores (LEE et al., 2010a) descreveram que a disfunção neurológica com crises convulsivas foi detectada em 3 dos 16 ratos tratados CTM (19\%). Em ensaios clínicos não controlados, a disfunção neurológica foi observada em 13 dos 53 (25\%) pacientes humanos (ZHANG et al., 2010; HONMOU et al., 2011; KARUSSIS et al., 2011). No presente estudo, $12,5 \%$ dos animais desenvolveram algum tipo de alteração neurológica durante a aplicação das CTM, o que aventa a possibilidade de que a agregação das CTM pode causar embolia em vasos capilares cerebrais, como sugerido por Karussis e colaboradores (KARUSSIS et al., 2011).

Quanto as justificativas dos óbitos que ocorreram durante o período de acompanhamento do estudo, no Grupo A (estágio 2 da DRC) não foi constatado nenhum evento, entretanto para o Grupo B (estágio 3 da DRC), o óbito ocorreu 
em $50 \%$ (3 do total de 6 ) dos cães do subgrupo B-SF, frequência esta que poderia ser justificada pelo curso natural da doença para esse estágio mais avançado da DRC, pois nesta fase já estaria ocorrendo perda importante das unidades funcionais dos rins, mas há de se ressaltar que, neste referido subgrupo, o óbito decorrente de crise urêmica, pela descompensação da função renal, ocorreu em apenas um dos cães, sendo que para os outros dois, a eutanásia havia sido indicada por motivos extrarrenais. Portanto, esta informação pode limitar a análise dos resultados observados no subgrupo B-SF e não sendo possível atribuir esses óbitos, diretamente, a causa da piora da DRC - disfunção renal.

No atinente ao subgrupo B-CTM, o número de óbitos foi maior em comparação ao B-SF, ou seja, 5 do total de 7 cães $(71,4 \%)$ e que evoluíram em decorrência da piora do quadro clínico, ou seja, pela crise urêmica, efetivamente pela piora da função renal que, portanto, poderia ser esperada face ao avanço no curso natural e progressão da DRC no estágio 3 (FINCO et al., 1999; BARTGES, 2012). Assim, para esses cães em que o óbito ocorreu durante 0 período de acompanhamento, não seria possível afirmar que o óbito estaria somente relacionado a algum efeito adverso da terapia com as CTM pois, também, especificamente para os cães do subgrupo B-CTM, estes já apresentavam proteinúria mais intensa desde o início do período de acompanhamento em comparação com o subgrupo B-SF, além de serem mais idosos, mas que a intensidade da proteinúria per se já poderia ser considerado como um fator importante de mau prognóstico como indicador de lesão renal mais grave (JACOB et al., 2005; LEES et al., 2005; VADEN; ELLIOTT, 2016). 
Em relação a proteinúria, na sua avaliação quantitativa pelo cálculo da razão proteína/creatinina urinária (RPC), no geral, os cães do Grupo B apresentaram proteinúria mais intensa que o Grupo $A$, sendo que a possibilidade da proteinúria ocorrer em estágios mais avançados da DRC poderia ser esperada (POLZIN, 2013). No subgrupo B-CTM, a intensidade da proteinúria oscilou de forma variada no mesmo animal (aumento ou diminuição) ao longo dos momentos da avaliação seriada, indicando que esta oscilação pode ser esperada, pois pode ocorrer variações fisiológicas ao longo do mesmo dia ou entre os dias (NABITY et al., 2007), mas, também, pode indicar uma condição patológica devido a lesões em glomérulos e/ou túbulos e, portanto, que a interpretação das oscilações dos valores da RPC não podem ser atribuídas exclusivamente a melhora ou a piora de um processo de lesão renal, mas suscita-se, nesse momento, a necessidade da investigação mais verticalizada dos tipos de proteínas existentes na urina para assim identificar a gravidade do comprometimento renal. Ainda, a hipertensão arterial sistêmica pode causar a intensificação da proteinúria, como resultado da hipertensão intraglomerular a qual pode resultar em hipertrofia do glomérulo, alterando sua morfologia e função, como foi detectado no cão B3 do subgrupo B-SF, e no subgrupo B-CTM nos cães B7, B8 e B10 (JACOB et al., 2005; WEHNER; HARTMANN; HIRSCHBERGER, 2008; HARLEY; LANGSTON, 2012). Entretanto, o aumento da pressão arterial também está associado a condição de estresse, fato este factível devido as condições do ambiente hospitalar, e assim pode ser justificado aqueles momentos pontuais de aumento da pressão sistólica, pois para ser uma condição patológica, esses valores deveriam permanecer em patamares 
próximo ou os valores aumentados serem sustentados ao longo dos tempos de observação (BROWN et al., 2007).

Ainda sobre a proteinúria, é importante ressaltar que somente a avaliação quantitativa da proteinúria, pela determinação da RPC, não permitiria a identificação específica das proteínas, ou seja, na dependência do tipo de proteína, esta estaria relacionada a origem do segmento lesado do néfron, o qual gerou a perda de tais proteínas e, portanto, a avaliação somente da RPC limitaria essas informações e não forneceria subsídios para a identificação do segmento comprometido do néfron, ou seja, se oriundas de lesões no glomérulo e/ou túbulo-intersticio (SCHULTZE; JENSEN, 1998; ZINI; BONFANTI; ZATELLI, 2004; GIORI et al., 2011). Dessa forma, a adição de um estudo qualitativo das proteínas urinárias seria de grande importância para complementar e trazer informações adicionais que pudessem nortear uma discussão verticalizada e com mais propriedade.

Assim, corroborando a informação de que o aumento da intensidade da proteinúria pode acompanhar a progressão da doença renal, ou seja, que pelo entendimento da fisiopatologia há a ativação dos mecanismos compensatórios, os néfrons remanescentes tornam-se hiperativos ou com hiperfunção e ao longo do tempo as estruturas tornam-se vulneráveis a lesões (FINCO et al., 1999; BARTGES, 2012; VEJAKAMA et al., 2017). Assim, como foi observado no presente estudo, a possibilidade da proteinúria ocorrer com maior frequência seria no estágio 3 da DRC, e menos intensa ou ausente nos cães do Grupo A (estágio 2 da DRC). Considerando esse raciocínio, observou-se que somente um cão (A1) do subgrupo A-SF, que era portador de doença renal juvenil, apresentava proteinúria desde o início do período de acompanhamento e que 
esta perdurou com intensidade discreta (RCP média de 1,49) durante todo o tempo de acompanhamento. No relativo ao subgrupo A-CTM, os cães que iniciaram não proteinúricos, assim permaneceram ao longo dos tempos de acompanhamento, indicando provável estabilidade dos mecanismos compensatórios e sem evoluir para lesão renal mais grave.

A detecção de proteinúria mais intensa desde o momento T0 nos cães do Grupo B, principalmente no subgrupo B-CTM, ocorreu provavelmente devido ao processo de randomização para a distribuição dos cães nos subgrupos e, assim, houve a formação de um subgrupo (B-CTM) de cães mais proteinúricos. Para o Grupo A, a distribuição randomizada resultou para que o subgrupo A-CTM fosse constituído por um número menor de cães em comparação com o subgrupo ASF (50\% menos) e, assim, esperar-se-ia, devido ao número maior de cães no referido subgrupo, de que a probabilidade da proteinúria fosse mais evidente no subgrupo A-SF. Entretanto, a proteinúria foi detectada somente em um cão do subgrupo A-SF (A1) que apresentava doença renal juvenil, e que evoluiu segundo o curso natural da DRC (CHANDLER et al., 2007; SMETS et al., 2010b).

Por outro lado, para o Grupo B e, principalmente, para o subgrupo B-CTM, a proteinúria persistiu ao longo de todos os momentos de observação; em alguns cães foram detectados períodos com aumento da intensidade da proteinúria e outros com a manutenção dos valores, mas nos patamares superiores. $O$ subgrupo B-CTM foi diferente em relação ao subgrupo B-SF $(P<0,0001)$, portanto, a proteinúria observada em $71,4 \%$ dos cães do subgrupo B-CTM, desde o início do acompanhamento em comparação com 17\% do subgrupo BSF, pode indicar presença de lesão renal mais extensa e que dificultou a análise 
comparativa dos resultados dos subgrupos para determinar ou não a eficácia da terapia com a CTM.

É importante ressaltar que a determinação da RPC foi conduzida de forma seriada, ou seja, observada ao longo da evolução da doença, sendo que este presente estudo pode ser considerado inédito em cães com DRC, devido ao longo tempo de acompanhamento após realizada a terapia celular, e que a avaliação seriada, pelo menos mensalmente, permitiu a obtenção de resultados para uma análise mais fidedigna, pois a possibilidade de variação fisiológica da proteína urinária, ou mesmo devido a fatores extrarrenais, pode levar a conclusões precipitadas e os achados devem ser avaliados com cautela. Há de se ressaltar que a avaliação seriada é uma recomendação do consenso sobre proteinúria do American College of Veterinary Internal Medicine, e que deve ser estendido não só para a confirmação da presença de proteinúria patológica, como também para avaliar, sequencialmente, durante a evolução da doença, como também após instituição de terapia (LEES et al., 2005; SEGEV, 2010; GRAUER, 2011; HARLEY; LANGSTON, 2012).

Para o melhor entendimento da proteinúria, pois a RPC constitui-se na somatória de todas as proteínas presentes na urina, é preciso identificar os tipos de proteínas e a sua origem, além de acompanhar a intensidade de cada uma delas durante a evolução da doença renal (LE BRICON et al., 1998; SCHULTZE; JENSEN, 1998; ZARAGOZA et al., 2003; ZINI; BONFANTI; ZATELLI, 2004; GIORI et al., 2011).

Assim, no que tange a análise qualitativa das proteínas na urina, no atinente ao peso molecular, esta informação pode se tornar uma importante ferramenta para a identificação dos segmentos do néfron que possam estar 
lesados e, portanto, causando a perda de proteínas específicas na urina. Nos cães clinicamente normais do grupo controle, como também de acordo com os dados da literatura (BACIC et al., 2010b; CARAGELASCO et al., 2017; CHACAR et al., 2017; MARTORELLI, KOGIKA, CARAGELASCO, 2016; SCHULTZE; JENSEN, 1998), apontam que em condições normais há apenas uma pequena quantidade de proteína total na urina, cujo valor da RPC não sobrepujaria 0,5, e que o predomínio seria de proteínas de alto peso molecular (HARLEY; LANGSTON, 2012; LITTMAN et al., 2013). Os cães do Grupo A apesar de não proteinúricos, a exceção do cão $\mathrm{A} 1$, apresentaram porcentagem menor de proteínas de alto peso molecular na urina em comparação com os cães clinicamente normais, o que, por conseguinte, apesar dos valores da RPC ainda na faixa de normalidade, este fato já poderia indicar a perda urinária maior de proteínas de baixo peso molecular, suscitando-se a possibilidade já da ocorrência de lesões tubulares no segmento proximal, ou seja, a detecção precoce da lesão e que já estaria comprometendo a reabsorção dessas proteínas (ZINI; BONFANTI; ZATELLI, 2004; CHACAR et al., 2017).

O mesmo padrão de perda de proteínas de baixo peso molecular também foi detectado na urina dos cães do Grupo B, sendo que o mais evidente ocorreu nos cães do subgrupo B-CTM, confirmado não só pela porcentagem maior de proteínas na região $\mathrm{B}$, como também pelo maior número de bandas de proteínas de baixo PM, sendo que esta alteração perdurou ao longo do período de acompanhamento nos diversos momentos de avaliação e, ainda, esta afirmação foi corroborada pelo valor da área calculada sob a curva do subgrupo B-CTM que foi maior quando comparado ao grupo controle. É importante mencionar que um maior número de bandas de proteína de baixo peso molecular $(<60 \mathrm{kDa})$ 
também foi detectado no subgrupo B-SF, indicando que pela própria evolução da lesão tubular na da DRC, no estágio 3, já justificaria o comprometimento evidente da capacidade de reabsorção de proteínas normalmente presentes no filtrado glomerular pelas células dos túbulos contornados proximais (HOLM; HEMMINGSEN; NIELSEN, 1993; SMETS et al., 2010b; GRAUER, 2011).

Verticalizando a análise qualitativa das proteínas urinárias, ou seja, pela imunodetecção de proteínas específicas tais como a albumina, as proteínas ligadas ao retinol ou a vitamina $\mathrm{D}$ e a proteína de Tamm-Horsfall, esta investigação pode trazer informações adicionais e importantes para o melhor entendimento da origem da proteinúria, como também da evolução da lesão renal, e que também pode trazer subsídios para nortear a indicação de terapia e o prognóstico (BACIC et al., 2010b; RAILA; SCHWEIGERT; KOHN, 2014; TIAN et al., 2014; CHACAR et al., 2017).

No estudo específico para a imunodetecção de albumina urinária no Grupo A, quanto à comparação dos seus respectivos subgrupos (A-SF e ACTM), nota-se que o subgrupo A-CTM apresentou diminuição da porcentagem da densitometria referente a albumina urinária em dois cães (A7 e A9) do total de três cães, respectivamente de 43,2 e 49,6\%, mas com estes achados ainda seria precoce afirmar que as CTM pudessem ter causado algum efeito benéfico, a nível glomerular ou tubular, pois o número de cães que compuseram esse grupo foi pequeno. Assim, estudos futuros com a administração de CTM devem ser encorajados para um número maior de cães com DRC no estágio 2.

Ainda, no subgrupo A-SF, no início do acompanhamento foi observado o aumento discreto da densitometria para a albumina em três (A1, A5 e A6) do total de seis cães, sendo que os cães A5 e A6 mantiveram esses valores 
discretamente aumentados em patamares semelhantes ao longo de todo 0 período de observação (variação de $118,6 \%$ a 125,4\%), e quanto a aquele cão A1 que iniciou com albuminúria em T0, houve a normalização após T6 (83,9\%) e T12 (77,7\%), ocorrendo a diminuição da intensidade da albuminúria de 39,6\%. Portanto, nota-se que durante a evolução natural da DRC nos seis cães avaliados no subgrupo A-SF, ao longo de aproximadamente 12 meses, não houve a evolução para lesão renal grave que causasse o aumento da perda de albumina na urina, e se houve a perda, esta foi discreta.

O cão A1 do subgrupo A-SF apresentou a média da RPC de 1,49 $\pm 0,65$ (média \pm DP), e a albuminúria não foi intensa, somente observada em T0 e, portanto, o aumento da RPC deveria estar relacionada a presença de outros tipos de proteínas; assim, para o referido cão, na eletroforese de proteínas urinária foi constatado um maior número de bandas de proteínas de baixo PM, de 3 a 4 bandas, a partir do momento T5, sugerindo a perda de proteínas decorrente da não reabsorção das proteínas no segmento proximal dos néfrons. Os cães A7 e A8 do subgrupo A-CTM que apresentaram a porcentagem da densitometria para albuminúria maior nos tempos T0 e T6, respectivamente, mas os valores da RPC nesses momentos eram normais, ou seja, de 0,26 e 0,19, esses achados destacam que caso a análise fosse somente realizada pela RPC, não seria possível precocemente detectar a presença de lesão renal, no caso, possivelmente de comprometimento glomerular.

Os subgrupos B-SF e B-CTM apresentaram albuminúria intensa desde o início do período de acompanhamento e que perdurou até próximo a T5 para ambos os subgrupos, observando-se, após, diminuição da albuminúria, entretanto, a ocorrência de vários óbitos durante o período de acompanhamento 
invalida a análise adequada de que a terapia com a CTM pudesse ter colaborado na diminuição da albuminúria pela recuperação ou não progressão da lesão renal, pois esse perfil foi também observado no subgrupo B-SF. Portanto, esses achados, até o presente momento, ainda não trazem evidências significantes de que a terapia com CTM poderia ter causado efeito benéfico ao subgrupo B-CTM e, ainda, que na avaliação individual desses cães, não foi constatada diminuição da perda de albumina urinária ao longo do período de observação. Dos três cães do Grupo B que apresentaram albuminúria em maior intensidade, B3 (subgrupo B-SF), B12 e B13 (subgrupos B-CTM), os cães B3 e B13 apresentaram a RPC de 3,43 a 6,23, respectivamente, corroborando com a informação da literatura veterinária de que a RPC $>2,0$ pode ser indicativa de perda de albumina urinária (LEES et al., 2005; PERKINS et al., 2007; SEGEV, 2010; GRAUER, 2011). Entretanto, o cão B12 que também apresentava albuminúria intensa, a RPC era inferior a 0,7 e a densitometria para albuminúria de 468,9 e 469,0\%, respectivamente, em T0 e T1 e na análise das proteínas pela eletroforese foi observada a porcentagem de $100 \%$ de proteínas de baixo peso molecular, ou seja, ausência de albumina; esses resultados podem reforçar a necessidade da execução de métodos tanto quantitativo como qualitativo para a interpretação e avaliação adequada da proteinúria e sua origem como também da necessidade de estudos de sensibilidade e especificidade dos diversos métodos de avaliação da proteinúria.

Entretanto, especificamente para esse cão B12 em T0 e T1, há a possibilidade da justificativa da presença de albuminúria estar relacionada ao comprometimento das células tubulares do segmento proximal, comprometendo a reabsorção da albumina que estaria normalmente em pequena quantidade no 
filtrado glomerular, e não somente relacionada a alteração em glomérulos, pois lesões tubulares também podem causar albuminúria, sendo no início desse processo o achado de microalbuminúria (AMSELLEM et al., 2010; OHSE et al., 2006). Ainda ressaltando esta possibilidade da albuminúria no cão B12 ser também proveniente de lesão tubular, esta hipótese pode ser alicerçada pela detecção concomitante na urina da proteína ligada ao Retinol que estaria presente somente na lesão tubular (CHACAR et al., 2017).

A imunodetecção da proteína ligada a vitamina D (VDBP) no Grupo A em quantidades discretamente elevadas estavam presentes nos cães A1 e A7 desde o início do acompanhamento, indicando a presença de lesão em túbulos proximais que comprometeram a sua reabsorção, e também não foi detectada a piora ao longo do período de observação. Como já mencionado, o cão A1 é aquele que apresentou RPC média de 1,49, mas sem a presença de albuminúria e, portanto, a proteinúria foi caracterizada pela perda de proteínas de baixo PM, e confirmada pela imunodetecção especifica da VDBP, pois não foi detectada a perda da proteína ligada ao retinol (RBP). Em relação ao cão A7 (subgrupo ACTM), apesar da média da RPC ao longo do período de acompanhamento ter oscilado praticamente na faixa de normalidade $(0,36 \pm 0,12)$, observou-se 0 aumento da VDBP na urina, indicando a detecção precoce de lesão tubular renal (RAILA; SCHWEIGERT; KOHN, 2014; TIAN et al., 2014; CHACAR et al., 2017). Portanto, esses achados indicam a importância da avaliação da proteinúria por vários métodos laboratoriais, não só para avaliar o local de lesão que está causando essa perda, mas também pela possibilidade do diagnóstico precoce que pode estar atrelado ao prognóstico. Os dados obtidos não permitiram 
evidenciar que a terapia com a CTM pudesse ter alterada a quantidade de VDBP na urina ao longo dos tempos de acompanhamento no subgrupo A-CTM.

No atinente ao Grupo B, os três cães do subgrupo B-CTM (B8, B9 e B10) que apresentaram desde o início do acompanhamento aumento da VDBP e sendo que em dois (B8 e B9) cães esses valores permaneceram nos mesmos patamares ao longo do acompanhamento, e somente no cão B10 houve a diminuição de $21,3 \%$, entretanto essa observação ainda não alicerça que a terapia com as CTM pudesse ter contribuído positivamente. Desses cães citados, a RPC estava aumentada nos cães B8, B9 e B10 e o aumento também da proteína ligada ao retinol (RBP) foi detectado somente nos cães B8 e B10, sugerindo que para o cão B9, a perda maior de proteína na urina seria representada pela VDBP, pois não havia sido observada albuminúria neste cão e, portanto, corroborada pela detecção de maior número de bandas de proteínas de baixo pelo molecular, indicativa de lesão em células tubulares do segmento proximal. Os cães do subgrupo B-CTM, B7 e B12, que não apresentaram perda de VDBP urinária, e com RPC média de 1,85 $\pm 0,52$ e 0,47 $\pm 0,28$, respectivamente, tinham perda intensa de RBP a semelhança ao observado nos cães B2 e B3 (subgrupo B-SF), indicando a necessidade da avaliação não só de um biomarcadores para constatar a presença de lesão tubular. A detecção concomitante de albuminúria constatada no cão B3 pode indicar a presença de lesões tanto em glomérulos como nos túbulos proximais ou somente no segmento tubular. O aumento na RBP é considerado um biomarcador de lesão tubulointersticial em seres humanos, sendo observada correlação entre a RBP urinária e fibrose intersticial renal em pacientes com DRC (PALLET et al., 2014), como também foi relatada em cães (SMETS et al., 2010b; NABITY et al., 2011; 
HOKAMP et al., 2016), e Nabity et al. (NABITY et al., 2011) demonstraram em um modelo de glomerulopatia em cães que a imunodetecção da proteína ligada ao retinol foi cada vez mais evidente conforme a doença avançava, fato este que também pode ser verificado no presente estudo.

Quanto a proteínas de Tamm-Horsfall, a sua diminuição foi mais evidente na urina dos cães do Grupo B em comparação com o Grupo A, indicando a perda importante do número de néfrons dos cães do estágio 3 , pois esta proteína é normalmente sintetizada na alça de Henle e no túbulo distal (DEVUSYST; DAHAN; PIRSON, 2005; RAMPOLDI et al., 2011). Não foi evidenciado o aumento da síntese da THP nos cães que receberam a CTM em ambos os subgrupos, A-CTM (estágio 2 da DRC) e B-CTM (estágio 3 da DRC), e todos os cães do subgrupo B-CTM já apresentavam diminuição da THP (densitometria < 65\%; normal seria de próximo de 100\%) desde o início do acompanhamento e no subgrupo B-SF, essa diminuição foi constatada em $50 \%$ dos cães. Assim, na randomização ocorreu a distribuição dos cães do estágio 3 da DRC (B-CTM) em evolução mais avançada que os do subgrupo B-SF e este fato pode ter influenciado para a comparação das terapias. Ainda, o óbito decorrente de descompensação da função renal e, consequente crise urêmica, foi mais frequente no subgrupo B-CTM sugerindo que a diminuição na urina da THP poderia indicar, precocemente, a perda importante do número de néfrons e que, ainda, pela classificação da DRC baseada somente nas concentrações séricas de ureia e creatinina não seria capaz de indicar o real grau de comprometimento e perda de outras funções dos rins e, portanto, a avaliação qualitativa das proteínas urinárias, não só quantitativamente pela RPC, poderia trazer informações adicionais que pudessem contribuir para o reconhecimento mais 
adequado de estágio da doença renal e do comprometimento de néfrons (CHACAR et al., 2017).

Aparentemente o grupo B não foi beneficiado com a aplicação da CTM, não apresentando diminuição ou alterações em seu padrão de perda de proteínas para a DRC, diferentemente do estudo com ratos com DRC induzida que receberam CTM provenientes de cordão umbilical humano em que se observou melhora significante nos marcadores de lesão renal (VAN KOPPEN et al., 2012). Recentemente em um estudo com cães que receberam células-tronco autólogas para o tratamento de injuria renal aguda induzida experimentalmente por cisplatina, a referida terapia preveniu a fibrose renal e estimulou a produção de fator de crescimento endotelial, a proliferação de células epiteliais dos túbulos renais, e uma menor expressão de fator de necrose tumoral $\alpha$, quando comparado com o grupo controle, mas sem apresentar qualquer efeito nas concentrações séricas de ureia e creatinina, como na excreção urinária de proteínas, avaliada pela RPC (LIM et al., 2016). 


\section{Considerações Gerais}

Os resultados obtidos nesse estudo, segundo o delineamento aplicado, não permitiu definir conclusões contundentes de que a terapia com a CTM tenha causado alterações importantes que indicasse o seu benefício nos cães com DRC nos estágios 2 e 3. Para o Grupo A (estágio 2 da DRC), o tempo de acompanhamento dos cães foi de 12 a 15 meses, possibilitando o acompanhamento seriado e que permitiu obter informações mais fidedignas acerca da evolução das lesões renais, entretanto, na randomização, o número de cães não foi similar para cada um dos subgrupos, e este fato talvez tenha prejudicado a análise. No que se refere ao estágio 3 (Grupo B), há de se ressaltar que devido aos óbitos, e a detecção de alterações em vários biomarcadores de proteinúria, desde o início do acompanhamento, já indicaram a existência de comprometimento renal importante nesses cães com DRC no estágio 3, não sendo possível concluir que a terapia com a CTM possa ter trazido algum benefício.

Ainda, os resultados obtidos no presente estudo questionam o momento ou a fase de evolução da DRC adequada para a indicação da terapia com a CTM para que este procedimento possa trazer benefícios, pois uma vez os rins já gravemente comprometidos, como detectado no estágio 3 pelos biomarcadores, as ações benéficas da CTM poderiam ser comprometidas para essa fase mais avançada da doença.

O uso de biomarcadores, particularmente pela avaliação da proteinúria e verticalização na identificação de proteínas específicas, objeto deste estudo, 
pode, no conjunto, fornecer informações acerca do grau de comprometimento dos rins, pois a detecção de alterações dos biomarcadores que já indiquem a presença de lesões glomerulares ou tubulares, esses pacientes poderiam ser os menos favorecidos pela ação benéfica das CTM devido ao comprometimento mais avançado da DRC. Os dados observados neste estudo sugerem que os cães com DRC no estágio 2 poderiam ser os mais favorecidos a terapia celular, e não os cães do estágio 3, entretanto mais estudos contemplando um número maior de animais, bem como o maior tempo de acompanhamento (> 12 meses) poderiam ser conduzidos para tal investigação.

Ainda, os efeitos adversos decorrente da administração intravenosa de CTM devem ser considerados, pois devido a própria característica dessas células, há a possibilidade de causar formação de êmbolos na circulação, como também o resquício das substâncias do meio de cultura celular pode predispor o aparecimento de reações adversas. 
8. Conclusões

- métodos quantitativo e qualitativo para a avaliação da proteinúria devem ser realizados em conjunto, pois permitem a identificação do segmento do néfron e da precocidade da lesão renal;

- o aumento da RPC somente pode não indicar perda de albumina urinária por lesão em glomérulos, pois este método além de detectar a albumina, também mensura outros tipos de proteínas, não sendo fidedigna para caracterizar somente proteinúria de origem glomerular para os cães;

- a RPC aumentada também pode indicar proteinúria pela perda de proteínas de baixo peso molecular tais como a VDBP e RBP;

- a terapia com CTM no estágio 3 da DRC em cães não permitiu identificar evidencias de benefícios, pois o óbito foi frequente nesse estágio, indicando fase avançada da doença;

- cães com DRC no estágio 2 podem ser aqueles que mais se beneficiem com a terapia de CTM em comparação com o estágio 3, mas estudos de avaliação seriada por tempo mais prolongado ainda devem ser conduzidos, contemplando um número maior de cães. 
9. Referências Bibliográficas

AL-AWQATI, Q.; OLIVER, J. A. Stem cells in the kidney. Kidney International, v. 61, p. 387-395, 2002.

ANNESLEY, T. M.; ROCKWOOD, A. L.; SHERMAN, N. E. MasS Spectofotometry. In: Fundaments of Clinical Chemestry. 6. ed. St. Louis: Saunders Elsevier, 2008. p. 128-136.

BACIC, A.; KOGIKA, M. M.; BARBARO, K. C.; IUAMOTO, C. S.; SIMÕES, D. M. N.; SANTORO, M. L. Evaluation of albuminuria and its relationship with blood pressure in dogs with chronic kidney disease. Veterinary clinical pathology / American Society for Veterinary Clinical Pathology, v. 39, n. 2, p. 203-9, jun. 2010a. Disponível em: <http://www.ncbi.nlm.nih.gov/pubmed/20059754>. Acesso em: 3 jun. 2013.

BACIC, A.; KOGIKA, M. M.; BARBARO, K. C.; IUAMOTO, C. S.; SIMÕES, D. M. N.; SANTORO, M. L. Evaluation of albuminuria and its relationship with blood pressure in dogs with chronic kidney disease. Veterinary clinical pathology / American Society for Veterinary Clinical Pathology, v. 39, n. 2, p. 203-9, jun. 2010b. Disponível em: <http://www.ncbi.nlm.nih.gov/pubmed/20059754>. Acesso em: 20 jul. 2012.

BARTGES, J. W. Chronic kidney disease in dogs and cats. The Veterinary clinics of North America. Small animal practice, v. 42, n. 4, p. 669-92, vi, jul. 2012. Disponível em: <http://www.ncbi.nlm.nih.gov/pubmed/22720808>. Acesso em: 12 ago. 2013.

BRADFORD, M. M. A rapid and sensitive method for the quantitation of microgram quantities of protein utilizing the principle of protein-dye binding. Analytical biochemistry, v. 72 , p. 248-54, 7 maio 1976. Disponível em: $<$ http://www.ncbi.nlm.nih.gov/pubmed/942051>.

BRODIE, J. C.; HUMES, H. D. Stem Cell Approaches for the Treatment of Renal Failure. PHARMACOLOGICAL REVIEWS, v. 57, n. 3, p. 299-313, 2005.

BROOKE, G.; COOK, M.; BLAIR, C.; HAN, R.; HEAZLEWOOD, C.; JONES, B.; KAMBOURIS, M.; KOLLAR, K.; MCTAGGART, S.; PELEKANOS, R.; RICE, A.; ROSSETTI, T.; ATKINSON, K. Therapeutic applications of mesenchymal stromal cells. Seminars in cell \& developmental biology, v. 18, n. 6, p. 846-58, dez. 2007. Disponível em: <http://www.ncbi.nlm.nih.gov/pubmed/18024097>. Acesso em: 12 ago. 2013.

BROWN, S. Doenças não infecciosas do sistema urinário em pequenos animais. In: Manual Merck de Veterinária. 9 ed. ed. São Paulo: Roca, 2008. p. 10821099.

BROWN, S. a; FINCO, D. R.; BROWN, C. a; CROWELL, W. a; ALVA, R.; ERICSSON, G. E.; COOPER, T. Evaluation of the effects of inhibition of 
angiotensin converting enzyme with enalapril in dogs with induced chronic renal insufficiency. American journal of veterinary research, v. 64, n. 3, p. 321-7, mar. 2003. Disponível em: <http://www.ncbi.nlm.nih.gov/pubmed/12661873>.

BROWN, S.; ATKINS, C.; BAGLEY, R.; CARR, A.; COWGILL, L.; DAVIDSON, M.; EGNER, B.; ELLIOTT, J.; HENIK, R.; LABATO, M.; LITTMAN, M.; POLZIN, D.; ROSS, L.; SNYDER, P.; STEPIEN, R. ACVIM Consensus Statement Guidelines for the Identification, Evaluation, and Management of Systemic Hypertension in Dogs and Cats. J Vet Intern Med, v. 21, p. 542-558, 2007.

BROWN, S.; ELLIOTT, J.; FRANCEY, T.; POLZIN, D.; VADEN, S. Consensus Recommendations for Standard Therapy of Glomerular Disease in Dogs. Journal of Veterinary Internal Medicine, v. 27, p. 27-43, 2013.

BRUNO, S.; GRANGE, C.; DEREGIBUS, M. C.; CALOGERO, R. a.; SAVIOZZI, S.; COLLINO, F.; MORANDO, L.; BUSCA, a.; FALDA, M.; BUSSOLATI, B.; TETTA, C.; CAMUSSI, G. Mesenchymal Stem Cell-Derived Microvesicles Protect Against Acute Tubular Injury. Journal of the American Society of Nephrology, v. 20, n. 5, p. 1053-1067, 2009. Disponível em: $<$ http://www.jasn.org/cgi/doi/10.1681/ASN.2008070798>.

BURKHOLDER, W. J. Dietary considerations for dogs and cats with renal disease. Journal of the American Veterinary Medical Association, v. 216, n. 11 , p. 1730-1734, 2000.

CAPCHA, J. M. C. Avaliação de células-tronco mesenquimais do cordão umbilical humano em lesão de orgãos e disfunção endotelial na sepse. 2015. Universidade de São Paulo, 2015.

CARAGELASCO, D. S.; KOGIKA, M. M.; MARTORELLI, C. R.; KANAYAMA, K. K.; SIMÕES, D. Urine protein electrophoresis study in dogs with pituitary dependent hyperadrenocorticism during therapy. Pesquisa veterinária brasileira, v. 37, n. 7, p. 734-740, 2017.

CAVAGLIERI, R. C.; MARTINI, D.; SOGAYAR, M. C.; NORONHA, I. L. Mesenchymal stem cells delivered at the subcapsule of the kidney ameliorate renal disease in the rat remnant kidney model. Transplantation proceedings, v. $41, \quad$ n. 3, p. 947-51, abr. 2009. Disponível em: <http://www.ncbi.nlm.nih.gov/pubmed/19376395>. Acesso em: 12 ago. 2013.

CAVALCANTE, C. Z.; KOGIKA, M. M.; BACIC, A.; SANTORO, M. L.; MIYASHIRO, S. I.; SAULT, J. P.; OYAFUSO, M. K.; Z, A. C. C.; KOGIKA, M. M.; BACIC, A.; SANTORO, M. L.; MIYASHIRO, S. I.; SAULT, J. P. Avaliação da albuminúria e da eletroforese de proteínas urinárias de cães com hiperadrenocorticismo e a relação com a pressão arterial sistêmica 1. Pesq. Vet. Bras, v. 33, n. 11, p. 1364-1370, 2013.

CAVALCANTE, C. Z.; KOGIKA, M. M.; SIMÕES, D. M. N.; OYAFUSO, M. K.; PROSSER, C. S.; MIYASHIRO, S. I.; DUARTE, R. Microalbuminuria in dogs with hyperadrenocorticism and relationship to blood pressure. Journal of Veterinary Internal Medicine, v. 21, p. 647-647, 2007.

CHACAR, F. C. Determinação urinária das proteínas albumina, ligadas à 
vitamina $D$ e ao retinol, e de Tamm-Horsfall, em cães com doença renal crônica. 2015. Universidade de São Paulo, 2015.

CHACAR, F.; KOGIKA, M.; SANCHES, T.; CARAGELASCO, D.; MARTORELLI, C.; RODRIGUES, C.; CAPCHA, J.; CHEW, D.; ANDRADE, L. Urinary TammHorsfall protein , albumin , vitamin D-binding protein , and retinol-binding protein as early biomarkers of chronic kidney disease in dogs. Physiological Reports, v. 5 , p. 1-9, 2017.

CHANDLER, M.; ELWOOD, C.; MURPHY, K.; GAJANAYAKE, I.; SYME, H. Juvenile nephropathy in 37 boxer dogs. Journal of Small Animal Practice, v. 48, n. December, p. 690-694, 2007.

CHOI, S.; PARK, M.; KIM, J.; HWANG, S.; PARK, S.; LEE, Y. The role of mesenchymal stem cells in the functional improvement of chronic renal failure. Stem cells and development, v. 18, n. 3, p. 521-9, abr. 2009. Disponível em: <http://www.ncbi.nlm.nih.gov/pubmed/18647091>. Acesso em: 12 ago. 2013.

CÓNDOR, J. .; RODRIGUES, C.; SOUSA, R.; CANALE, D.; VOLPINI, R.; SHIMIZU, M.; CAMARA, N.; NORONHA, I.; ANDRADE, L. Treatment with human Wharton's jelly-derived mesenchymal stem cells attenuates sepsos-induced kidney injury, liver injury, and endothelial dysfunction. Stem Cells Translational Medicine, v. 5, p. 1-10, 2016.

CR MARTORELLI, MM KOGIKA, DS CARAGELASCO, D. S. and K. K. Sequential evaluation of proteinuria, albuminuria and urinary protein electrophoresis in dogs with diabetes mellitus. Online Journal of Veterinary Research, v. 20, n. 8, p. 547-556, 2016.

DEVUSYST, O.; DAHAN, K.; PIRSON, Y. Tamm-Horsfall protein or uromodulin: new ideas about an old molecule. Nephrology Dialysis Transplantation, v. 20, n. 7, p. 1290-1294, 2005.

FINCO, D. R.; BROWN, S. a; BROWN, C. a; CROWELL, W. a; COOPER, T. a; BARSANTI, J. a. Progression of chronic renal disease in the dog. Journal of Veterinary Internal Medicine, v. 13, p. 516-528, 1999. Disponível em: <papers2://publication/uuid/1900DC28-3148-4E2F-8A3E-1E776209BB91>.

GATTI, S.; BRUNO, S.; DEREGIBUS, M. C.; SORDI, A.; CANTALUPPI, V.; TETTA, C.; CAMUSSI, G. Microvesicles derived from human adult mesenchymal stem cells protect against ischaemia-reperfusion-induced acute and chronic kidney injury. Nephrology Dialysis Transplantation, v. 26, n. 5, p. 1474-1483, 2011.

GIORI, L.; TRICOMI, F. M.; ZATELLI, A.; ROURA, X.; PALTRINIERI, S. Highresolution gel electrophoresis and sodium dodecyl sulphate-agarose gel electrophoresis on urine samples for qualitative analysis of proteinuria in dogs. Journal of veterinary diagnostic investigation, v. 23, n. 4, p. 682-90, 2011. Disponível em: <http://www.ncbi.nlm.nih.gov/pubmed/21908309>.

GRAUER, G. F. Measurement, interpretation, and implications of proteinuria and albuminuria. The Veterinary clinics of North America. Small animal practice, v. 37, n. 2, p. 283-95, vi-vii, mar. 2007. Disponível em: 
<http://www.ncbi.nlm.nih.gov/pubmed/17336676>. Acesso em: 17 mar. 2012.

GRAUER, G. F. Proteinuria: measurement and interpretation. Topics in companion animal medicine, v. 26, n. 3, p. 121-7, ago. 2011. Disponível em: <http://www.ncbi.nlm.nih.gov/pubmed/21782142>. Acesso em: 8 abr. 2012.

GREGORY F. GRAUER. Manifestações clínicas dos disturbios urinários. In: NELSON, R. W.; COUTO, C. G. (Ed.). Medicina Interna de Pequenos Animais. 4. ed. Rio de Janeiro: Elsevier Saunders, 2010. p. 620-622.

HARE, J. M.; TRAVERSE, J. H.; HENRY, T. D.; DIB, N.; STRUMPF, R. K.; SCHULMAN, S. P.; GERSTENBLITH, G.; DEMARIA, A. N.; DENKTAS, A. E.; GAMMON, R. S.; HERMILLER, J. B.; REISMAN, M. A.; SCHAER, G. L.; SHERMAN, W. A Randomized, Double-Blind, Placebo-Controlled, DoseEscalation Study of Intravenous Adult Human Mesenchymal Stem Cells ( Prochymal ) After Acute Myocardial Infarction. journal of the american college of cardiology, v. 54, n. 24, p. 2277-2286, 2009. Disponível em: <http://dx.doi.org/10.1016/j.jacc.2009.06.055>.

HARLEY, L.; LANGSTON, C. Proteinuria in dogs and cats. Canadian Veterinary Journal, v. 53, n. 6, p. 631-638, 2012.

HOFFMAN, A. M.; DOW, S. W. Concise Review: Stem Cell Trials Using Companion Animal Disease Models. Stem Cells, v. 34, p. 1709-1729, 2016.

HOKAMP, J. a.; CIANCIOLO, R. E.; BOGGESS, M.; LEES, G. E.; BENALI, S. L.; KOVARSKY, M.; NABITY, M. B. Correlation of Urine and Serum Biomarkers with Renal Damage and Survival in Dogs with Naturally Occurring Proteinuric Chronic Kidney Disease. Journal of Veterinary Internal Medicine, p. n/a-n/a, 2016. Disponível em: <http://doi.wiley.com/10.1111/jvim.13832>.

HOLM, J.; HEMMINGSEN, L.; NIELSEN, N. V. Low-molecular-mass proteinuria as a marker of proximal renal tubular dysfunction in normo- and microalbuminuric non-insulin-dependent diabetic subjects. Clinical chemistry, v. 39, n. 3, p. 5179, mar. 1993. Disponível em: <http://www.ncbi.nlm.nih.gov/pubmed/8448868>.

HONMOU, O.; HOUKIN, K.; MATSUNAGA, T.; NIITSU, Y.; ISHIAI, S.; ONODERA, R.; WAXMAN, S. G.; KOCSIS, J. D. Intravenous administration of auto serum-expanded autologous mesenchymal stem cells in stroke. Brain, $v$. 134, n. 6, p. 1790-1807, 2011.

JACOB, F.; ARIZA, P.; OSBORN, J. W. Renal denervation chronically lowers arterial pressure independent of dietary sodium intake in normal rats. Am $\mathbf{J}$ Physiol Heart Circ Physiol, v. 284, p. 2302-2310, 2003.

JACOB, F.; POLZIN, D. J.; OSBORNE, C. A.; NEATON, J. D.; KIRK, C. A.; ALLEN, T. A.; SWANSON, L. L. Evaluation of the association between initial proteinuria and morbidity rate or death in dogs with naturally occurring chronic renal failure. Journal of the American Veterinary Medical Association, v. 226, n. 3, p. 393-400, 2005.

KARUSSIS, D.; KARAGEORGIOU, C.; VAKNIN-DEMBINSKY, A.; GOWDAKURKALLI, B.; GOMORI, J. M.; KASSIS, I.; BULTE, J. W. M.; PETROU, P.; BEN- 
HUR, T.; ABRAMSKY, O.; SLAVIN, S. Safety and Immunological Effects of Mesenchymal Stem Cell Transplantation in Patients With Multiple Sclerosis and Amyotrophic Lateral Sclerosis. Arch Neurol, v. 67, n. 10, p. 1187-1194, 2010.

KARUSSIS, D.; KARAGEORGIOU, C.; VAKNIN-DEMBINSKY, A.; GOWDAKURKALLI, B.; GOMORI, J. M.; KASSIS, I.; BULTE, J. W. M.; PETROU, P.; BENHUR, T.; ABRAMSKY, O.; SLAVIN, S. Safety and Immunological Effects of Mesenchymal Stem Cell Transplantation in Patients With Multiple Sclerosis and Amyotrophic Lateral Sclerosis. Arch Neurol, v. 67, n. 10, p. 1187-1194, 2011.

KSHIRSAGAR, B.; WIGGINS, R. C. A map of urine proteins based on onedimensional SDS-polyacrylamide gel electrophoresis and Western blotting using one microliter of unconcentrated urine. Clinica chimica acta; international journal of clinical chemistry, v. 158, n. 1, p. 13-22, 15 jul. 1986. Disponível em: <http://www.ncbi.nlm.nih.gov/pubmed/2427261>.

LAZARUS, H. M.; KOC, O. N.; DEVINE, S. M.; CURTIN, P.; MAZIARZ, R. T.; HOLLAND, H. K.; SHPALL, E. J.; MCCARTHY, P.; ATKINSON, K.; COOPER, B. W.; GERSON, S. L.; LAUGHLIN, M. J.; LOBERIZA, F. R.; MOSELEY, A. B. Cotransplantation of HLA-Identical Sibling Culture-Expanded Mesenchymal Stem Cells and Hematopoietic Stem Cells in Hematologic Malignancy Patients. biology of blood and marrow transplantation, v. 11, p. 389-398, 2005.

LE BRICON, T.; ERLICH, D.; BENGOUFA, D.; DUSSAUCY, M.; GARNIER, J. P.; BOUSQUET, B. Sodium dodecyl sulfate-agarose gel electrophoresis of urinary proteins: application to multiple myeloma. Clinical chemistry, v. 44, n. 6 Pt 1, p. 1191-7, jun. 1998. Disponível em: <http://www.ncbi.nlm.nih.gov/pubmed/9625042>.

LEE, D.; GLEICH, K.; FRASER, S. a; KATERELOS, M.; MOUNT, P. F.; POWER, D. a. Limited capacity of proximal tubular proteolysis in mice with proteinuria. American journal of physiology. Renal physiology, v. 304, n. 7, p. F1009-19, 1 abr. 2013. Disponível em: <http://www.ncbi.nlm.nih.gov/pubmed/23344573>. Acesso em: 7 fev. 2014.

LEE, J. S.; HONG, J. M.; MOON, G. J.; LEE, P. H.; AHN, Y. H.; BANG, O. Y.; STARTING COLLABORATORS. A long-term follow-up study of intravenous autologous mesenchymal stem cell transplantation in patients with ischemic stroke. Stem cells, v. 28, n. 6, p. 1099-1106, 2010a.

LEE, O. K.; KUO, T. K.; CHEN, W.-M.; LEE, K.-D.; HSIEH, S.-L.; CHEN, T.-H. Isolation of multipotent mesenchymal stem cells from umbilical cord blood. Blood, v. 103, n. 5, p. 1669-75, 1 mar. 2004. Disponível em: <http://www.ncbi.nlm.nih.gov/pubmed/14576065>. Acesso em: 12 ago. 2013.

LEE, S.-R.; LEE, S.-H.; MOON, J.-Y.; PARK, J.-Y.; LEE, D.; LIM, S. J.; JEONG, K.-H.; PARK, J.-K.; LEE, T.-W.; IHM, C.-G. Repeated administration of bone marrow-derived mesenchymal stem cells improved the protective effects on a remnant kidney model. Renal failure, v. 32, n. March 2016, p. 840-848, 2010b.

LEES, G. E. Early diagnosis of renal disease and renal failure. The Veterinary clinics of North America. Small animal practice, v. 34, n. 4, p. 867-85, v, jul. 2004. Disponível em: <http://www.ncbi.nlm.nih.gov/pubmed/15223206>. Acesso 
em: 12 ago. 2013.

LEES, G. E.; BROWN, S. A.; ELLIOTT, J.; GRAUER, G. F.; VADEN, S. L. Assessment and Management of Proteinuria in Dogs and Cats: 2004 ACVIM Forum Consensus Statement (Small Animal). J Vet Intern Med, v. 19, p. 377385, 2005.

LIM, C.-Y.; HAN, J.-I.; KIM, S.-G.; LEE, C.; PARK, H. Effect of autologous bone narrow-derived mesenchymal stem cells on renal regeneration after experimentally induced acute kidney injury in dogs. American journal of veterinary research, v. 77, n. 2, p. 199-207, 2016.

LIM, J. Y.; JEONG, C. H.; JUN, J. A.; KIM, S. M.; RYU, C. H.; HOU, Y.; OH, W.; CHANG, J. W.; JEUN, S.-S. Therapeutic effects of human umbilical cord bloodderived mesenchymal stem cells after intrathecal administration by lumbar puncture in a rat model of cerebral ischemia. Stem cell research \& therapy, v. 2, n. 5, p. 38, jan. 2011. Disponível em: $<$ http://www.pubmedcentral.nih.gov/articlerender.fcgi?artid=3308035\&tool=pmc entrez\&rendertype =abstract $>$.

LITTMAN, M.; DAMINET, S.; GRAUER, G.; LEES, G.; VAN DONGEN, A. Consensus recommendations for the diagnostic investigation of dogs with suspected glomerular disease. journal of veterinary internal medicine, v. 27, p. 19-26, 2013.

LUSTGARDEN, J. A.; WENK, R. E. Simple rapid kinetic method for serum creatinin measurement. American Association for Clinical Chemistry, v. 8, p. 1419-1422, 1972.

MARSHALL, T.; WILLIAMS, K. M. Total protein determination in urine: elimination of a differential response between the coomassie blue and pyrogallol red protein dye-binding assays. Clinical chemistry, v. 46, n. 3, p. 392-8, mar. 2000. Disponível em: <http://www.ncbi.nlm.nih.gov/pubmed/10702527>.

MAYANI, H.; LANSDORP, P. M. Biology of human umbilical cord blood-derived hematopoietic stem/progenitor cells. Stem cells (Dayton, Ohio), v. 16, n. 3, p. 153-65, jan. 1998. Disponível em: <http://www.ncbi.nlm.nih.gov/pubmed/9617891>.

MCELDERRY, L. A.; TARBIT, I. F.; PIERCE, K. Six Methods for Urinary Protein Compared. clinical chemestry, v. 28, n. 2, p. 356-360, 1982.

MOLLURA, D. J.; HARE, J. M.; RABB, H. Stem-Cell Therapy for Renal Diseases. Americal Journal of Kidney Diseases, v. 42, n. 5, p. 891-905, 2003.

MORIGI, M. Mesenchymal Stem Cells Are Renotropic, Helping to Repair the Kidney and Improve Function in Acute Renal Failure. Journal of the American Society of Nephrology, v. 15, n. 7, p. 1794-1804, 1 jul. 2004. Disponível em: <http://www.jasn.org/cgi/doi/10.1097/01.ASN.0000128974.07460.34>. Acesso em: 10 ago. 2013.

NABITY, M. B.; BOGGESS, M. M.; KASHTAN, C. E.; LEES, G. E. Day-to-Day Variation of the Urine Protein: Creatinine Ratio in Female Dogs with Stable 
Glomerular Proteinuria Caused by X-Linked Hereditary Nephropathy. journal of veterinary internal medicine, v. 21, p. 425-430, 2007.

NABITY, M. B.; LEES, G. E.; DANGOTT, L. J.; CIANCIOLO, R.; SUCHODOLSKI, J. S.; STEINER, J. M. Proteomic analysis of urine from male dogs during early stages of tubulointerstitial injury in a canine model of progressive glomerular disease. Veterinary clinical pathology / American Society for Veterinary Clinical Pathology, v. 40, n. 2, p. 222-36, jun. 2011. Disponível em: <http://www.ncbi.nlm.nih.gov/pubmed/21446987>. Acesso em: 17 mar. 2014.

NINICHUK, V.; GROSS, O.; SEGERER, S.; HOFFMANN, R.; RADOMSKA, E.; BUCHSTALLER, a; HUSS, R.; AKIS, N.; SCHLÖNDORFF, D.; ANDERS, H.-J. Multipotent mesenchymal stem cells reduce interstitial fibrosis but do not delay progression of chronic kidney disease in collagen4A3-deficient mice. Kidney International, v. $70, \quad$ n. 1, p. 121-129, 2006. Disponível em: <http://www.ncbi.nlm.nih.gov/pubmed/16723981\%5Cnhttp://www.nature.com/d oifinder/10.1038/sj.ki.5001521>.

NORRIS, C. R.; WILLIAMS, B. J.; LING, G. V; FRANTI, C. E.; JOHNSON; RUBY, a $L$. Recurrent and persistent urinary tract infections in dogs: 383 cases (19691995). Journal of the American Animal Hospital Association, v. 36, n. 6, p. 484-92, $2000 . \quad$ Disponível em: <http://www.ncbi.nlm.nih.gov/pubmed/11105884>.

PALLET, N.; CHAUVET, S.; CHASSÉ, J. F.; VINCENT, M.; AVILLACH, P.; LEVI, C.; MEAS-YEDID, V.; OLIVO-MARIN, J. C.; NGA-MATSOGO, D.; BEAUNE, P.; THERVET, E.; KARRAS, A. Urinary retinol binding protein is a marker of the extent of interstitial kidney fibrosis. PLoS ONE, v. 9, n. 1, 2014.

PAREKH, R. S.; KAO, W. H. L.; MEONI, L. a; IPP, E.; KIMMEL, P. L.; LA PAGE, J.; FONDRAN, C.; KNOWLER, W. C.; KLAG, M. J. Reliability of urinary albumin, total protein, and creatinine assays after prolonged storage: the Family Investigation of Nephropathy and Diabetes. Clinical journal of the American Society of Nephrology : CJASN, v. 2, n. 6, p. 1156-62, nov. 2007. Disponível em: <http://www.ncbi.nlm.nih.gov/pubmed/17928473>. Acesso em: 20 mar. 2014.

PERKINS, B. a; FICOCIELLO, L. H.; OSTRANDER, B. E.; SILVA, K. H.; WEINBERG, J.; WARRAM, J. H.; KROLEWSKI, A. S. Microalbuminuria and the risk for early progressive renal function decline in type 1 diabetes. Journal of the American Society of Nephrology: JASN, v. 18, n. 4, p. 1353-61, abr. 2007. Disponível em: <http://www.ncbi.nlm.nih.gov/pubmed/17329575>. Acesso em: 11 abr. 2014.

POLZIN, D. Chronic Kidney Disease. In: Nephrology and Urology of Small Animals. $1^{\circ}$ ed. [s.I.] Willey-Blackwell, 2011. p. $433-471$.

POLZIN, D. J. Evidence-based step-wise approach to managing chronic kidney disease in dogs and cats. Journal of veterinary emergency and critical care (San Antonio, Tex.: 2001), v. 23, n. 2, p. 205-15, 2013. Disponível em: <http://www.ncbi.nlm.nih.gov/pubmed/23470210>. Acesso em: 12 ago. 2013.

POLZIN, D.; OSBOURNE, C.; ROSS, S. Chronic Kidney Disease. In: ETTINGER, 
S.; FELDMAN, E. (Ed.). Textbook of Veterinary Internal Medicine. 6 ed. ed. St. Louis: Elsevier Saunders, 2005. p. 1756-1785.

QUAGLIA, M.; STRATTA, P. Idiopathic membranous nephropathy: management strategies. Drugs, v. 69, n. 10, p. 1303-17, 9 jul. 2009. Disponível em: $<$ http://www.ncbi.nlm.nih.gov/pubmed/20707756>.

QUIMBY, J. M.; WEBB, T. L.; HABENICHT, L. M.; DOW, S. W. Safety and efficacy of intravenous infusion of allogeneic cryopreserved mesenchymal stem cells for treatment of chronic kidney disease in cats: results of three sequential pilot studies. Stem cell research \& therapy, v. 4, n. 2, p. 48, 2013. Disponível em: <http://www.ncbi.nlm.nih.gov/pubmed/23632128>.

RAILA, J.; AUPPERLE, H.; RAILA, G.; SCHOON, H.; SCHWEIGERT, F. J. Case Report Renal Pathology and Urinary Protein Excretion in a 14-Month-Old Bernese Mountain Dog with Chronic Renal Failure. Forschung, v. 135, p. 131135, 2007.

RAILA, J.; SCHWEIGERT, F. J.; KOHN, B. Relationship between urinary TammHorsfall protein excretion and renal function in dogs with naturally occurring renal disease. Veterinary Clinical Pathology, v. 43, n. 2, p. 261-265, 2014.

RAMPOLDI, L.; SCOLARI, F.; AMOROSO, A.; GHIGGERI, G.; DEVUYST, O. The rediscovery of uromodulin (Tamm-Horsfall protein): from tubulointerstitial nephropathy to chronic kidney disease. Kidney International, v. 80, n. 4, p. 338347, 2011. Disponível em: <http://dx.doi.org/10.1038/ki.2011.134>.

RINGDE, O.; UZUNEL, M.; RASMUSSON, I.; REMBERGER, M.; SUNDBERG, B.; LONNIES, H.; MARSCHALL, H.; DLUGISZ, A.; SZAKOS, A.; HASSAN, Z.; OMAZIC, B.; ASCHAN, J.; BARKHOLT, L.; LE BLANC, K. Mesenchymal Stem Cells for Treatment of therapy-resistant graft-versus-host disease. transplantation, v. 81, n. 10, p. 1390-1397, 2006.

RODRIGUES, C. E.; CAPCHA, J. M. C.; DE BRAGANÇA, A. C.; SANCHES, T. R.; GOUVEIA, P. Q.; DE OLIVEIRA, P. A. F.; MALHEIROS, D. M. A. C.; VOLPINI, R. A.; SANTINHO, M. A. R.; SANTANA, B. A. A.; CALADO, R. do T.; NORONHA, I. de L.; ANDRADE, L. Human umbilical cord-derived mesenchymal stromal cells protect against premature renal senescence resulting from oxidative stress in rats with acute kidney injury. Stem Cell Research \& Therapy, v. 8, n. 1, p. 19, 2017. Disponível em: <http://stemcellres.biomedcentral.com/articles/10.1186/s13287017-0475-8>.

ROSS, L. A. Hypertension and chronic renal failure. Seminars in Veterinary Medicine and Surgery (Small Animal), v. 7, p. 221-226, 1992.

SCHULTZE, A.; JENSEN, R. Sodium dodecyl sulfate polyacrylamide gel electrophoresis of canine urinary proteins for the analysis and differentiation of tubular and glomerular diseases. Vet Clin Pathol, v. 18, n. 4, p. 93-97, 1998.

SEGEV, G. Proteinuria. In: ETTINGER, S. J.; FELDMAN, E. C. (Ed.). Textbook of Veterinary Internal Medicine. 7. ed. St. Louis: Elsevier Saunders, 2010. p. 168-172. 
SEMEDO, P.; CORREA-COSTA, M.; CENEDEZE, M. A.; MALHEIROS, D. M. A. C.; DOS REIS, M. A.; SHIMIZU, M. H.; SEGURO, A. C.; PACHECO-SILVA, A.; CAMARA, N. O. S. Mesenchymal stem cells attenuate renal fibrosis through immune modulation and remodeling properties in a rat remnant kidney model. Stem Cells, v. 27, n. 12, p. 3063-3073, 2009.

SHAHDADFAR, A.; FRONSDAL, K.; HAUG, T.; REINHOLT, F.; BRINCHMANN, $\mathrm{J}$. In vitro expansion of human mesenchymal stem cells: choice of serum is a determinant of cell proliferation, diferentiation, gene expression, and transcriptome stability. stem cells, v. 23, p. 1357-1366, 2005.

SMETS, P. M. Y.; MEYER, E.; MADDENS, B.; DUCHATEAU, L.; DAMINET, S. Effect of Sampling Method and Storage Conditions on Albumin, Retinol-Binding Protein, And N-Acetyl--D-Glucosaminidase Concentrations in Canine Urine Samples. Journal of Veterinary Diagnostic Investigation, v. 22, n. 6, p. 896902, 1 nov. 2010a. Disponível em: <http://vdi.sagepub.com/lookup/doi/10.1177/104063871002200607>. Acesso em: 17 mar. 2014.

SMETS, P. M. Y.; MEYER, E.; MADDENS, B. E. J.; DUCHATEAU, L.; DAMINET, $S$. Urinary markers in healthy young and aged dogs and dogs with chronic kidney disease. Journal of veterinary internal medicine / American College of Veterinary Internal Medicine, v. 24, n. 1, p. 65-72, 2010b. Disponível em: <http://www.ncbi.nlm.nih.gov/pubmed/20041990>.

SPEES, J. L.; GREGORY, C. A.; SINGH, H.; TUCKER, H. A.; PEISTER, A.; LYNCH, P. J.; HSU, S.; SMITH, J.; PROCKOP, D. J. Internalized Antigens Must Be Removed to Prepare Hypoimmunogenic Mesenchymal Stem Cells for Cell and Gene Therapy. Molecular Therapy, v. 9, n. 5, p. 747-756, 2004. Disponível em: <http://dx.doi.org/10.1016/j.ymthe.2004.02.012>.

STAGG, J. Immune regulation by mesenchymal stem cells: two sides to the coin. Tissue antigens, v. 69, n. 1, p. 1-9, jan. 2007. Disponível em: <http://www.ncbi.nlm.nih.gov/pubmed/17212702>. Acesso em: 4 fev. 2014.

TALLARIDA, R. J.; MURRAY, R. B. Area Under a Curve: Trapezoidal and Simpson's Rules. In: Manual of Pharmacologic. [s.l: s.n.]

TIAN, X.-Q.; ZHAO, L.-M.; GE, J.-P.; ZHANG, Y.; XU, Y.-C. Elevated urinary level of vitamin D-binding protein as a novel biomarker for diabetic nephropathy. Experimental and therapeutic medicine, v. 7, n. 2, p. 411-416, fev. 2014. Disponível em: $<$ http://www.pubmedcentral.nih.gov/articlerender.fcgi?artid=3881051\&tool=pmc entrez\&rendertype=abstract>. Acesso em: 12 fev. 2014.

VADEN, S. L.; ELLIOTT, J. management of proteinuria in dogs and cats with chronic kidney disease. Veterinary Clinics of NA: Small Animal Practice, v. 46, n. 6, p. 1115-1130, 2016. Disponível em: <http://dx.doi.org/10.1016/j.cvsm.2016.06.009>.

VAN KOPPEN, A.; JOLES, J. a.; VAN BALKOM, B. W. M.; LIM, S. K.; DE KLEIJN, D.; GILES, R. H.; VERHAAR, M. C. Human embryonic mesenchymal stem cellderived conditioned medium rescues kidney function in rats with established 
chronic kidney disease. PLoS ONE, v. 7, n. 6, p. 1-12, 2012.

VEJAKAMA, P.; INGSATHIT, A.; MCEVOY, M.; ATTIA, J.; THAKKINSTIAN, A. Progression of chronic kidney disease : an illness-death model approach. bmc nephrology, v. 18, n. 205, p. 1-8, 2017.

VIEIRA, N. M.; VALADARES, M.; ZUCCONI, E.; SECCO, M.; BUENO, C. R.; BRANDALISE, V.; ASSONI, a; GOMES, J.; LANDINI, V.; ANDRADE, T.; CAETANO, H. V. a; VAINZOF, M.; ZATZ, M. Human adipose-derived mesenchymal stromal cells injected systemically into GRMD dogs without immunosuppression are able to reach the host muscle and express human dystrophin. Cell transplantation, v. 21, n. 7, p. 1407-17, jan. 2012. Disponível em: <http://www.ncbi.nlm.nih.gov/pubmed/23168016>.

VILLANUEVA, S.; EWERTZ, E.; CARRIÓN, F.; TAPIA, A.; VERGARA, C.; CÉSPEDES, C.; SÁEZ, P. J.; LUZ, P.; IRARRÁZABAL, C.; CARREÑO, J. E.; FIGUEROA, F.; VIO, C. P. Mesenchymal stem cell injection ameliorates chronic renal failure in a rat model. Clinical science (London, England : 1979), v. 121, n. 11, p. 489-499, 2011.

WAGNER, W.; WEIN, F.; SECKINGER, A.; FRANKHAUSER, M.; WIRKNER, U.; KRAUSE, U.; BLAKE, J.; SCHWAGER, C.; ECKSTEIN, V.; ANSORGE, W.; HO, A. D. Comparative characteristics of mesenchymal stem cells from human bone marrow, adipose tissue, and umbilical cord blood. Experimental hematology, v. 33 , n. 11, p. 1402-16, nov. 2005. Disponível em: <http://www.ncbi.nlm.nih.gov/pubmed/16263424>. Acesso em: 6 ago. 2013.

WATERS, C. B.; ADAMS, L. G.; SCOTT-MONCRIEFF, J. C.; DENICOLA, D. B.; SNYDER, P. W.; WHITE, M. R.; GASPARINI, M. Effects of glucocorticoid therapy on urine protein-to-creatinine ratios and renal morphology in dogs. Journal of veterinary internal medicine / American College of Veterinary Internal Medicine, v. 11, n. 3, p. 172-7, 1997. Disponível em: <http://www.ncbi.nlm.nih.gov/pubmed/9183769>.

WEHNER, A.; HARTMANN, K.; HIRSCHBERGER, J. Associations between proteinuria, systemic hypertension and glomerular filtration rate in dogs with renal and non-renal diseases. Veterinary Record, v. 162, p. 141-147, 2008.

WOLF, G.; BUTZMANN, U.; WENZEL, U. O. The renin-angiotensin system and progression of renal disease: from hemodynamics to cell biology. Nephron Physiology, v. 93, p. 3-13, 2003.

YOKOO, T.; FUKUI, A.; OHASHI, T.; MIYAZAKI, Y.; UTSUNOMIYA, Y.; KAWAMURA, T.; HOSOYA, T.; OKABE, M.; KOBAYASHI, E. Xenobiotic kidney organogenesis from human mesenchymal stem cells using a growing rodent embryo. Journal of the American Society of Nephrology: JASN, v. 17, n. 4, p. 1026-34, abr. $2006 . \quad$ Disponível em: <http://www.ncbi.nlm.nih.gov/pubmed/16524947>. Acesso em: 13 ago. 2013.

ZARAGOZA, CONCEPCIÓN BARRERA, R.; CENTENO, F.; TAPIA, J.; DURÁN, E.; GONZÁLEZ, M.; MAÑÉ, M. C. SDS-PAGE and Western blot of urinary proteins in dogs with leishmaniasis. Vet. Res, v. 34, p. 137-151, 2003. 
ZARAGOZA, C.; BARRERA, R.; CENTENO, F.; TAPIA, J. a.; MAÑÉ, M. C. Characterization of Renal Damage in Canine Leptospirosis by Sodium Dodecyl Sulphate-Polyacrylamide Gel Electrophoresis (SDS-PAGE) and Western Blotting of the Urinary Proteins. Journal of Comparative Pathology, v. 129, n. $2-3$, p. 169-178, ago. 2003. Disponível em: <http://linkinghub.elsevier.com/retrieve/pii/S002199750300029X>. Acesso em: 3 jun. 2013.

ZHANG, X.; LI, J. Y.; CAO, K.; LU, H.; HONG, M.; QIAN, S.; WU, H.; LIU, P.; XU, W. Cotransplantation of HLA-identical mesenchymal stem cells and hematopoietic stem cells in Chinese patients with hematologic diseases. International Journal of Laboratory Hematology, v. 32, n. 2, p. 256-264, 2010.

ZHANG, Z.; GUAN, L.; ZHANG, K.; ZHANG, Q.; DAI, L. A combined procedure to deliver autologous mesenchymal stromal cells to patients with traumatic brain injury. Cytotherapy, v. 10, n. 2, p. 134-139, 2008. Disponível em: <http://dx.doi.org/10.1080/14653240701883061>.

ZHU, X.-Y.; LERMAN, A.; LERMAN, L. O. Concise review: mesenchymal stem cell treatment for ischemic kidney disease. Stem cells (Dayton, Ohio), v. 31, n. 9, p. 1731-6, $2013 . \quad$ Disponível em: <http://www.pubmedcentral.nih.gov/articlerender.fcgi?artid=3795813\&tool=pmc entrez\&rendertype $=$ abstract $>$.

ZINI, E.; BONFANTI, U.; ZATELLI, A. Diagnostic relevance of qualitative proteinuria evaluated by use of sodium dodecyl sulfate-agarose gel electrophosis and comparison with renal histologic findings in dogs. American Journal of Veterinary Research, v. 65, n. 7, p. 964-971, 2004.

ZUCCONI, E.; VIEIRA, N. M.; BUENO, C. R.; SECCO, M.; JAZEDJE, T.; COSTA VALADARES, M.; FUSSAE SUZUKI, M.; BARTOLINI, P.; VAINZOF, M.; ZATZ, $M$. Preclinical studies with umbilical cord mesenchymal stromal cells in different animal models for muscular dystrophy. Journal of biomedicine \& biotechnology, v. 2011, p. 715251, jan. 2011. Disponível em: $<$ http://www.pubmedcentral.nih.gov/articlerender.fcgi?artid=3139201\&tool=pmc entrez\&rendertype=abstract $>$. Acesso em: 13 ago. 2013. 


\section{APÊNDICES}

APÊNDICE A - Identificação dos cães clinicamente normais (grupo controle de C1 a C15) de acordo com prontuário de identificação no nosocômio, idade, definição racial ou não e sexo, atendidos no HOVET - Hospital Veterinário da Faculdade de Medicina Veterinária e Zootecnia da USP. São Paulo, 2017.

\begin{tabular}{ccccc}
\hline N & Prontuário* $^{*}$ & Idade (meses) & Definição racial & Sexo \\
\hline C1 & 233549 & 56 & SRD & Fêmea \\
C2 & 233400 & 140 & SRD & Fêmea \\
C3 & 220095 & 41 & Pinscher & Fêmea \\
C4 & 220094 & 41 & Pinscher & Macho \\
C5 & 233818 & 26 & SRD & Fêmea \\
C6 & 233854 & 12 & Buldogue Americano & Fêmea \\
C7 & 231159 & 92 & SRD & Fêmea \\
C8 & 234755 & 140 & SRD & Fêmea \\
C9 & 234756 & 24 & SRD & Fêmea \\
C10 & 233435 & 114 & Poodle & Fêmea \\
C11 & 236657 & 24 & Bulldogue Americano & Macho \\
C12 & 236765 & 26 & Bulldogue Americano & Fêmea \\
C13 & 239246 & 108 & Pitbull & Fêmea \\
C14 & 239247 & 108 & Lhasa Apso & Macho \\
C15 & 238013 & 16 & SRD & Macho \\
\hline \multicolumn{5}{c}{${ }^{*}$ rontuário HOVET FMVZ-USP; SRD = sem raça definida } \\
\end{tabular}

APÊNDICE B - Valores individuais e da estatística descritiva da proteína total sérica (PT) (g/dL), Albumina (Alb), alanina amino transferase (ALT), Fosfatase Alcalina (F.A.), Ureia, Creatinina (creat), Colesterol (Col), Triglicerides (Tri), Cloro (Cl), Sódio (Na), Potássio $(\mathrm{K})$, Fósforo $(\mathrm{P})$, Cálcio $(\mathrm{Ca})$ e Cálcio lonico (Cal) na avaliação pontual de cães do grupo controle - clinicamente normais (C1 a C15). São Paulo, 2017.

\begin{tabular}{|c|c|c|c|c|c|c|c|c|c|c|c|c|c|c|}
\hline Controle & PT & Alb & ALT & FA & Ureia & Creat & Col & Tri & $\mathrm{Cl}$ & $\mathrm{Na}$ & $K$ & $\mathbf{P}$ & $\mathrm{Ca}$ & Cal \\
\hline 1 & 6,30 & 4,40 & 27,40 & 8,30 & 40,50 & 1,00 & 256,80 & 78,60 & 111,80 & 146,80 & 3,90 & 2,20 & 9,50 & 1,44 \\
\hline 2 & 6,60 & 4,00 & 23,40 & 34,70 & 35,00 & 0,90 & 162,10 & 69,60 & 110,60 & 147,50 & 4,10 & 4,30 & 9,70 & 1,43 \\
\hline 3 & 6,20 & 3,80 & 40,30 & 14,70 & 36,50 & 0,90 & 203,70 & 74,20 & 111,30 & 147,60 & 3,80 & 4,20 & 9,30 & 1,43 \\
\hline 4 & 5,90 & 4,10 & 117,70 & 9,70 & 44,00 & 0,80 & 111,80 & 26,40 & 108,90 & 145,00 & 3,50 & 2,90 & 9,60 & 1,31 \\
\hline 5 & 5,80 & 3,50 & 20,20 & 29,70 & 39,80 & 1,00 & 141,90 & 46,60 & 112,10 & 147,70 & 3,90 & 3,50 & 9,40 & 1,44 \\
\hline 6 & 6,40 & 3,70 & 24,40 & 38,10 & 73,70 & 1,00 & 200,80 & 57,80 & 105,70 & 146,60 & 4,10 & 5,00 & 10,60 & 1,49 \\
\hline 7 & 6,20 & 3,80 & 30,30 & 15,50 & 52,70 & 1,00 & 181,10 & 46,40 & 113,70 & 148,70 & 4,30 & 3,00 & 9,40 & 1,39 \\
\hline 8 & 6,50 & 4,00 & 41,10 & 10,00 & 34,60 & 1,00 & 211,10 & 92,60 & 113,40 & 148,80 & 3,60 & 2,30 & 9,60 & 1,40 \\
\hline 9 & 7,40 & 4,60 & 20,80 & 11,40 & 47,30 & 0,70 & 225,50 & 103,00 & 109,90 & 149,40 & 3,70 & 4,90 & 10,10 & 1,34 \\
\hline 10 & 7,70 & 4,90 & 62,60 & 20,70 & 44,50 & 1,00 & 324,60 & 331,70 & 110,50 & 150,80 & 4,60 & 3,20 & 10,80 & 1,33 \\
\hline 11 & 7,00 & 4,20 & 65,70 & 46,60 & 41,00 & 1,10 & 202,30 & 60,50 & 107,40 & 145,40 & 4,60 & 6,60 & 11,40 & 1,60 \\
\hline 12 & 7,20 & 4,20 & 29,90 & 22,90 & 50,50 & 1,20 & 186,30 & 91,30 & 114,00 & 146,00 & 4,10 & 4,10 & 9,70 & 1,49 \\
\hline 13 & 6,80 & 3,70 & 32,60 & 31,90 & 38,70 & 1,10 & 181,10 & 78,20 & 112,00 & 150,70 & 3,70 & 2,60 & 10,20 & 1,44 \\
\hline 14 & 6,90 & 4,20 & 21,50 & 36,50 & 52,20 & 0,90 & 235,10 & 69,90 & 107,20 & 146,20 & 4,20 & 3,60 & 10,90 & 1,51 \\
\hline 15 & 5,70 & 3,50 & 40,70 & 73,80 & 28,30 & 0,90 & 208,60 & 38,90 & 108,00 & 143,80 & 3,50 & 6,00 & 11,10 & 1,47 \\
\hline Média & 6,57 & 4,04 & 39,90 & 26,96 & 43,95 & 0,96 & 202,18 & 84,38 & 110,43 & 147,40 & 3,97 & 3,94 & 10,08 & 1,43 \\
\hline D.P. & 0,59 & 0,39 & 25,69 & 17,72 & 10,74 & 0,12 & 49,47 & 71,61 & 2,54 & 2,02 & 0,35 & 1,34 & 0,70 & 0,07 \\
\hline Mediana & 6,50 & 4,00 & 30,30 & 22,90 & 41,00 & 1,00 & 202,30 & 69,90 & 110,60 & 147,50 & 3,90 & 3,85 & 9,70 & 1,44 \\
\hline EPM & 0,15 & 0,10 & 6,63 & 4,57 & 2,77 & 0,03 & 12,77 & 18,49 & 0,65 & 0,52 & 0,09 & 0,35 & 0,18 & 0,01 \\
\hline Min & 5,70 & 3,50 & 20,20 & 8,30 & 28,30 & 0,70 & 111,80 & 26,40 & 105,70 & 143,80 & 3,50 & 2,20 & 9,30 & 1,31 \\
\hline Max & 7,70 & 4,90 & 117,70 & 73,80 & 73,70 & 1,20 & 324,60 & 331,70 & 114,00 & 150,80 & 4,60 & 6,60 & 11,40 & 1,60 \\
\hline
\end{tabular}




\section{Eletroforese Grupo Controle}

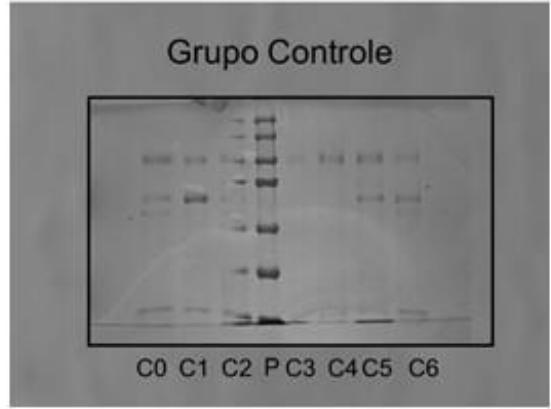

Apêndice F - Imagem obtida na eletroforese SDS-PAGE, dos animais do grupo controle



Apêndice G - Imagem obtida na eletroforese SDS-PAGE, dos animais do grupo controle

\section{Eletroforese Grupo A}

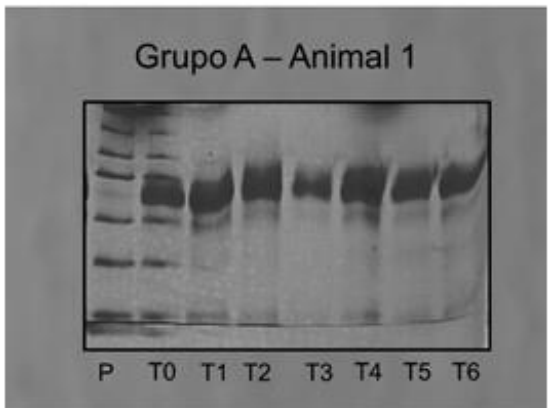

Apêndice H - Imagem obtida na eletroforese SDS-PAGE, do animal 1 do Grupo A (TO-T6)

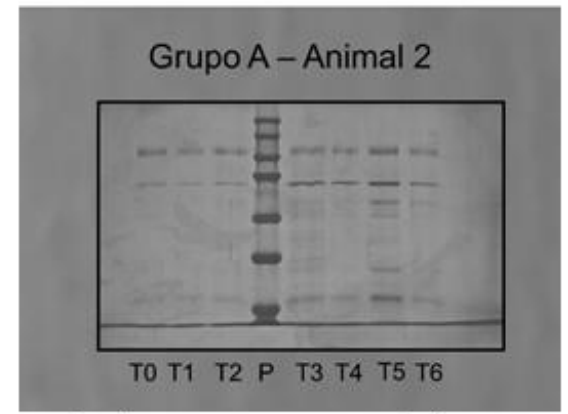

Apêndice J - Imagem obtida na eletroforese SDS-PAGE, do animal 2 do Grupo A (TO-T6)

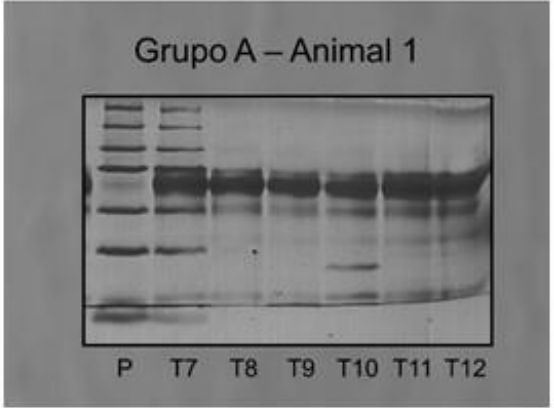

Apêndice I - Imagem obtida na eletroforese SDS-PAGE, do animal 1 do Grupo A (T7-T12)

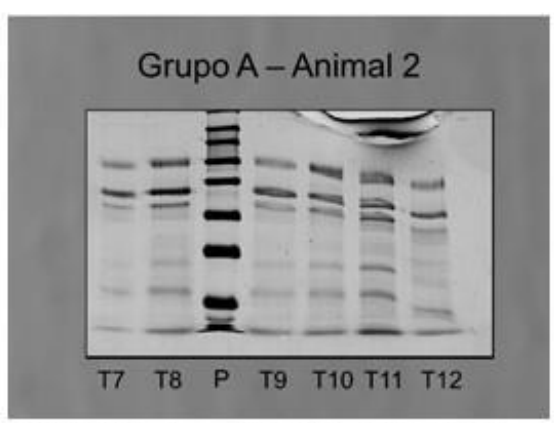

Apêndice L - Imagem obtida na eletroforese SDS-PAGE, do animal 2 do Grupo A (T7-T12) 


\section{Eletroforese Grupo A}

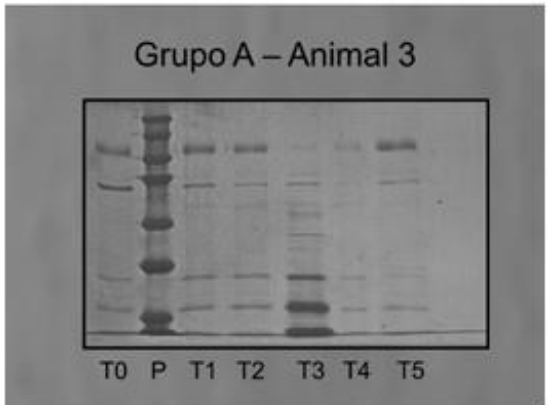

Apêndice $M$ - Imagem obtida na eletroforese SDS-PAGE, do animal 3 do Grupo A (TO-T6)

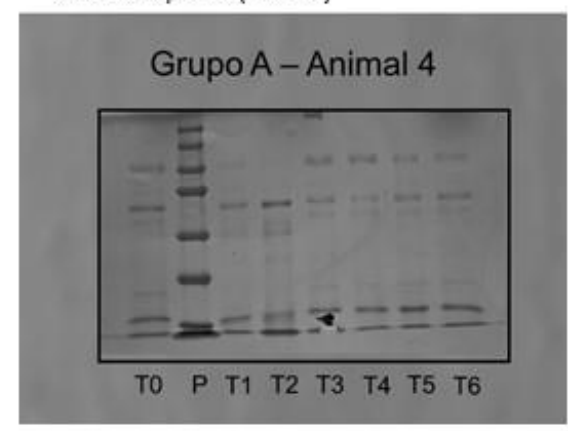

Apêndice $O$ - Imagem obtida na eletroforese SDS-PAGE, do animal 4 do grupo A (TO-T6)

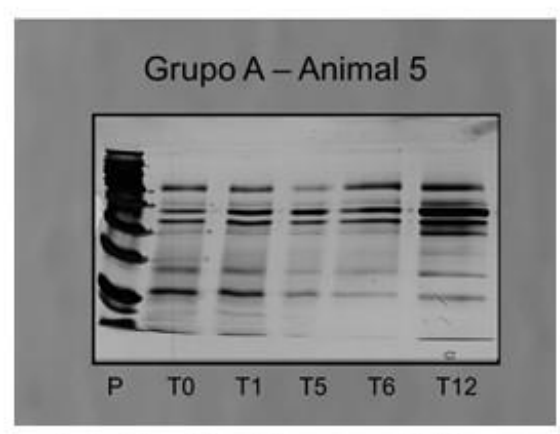

Apêndice Q - Imagem obtida na eletroforese SDS-PAGE, do animal 5 do grupo A (T0-T12)

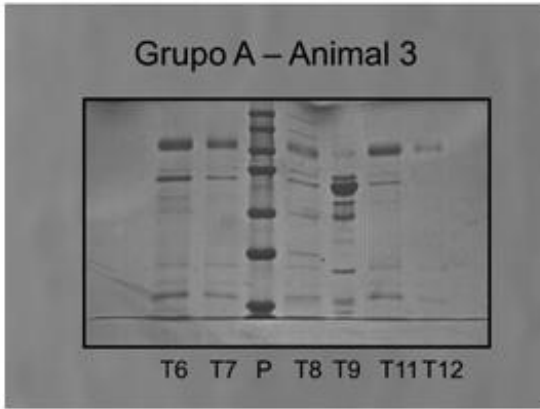

Apêndice N - Imagem obtida na eletroforese SDS-PAGE, do animal 3 do Grupo A (T7-T12)

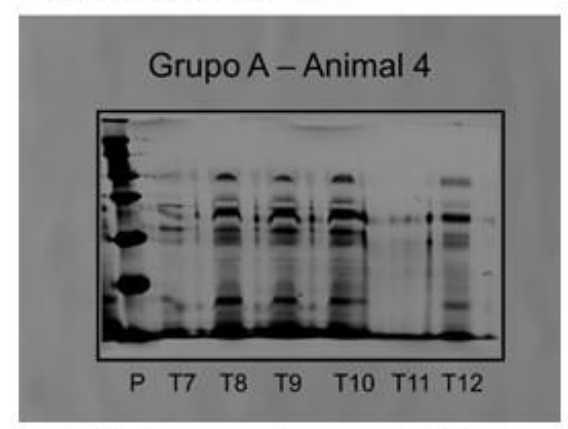

Apêndice $P$ - Imagem obtida na eletroforese SDS-PAGE, do animal 4 do grupo A (T7-T12) 


\section{Eletroforese Grupo A}

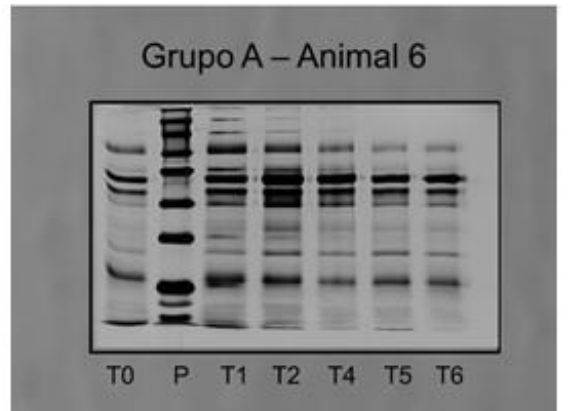

Apêndice R - Imagem obtida na eletroforese SDS-PAGE, do animal 6 do Grupo A (T0-T6)

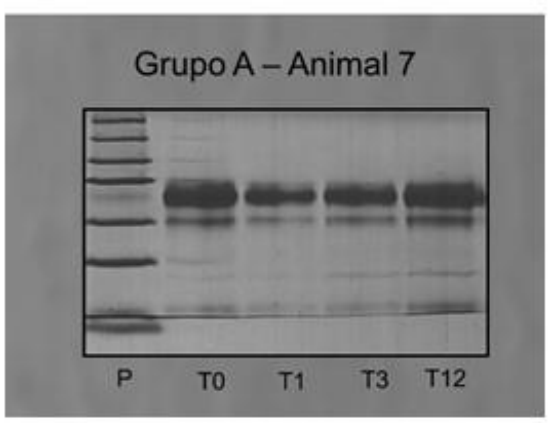

Apêndice T - Imagem obtida na eletroforese SDS-PAGE, do animal 7 do grupo A (T0-T12)



Apêndice U - Imagem obtida na eletroforese SDS-PAGE, do animal 8 do grupo A (T0-T6)



Apêndice S - Imagem obtida na eletroforese SDS-PAGE, do animal 6 do Grupo A (T7-T12)

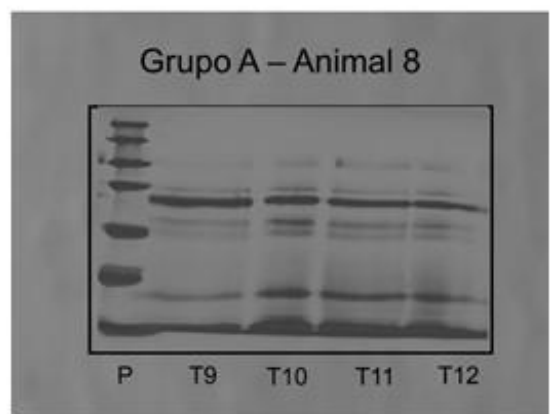

Apêndice V - Imagem obtida na eletroforese SDS-PAGE, do animal 8 do grupo A (TO-T6) 


\section{Eletroforese Grupo A}

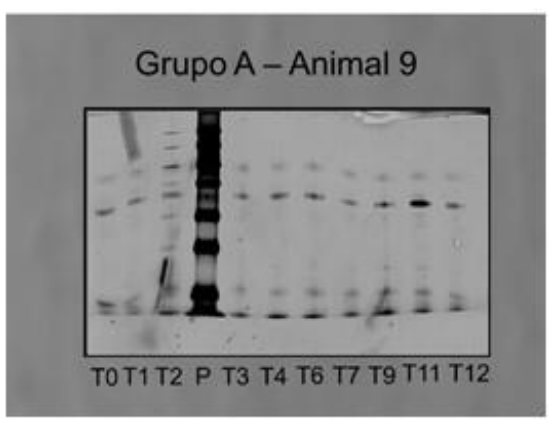

Apêndice $X$ - Imagem obtida na eletroforese SDS-PAGE, do animal 9 do grupo $A$ (T0-T12)

\section{Eletroforese Grupo B}

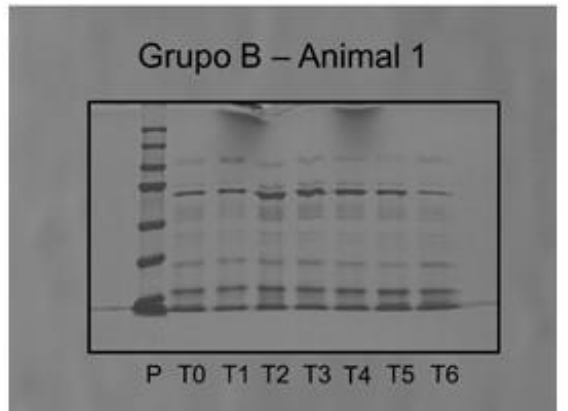

Apêndice Z - Imagem obtida na eletroforese SDS-PAGE, do animal 1 do Grupo B (TO-T6)

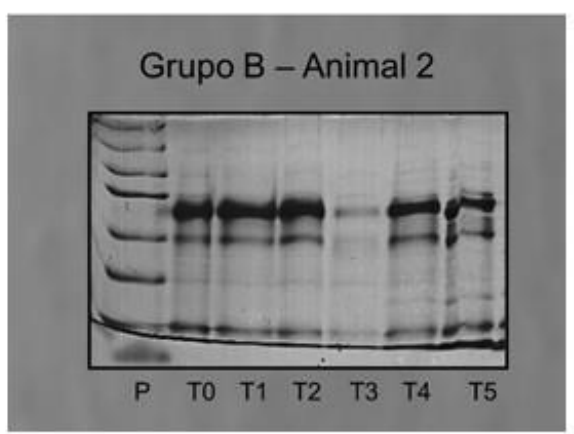

Apêndice BA- Imagem obtida na eletroforese SDS-PAGE, do animal 2 do Grupo B (T0-T6)

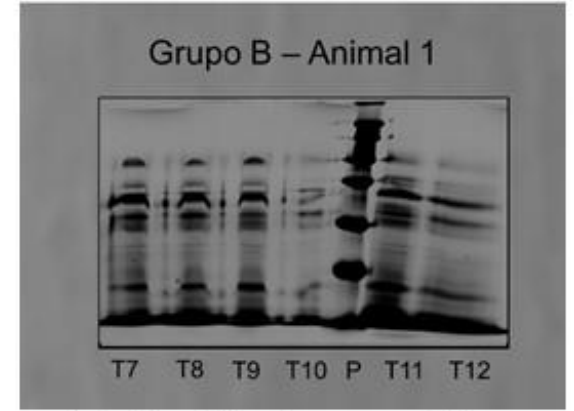

Apêndice AA - Imagem obtida na eletroforese SDS-PAGE, do animal 1 do Grupo B (T7-T12) 


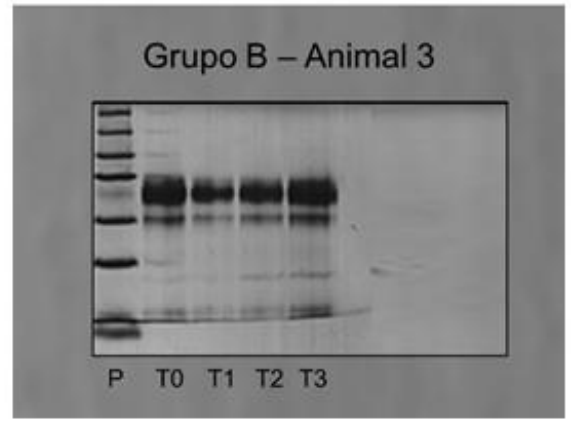

Apêndice CA - Imagem obtida na eletroforese SDS-PAGE, do animal 3 do Grupo B (TO-T3)

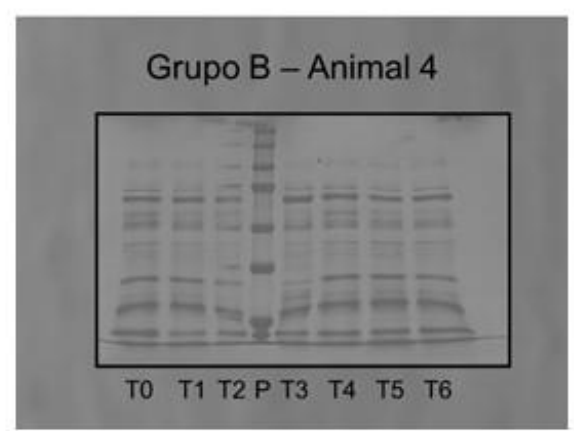

Apêndice DA - Imagem obtida na eletroforese SDS-PAGE, do animal 4 do Grupo B (TO-T6)



Apêndice FA - Imagem obtida na eletroforese SDS-PAGE, do animal 5 do Grupo B (TO-T6)

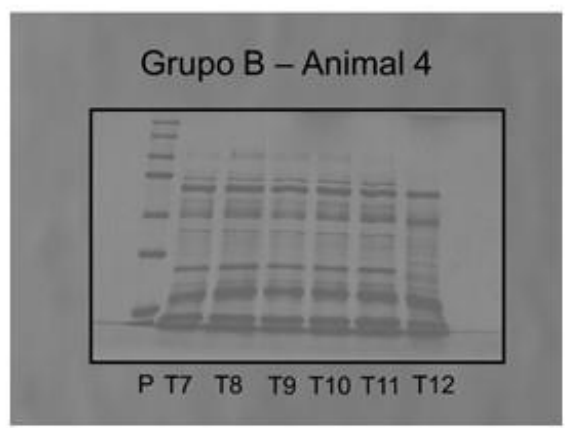

Apêndice EA - Imagem obtida na eletroforese SDS-PAGE, do animal 4 do Grupo B (T7-T12) 


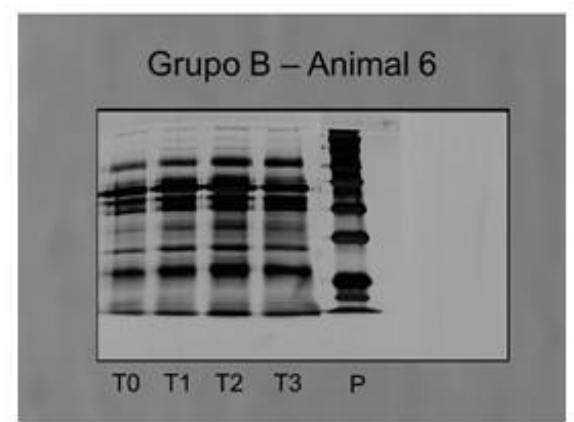

Apêndice GA - Imagem obtida na eletroforese SDS-PAGE, do animal 6 do Grupo B (TO-T3)

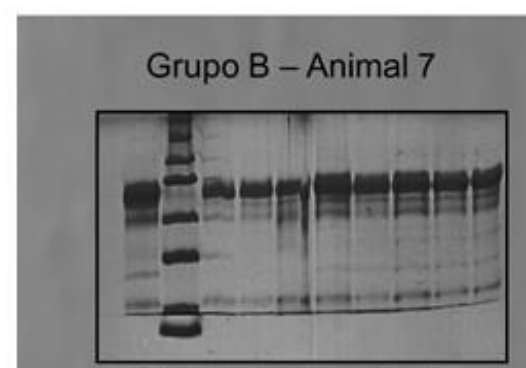

T0 P T1 T2 T3 T4 T5 T6 T7 T8

Apêndice HA- Imagem obtida na eletroforese SDS-PAGE, do animal 7 do Grupo B (TO-T9)

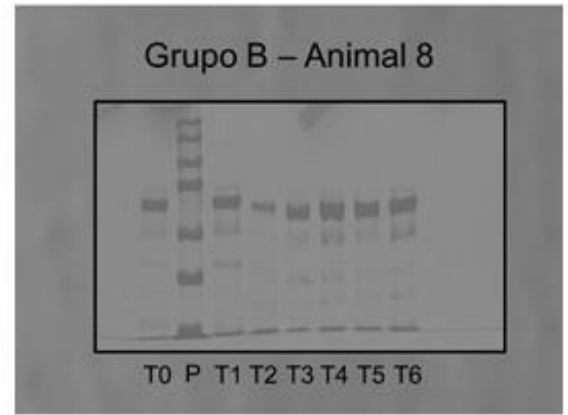

Apêndice IA - Imagem obtida na eletroforese SDS-PAGE, do animal 8 do Grupo B (T0-T6)

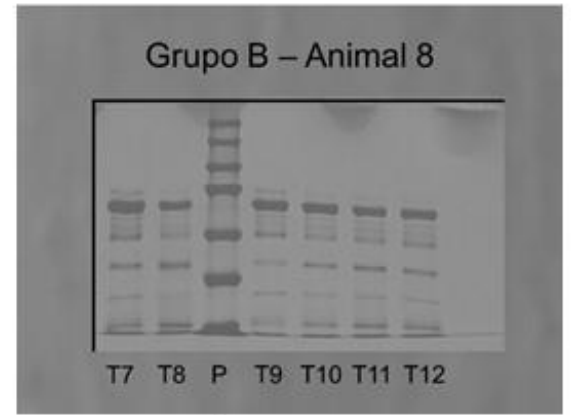

Apêndice JÁ - Imagem obtida na eletroforese SDS-PAGE, do animal 8 do Grupo B (T7-T12) 


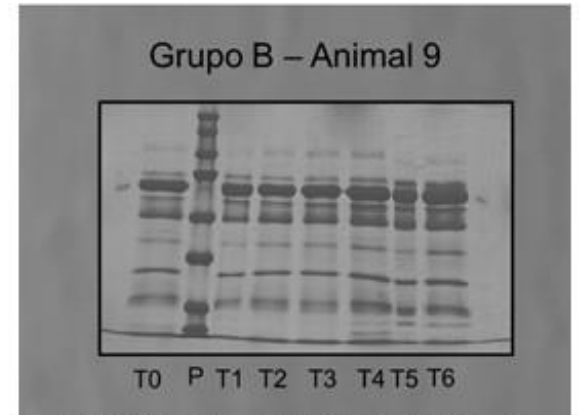

Apêndice LA- Imagem obtida na eletroforese SDS-PAGE, do animal 9 do Grupo B (T0-T6)

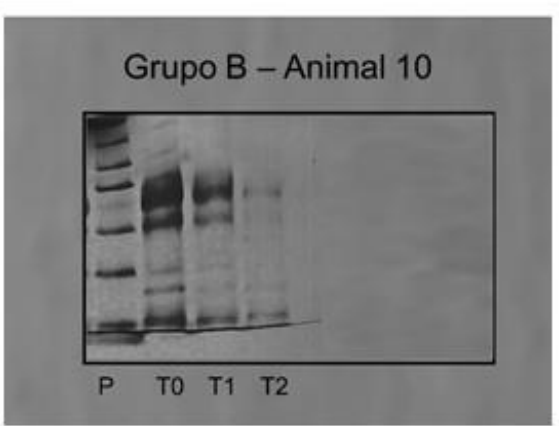

Apêndice NA- Imagem obtida na eletroforese SDS-PAGE, do animal 10 do Grupo B (TO-T2)

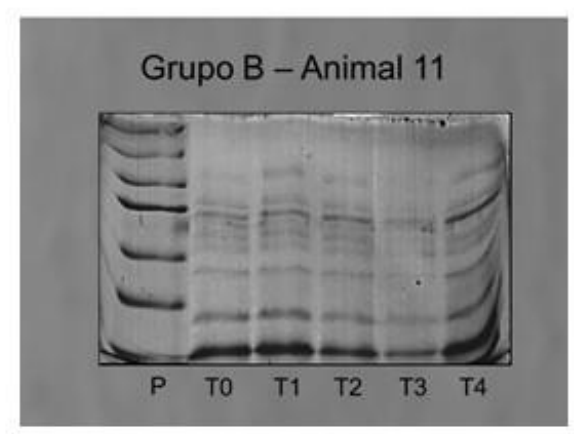

Apêndice OA- Imagem obtida na eletroforese SDS-PAGE, do animal 11 do Grupo B (TO-T4)



Apêndice MA- Imagem obtida na eletroforese SDS-PAGE, do animal 9 do Grupo B (T7-T12) 


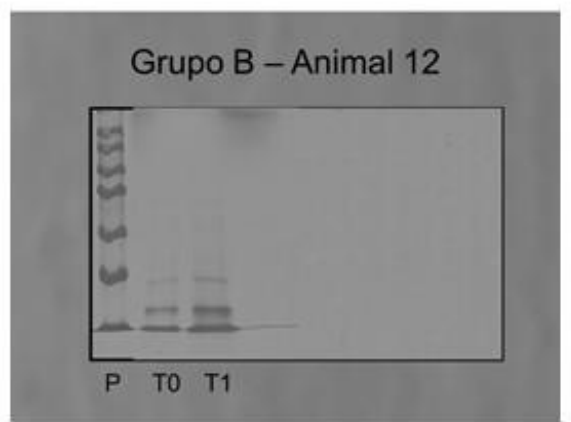

Apêndice PA- Imagem obtida na eletroforese SDS-PAGE, do animal 12 do Grupo B (T0-T1)



Apêndice QA- Imagem obtida na eletroforese SDS-PAGE, do animal 13 do Grupo B (TO-T6) 


\section{Imunodetecção de Albumina}



Apêndice RA - Imunodetecção de albumina, por western Blot de cães clinicamente normais (controle) e cães doentes renais crônicos -São Paulo, 2017



Apêndice TA- Imunodetecção de albumina, por western Blot de cães clinicamente normais (controle) e cães doentes renais crônicos -São Paulo, 2017

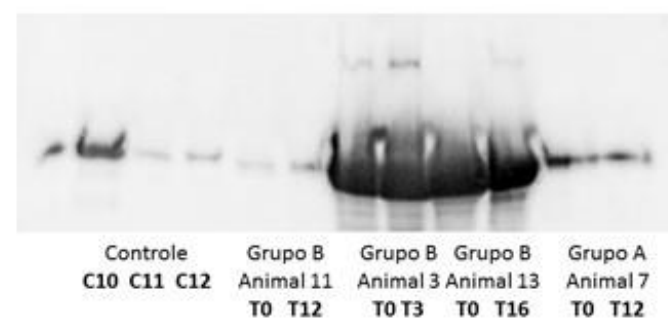

Apêndice VA- Imunodetecção de albumina, por western Blot de cães clinicamente normais (controle) e cães doentes renais crônicos -São Paulo, 2017

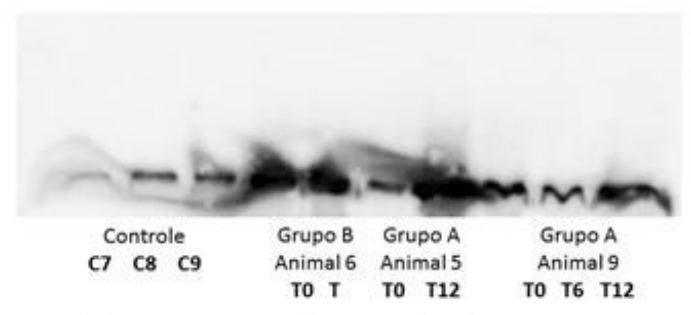

Apêndice ZA- Imunodetecção de albumina, por western Blot de cães clinicamente normais (controle) e cães doentes renais crônicos -São Paulo, 2017

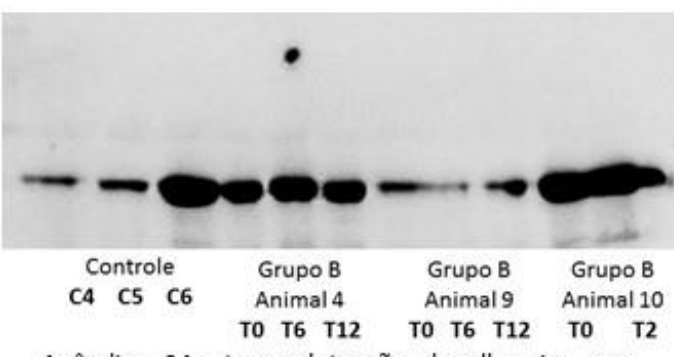

Apêndice SA- Imunodetecção de albumina, por western Blot de cães clinicamente normais (controle) e cães doentes renais crônicos -São Paulo, 2017

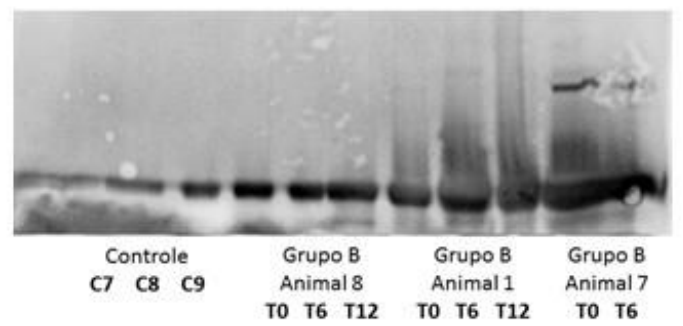

Apêndice UA- Imunodetecção de albumina, por western Blot de cães clinicamente normais (controle) e cães doentes renais crônicos -São Paulo, 2017

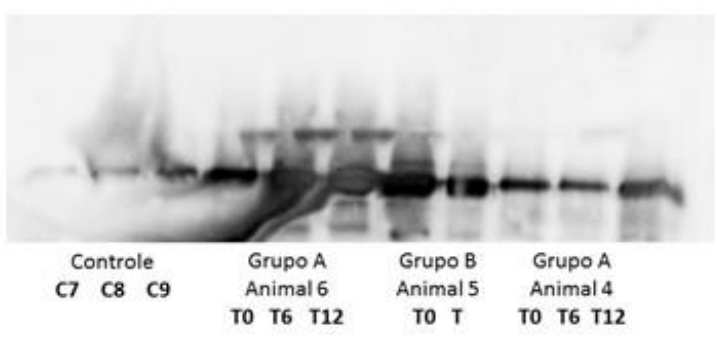

Apêndice XA- Imunodetecção de albumina, por western Blot de cães clinicamente normais (controle) e cães doentes renais crônicos -São Paulo, 2017 


\section{Imunodetecção de Proteina Ligada à Vitamina D}

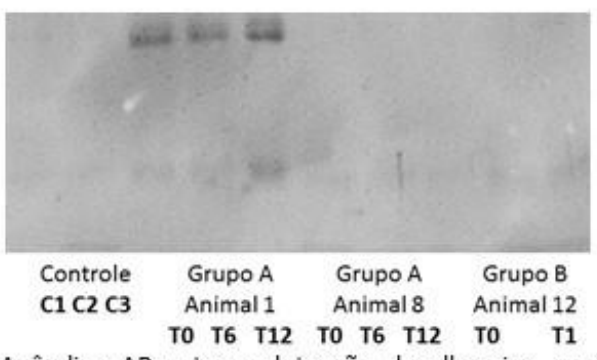

Apêndice $A B$ - Imunodetecção de albumina, por western Blot de cães clinicamente normais (controle) e cães doentes renais crônicos -São Paulo, 2017

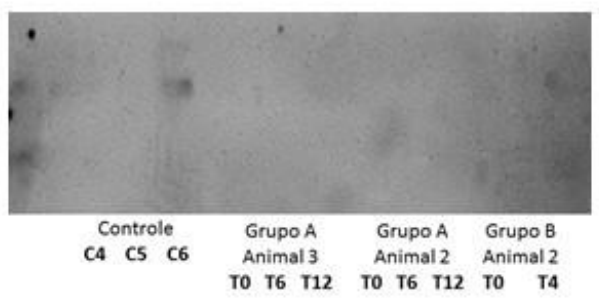

Apêndice $\mathrm{CB}$ - Imunodetecção de albumina, por western Blot de cães clinicamente normais (controle) e cães doentes renais crônicos -São Paulo, 2017



Apêndice EB- Imunodetecção de albumina, por western Blot de cães clinicamente normais (controle) e cães doentes renais crônicos -São Paulo, 2017

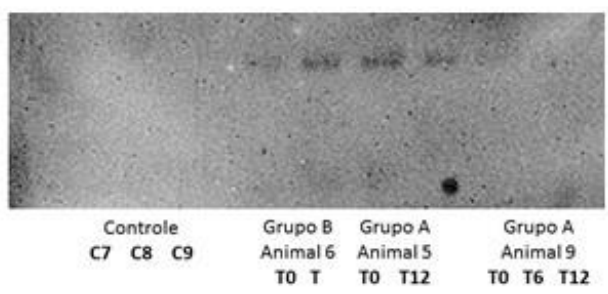

Apêndice GB- Imunodetecção de albumina, por western Blot de cães clinicamente normais (controle) e cães doentes renais crônicos -São Paulo, 2017

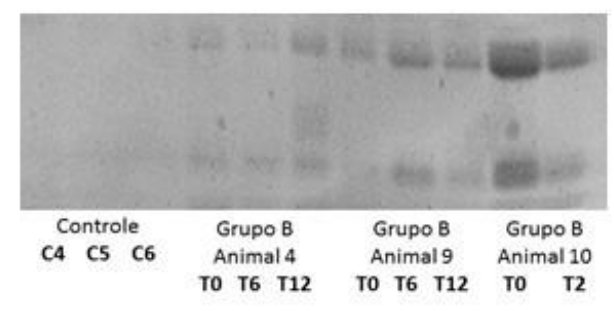

Apêndice BB- Imunodetecção de albumina, por western Blot de cães clinicamente normais (controle) e cães doentes renais crônicos -São Paulo, 2017

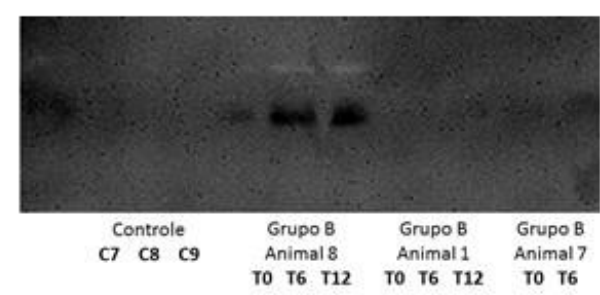

Apêndice DB- Imunodetecção de albumina, por western Blot de cães clinicamente normais (controle) e cães doentes renais crônicos -São Paulo, 2017

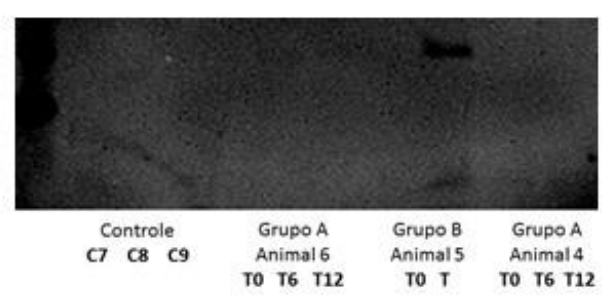

Apêndice FB- Imunodetecção de albumina, por western Blot de cães clinicamente normais (controle) e cães doentes renais crônicos -São Paulo, 2017 


\section{Imunodetecção de Proteína Ligada ao Retinol}

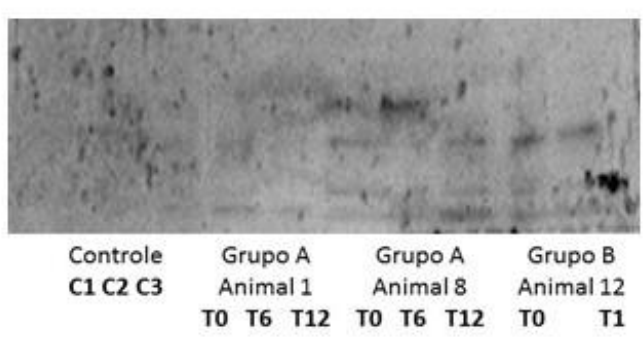

Apêndice HB - Imunodetecção de proteína ligada ao retinol, por western Blot de cães clinicamente normais (controle) e cães doentes renais crônicos São Paulo, 2017

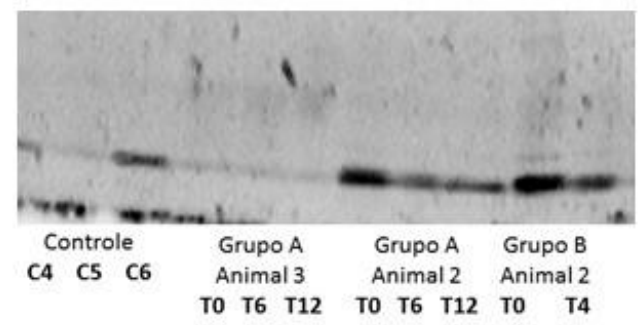

Apêndice JB-Imunodetecção de proteína ligada ao retinol, por western Blot de cães clinicamente normais (controle) e cães doentes renais crônicos São Paulo, 2017

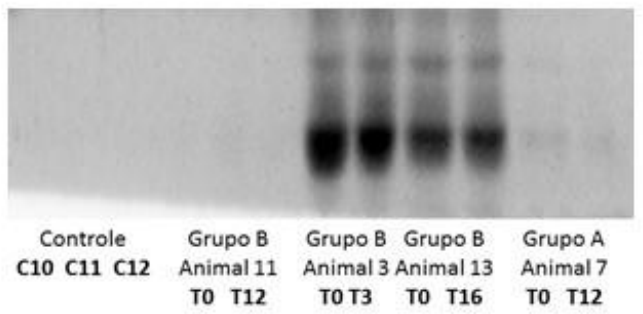

Apêndice MB- Imunodetecção de proteína ligada ao retinol, por western Blot de cães clinicamente normais (controle) e cães doentes renais crônicos São Paulo, 2017

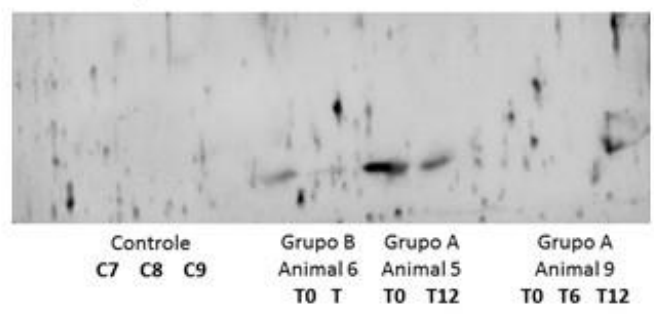

Apêndice $\mathrm{OB}$ - Imunodeteç̧ão de proteína ligada ao retinol, por western Blot de cães clinicamente normais (controle) e cães doentes renais crônicos São Paulo, 2017

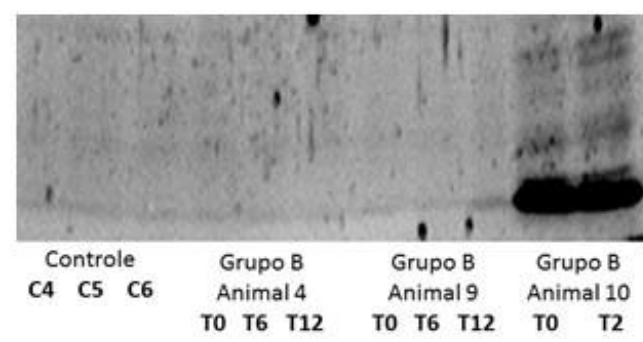

Apêndice IB-Imunodetecção de proteína ligada ao retinol, por western Blot de cães clinicamente normais (controle) e cães doentes renais crônicos São Paulo, 2017

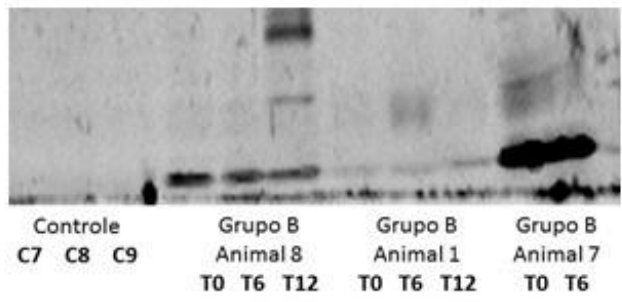

Apêndice LB- Imunodetecção de proteína ligada ao retinol, por western Blot de cães clinicamente normais (controle) e cães doentes renais crônicos São Paulo, 2017



Apêndice NB- Imunodetecção de proteína ligada ao retinol, por western Blot de cães clinicamente normais (controle) e cães doentes renais crônicos São Paulo, 2017 


\section{Imunodetecção de Tamm-Horsfall}

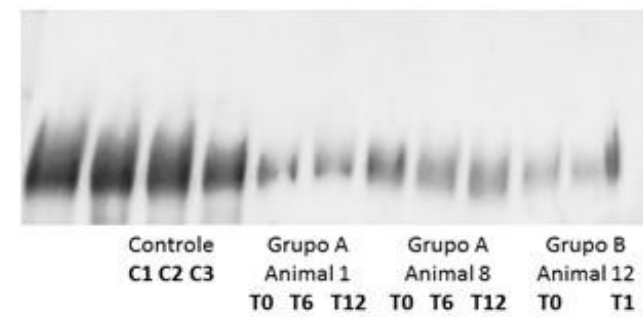

Apêndice PB - Imunodetecção de proteína de Tamm-Horsfall, por western Blot de cães clinicamente normais (controle) e cães doentes renais crônicos -São Paulo, 2017

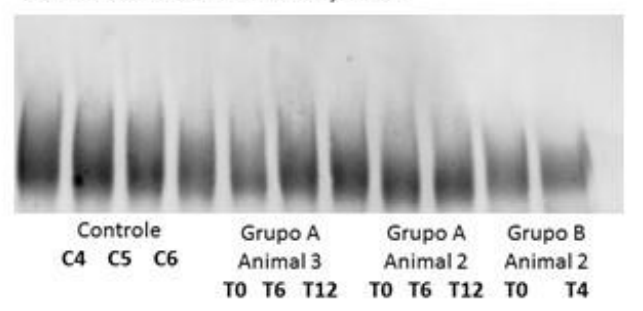

Apêndice RB- Imunodetecção de proteína de Tamm-Horsfall,, por western Blot de cães clinicamente normais (controle) e cães doentes renais crônicos -São Paulo, 2017

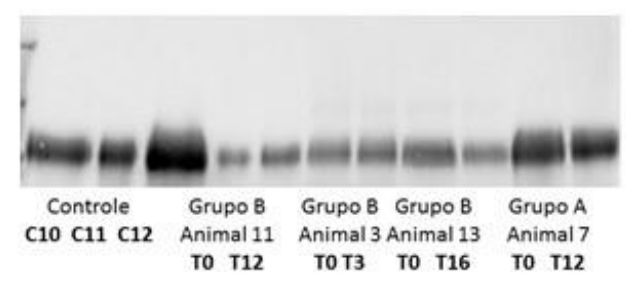

Apêndice TB- Imunodetecção de proteína de Tamm-Horsfall,, por western Blot de cães clinicamente normais (controle) e cães doentes renais crônicos -São Paulo, 2017

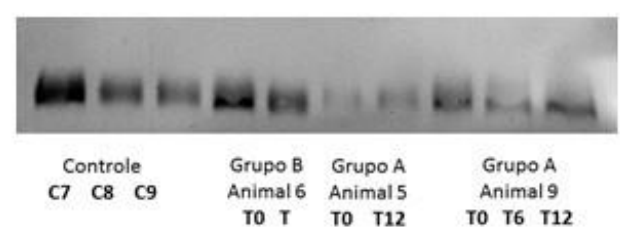

Apêndice VB- Imunodetecção de proteína de Tamm-Horsfall,, por western Blot de cães clinicamente normais (controle) e cães doentes renais crônicos -São Paulo, 2017



Apêndice QB- Imunodetecção proteína de TammHorsfall,, por western Blot de cães clinicamente normais (controle) e cães doentes renais crônicos São Paulo, 2017

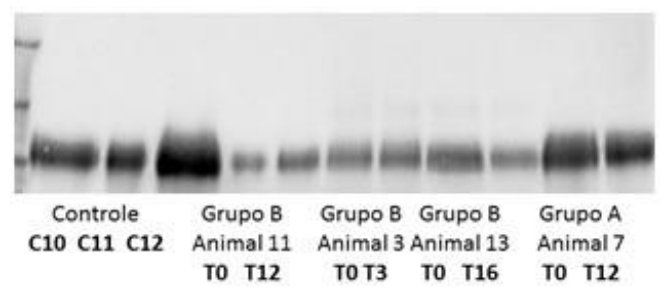

Apêndice SB- Imunodetecção de proteína de Tamm-Horsfall, por western Blot de cães clinicamente normais (controle) e cães doentes renais crônicos -São Paulo, 2017

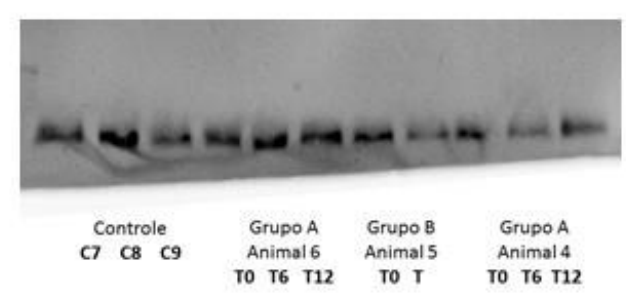

Apêndice UB- Imunodetecção de proteína de Tamm-Horsfall,, por western Blot de cães clinicamente normais (controle) e cães doentes renais crônicos -São Paulo, 2017 